\title{
Definição de uma Metodologia para o Desenvolvimento de Aplicações Paralelas
}

\author{
André Luís Olivete
}

Orientador: Prof. Dr. Onofre Trindade Junior

Dissertação apresentada ao Instituto de Ciências Matemáticas e de Computação - ICMC-USP, como parte dos requisitos para obtenção do título de Mestre em Ciências - Área: Ciências de Computação e Matemática Computacional. 
Dedico este trabalho aos meus pais que sempre souberam me apoiar nos momentos dificeis $e$ me mostraramo valor do conhecimento. 
Sonho que se sonha só é só um sonho,

Sonho que se sonha junto é realidade.

Raul Seixas 


\section{Agradecimentos}

Ao meu orientador, Prof. Onofre Trindade Júnior, pela orientação, apoio, incentivo, muita dedicação e ensinamentos sem os quais esse trabalho não teria sido concluído.

Aos amigos de republica: Mário, Milton, Robson, Rogério, Ronaldo, Shiro e Silvio, pela amizade, companheirismo, apoio e disposição para incentivar e colaborar.

Aos amigos da república 33: André (Maluquinho), Kleber, Reginaldo (Ré) e Rodrigo (Cabeção) pela horas de lazer e churrascos que refrescaram a cabeça em momentos difíceis.

Aos amigos da FIPP, Faculdade de Informática de Presidente Prudente, pelo apoio no decorrer desse trabalho, em especial ao Diretor Moacir Del Trejo.

Aos Colegas de mestrado do ICMC pelos momentos de estudo e alegria compartilhados. trabalho.

A todos os funcionários do ICMC que direta e indiretamente contribuíram com este trabalho.

A todas as pessoas que de alguma forma me incentivaram ou contribuíram com este

A todos os amigos do LCAD, Emilio, Rômulo, Maxwell e todos os outros que estiveram comigo nesta etapa da vida.

Especialmente ao CNPq pelo apoio financeiro, que foi de grande importância para a conclusão deste trabalho.

A minha namorada Kátia e todos os amigos de Adamantina.

Aos meus pais e irmãos Luís Alexandre, Ana Luísa e Celso que sempre me apoiaram e incentivaram. 


\section{Índice}

Lista das Figuras......................................................................................................................................v

Lista das Tabelas........................................................................................................................vii

Resumo ............................................................................................................................................... viii

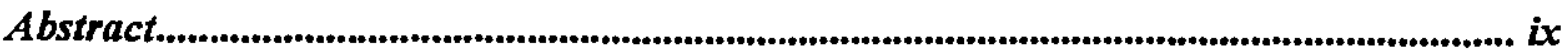

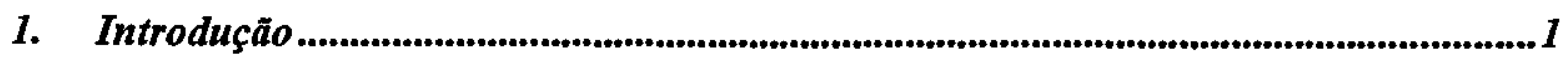

1.1. Aspectos Gerais .................................................................................................................................... 1

1.2. Estrutura do Texto.............................................................................................................................. 3

2. Computação Paralela............................................................................................................4

2.1. Consideraçōes Iniciais ...................................................................................................................... 4

2.2. Arquiteturas Paralelas................................................................................................................... 4

2.2.1. Classificação de Flynn ........................................................................................................ 4

2.2.2. Classificą̧ão de Duncan ...............................................................................................................

2.3. Programação Paralela .................................................................................................. 12

2.3.1. Terminologia.............................................................................................................. 12

2.3.2. Modos de Programą̧ão..................................................................................................... 14

2.3.3. Mecanismos de Cooperação entre Processos............................................................................17

2.4. Consideraçōes Finais ....................................................................................................................... 18

3. Ferramentas para Programaçāo Paralela ....................................................................19

3.1. Considerações Iniciais .......................................................................................................... 19

3.2. Classificação das Ferramentas.......................................................................................... 19

3.3. Ferramentas de Desenvolvimento de Programas Paralelos ................................................ 20

3.3.1. Linguagens de Programą̧ão Paralela ................................................................................. 21

3.3.2. Bibliotecas e Sistemas para Programação Paralela...................................................................2

3.3.3. Ambientes de Desenvolvimento ................................................................................................. 32

3.4. Ferramentas para Paralelização de Programas Seqüenciais ............................................. 35

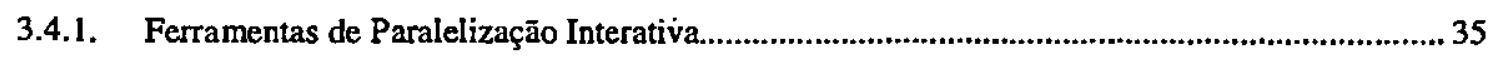


3.4.2. Ferramentas de Paralelização Automáticas

3.5. Ferramentas de Análise de Desempenho e Depuração...................................................... 39

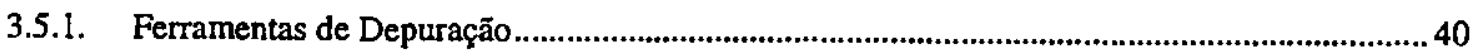

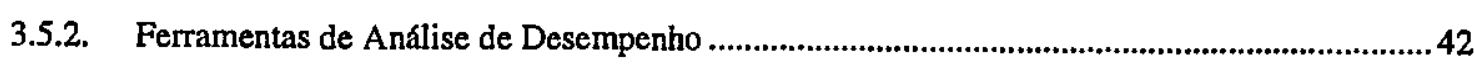

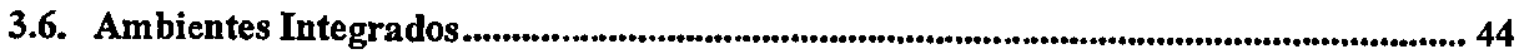

3.7. Outras Ferramentas para Processamento Paralelo...................................................... 48

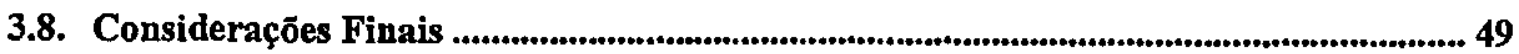

4. Metodologias Orientadas a Objetos para o Desenvolvimento de Software ................57

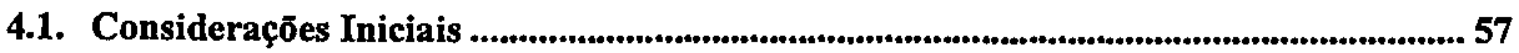

4.2. Tecnologia da Orientação a Objetos ....................................................................... 57

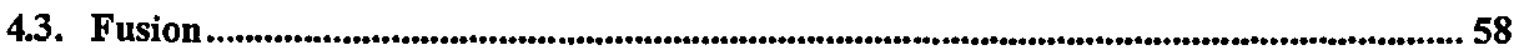

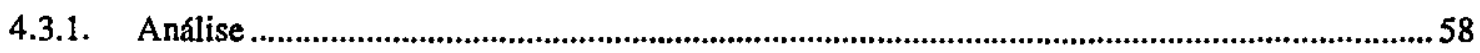

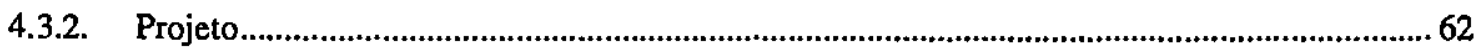

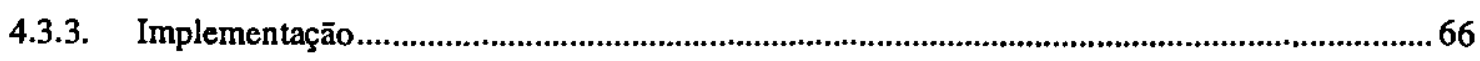

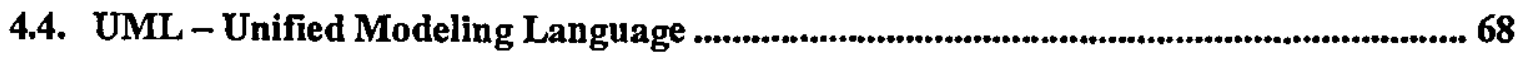

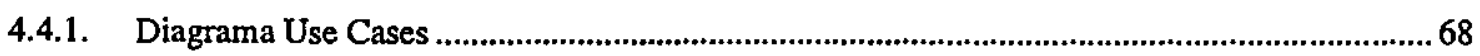

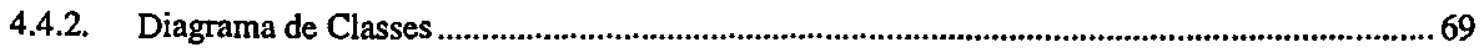

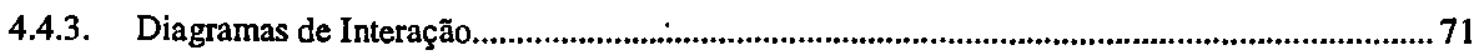

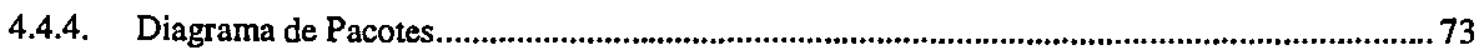

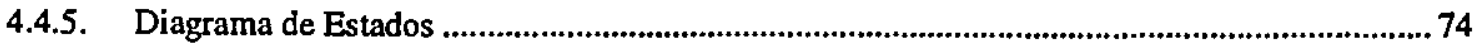

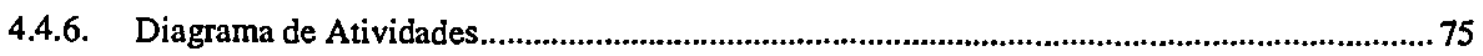

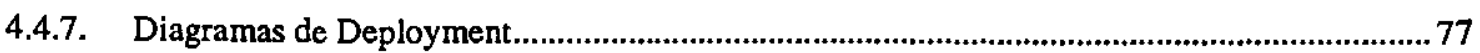

4.5. A Utilização das Metodologias no Desenvolvimento de Aplicações Paralelas............... 78

4.5.1. Requisitos Essenciais para Aplicaçōes Paralelas ....................................................................78

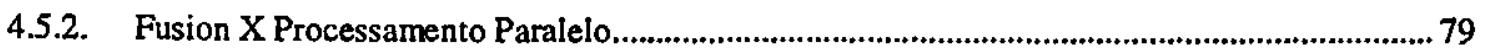

4.5.3. Unified Modeling Language X Processamento Paralelo ....................................................... 80

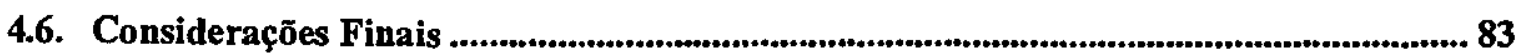

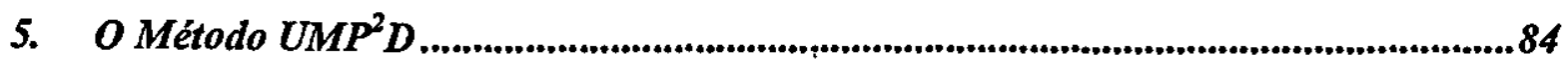

5.1. Considerações Iniciais ....................................................................................................... 84

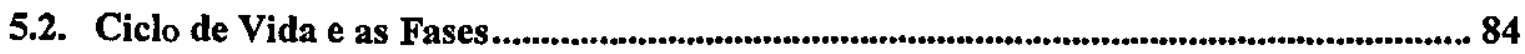

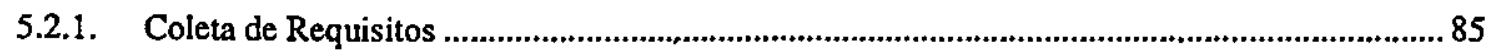




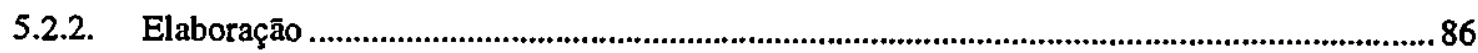

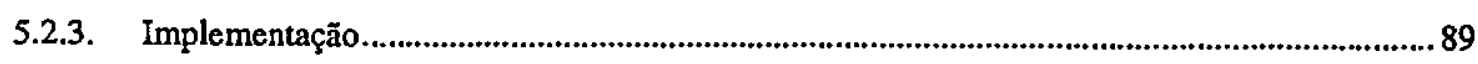

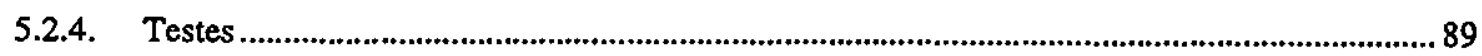

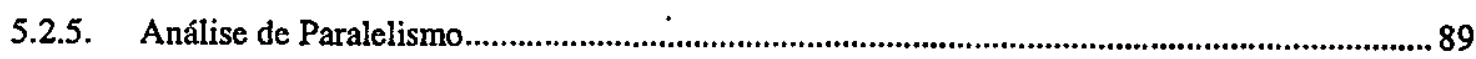

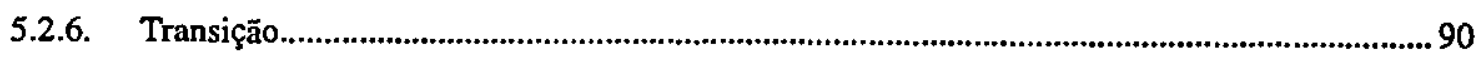

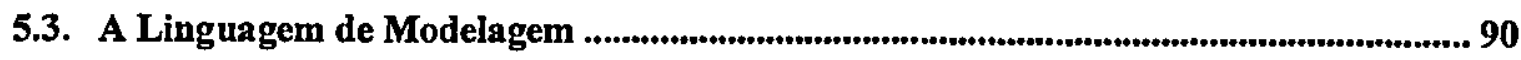

5.4. A Metodologia UMPP D e os Requisitos das Aplicações Paralelas .................................. 92

5.5. Estudo de Caso - Multiplicaçăo de Matrizes......................................................................... 94

5.5.1. Definiçăo do problema........................................................................................................... 94

5.5.2. Utilização da Metodologia para a Resolução do Problema..................................................... 95

5.6. Estudo de Caso - Transformada Rápida de Fourier ................................................. 113

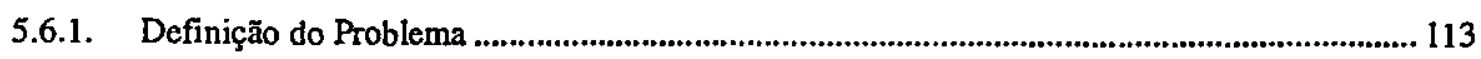

5.6.2. Utilização da Metodologia para a Resolução do Problema................................................... 117

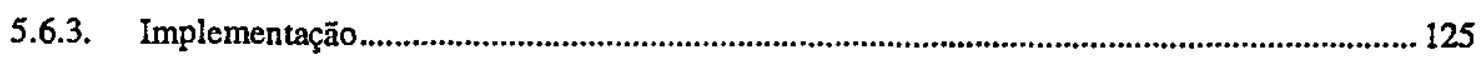

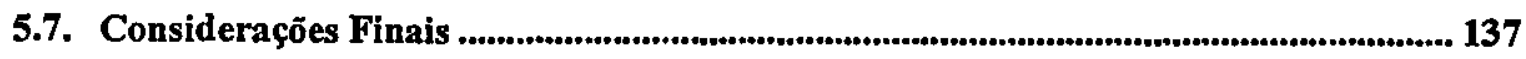

6. Ferramenta CASE para o Método UMP ${ }^{2} D$...........................................................139

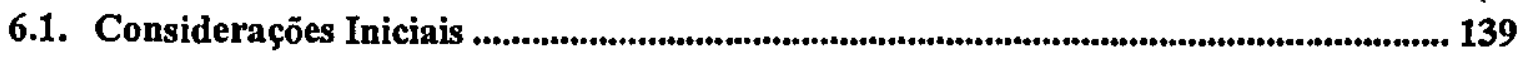

6.2. Características Essenciais da Ferramenta.................................................................. 139

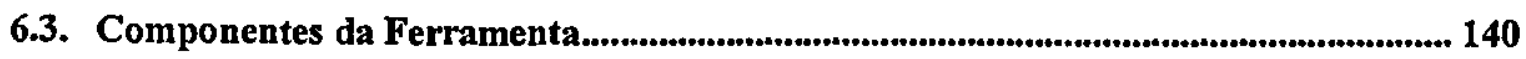

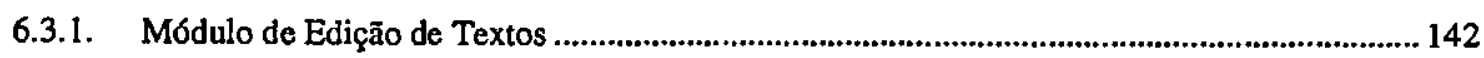

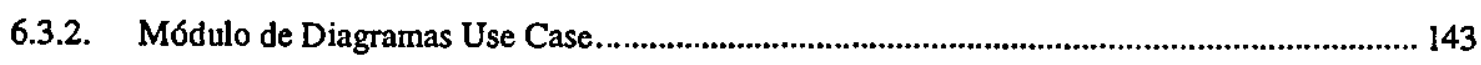

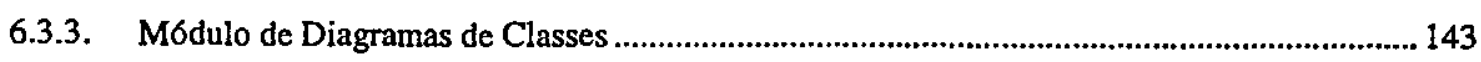

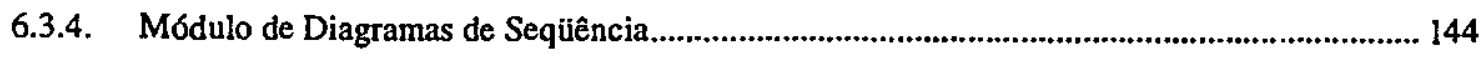

6.3.5. Módulo de Diagramas de Colaboraçāo ............................................................................ 145

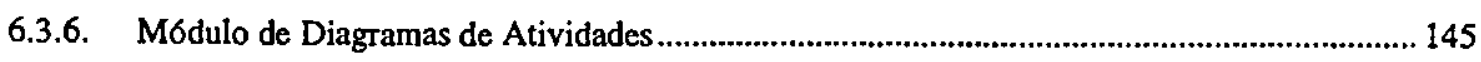

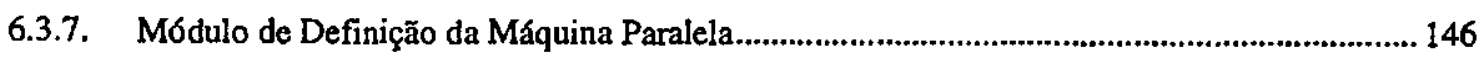

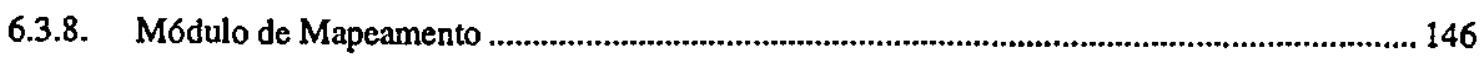

6.3.9. Módulo de Análise e Previsão de Desempenho .................................................................. 147

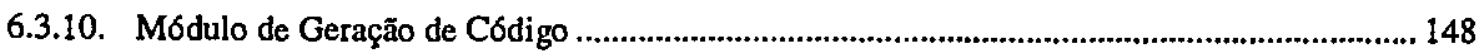

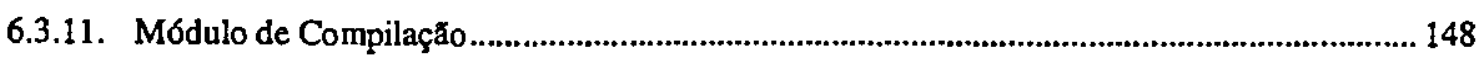

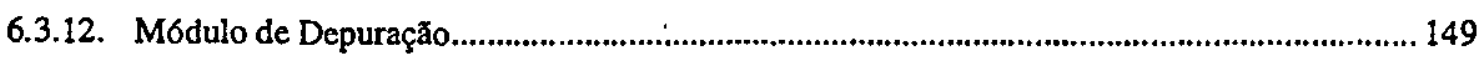

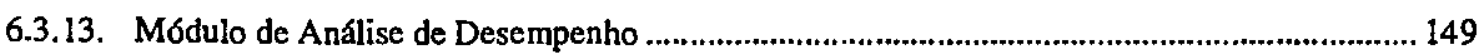

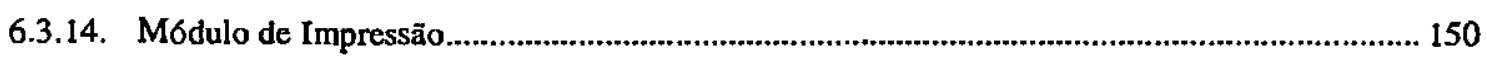




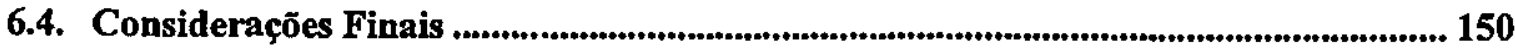

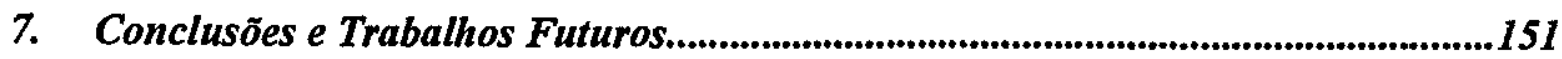

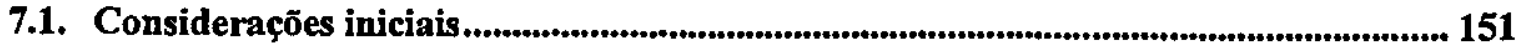

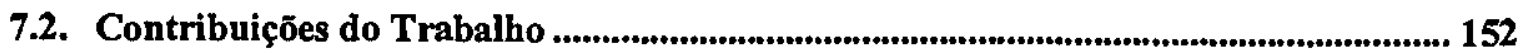

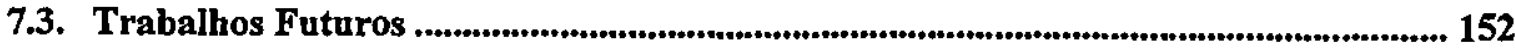

7.3.1. Utilização da UMP² D no Desenvolvimento de uma Aplicação Paralela de Grande Porte ..... 152

7.3.2. Implementação da Ferramenta CASE................................................................................. 153

7.3.3. Utilização de Ferramentas Existentes na Implementação da Metodologia ............................... 153

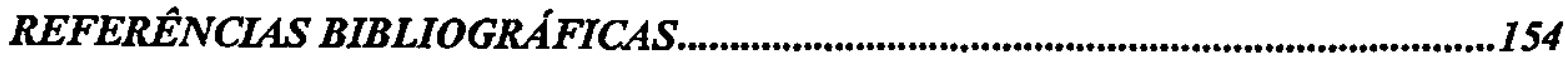




\section{Lista das Figuras}

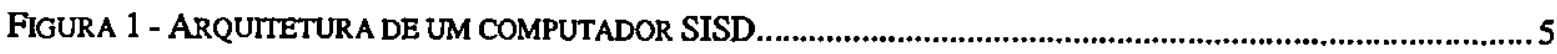

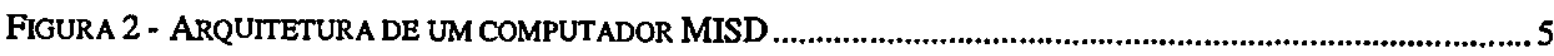

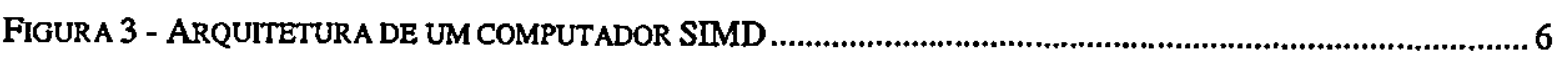

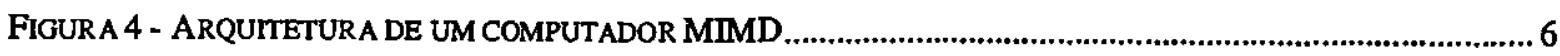

FIGURA 5 - ORGANIZAÇĀO DE UM PROCESSADOR PIPELINE VETORIAL ...........................................................8

FIGURA 6 - MÁQUINA MIMD COM MEMÓRIA COMPARTILHADA ..............................................................9

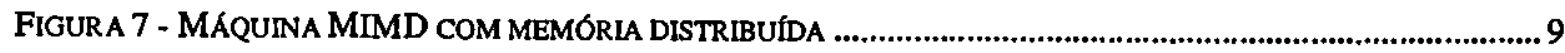

FIGURA 8 - FUNCIONAMENTO DE UMA MÁQUINA BASEADA EM FLUXO DE DADOS ........................................... 10

FIGURA 9 - FUNCIONAMENTO DE UMA MÁQUINA DE REDUÇÄO .................................................................11

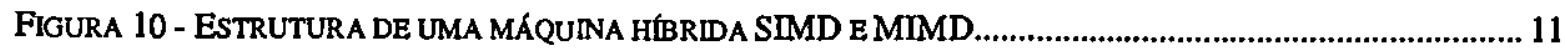

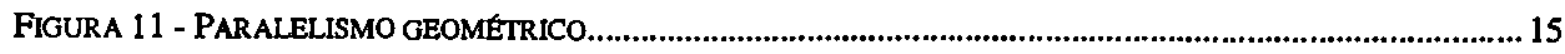

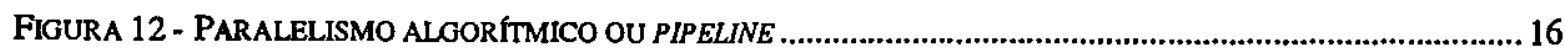

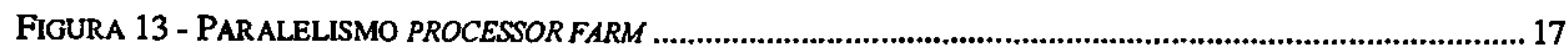

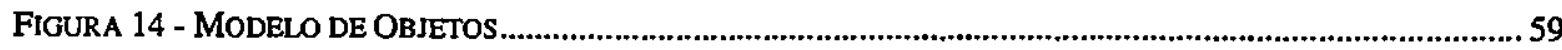

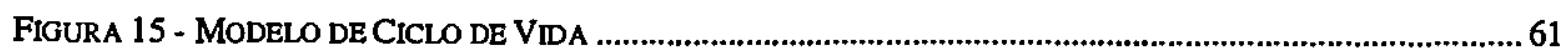

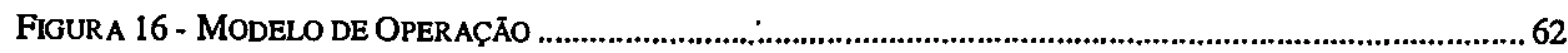

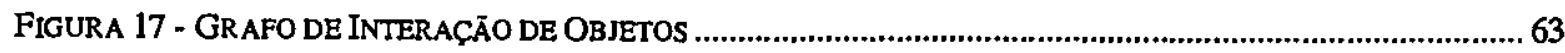

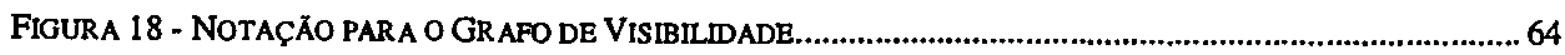

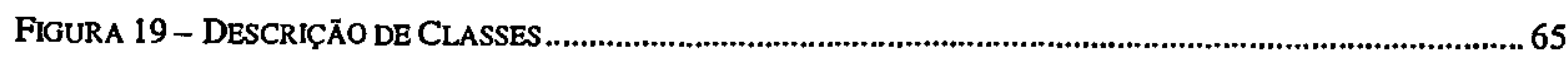

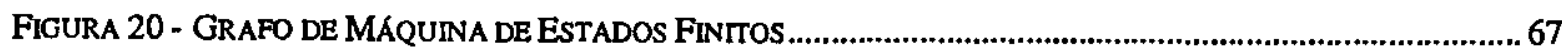

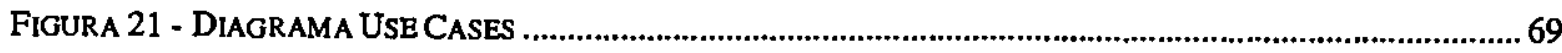

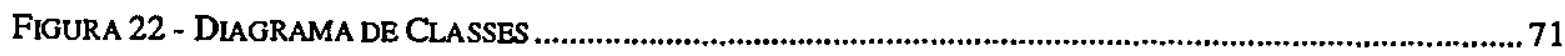

FIGURA 23 - DIAGRAMA DE SEQUENCIA

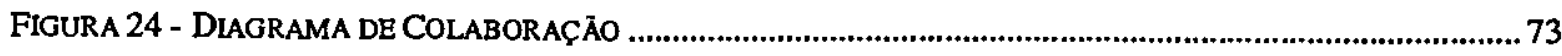

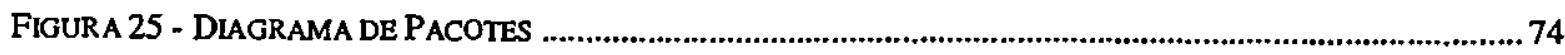

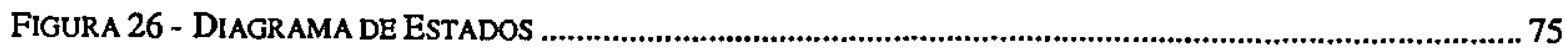

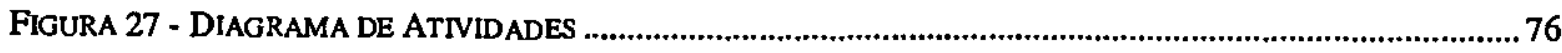

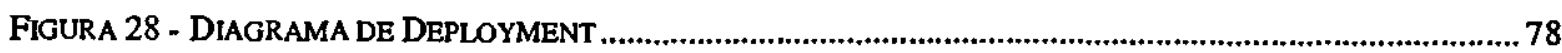

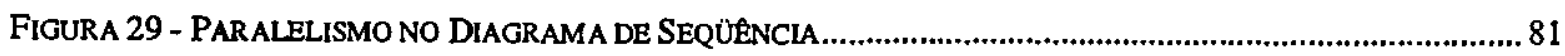

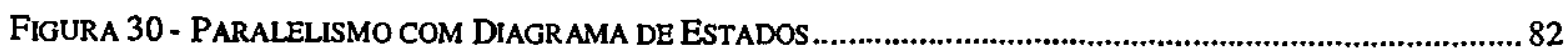

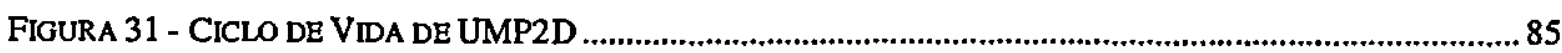

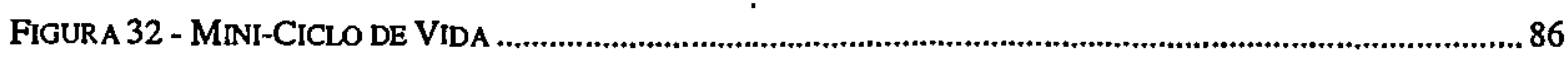

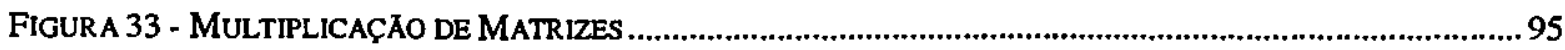




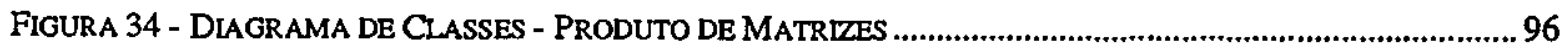

FIGURA 35 - DIAGRAMA DE COLABORAĢÃO - MULTIPLICAÇĀO DE MATRIZES ................................................. 98

FIGURA 36 - DIAGRAMA DE SEQUUENCIA - MULTIPLICAÇÃo DE MATRIZES ................................................99

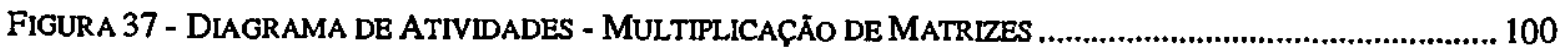

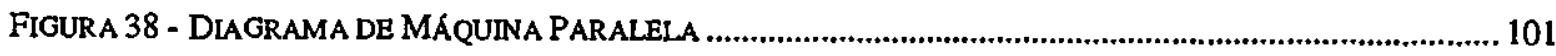

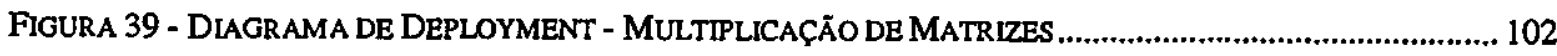

FIGURA 40 - FUNCIONAMENTO DO ALGORITMO DE MULTIPLICAÇÃO DE POLINÓMIOS .....................................114

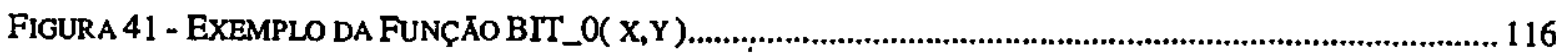

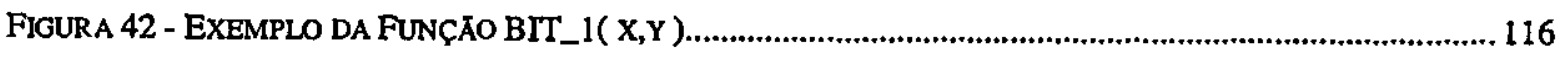

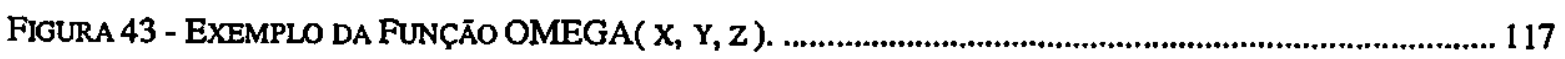

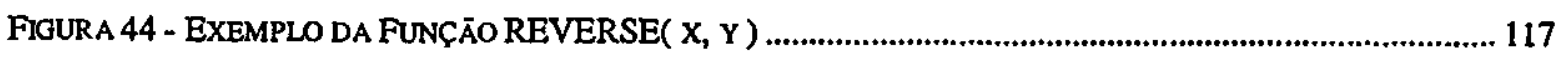

FigURA 45 - DIAGRAMA DE CLASSES - TRANSFORMADA DE FOURIER....................................................119

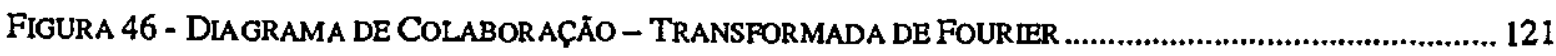

FIGURA 47 - DIAGRAMA DE SEQÜENCIA - TRANSFORMADA DE FOURIER ............................................... 122

FIGURA 48 - DIAGRAMA DE ATIVIDADES - TRANSFORMADA DE FOURIER .................................................... 123

FIGURA 49 - DIAGRAMA DE DEPLOYMENT - TRANSFORMADA DE FOURIER................................................. 124

FIGURA 50 - ESTRUTURA INTERNA DA FERRAMENTA 


\section{Lista das Tabelas}

Tabela 1 - Ferramentas para Desenvolvimento de Programas Paralelos ......................................49

Tabela 2 - Ferramentas para Paralelizaçāo de Programas Seqúnciais.......................................52

TABELA 3 - FERRAMENTAS PARA DEPURAÇĀo E ANÁLISE DE DESEMPENHO.................................................53

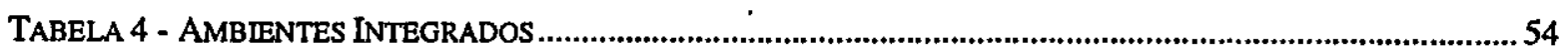

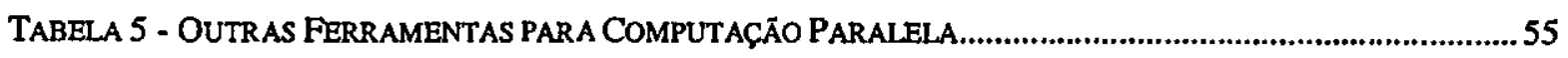

TABELA 6 - OPERADORES DAS EXPRESSŐES REGULARES DO MODELO DE CICLO DE VIDA ..............................61 


\section{Resumo}

O desenvolvimento de aplicações paralelas é uma tarefa complexa. Esse tipo de aplicação possui um grande potencial para comportamento não determinístico. Para a resolução deste problema podem ser utilizadas ferramentas de auxílio à programação paralela. Também são necessárias metodologias de desenvolvimento de software para a obtenção de programas com qualidade e desempenho satisfatórios.

Este trabalho apresenta a $U M P^{2} D$, uma metodologia orientada a objetos para o desenvolvimento de aplicações paralelas. Esta metodologia faz o uso da UML (Unified Modeling Language) como linguagem de modelagem e introduz novos processos de desenvolvimento de aplicações paralelas. A UMP ${ }^{2} \mathrm{D}$ atende aos principais requisitos de desenvolvimento de programas paralelos tais como o balanceamento eficiente de carga, a minimização da comunicação entre os elementos de processamento e a maximização da eficiência computacional.

Neste trabalho tamberm é proposto um ambiente CASE (Computer Aided Software Engineering) para o desenvolvimento de aplicações paralelas utilizando a metodologia $\mathrm{UMP}^{2} \mathrm{D}$. 


\section{Abstract}

The development of parallel software is a complex task. Parallel programs have high potential to non-deterministic behavior. Parallel tools can be used to overcome this problem, but software methodologies are needed in order to obtain high-performance and high-quality software.

The $\mathrm{UMP}^{2} \mathrm{D}$ is an object-oriented methodology for the development of parallel software. This methodology makes extensive use of UML (Unified Modeling Language) diagrams and presents a new development process for parallel applications. UMP ${ }^{2} D$ provides support to the main parallel software requirements, namely, load balancing, reduced inter-process communication and maximum computing efficiency.

This work also presents a proposal for a CASE (Computer Aided Software Engineering) environment for the development of parallel software using UMP ${ }^{2} \mathrm{D}$. 


\section{Introdução}

\subsection{Aspectos Gerais}

O crescimento da utilização de computadores na área científica para a solução de problemas matemáticos, físicos e químicos exige computadores cada vez mais velozes. $\mathrm{Na}$ verdade, o aumento da complexidade dos problemas acompanha o aumento do poder computacional disponível para resolvê-los.

Para aumentar a velocidade do processamento pode-se seguir três caminhos. $O$ primeiro consiste no aumento da velocidade de clock da CPU, limitado por fatores físicos. O segundo consiste na inclusão de melhorias na arquitetura, como melhores hierarquias de memória e maior número de pipelines. O terceiro caminho é a utilização de várias unidades de processamento trabalhando de forma associativa para a solução de problemas. Essa alternativa é chamada processamento paralelo.

O processamento paralelo deve ser explorado através do desenvolvimento de programas paralelos. Diversas técnicas podem ser utilizadas para o desenvolvimento desses programas, que é significativamente mais complicado e difícil que o desenvolvimento de programas seqüenciais. Os programas paralelos freqüentemente possuem um grande potencial para comportamento não determinístico. Esse comportamento pode ser causado pelo tempo utilizado na comunicação entre os vários processadores, velocidades diferentes dos processadores e falta de sincronização entre tarefas.

O desenvolvimento de aplicaçōes paralelas pode ser simplificado com a utilização de ferramentas para cada uma das fases desse processo. Várias ferramentas foram desenvolvidas com esse propósito, cada uma delas com características diferentes. Essas diferenças criam grupos distintos de ferramentas para processamento paralelo. No decorrer do trabalho foi realizada uma pesquisa sobre as ferramentas de programação paraleia existentes, analisando-se suas características principais e sua utilização, tendo sido proposta uma nova classificação para essas ferramentas.

O grupo de ferramentas paralelas de maior importância é aquele formado peios ambientes integrados de desenvolvimento. Esses ambientes geralmente são formados por 
um conjunto de ferramentas que auxiliam o desenvolvedor de programas paralelos em todas as fases do desenvolvimento.

Apesar da grande quantidade de ferramentas para o desenvolvimento de aplicações paralelas, esse desenvolvimento é feito sem a utilização de metodologias de engenharia de software. Desenvolvendo-se dessa forma o software geralmente não possui documentação adequada, dificultando uma posterior manutenção, e pode apresentar baixa qualidade. Para suprir essa deficiência, foi realizada uma pesquisa sobre as metodologias de desenvolvimento de programas seqüenciais mais utilizadas.

O objetivo principal deste projeto é a definição de uma metodologia orientada a objetos para o desenvolvimento de aplicações paralelas, utilizando tecnologia atual de desenvolvimento de programas sequienciais e atendendo os principais requisitos para o desenvolvimento de programas paralelos: balanceamento eficiente de carga, minimização da comunicaçāo e maximização da eficiência computacional.

A utilização em larga escala de linguagens orientadas a objetos motivou a utilização de metodologias orientadas a objetos em todas as fases de desenvolvimento de software, principalmente nas fases de análise e projeto. Diversas metodologias surgiram entre as quais Fusion, OMT, Booch e UML:

Através de um estudo detalhado das principais metodologias orientadas a objetos utilizadas em aplicações convencionais, é feita uma análise para verificar a possibilidade de utilização dessas metodologias no desenvolvimento de aplicações paralelas.

Foi utilizada neste trabalho a UML como linguagem de modelagem e foi definido um processo de desenvolvimento adequado para o desenvolvimento de aplicações paralelas. 


\subsection{Estrutura do Texto}

O texto está estruturado em 7 capítulos. No capítulo 2 é feita uma revisão de literatura focando a computação paralela. São apresentados os principais conceitos sobre processamento e programação paralela, as arquiteturas paralelas e suas classificações, os modelos de programação e a terminologia utilizada.

No capítulo 3 é apresentada a pesquisa realizada sobre as ferramentas disponíveis para computação paralela. É definida uma classificação para essas ferramentas de acordo com as suas características principais.

O capítulo 4 apresenta o estudo realizado sobre as metodologias orientadas a objetos existentes para o desenvolvimento de aplicações convencionais, enfocando UML e Fusion, suas características principais, além de uma análise da possível utilização dessas metodologias no desenvolvimento de aplicações paralelas.

No capítulo 5 é apresentada a metodologia proposta neste trabalho, a UMP'D, mostrando-se o ciclo de vida da metodologia, o processo de desenvolvimento, suas fases e os diagramas utilizados nessas fases. Nesse capítulo também são apresentados estudos de caso, utilizando-se problemas simples para exemplificar a utilização da metodologia.

O sexto capítulo apresenta a especificação de uma ferramenta CASE para a automatização da metodologia proposta, sua estrutura intema e alguns detalhes da sua implementação.

Finalmente, no capítulo 7 são apresentadas as conclusões sobre o trabalho realizado, como também algumas propostas para trabalhos futuros. 


\section{Computação Paralela}

\subsection{Considerações Iniciais}

Para um melhor entendimento do projeto a ser desenvolvido é necessária a definição de alguns conceitos relacionados com computação paralela, sua terminologia e arquiteturas utilizadas. Também são apresentadas algumas classificaçðes para as arquiteturas paralelas existentes.

No item 2.2 são referenciadas algumas classificaçðes de arquiteturas utilizadas para o processamento paralelo. $O$ item 2.3 define alguns conceitos sobre a programação paralela como terminologia, modelos e mecanismos de cooperação entre processos.

\subsection{Arquiteturas Paralelas}

Com o desenvolvimento das pesquisas em computação paralela, verificou-se a necessidade de se classificar as diversas arquiteturas existentes. Vários pesquisadores estudaram as principais características das arquiteturas paralelas e propuseram métodos para a classificação dessas arquiteturas. Algumas dessas classificações não tiveram repercussão no meio científico e não são utilizadas. Nos itens seguintes são apresentadas as duas classificações de uso mais comum.

\subsubsection{Classificação de Flynn}

A taxinomia proposta por Flynn [Nav89, Alm94] é uma classificação clássica de arquitetura de computadores, baseada na maneira segundo a qual fluxos de dados e de instruçōes são tratados. Segundo a abordagém de Flynn, os computadores são divididos em quatro categorias:

\subsubsection{SISD (Single Instruction Single Data)}

Categoria composta por computadores escalares tradicionais em que uma cadeia de instruções é processada seqüencialmente, uma após a outra. Esta categoria inclui a . arquitetura seqüencial de von Neumann e arquiteturas com alguns melhoramentos para 
aumento de desempenho tais como os pipelines de execução. A estrutura de uma máquina SISD é apresentada na Figura 1.

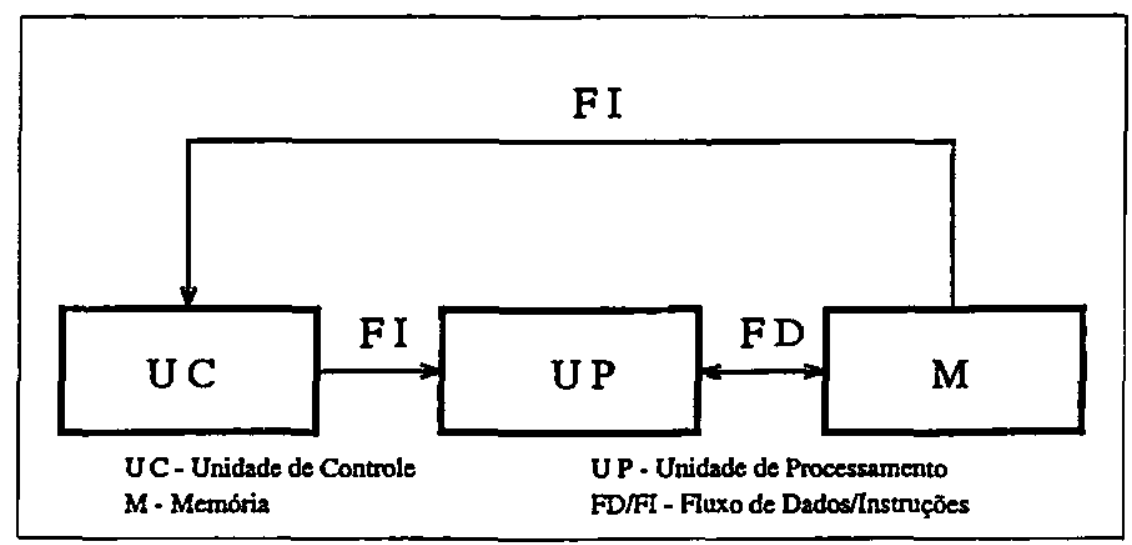

Figura 1 - Arquitetura de um computador SISD

\subsubsection{MISD (Multiple Instruction Single Data)}

Nessa categoria várias instruções são executadas simultaneamente em um mesmo fluxo de dados. Essa arquitetura nunca é adotada na prática, sendo incluída aqui apenas para tornar a classificação de Flynn completa. Alguns autores, entretanto, costumam incluir nessa categoria os processadores com unidades funcionais baseadas em pipelines. A Figura 2 apresenta a arquitetura de uma máquina MISD.

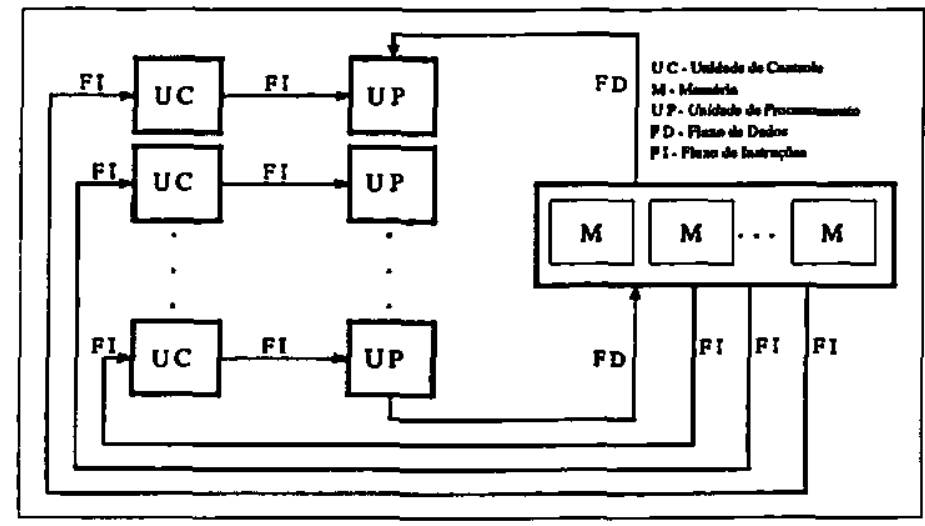

Figura 2 - Arquitetura de um computador MISD 


\subsubsection{SIMD (Single Instruction Multiple Dàta)}

Na categoria SIMD estão as arquiteturas de computadores que executam simultaneamente, de maneira sincronizada, a mesma cadeia de instruções em fluxos de dados múltiplos. $\mathrm{Na}$ Figura 3 é apresentada a estrutura de uma máquina SIMD.

Nessa categoria estão máquinas paralelas com grande número de processadores. Também são classificados nesta categoria, os computadores puramente vetoriais, que executam em suas unidades vetoriais uma mesma instrução em conjuntos de dados denominados vetores.

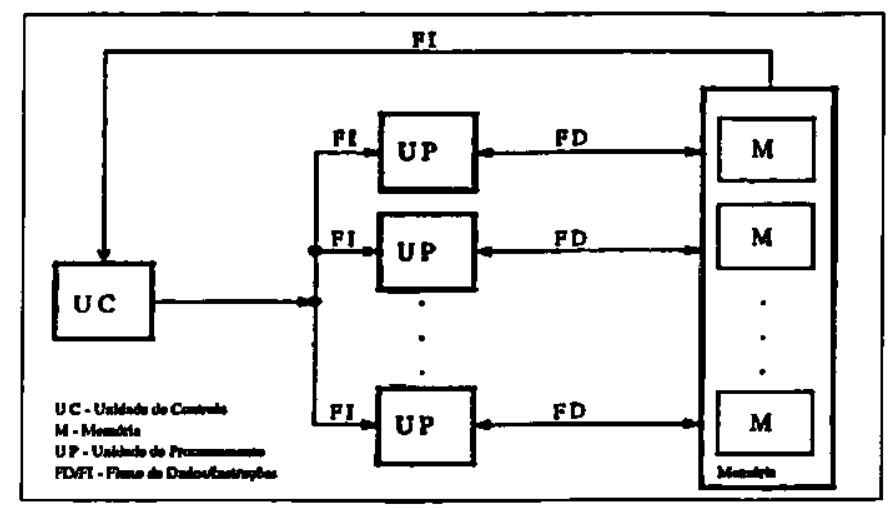

Figura 3 - Arquitetura de um computador SIMD

\subsubsection{MIMD (Multiple Instruction Multiple Data)}

Essa é a categoria mais flexível, permitindo que diferentes tarefas sejam executadas simultaneamente, em paralelo, em conjuntos de dados distintos. A arquitetura de uma máquina MIMD é mostrada na Figura 4. Nessa categoria encontra-se a grande maioria dos computadores de alto desempenho atuais.

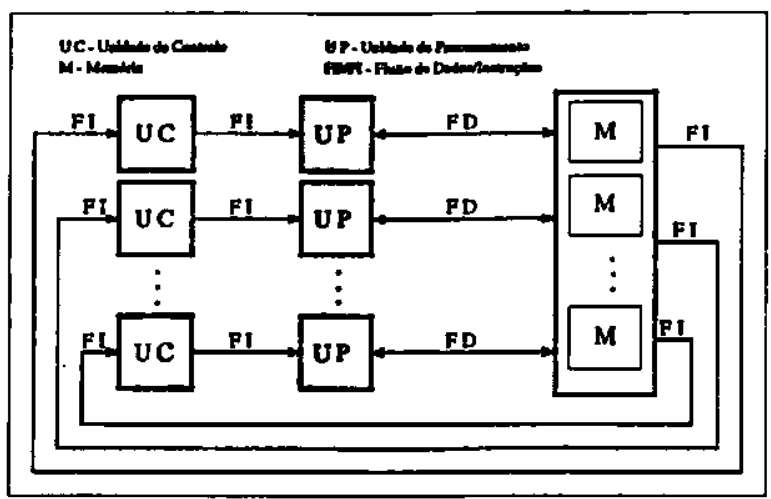

Figura 4 - Arquitetura de um computador MIMD 
A classificação de Flynn apresenta alguns problemas, pois ela não enquadra perfeitamente algumas arquiteturas como os processadores vetoriais pipeline, as arquiteturas sistolicas e de fluxo de dados.

\subsubsection{Classificação de Duncan}

Para corrigir as falhas na classificação de Flynn em acomodar algumas arquiteturas, Duncan [Alm94, Dun90, Per96] fez um estudo e sugeriu uma outra classificação que se baseou na existência de um clock central para sincronização, utilizando as seguintes diretrizes:

- Excluir máquinas de um único processador que apresentam baixo nível de paralelismo como aquelas que possuem somente pipeline de instruções, múltiplas unidades funcionais ou processadores gráficos e de ponto-flutuante;

- Manter a essência da taxinomia de Flynn, baseada na quantidade de fluxos de dados e de instruçōes;

- Estender a taxinomia de Flynn para incorporar arquiteturas que são claramente paralelas mas que não se enquadram no esquema original.

De acordo com essas diretrizes ele propôs a seguinte classificação:

\subsubsection{Arquiteturas Síncronas}

Arquiteturas paralelas síncronas são aquelas que se caracterizam por apresentar um único clock global e unidades de controle centrais que podem executar qualquer uma das threads correntes. Entre as arquiteturas síncronas podem ser citadas:

\subsection{Processadores Pipeline Vetoriais}

São máquinas projetadas para explorar o paralelismo temporal envolvido na execução de operações sobre vetores e matrizes. Essas máquinas dispõem de um hardware específico que permite a execução de. uma sequiência de operações idênticas sobre um conjunto de dados arranjados em uma estrutura do tipo vetor. Na Figura 5 é apresentada a organização de um processador pipeline vetorial. 
Sua organização básica consiste em um processador de instruções que busca e decodifica instruçōes, uma unidade de processamento vetorial para a execução de operações vetoriais e um processador escalar para executar a parcela não vetorizável do programa. Para aumentar o desempenho, os processadores vetoriais utilizam a técnica de pipeline.

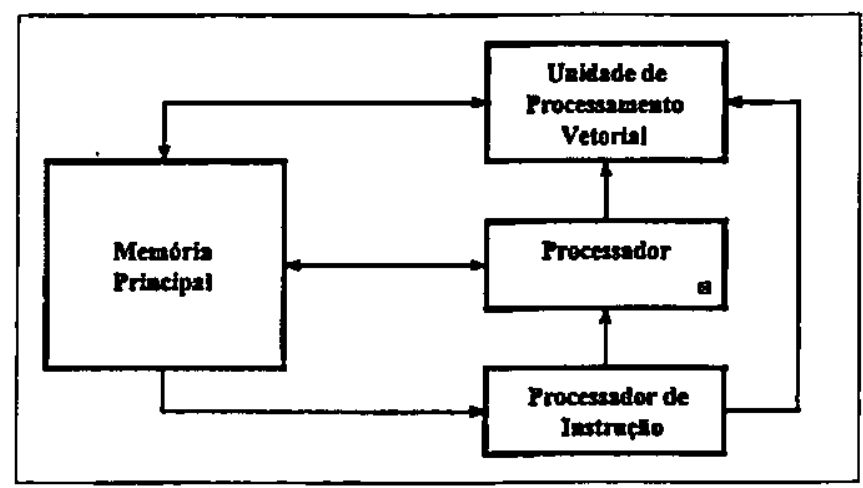

Figura 5 - Organização de um processador pipeline vetorial

\subsection{SIMD}

Nessas máquinas uma unidade de controle central envia instruçōes para muitas unidades de processamento que agem sobre conjuntos de dados em paralelo.

\subsection{Arranjos Sistólicos}

Em máquinas do tipo Arranjo Sistólico os dados são bombeados ritmicamente através de uma matriz de processadores que executam as transformações desejadas e depois passam os resultados para os próximos processadores do arranjo.

\subsubsection{Arquiteturas Assíncronas Convencionais - MIMD}

As arquiteturas MIMD são constituídas por elementos de processamento assíncronos que atuam de forma autônoma. A forma de comunicação entre esses elementos de processamento dá origem a duas subclasses, definidas a seguir.

\subsection{Memória compartilhada}

Os sistemas MIMD com memória compartilhada são caracterizados pelo fato de que os elementos de processamento compartilham um único espaço de endereçamento, podendo* 
acessar uma região de memória comum, como mostrado na Figura 6. Geralmente são chamados de multiprocessadores ou arquiteturas MIMD fortemente acopladas.

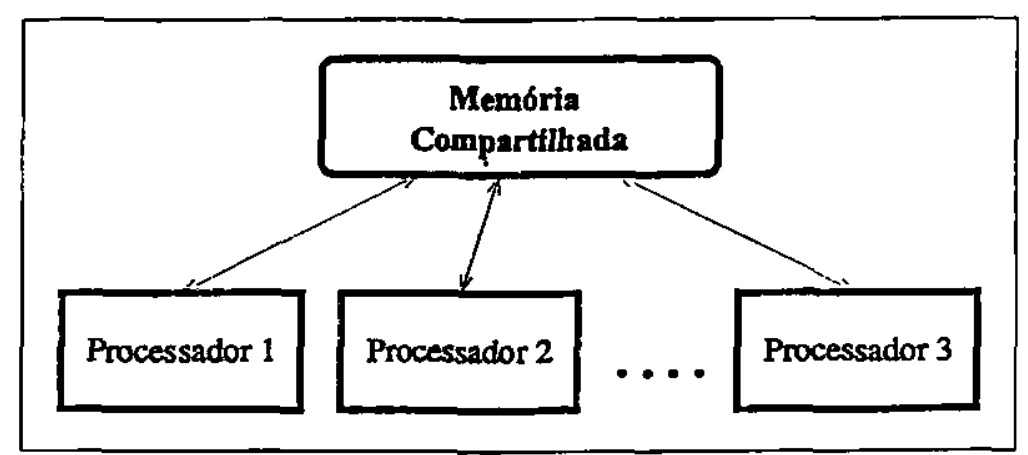

Figura 6 - Máquina MIMD com memória compartilhada

\subsubsection{Memória Distribuída}

As arquiteturas MIMD com memória distribuída são constituídas por processadores autônomos com memórias locais, como apresentado na Figura 7. O espaço de endereçamento é distinto para cada processador. Essas arquiteturas são denominadas de multicomputadores ou arquiteturas MIMD fracamente acopladas. As informações nesses sistemas são compartilhadas através da troca de mensagens explícita entre os elementos de processamento.

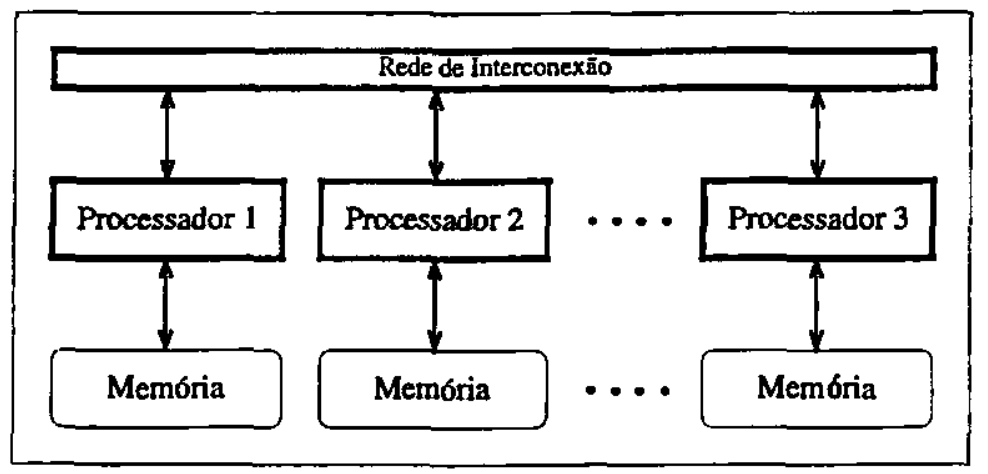

Figura 7 - Máquina MIMD com memória distribuída

Essas máquinas constituem a plataforma mais prática para o processamento paralelo de propósito geral, devido a facilidade de implementação, baixo custo e elevada escalabilidade. 


\subsubsection{Arquiteturas Assíncronas Não Convencionais}

Várias arquiteturas paralelas apresentam características e estruturas internas que não se enquadram nas classificações anteriores.

\subsection{Arquiteturas Dataflow - Fluxo de Dados}

Essas arquiteturas são caracterizadas pela forma de controle que faz com que as instruções sejam executadas quando os operandos se tornam disponíveis, isto é, a execução é dependente do fluxo dos dados. O funcionamento deste tipo de arquitetura é mostrado na Figura 8.

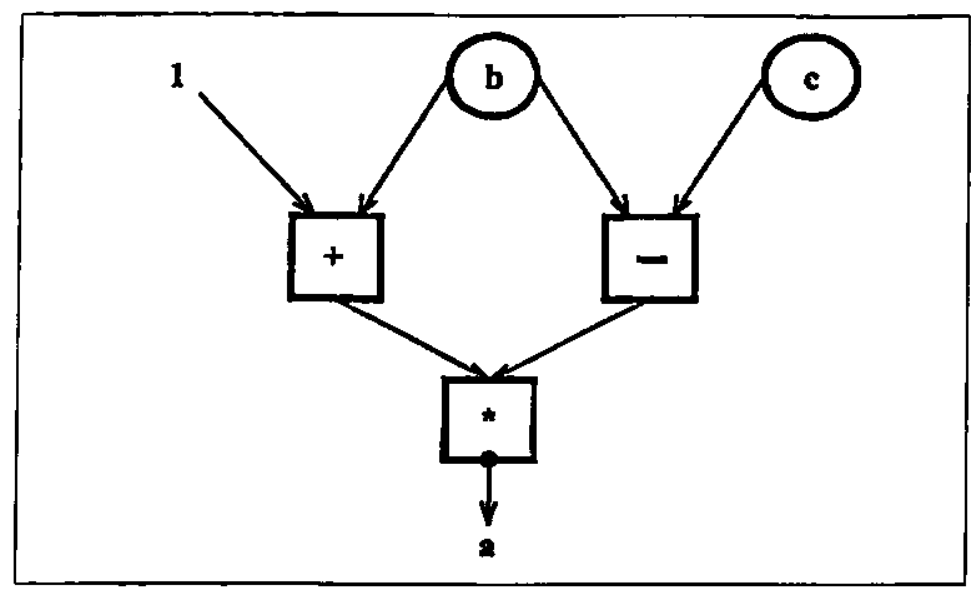

Figura 8 - Funcionamento de uma máquina baseada en fluxo de dados

\subsection{Arquiteturas de Redução}

Essa arquitetura é caracterizada pela execução sob demanda, isto é, as expressð̃es são calculadas de acordo com a necessidade do valor das mesmas. Na Figura 9, os valores de tl e t2 serão calculados somente quando forem necessários para calcular o valor da expressão representada pela variável a. 


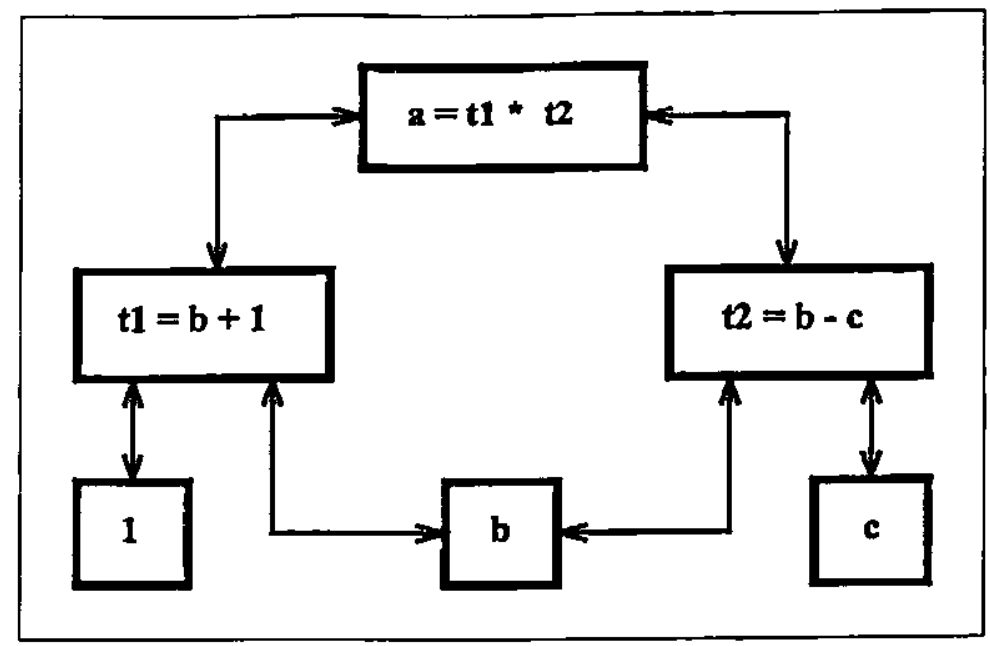

Figura 9 - Funcionamento de uma máquina de redução

\subsection{Arquiteturas Hibridas - SIMD e MIMD}

Algumas arquiteturas hîbridas são obtidas pela substituição de partes de uma arquitetura MIMD por partes do tipo SIMD. Este tipo de arquitetura proporciona bastante flexibilidade, tornando-se atraente para determinados tipos de aplicação. A estrutura de uma máquina híbrida - SIMD/MIMD é mostrada na Figura 10.

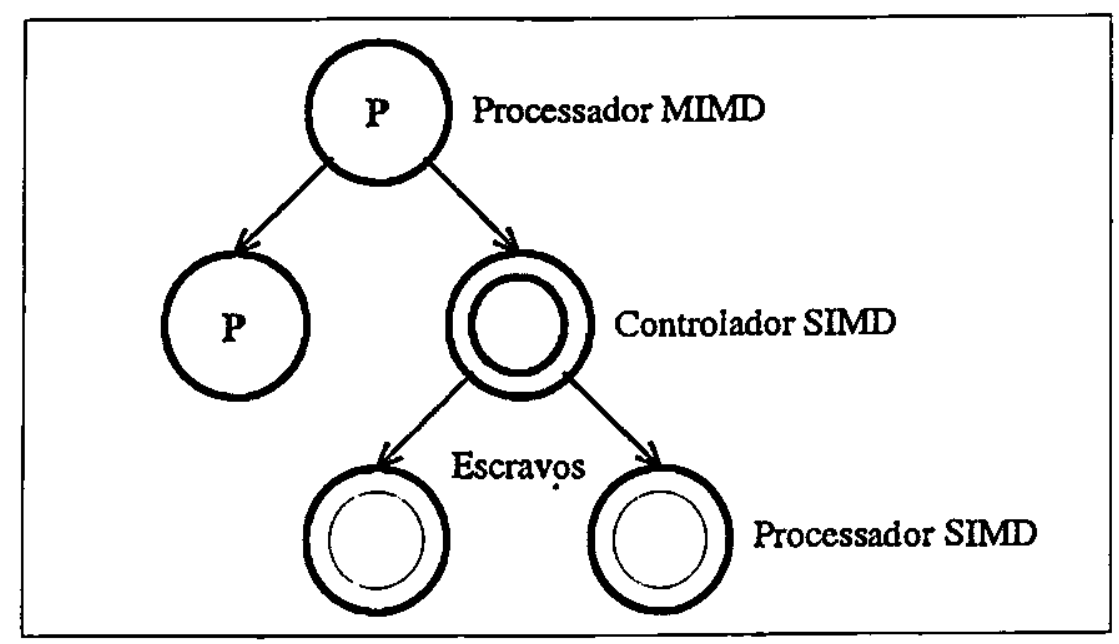

Figura 10 - Estrutura de uma máquina híbrida SIMD e MIMD 


\subsection{Programação Paralela}

Esta seção apresenta algumas considerações importantes sobre programação paralela e a definição de alguns conceitos que serão mencionados no decorrer do trabalho. Os termos mais utilizados nessa área são definidos e são apresentados os modelos de programação e mecanismos de cooperação utilizados em processamento paralelo.

\subsubsection{Terminologia}

Alguns termos [Eli95, Fos95, Car89] utilizados em processamento paralelo são descritos a seguir:

- Tarefa ou processo: uma unidade logicamente distinta de um programa.

- Execução seqüencial: execução de um programa em um único processador, onde uma instrução é processada de cada vez.

- Paralelização de código: transformação de um programa seqüencial em paralelo, através da identifícação de tarefas independentes no programa. As tarefas definidas podem ser executadas em paralelo. Geralmente, a paralelização requer mudanças no código e no algoritmo utilizado no programa seqüencial.

- Aceleração de um programa (SpeedUp): razão entre os tempos de execução das versões seqüencial e paralela de um mesmo programa ou algoritmo. Para um determinado algoritmo, considera-se a implementação seqüencial executada em menor tempo como referencia para a comparação com a implementação paralela:

$$
\text { Aceleração }(\text { SpeedUp })=\frac{\text { Tempo de execução do programa seqüencial }}{\text { Tempo de execução da versão paralela }}
$$

- Eficiência de um programa: razão entre a aceleração de um programa e o número de processadores utilizados para a execução do programa. Este parâmetro é uma medida da fração do tempo em que o processador está sendo utilizado para executar o algoritmo. Idealmente, se p processadores utilizassem $100 \%$ do seu tempo somente para operações de computação do algoritmo, a eficiência seria igual a 1. Como o programa paralelo 
requer comunicação entre os processadores, parte do tempo dos processadores é gasto nessa atividade, levando a valores de eficiência inferiores a 1.

- Sincronização: coordenação temporal entre tarefas, usada para a troca de informações entre elas. É um fator de decréscimo na aceleração atingida por um programa paralelo, pois alguns processadores podem ficar inativos, esperando pelo término de outras tarefas em outros processadores. A comunicação entre processadores é dita síncrona quando exige sincronização para ser realizada.

- Granulosidade: volume de processamento realizado por cada tarefa, em reiação ao volume de comunicação existente entre as tarefas. Um programa de granulosidade fina possui tarefas que realizam poucas instruções e necessitam se comunicar muito, enquanto um programa de granulosidade grossa possui tarefas que executam muitas instruções e utilizam pouca comunicação. Programas com granulosidade mais grossa necessitam de sincronização mais freqüente, introduzindo períodos de inatividade nos processadores e aumentando o tempo total de execução.

- Escalabilidade: diz-se que um sistema definido por um algoritmo paralelo e uma máquina paralela é escalável se a aceleração atingida cresce proporcionalmente com o número de processadores. Os fatores que contribuem para a escalabilidade de um sistema são o hardware do sistema, o algoritmo utilizado e o código implementado.

- Balanceamento de carga: distribuição das tarefas entre os processadores, de modo a garantir a execução mais eficiente possível do programa paralelo. Esse balanceamento pode ser feito de maneira estática, antes do início da execução, ou de maneira dinâmica, em tempo de execução.

- SPMD (Single Program Multiple Data): modelo de programação bastante utilizado, no qual todos os processadores executam o mesmo programa sobre diferentes conjuntos de dados.

- Determinismo: um algoritmo ou programa é determinístico se a sua execução com uma determinada entrada sempre resulta na mesma saída. Diz-se que um programa é não-determinístico caso exista a possibilidade de se obter saídas diferentes para várias execuções do programa, utilizando-se sempre os mesmos dados de entrada. 
- Comunicação bloqueante: em uma comunicação bloqueante o transmissor envia a mensagem para o receptor e aguarda até que esse confirme o recebimento da mensagem enviada. Se um dos lados da comunicação não estiver pronto, o outro fica bloqueado (parado) aguardando. Após a confirmação de recebimento os dois ficam liberados. Este tipo de comunicação não utiliza buffers.

- Comunicação não-bloqueante: neste tipo de comunicação o transmissor envia a mensagem e continua sua execução sem sofrer nenhum tipo de bloqueio. Se o receptor não estiver pronto essa mensagem fica armazenada em um buffer. Se o receptor estiver pronto e não há mensagens a serem recebidas, ele fica bloqueado.

- Concorrência: a concorrência existe quando dois ou mais processos iniciaram a sua execução e ainda não terminaram. A concorrência pode existir em um processador ou em vários. Quando há concorrência em um processador, o tempo é compartilhado pelos processos ativos.

- Paralelismo: o paralelismo ocorre quando há dois ou mais processos sendo executados no mesmo intervalo de tempo em diferentes elementos de processamento.

\subsubsection{Modos de Programação}

Há várias maneiras de implementar um programa paralelo, e essas dependem da natureza do problema. Para isso podem ser consideradas basicamente três abordagens. Cada uma delas envolve uma visão diferente dos processos e da distribuição dos dados.

De acordo com Carriero e outros pesquisadores [Eli95, Car89, Smi92], a construção do algoritmo pode ser feita através do paralelismo de resultados ou geométrico, do paralelismo pipeline ou algorítmico ou do paralelismo tipo processor farm.

\subsubsection{Paralelismo de Resultados ou Geométrico}

Essa abordagem leva esse nome devido ao fato de se definir as tarefas de cada um dos processadores partindo-se do produto final, do resultado a ser alcançado. Ela geralmente é apropriada para problemas nos quais o espaço de dados pode ser dividido em regiōes que são alocadas aos diversos processos, como mostrado na Figura 11. 
Normalmente o algoritmo executado em todos os processos é o mesmo, seguindo desta maneira, o modelo SPMD, onde há vários conjuntos de dados sendo manipulados com um mesmo algoritmo em vários processadores.

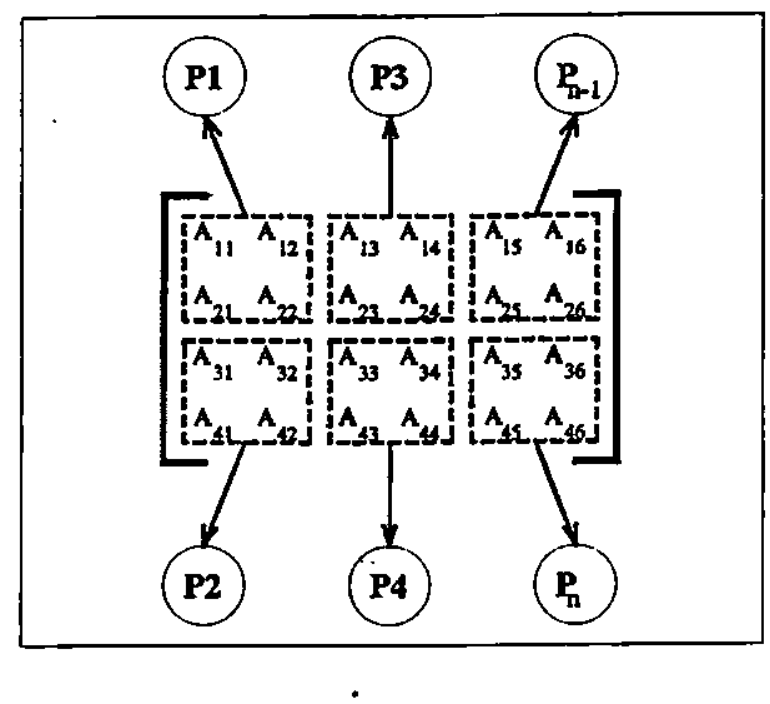

Figura 11 - Paralelismo geométrico

Esse tipo de paralelismo é também conhecido como paralelismo de dados, pois os dados são distribuídos entre os processadores que executam a mesma sequiência de instruçōes sobre eles.

Um fator importante para a implementação eficiente desse tipo de programação é o gerenciamento da localização dos dados. Para que um programa desse tipo execute eficientemente em máquinas com memória distribuída, os dados devem estar alocados na memória de processadores próximos daqueles que vão necessitar dos dados.

\subsubsection{Paralelismo Pipeline ou Algorítmico}

Neste tipo de paralelismo, o problema todo é divido em pequenas partes e cada um dos processos gerados durante essa separação é responsável por uma parte do algoritmo. Existe uma especialização de cada um dos processos.

O paralelismo pipeline, também é conhecido como paralelismo de tarefas, o programa é particionado em tarefas cooperativas. Essas tarefas podem executar procedimentos bastante diferentes entre si, cujo processamento pode ser feito de maneira 
assíncrona. Para maior eficiência da implementação dos programas, deve-se levar em conta ó gerenciamento da localização dos dados e o nível de granulosidade de cada tarefa.

Este paralelismo funciona como uma linha de montagem de uma indústria, onde cada um dos funcionários faz apenas uma pequena parte do trabalho e passa o restante para o próximo da linha até que o produto final esteja pronto. A Figura 12 apresenta o modelo de execução de um algoritmo que segue este modelo.

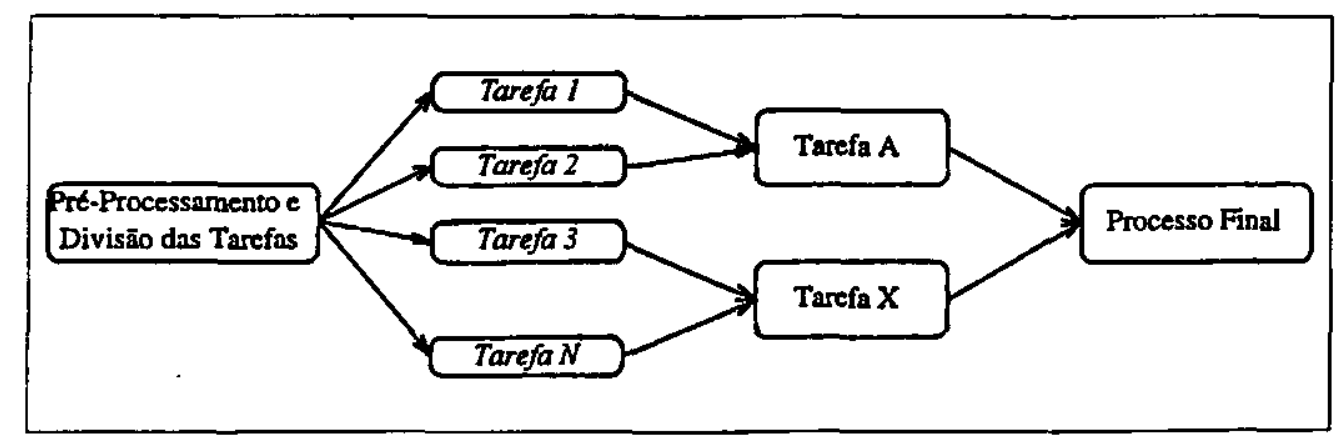

Figura 12 - Paralelismo algorítmico ou pipeline

Seguindo essa linha de pensamento, o processol executa o primeiro passo do programa e passa os resultados para o processo2, que executa o segundo passo, mas nesse mesmo tempo o processol executa o primeiro passo sobre uma outra parte dos dados.

Essa técnica tende a restringir a quantidade de paralelismo que pode ser explorado e é raramente eficiente, pois os últimos passos devem esperar até que os dados cheguem até eles.

\subsubsection{Paralelismo Processor Farm}

Também conhecido como mestre e escravo, nesse tipo de paralelismo existe um processo mestre que é responsável por passar as tarefas e distribuir os dados para os processos escravos.

Todos os processos são executados em paralelo. Quando um escravo termina a tarefa que lhe foi atriburda o processo mestre pode alocar outra tarefa para ele. No final das tarefas, é responsabilidade do processo mestre a combinação dos resultados parciais para a 
geração do resultado final do problema. Na Figura 13 é apresentada o modelo de execuçāo de um algoritmo com paralelismo do tipo processor farm.

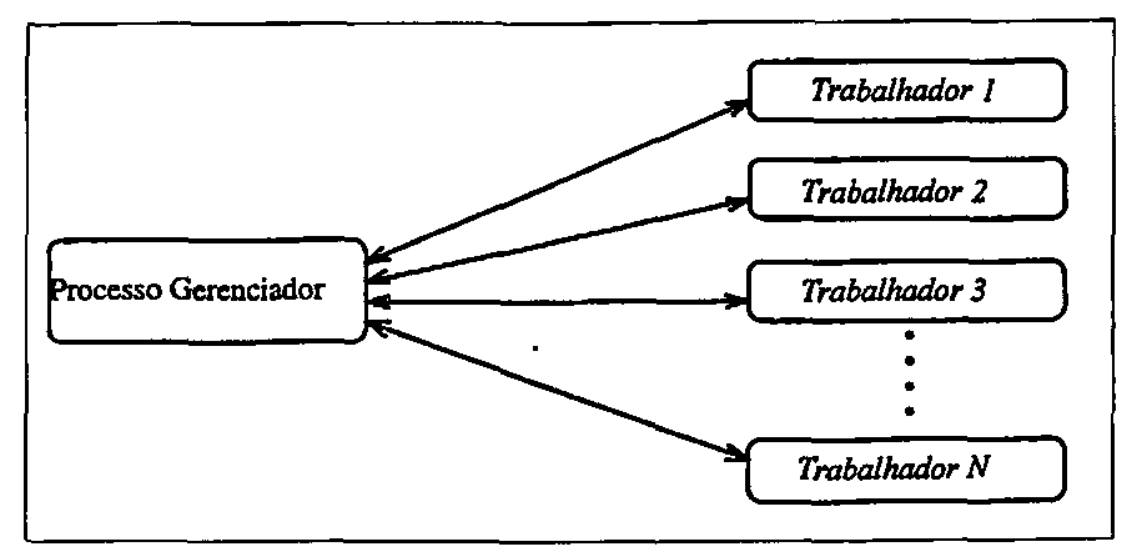

Figura 13 - Paraleiismo processor farm

Esse tipo de paralelismo trabalha com uma lista de tarefas que são alocadas de acordo com a disponibilidade dos processadores escravos para se conseguir uma execução com maior desempenho.

\subsubsection{Mecanismos de Cooperação entre Processos}

Para a execução dos processos de uma aplicação de forma paralela é necessário que esses processos troquem informaçð̌es. Para isso existem basicamente dois mecanismos:

\subsubsection{Mecanismo Baseado em Mensagens (Troca de Mensagens)}

Este mecanismo consiste no envio e recebimento de mensagens entre os processos em execução em diferentes processadores. Essas mensagens possuem dados e/ou sinais para a sincronização entre os processos. Através da troca de mensagens é possível definir barreiras ou sinais para a sincronização entre os processos.

O mecanismo de passagem de mensagens não é somente um componente de baixo nível indispensável para as arquiteturas MIMD de memória distribuída, mas também é uma técnica poderosa que torna transparente a interação entre os processos. 


\subsubsection{Mecanismo Baseado em Dados Compartilhados}

Ao contrário do mecanismo de troca de mensagens, não há o envio e recebimento das mensagens, apenas uma área de endereçamento global onde todos os processos conseguem ter acesso e compartilhar as informaçōes necessárias para a execução da aplicação. Para manter os resultados da aplicação corretos e confiáveis são necessários vários mecanismos para manter a consistência dessa área, pois há vários processos acessando esses dados ao mesmo tempo. A técnica utilizada para este fim é o acesso mutuamente exclusivo dos dados em áreas críticas (áreas que dois ou mais processos tentam acessar ao mesmo tempo, podendo ocorrer uma inconsistência nos dados) através de busy-waiting, semáforos ou monitores.

\subsection{Considerações Finais}

Neste capitulo foram apresentados conceitos importantes para o entendimento do trabalho realizado como as arquiteturas desenvolvidas para a execução de aplicaçōes paralelas, a terminologia utilizada em computação paralela, os modos de programação utilizados no desenvolvimento de programas paralelos e os mecanismos para troca de informações entre processos.

No próximo capítulo são apresentadas as ferramentas utilizadas na computação paralela e é definida uma classificação para essas ferramentas. Para essa classificação foi realizada uma ampla pesquisa, envolvendo grande parte das ferramentas existentes para computação paralela. 


\section{Ferramentas para Programação Paralela}

\subsection{Considerações Iniciais}

Com o crescente interesse na área da programação paralela, verificou-se a necessidade de ferramentas de auxílio ao desenvolvimento dessa classe de programas. Na programação paralela não são necessárias apenas ferramentas para o desenvolvimento de programas, mas também visualizadores, depuradores, monitores e outras ferramentas especificamente voltadas para a programação paralela.

Com os esforços para se conseguir progressos nessa área surgiram uma grande gama de ferramentas para se trabalhar com programação paralela. Com o aumento no número de ferramentas se tornou necessária uma classificação dessas ferramentas para que seja possível analisar sua eficiência, através de comparações entres ferramentas pertencentes a uma mesma classe.

Na seção 3.2 é descrita uma classificação, que foi proposta através da análise e pesquisa das ferramentas existentes. As seções 3.3, 3.4, 3.5, 3.6 e 3.7 descrevem sucessivamente, as classes de Ferramentas de Desenvolvimento de Programas Paralelos, Ferramentas para Paralelização de Programas Seqüenciais, Ferramentas de Análise de Desempenho e Depuração, Ambientes Integrados e Outras Ferramentas para Processamento Paralelo. Nessas seções são apresentados exemplos de ferramentas de cada uma das classes.

\subsection{Classificação das Ferramentas}

Através da análise de algumas classificações [Tur93, Che93, Per96] e a pesquisa das ferramentas existentes (cerca de 180 ferramentas distribuídas entre as classes) a seguinte classificação foi proposta:

\section{Ferramentas de Desenvolvimento}

\subsection{Linguagens para Programação Paralela}

\subsection{Bibliotecas e Sistemas para Programação Paralela}

\subsection{Ambientes de Desenvolvimento}




\section{Ferramentas de Paralelização}

\subsection{Automáticas}

\subsection{Interativas}

\section{Ferramentas de Análise de Desempenho e Depuração}

\subsection{Depuração}

\subsection{Análise de Desempenho}

\section{Ambientes Integrados}

\section{Outras Ferramentas para Processamento Paralelo}

Essa classificação reflete os métodos utilizados no desenvolvimento de aplicações paralelas e divide as ferramentas em quatro grandes classes. A primeira classe categoriza as ferramentas existentes para o processo de desenvolvimento de novos programas paralelos. A segunda classe engloba as ferramentas que de alguma forma trabalham com a paralelização de programas sequienciais. Na terceira classe estão as ferramentas de análise, para avaliação de desempenho ou para a depuração dos programas paralelos. Na quarta classe estão os ambientes integrados, que se caracterizam por oferecer ferramentas necessárias para o desenvolvimento de programas paralelos, paralelizaçāo de programas seqüenciais, análise de desempenho e depuração dos programas paralelos gerados.

\subsection{Ferramentas de Desenvolvimento de Programas Paralelos}

Nessa classe estão todas as ferramentas que fazem parte do processo de desenvolvimento de novos programas paralelos. Nesse grupo estāo aquelas ferramentas em que o desenvolvedor tem um problema a ser resolvido e desenvolve a aplicação a partir da análise deste problema.

Essa classe se divide em 3 subclasses:

Linguagens para Programaçăo Paralela

Bibliotecas e Sistemas para Programação Paralela

Ambientes de Desenvolvimento 


\subsubsection{Linguagens de Programação Paralela}

Nessa categoria de ferramentas para programação paralela, encontram-se todas as linguagens de programação que podem expressar o paralelismo através de primitivas, novos comandos e diretivas para o compilador.

Essa classe é bem extensa e as características de cada um de seus componentes pode variar muito. Desta forma, ela foi dividida em várias subclasses que são definidas abaixo.

\subsubsection{Linguagens Intrinsecamente Paralelas}

Essa subclasse é formada por linguagens paralelas que foram criadas especialmente para esse tipo de programação. Durante todo o seu desenvolvimento foi considerada a sua utilização em arquiteturas paralelas. Uma das linguagens mais características desse grupo é a linguagem OCCAM[Bar90].

\section{OCCAM}

A linguagem OCCAM foi implementada para a programação paralela em processadores transputer, ou redes de transputers. Sua definição é de origem intrinsecamente paralela e não derivada de uma linguagem seqüencial.

No modelo de programação OCCAM, os processos são conectados para formar sistemas concorrentes. Cada processo pode ser considerado como uma "caixa preta" com um estado interno. Os processos se comunicam com outros processos usando canais de comunicação ponto-a-ponto.

Cada processo inicia, executa um número de ações e então termina. Uma ação pode ser um conjunto de processos seqüenciais executados um após o outro, como numa linguagem de programação convencional, ou um conjunto de processos paralelos executados ao mesmo tempo.

Os processos comunicam-se através de canais. Essa comunicação ocorre de forma sincronizada e sem o uso de buffers. Se um canal é usado para entrada em um processo e para saída em outro, a comunicação só ocorrerá quando os dois estiverem prontos. Uma característica importante de OCCAM é a habilidade de decompor sucessivamente um processo em processos componentes com execução concorrentes. 
O principal objetivo do projeto de OCCAM foi o de fornecer uma linguagem que pudesse ser diretamente utilizada por uma rede de elementos de processamento e pudesse expressar diretamente algoritmos concorrentes. Em vários aspectos, OCCAM pode ser considerada a linguagem assembly $\mathrm{em}$ tais sistemas.

A linguagem OCCAM pode apresentar localidade do processamento, onde cada processo tem variáveis locais. Pode também apresentar localidade da comunicação, onde cada canal conecta somente dois processos.

Outra característica importante no projeto de OCCAM é o uso das mesmas técnicas de programação concorrente para um único computador e para uma rede de computadores. $\mathrm{Na}$ prática isso significa que a escolha das características de OCCAM foi parcialmente determinada pela necessidade de uma implementação distribuída eficiente. Isso talvez explique algumas das diferenças entre OCCAM e as outras linguagens concorrentes e paralelas.

Em OCCAM é garantido que o comportamento lógico de um programa não será alterado pelo modo no qual os processos são mapeados nos processadores ou pela velocidade do processamento e da comunicação.

A comunicação sincronizada e sem buffers em grande parte simplifica a programação e pode ser eficientemente implementada. Comunicação sem buffers elimina a necessidade de área de armazenamento e impede perdas de dados acidentais originárias de erros de programação.

O acesso a portas de entrada e saída em OCCAM funciona de forma semelhante aos canais e uma porta $\epsilon$ usada como fosse um canal. Porém, tem o efeito de transferir informação para e de um bloco de endereços associados com um periférico. Portas comportam-se como os canais e somente um processo pode ler de uma porta e somente um pode escrever nela.

\subsubsection{Linguagens Orientadas a Objetos}

Nessa subclasse estão todas as linguagens que utilizam o paradigma da programação orientada a objetos e possuem diretivas, comandos ou funções para a programação paralela. 
Geralmente possuem uma hierarquia de classes para definir todos os objetos que fazem parte da implementação do paralelismo.

Nessa subclasse estão CHARM++.[Kal94, Uil97], HPC++, C** [Lar92], Object Oriented FORTRAN [Ree91, Smi92a], CC++ e COOL (Concurrent Object Oriented Language) [Gup92, Hen93].

\section{HPC+t (High Performance C+t)}

A linguagem High Performance $\mathrm{C}++[\mathrm{Bec} 96]$ é uma extensão de linguagem que está sendo desenvolvida pelo HPC + Consortium como um modelo padrão para programação paralela portátil em $\mathrm{C}++$.

Existem dois modelos para execução de programas HPC ++ . No modelo de contexto simples, um programa HPC + é executado como um programa $\mathrm{C}+$ com um thread de controle único. Dessa maneira o paralelismo pode ser explorado pelas diretivas de loops paralelos, pelo HPC++ Parallel Standard Template Library ou pela criação de novos threads de controle. No modelo de contextos múltiplos, um programa HPC+ lança um thread de controle para cada contexto.

Uma grande mudança do $\mathrm{C}++$ para o $\mathrm{HPC}++$ é a adição de uma biblioteca chamada STL (Standard Template Library), que possui quatro componentes: (1) $a$ Container Class Templates, que fornece definições padrão para estruturas de dados agregadas comuns como vetores, listas, filas, estendendo estes tipos para containers distribuídos; (2) Iterators, que generaliza o conceito de ponteiro, estendendo esse conceito para Parallel Iterators; (3) Generic Algorithms que permite operaçōes padrão em containers, e; (4) Adaptors para facilitar a criação de tipos abstratos de dados.

A linguagem HPC ++ também teve a adição de uma classe container Array, devido a grande utilização dessas estruturas em computação científica. A biblioteca para trabalhar com esse novo tipo de dados possui mais de 100 funções, entre elas, funções para a distribuição dos dados sobre os processadores, operações sobre arrays paralelos e outras.

O High Performance $\mathrm{C}++$ está em constante desenvolvimento e estudo em vários grupos por todo o mundo. O principal grupo desta padronização é o HPC++ Consortium. 


\section{CC++ (Compositional C++)}

A linguagem Compositional $\mathrm{C}++(\mathrm{CC}++)[\mathrm{Cha93,} \mathrm{Kes93]} \mathrm{fornece} \mathrm{algumas} \mathrm{extensōes} \mathrm{para}$ a linguagem seqüencial $\mathrm{C}_{++}$, de modo a fornecer um sistema que seja adequado para uma ampla variedade de modos de programação paraiela.

Podendo ser utilizada em ambientes com memória compartilhada ou distribuída, possibilita o desenvolvimento de programas com diferentes granulosidades. Permite o uso de diferentes paradigmas de programação (tais como paralelismo de dados ou de tarefas, ou ainda ambos conjuntamente) e oferece mecanismos de sincronização razoavelmente poderosos.

Para atingir os objetivos acima expostos, a linguagem $\mathrm{C}++$ foi estendida com oito novas construções. Estas novas construções fornecem mecanismos para o usuário definir as tarefas que devem ser executadas em paralelo, sincronizá-las, controlar o acesso a dados compartilhados, definir a distribuição dessas tarefas nos processadores que não possuem memória compartilhada e definir o modo de transferência de dados entre esses processadores.

As construçōes para execução seqüencial em $\mathrm{CC}++$ são as mesmas do $\mathrm{C}++$. Existem duas construções adicionais para a execução concorrente: os blocos paralelos e o spawn de processos. Os blocos paralelos são executados em paralelo e o spawn de processos cria um novo processo que é .executado concorrentemente com o processo criador.

O objeto logic processor é uma abstração de um recurso físico disponível em um sistema de computadores e cada um desses objetos é mapeado indivisivelmente em um recurso de processamento físico, podendo-se através desses objetos expressar localidade.

Além dessas abstraçōes que foram adicionadas ao $\mathrm{C}++, 0 \mathrm{CC}++$ possui algumas outras extensões como: funções atômicas, ponteiros globais e variáveis Sync para a sincronização de processos.

A linguagem $\mathrm{CC}++e ́$ de domínio público e pode ser obtida através de ftp anônimo

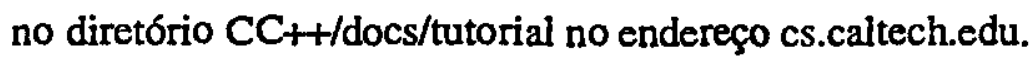




\subsubsection{Linguagens Derivadas da Linguagem C}

Nessa subclasse estão as linguagens baseadas na linguagem $C$, ou seja, as linguagens que possuem todas as estruturas e funçōes da linguagem $\mathrm{C}$ com funções e diretivas de compilador voltadas para a programação paralela.

Essas linguagens são dialetos do $\mathrm{C}$ e estão sendo cada vez mais utilizadas na programação cientifica, podendo-se citar: CPAR, JADE[Rin92, Lam91], CHARM[Ka192], CID[Nik94] e P-Languages - PC [Sco92]. Para efeito de exemplo, será descrita a linguagem CPAR.

\section{CPAR}

Buscando o equilibrio entre alto desempenho, facilidades de programação e portabilidade, a linguagem CPAR [Sat92] foi projetada visando oferecer construçōes simples para a exploração do paralelismo em múltiplos níveis.

A linguagem CPAR é uma extensão da linguagem $C$ na qual foram acrescentadas construçōes para expressar o paralelismo. Em seu projeto, algumas características tiveram a sua origem baseada na linguagem Concurrent $C$ [Geh88, Geh92] e na linguagem ADA [89], que oferecem um modelo de programação multitarefas com passagem de mensagens.

O modelo de programação suportado pela linguagem CPAR permite o uso de múltiplos níveis de paralelismo. Os custos referentes à criação de processos e ao acesso à memória compartilhada foram amenizados pela adoção de uma combinação das técnicas conhecidas como microtasking e macrotasking.

A técnica macrotasking ou multitasking consiste em particionar o programa em múltiplas macrotarefas, as quais devem envolver uma parcela de computação significativa, caracterizando uma granulosidade grossa. $O$ custo da comunicação não deve inviabilizar a obtenção de um bom desempenho. Em cada macrotarefa podem estar presentes múltiplas microtarefas, que exploram o paralelismo com granulosidade média ou fina, no nível de loops ou blocos paralelos de instruções.

Somente as variáveis compartilhadas entre as várias macrotarefas devem ocupar a área de memória compartilhada global. As variáveis compartilhadas entre as microtarefas de uma macrotarefa devem ocupar a memória compartilhada local. As estratégias adotadas 
exploram a hierarquia de memória fornecida pelo modelo de programação, minimizam o custo referente à criação de processos e proporcionam uma melhor utilização dos processos criados.

Além desse modelo de programação e estratégias de hierarquia de memória, a linguagem CPAR apresenta as seguintes características: oferece primitivas para explicitar blocos paralelos e macroblocos que encapsulam blocos paralelos; permite declarar e colocar em execução as macrotarefas; permite declarar variáveis locais, variáveis compartilhadas globais e locais; permite que a comunicação entre macrotarefas seja efetuada por memória compartilhada ou passagem de mensagens; permite a sincronização entre macrotarefas através do uso de semáforos ou eventos e; fornece um mecanismo de exclusão mútua, que permite a utilização segura da memória compartilhada.

\subsubsection{Linguagens Derivadas da Linguagem FORTRAN}

Assim como as linguagens paralelas derivadas do $\mathrm{C}$, as linguagens paralelas derivadas do FORTRAN também foram criadas em função da grande utilização do FORTRAN em computação científica.

Geralmente as implementações de dialetos paralelos do FORTRAN são para máquinas específicas, ou para máquinas maciçamente paralelas e com o paralelismo de dados do tipo SPMD.

Nessa classe há uma grande quantidade de linguagens que são muito conhecidas pelos cientistas, entre elas estão HPF (High Performance FORTRAN), FORTRAN 90, Fortran M [Fos92], além de outras. Abaixo serão descritas duas linguagens importantes dessa classe.

\section{FORTRAN 90}

A linguagem Fortran 90 [Iso91, Mar96], o ứltimo padrão ISO para Fortran, é uma extensão sobre a linguagem Fortran 77. De uma maneira geral, essas extensões tornaram a linguagem Fortran mais próxima de linguagens mais atuais como as linguagens $\mathrm{C} \mathrm{e} \mathrm{C}++$, além de oferecer recursos exclusivos, como as operações sobre arrays. 
As extensōes Fortran 90 sobre a linguagem Fortran 77 podem ser classificadas em construções de arrays, alocação dinâmica de memória, ponteiros, novos tipos de dados e estruturas, novas funçőes intrínsecas, novas estruturas de controle e interfaces de procedimentos.

As construçōes de arrays permitem programas Fortran 90 especificarem operações sobre todos os elementos dos arrays. Isto permite ao compilador traduzir essas construçöes em instruções vetoriais ou paralelas, dependendo da arquitetura da máquina. A linguagem especifica somente que a computação é executada em paralelo. Este recurso não é limitado para arrays unidimensionais, podendo ser empregado para arrays genéricos.

No passado, programadores Fortran adotavam a estratégia de pré-alocar um grande espaço extra para tratar as necessidades de memória no programa. Isto fazia com que se desperdiçasse memória. A linguagem Fortran 90 elimina a necessidade desse artifício com o acréscimo dos arrays alocáveis dinamicamente. A alocação dinâmica de arrays permite ao programador especificar o espaço a ser alocado em função do conteúdo de outras variáveis do programa.

As novas funções intrínsecas introduzidas por Fortran 90 se referem principalmente a operações sobre arrays. Além da extensẫo natural das antigas funções intrínsecas para operar sobre arrays, como SQRT, LOG, as novas funções podem ser agrupadas principalmente em:

- reduções: funções que operam sobre arrays e retornam um único valor.

- informação: SHAPE, SIZE, LBOUND, UBOUND são disponíveis para a obtenção de informação sobre um array.

As principais estruturas de controle adicionadas foram a WHERE e a CASE. A WHERE permite o controle da atribuição baseado em uma máscara e a construção CASE é similar ao comando equivalente da linguagem C para a seleção de expressōes inteiras, lógicas e de caracteres. 


\section{HPF (High Performance FORTRAN)}

Devido a grande dificuldade de portabilidade dos programas paralelos, um conjunto de grupos de pesquisa e de empresas iniciou um esforço comum para a definição de uma linguagem portátil para a programação de aplicações científicas em multiprocessadores. Depois de uma série de reuniôes e discussões foi definida em 1993 a primeira versão da linguagem HPF [Hig93, Mar96].

O modelo de programação paralela adotado pela HPF é o paralelismo de dados. O paralelismo é proveniente de operações independentes sobre os elementos de grandes estruturas de dados. Como a HPF é baseada na linguagem Fortran 90, essas estruturas de dados são normalmente arrays $\mathrm{e}$ as operações paralelas, aritmética sobre arrays. Tipicamente as máquinas possuem dezenas (ou centenas) de processadores e as aplicações científicas, milhares (ou milhões) de elementos. A alocação desses elementos nos processadores é especificada em programas HPF através de diretivas de mapeamento de dados de alto nível.

Os recursos da linguagem HPF podem ser descritos como sendo constituídos por: recursos da linguagem Fortran 90, suporte para a especificação de paralelismo e suporte para o mapeamento de dados.

Os recursos da linguagem FORTRAN 90 adotados pela HPF são as construções de arrays, alocação dinâmica de memória, ponteiros, novos tipos de dados e estruturas, novas funções intrínsecas, novas estruturas de controle e interfaces de procedimentos.

A especificação do paralelismo na High Performance Fortran é feito através de três formas: o comando FORALL, uma generalização do comando de atribuição de elementos de array, as funções PURE que podem ser chamadas dentro de um FORALL, e a diretiva INDEPENDENT, que indica a possibilidade de execução paralela de um loop. Dentro do corpo do FORALL não pode haver chamadas a funções que não sejam do tipo PURE, porque uma chamada a subrotina pode alterar uma variável global, levando a um resultado errôneo no processamento.

O mapeamento de dados em HPF é realizado através da especificação da forma como os dados são distribuídos entre os processadores. É utilizada uma estratégia dividida em duas fases: a diretiva ALIGN que efetua o alinhamento dos elementos de arrays 
distintos, permitindo que sejam sempre armazenados no mesmo processador e a diretiva DISTRIBUTE que particiona os elementos de arrays pelos processadores.

Durante o ano de 1995, uma série de reuniões deu início os trabalhos para a definiçāo da HPF 2.0, onde se tentou incorporar uma série de recursos, como: suporte para o paralelismo de tarefas (ou de controle), suporte para a distribuiçăo irregular de dados e estruturas de dados mais complexas e suporte para E/S paralela.

\subsubsection{Outras Linguagens}

As linguagens dessa classe possuem características que não se enquadram em nenhuma das subclasses acima. A principal característica que as separam dos grupos acima é que essas linguagens não são derivadas das linguagens C e Fortran. Nessa classe estão linguagens como Modula 2* [Tic90] e STRAND88 [Fos89].

\subsubsection{Bibliotecas e Sistemas para Programação Paralela}

Essa categoria vem crescendo bastante devido ao aumento da velocidade das redes de computadores, da sua grande utilização e do baixo custo dos microcomputadores. Nesse contexto, as bibliotecas de rotinas de comunicação são as mais utilizadas em máquinas ou redes de computadores, classificadas como arquiteturas MIMD com memória distribúda.

Entre as máquinas MMD de memória distribuída estão os clusters de estações de trabalho e microcomputadores. As bibliotecas de comunicação consistem em um conjunto de rotinas e primitivas de comunicação e sincronização utilizadas para a construção de programas paralelos, geralmente de granulosidade grossa.

Um outro grande atrativo desse tipo de ferramenta é a facilidade de alterações e extensões desses sistemas, além da facilidade no desenvolvimento de programas. No desenvolvimento de aplicações paralelas utilizando bibliotecas de comunicação é possível utilizar linguagens convencionais como $\mathrm{C}, \mathrm{C}++$ e Fortran, sem a necessidade de nenhuma alteração no compilador ou na linguagem.

Nesse grupo está o PVM (Parallel Virtual Machine), o MPI (Message-Passing Interface), o P4 (Portable Programs for Parallel Processors) [Lus92, But92], o PICL [Gei90] e outros. 


\section{PVM ( Parallel Virtual Machine)}

O sistema PVM [Beg94, Sun92] foi definido visando o desenvolvimento de programas paralelos e distribuídos a serem executados em um conjunto heterogêneo de máquinas interligadas. É composto basicamente por dois componentes: um daemon chamado pvmd e uma biblioteca de rotinas que estabelece a interface entre o programa do usuário e o sistema.

O processamento paralelo é tratado pelo PVM como uma coleção de processos que se comunicam através de mensagens. Essas mensagens são transmitidas utilizando-se o protocolo UDP/TCP, no caso de redes de computadores, ou qualquer outro mecanismo de comunicação disponível. Para a emissão e recebimento de mensagens são utilizados buffers dinâmicos, de tal forma que o tamanho das mensagens é limitado apenas pela disponibilidade de memoria.

O núcleo do modelo utilizado pelo PVM é uma máquina paralela virtual. Essa máquina virtual é composta por um conjunto de máquinas físicas interligadas, sendo utilizada pelo usuário como uma máquina paralela fracamente acoplada onde os programas paralelos são executados.

A máquina virtual é composta por computadores interligados e gerenciados por uma coleção de processos daemons disparados por um mesmo usuário.

Para que um computador possa fazer parte desta máquina virtual, é necessário que o processo daemon esteja sendo executado por ele. $O$ daemon pode ser iniciado na console da máquina pelo usuário ou por um programa que já esteja sendo executado na máquina paralela virtual.

Para que um programa possa ser executado nessa máquina virtual, é necessário que ele se registre com o daemon pvmd da estação correspondente, através da chamada de uma função da biblioteca do PVM. Após ser registrado, ele pode utilizar as várias funções que o PVM oferece, tais como iniciar processos em outros computadores, verificar o estado dos processos que estão sendo executados na máquina virtual, enviar e receber mensagens de modo bloqueante ou não-bloqueante, enviar mensagens de difusão (broadcast), executar rotinas do tipo barreira e rotinas globais de comunicação de dados. 
Este sistema é de domínio público e pode ser obtido através do endereço http://www.netlib.org/pvm3/index.htmi.

\section{MPI ( Messago-Passing Interface)}

O MPI [Gro92, Sni95] nāo é propriamente uma implementação de um sistema, mas sim uma proposta de padronização para a interface de troca de mensagens em máquinas paralelas com memória distribuída. A idéia de se padronizar essa interface é a de possibilitar a portabilidade dos programas entre as diferentes máquinas e facilitar o seu uso.

O padrão MPI não contém nenhuma definição de suporte para tolerância a falhas e assume que o ambiente em que será executado é confiável. Ele define uma interface de troca de mensagens e não pretende definir um ambiente completo para programação paralela. Por essa razão, não são tratados tópicos como entrada/saída paralela, estruturação do programa paralelo e depuração.

Também não é definido nenhum suporte explícito para multithreading, apesar de ser um dos objetivos do projeto do padrão o de garantir que ele possa ser implementado de maneira eficiente em ambientes que possibilitem multithreading.

O núcleo do MPI é formado por rotinas para comunicação ponto a ponto entre pares de processos. Essas rotinas podem ser chamadas de forma bloqueante ou não bloqueante. Existem três modos de comunicação: ready, no qual a mensagem só pode ser enviada se uma operação de recepção correspondente já tiver sido iniciada; standard, no qual a mensagem pode ser enviada independentemente de haver uma operação de recepção para ela; e synchronous, que funciona de maneira semelhante ao modo standard, com a diferença de que a operação de envio não será considerada finalizada até que a operação de recepção correspondente seja iniciada no processo de destino.

Outras facilidades definidas são as rotinas para grupos de processos, que visam coordenar a comunicação entre os processos pertencentes a um determinado grupo. Essas rotinas permitem a transmissão coletiva dos dados e oferecem as seguintes funcionalidades:

- Envio de um mesmo dado por um determinado participante do grupo para todos os demais (broadcast); 
- Envio de dados diferentes por um determinado participante do grupo para todos os demais (scatter);

- Envio de dados de todos os participantes do grupo para um determinado participante (gather);

- Envio de dados de cada participante para todos os demais (allgather);

- Envio de dados diferentes de cada participante para todos os demais (alltoall).

Também são definidas operaçōes para a computação de certas funçōes sobre dados pertencentes aos participantes de um determinado grupo. Essas operaçōes são denominadas redução e varredura. Na operação de redução, uma função pré-definida ou definida pelo usuário é aplicada sobre os dados localizados nos diversos processadores que estão executando os processos pertencentes a um determinado grupo. $O$ resultado dessa função pode ser enviado a todos os participantes do grupo ou a somente para um deles.

Um exemplo dessa operação seria determinar o valor máximo de um conjunto de dados, onde cada elemento desse conjunto está associado a um processo pertencente a um determinado grupo. A operação de varredura executa o mesmo procedimento que a redução, mas sobre subconjuntos dos participantes do grupo.

Uma implementação desse padrão pode ser obtida através de ftp anônimo para o diretório pub/mpi no endereço info.mcs.anl.gov.

\subsubsection{Ambientes de Desenvolvimento}

Nessa subclasse de ferramentas de desenvolvimento de programas paralelos estão incluídas aquelas ferramentas em que o usuário é responsável pelo paralelismo, definindo os blocos que serão executados em paralelo.

Geralmente essa definição é feita por um grafo que mostra todos os módulos do programa e como eles são interligados, através de uma interface gráfica. O conteúdo de cada um dos módulos é definido de uma maneira textual, na linguagem suportada pela ferramenta. 
As ferramentas pertencentes a este grupo mais conhecidas são a CODE 2.0, a V (Visual Parallel Environment) [New95], e a HENCE (HEterogeneous Network Computing Enviromenmt).

\section{CODE 2.0}

A CODE [New92, Beg91a] é uma ferramenta para programação paralela gráfica que enfoca três metas principais: (1) a facilidade de utilização, (2) portabilidade, e (3) produção de código paralelo efíciente. A facilidade de utilização é fornecida pela interface gráfica e textual integrada, por um poderoso modelo dinâmico de computação paralela e um conceito integrado de reutilização de componentes de programas.

A CODE trabalha com o paralelismo de granulosidade média ou grossa, sendo que este é expressado pelo programador de forma direta e declarativa em alto nível de abstração na forma de grafos de dependência. Esses grafos são então automaticamente traduzidos para um código específico da arquitetura.

As principais características da CODE são: (1) paralelismo especificado pelo usuário, portanto a ferramenta não necessita descobrir automaticamente o paralelismo; (2) expressão declarativa da estrutura de comunicação e sincronização do algoritmo; (3) instanciação em tempo de execução; (4) criação tardia de instâncias (um objeto CODE não é instanciado enquanto ele não é necessário), e; (5) Retenção de estado.

A interface com o usuário, como já mencionado acima, é gráfica e textual, onde os grafos de dependência são criados a partir de um editor gráfico, simbolizando as comunicações e computaçōes através de arcos e nós respectivamente. Para a codificação de cada nó (computação sequiencial), é utilizado um editor de texto. Para a geração do código correspondente à arquitetura destino, a CODE utiliza o grafo de fluxo dos dados para gerar as chamadas a rotinas de comunicação do código digitado em cada um dos nós.

A versão 2.0 da CODE foi desenvolvida na Universidade do Texas em Austin, estando disponível para estações de trabalho SUN e IBM RS6000, com interface gráfica $X$ Windows. 


\section{HENCE ( HEterogeneous Network Computing Enviromenmt)}

O HeNCE [Beg91, Beg91a] é um ambiente de desenvolvimento de programas paralelos baseado na interface $X$-Windows, projetado para auxiliar cientistas no desenvolvimento de programas paralelos que são executados em uma rede de computadores.

Essa ferramenta foi construída sobre a biblioteca de passagem de mensagens PVM que fornece suporte ao gerenciamento e comunicação entre processos em uma rede heterogênea de estaçбes de trabalho. $O$ HeNCE é baseado na descrição de um programa por um grafo, onde os nós do grafo representam as subrotinas e os arcos representam as dependências de dados. Ele é composto de ferramentas gráficas integradas para criar, compilar, executar e analisar programas HeNCE.

A filosofia do HeNCE impõe ao programador a tarefa de especificar explicitamente o paralelismo da computação e a ferramenta auxilia nas tarefas de desenvolvimento do programa.

Os grafos do programa são especificados pelo programador através de uma interface gráfica $X$-Windows e os procedimentos referentes a cada nó são definidos de uma forma textual, podendo ser escritos na linguagem $C$ ou FORTRAN. Com o grafo e os procedimentos definidos, a ferramenta fornece facilidades para edição e compilação desses procedimentos em várias arquiteturas que foram definidas como a máquina paralela virtual, gerando o código referente a essa arquitetura.

Uma característica importante do HeNCE é a possibilidade do usuário especificar múltiplas implementações dos nós HeNCE baseadas na arquitetura destino.

A interface gráfica do HeNCE, além de ser utilizada para escrever programas, também possibilita a configuração da máquina virtual, visualização de informações de rastreio, além da compilação, execução e análise de programas HeNCE.

Essa ferramenta foi desenvolvida no Oak Ridge National Laboratory e Universidade do Tennessee e possui distribuição gratuita. 


\subsection{Ferramentas para Paralelização de Programas Seqüenciais}

Nesta classe estão as ferramentas que fazem parte do processo de paralelização de programas sequienciais. Tal paralelização consiste na transformação de um código sequiencial já existente em um código de mesma função, mas que possa ser executado em paralelo. Esse processo de paralelização pode ser automático ou interativo.

\subsubsection{Ferramentas de Paralelização Interativa}

Nessa subclasse estão todas as ferramentas que não geram o código paralelo automaticamente. Essas ferramentas auxiliam, de maneira interativa, o programador na construção de programas paralelos.

Esse tipo de ferramenta surgiu com a dificuldade da paralelização automática do código sequiencial, devido a necessidade de análise de dependência e de controle, que muitas vezes pode gerar um código que não apresenta eficiência ou desempenho. Essas ferramentas sugerem ao usuário algumas transformações no código seqüencial. Caso a transformação seja interessante ela é efetuada, caso contrário a ferramenta continua o processo de análise do código fonte a procura de novos pontos para transformação.

Nessa subclasse, as ferramentas criam uma interação entre as análises de dependência de dados, de fluxo e interprocedural e a intuição do usuário. Entre essas ferramentas estão FORGE, PAT (Parallelization Assistant Tool) [App89, Smi90] e PTOPP (Practical Toolset for the Optimization of Parallel Programs) [Mac92, Eig93]. No item seguinte é descrita a ferramenta FORGE.

\section{FORGE}

O Forge [Apr92] é um conjunto integrado de ferramentas interativas para facilitar e simplificar a paralelização de programas Fortran para máquinas de memória compartilhada e distribuída. Os primeiros esforços no desenvolvimento dessa ferramenta foram no sentido de converter grandes programas seqüenciais escritos em Fortran para a execução paralela em máquinas de memória distribuída. As ferramentas Forge permitem que o usuário analise um programa como uma entidade única antes de aplicar as transformações e a distribuição de dados. 
Uma das ferramentas do Forge é um browser interativo de programas Fortran para a análise do código, com visualização interprocedural. Esse browser possui interface Motif, baseada em menus e janelas, possibilitando o rastreamento de variáveis. É possível mostrar as referências a uma variável ou constantes em todo o código fonte.

O browser pode mostrar o fluxo de dados e de controle do código fonte. Existe a possibilidade de se fazer buscas de variáveis em todo o código. No Forge, pode-se fazer a instrumentação do programa sob análise para a geração de rastreios e a determinação dos tempos de execução de cảa parte do programa. Também é possível a alteração automática do formato de um programa de acordo com as preferências do usuário.

O DMP (Distributed Memory Parallelizer) gera programas FORTRAN 77 seguindo - paradigma SPMD. As iterações dos loops como também os arrays de dados são automaticamente distribuídos nos múltiplos processadores. O DMP após transformar o programa, faz uma checagem extensiva para garantir que o programa restruturado continue sendo executado corretamente. Essa ferramenta possui suporte para diferentes bibliotecas de passagem de mensagens como PVM, MPI e Express.

Além dessas características, o Forge possui ferramentas capazes de gerar tempos de execução, custos de comunicação e tempo de espera para cada uma das subrotinas ou loops paralelos. Esses resultados são utilizados para determinar o desempenho do programa paralelo, fazer ajustes e alterações no código e na distribuição de dados para se conseguir maior desempenho.

\subsubsection{Ferramentas de Paraleliząção Automáticas}

Essa subclasse engloba ferramentas que recebem um código fonte em uma linguagem paralela ou seqüencial e geram um código paralelo para uma arquitetura destino, de acordo com vários tipos de análises feitas sobre o código fonte original e sem a necessidade de intervenção do programador. Essas ferramentas geralmente possuem várias etapas até a geração do código paralelo:

- Análise de Fluxo - Essa etapa é responsável por analisar e determinar as dependências de dados e de controle, sendo essa uma das tarefas mais importantę e complexas na geração automática de programas paralelos; 
- Otimização do Programa - Nessa etapa são realizadas as transformações necessárias no código para explorar o paralelismo de acordo com a arquitetura destino. Muitos compiladores e pré-processadores são específicos para uma determinada arquitetura. Geralmente essa otimização é feita de código fonte para código fonte, onde são inseridas as primitivas paralelas;

- Geração do Código Paralelo - Essa etapa é apenas para os compiladores, pois neste estágio é gerado o programa executável, ou seja, o programa fonte resultante da otimização é traduzido para a linguagem de máquina da arqui tetura destino.

Dentre as ferramentas disponiveis pode-se citar o POLARIS [Pad93], ADAPTOR (Automatic DAta Parallelism TranslatOR), PARCEL[Har92], SUIF Compiler e Vienna Fortran Compilation System [Cha91]. Algumas dessas ferramentas possuem grande importância para a programação paralela. Nos itens seguintes serão descritas as ferramentas ADAPTOR e SUIF.

\section{ADAPTOR ( Automatic DAta Parallelism Translator)}

O ADAPTOR [Bra92, Bra92a] é um pré-processador que transforma programas escritos utilizando-se paralelismo de dados em programas paralelos com passagem de mensagens explícita. A linguagem de entrada é um subconjunto da High Performance Fortran (HPF) e Connection Machine Fortran (CMF).

Essa ferramenta possui basicamente 2 componentes: uma ferramenta de transformação do programa com paralelismo de dados para o(s) programa(s) paralelo(s) com passagem de mensagens (FADAPT - Fortran Automatic Data Parallelism Tool) e uma biblioteca com as rotinas de comunicação e de operações com arrays (DALIB - Distributed Array LIBrary), para a fase de link-edição do programa transformado.

Como resultado da transformação automática, o Adaptor gera, além do programa paralelo com passagem de mensagens explícita, um Makefile correspondente para sua compilação e link-edição pelo compilador Fortran 77 nativo. 
Para usar o fadapt o usuário tem que escolher, entre outras opções, qual o sistema de passagem de mensagens vai ser utilizado para a execução do programa paralelo. $O$ fadapt pode ser utilizado em qualquer estação em que o Adaptor esteja instalado.

A grande vantagem de usar o Adaptor é que o usuário não precisa conhecer as primitivas das bibliotecas de passagem de mensagens. $O$ usuário tem que entender algumas das premissas do paralelismo, escrevendo o seu programa com paralelismo de dados usando a linguagem Fortran do Adaptor. $O$ esforço despendido se concentra na programação seguindo o paradigma de paralelismo de dados.

O Adaptor não transforma automaticamente código serial em paralelo, ou seja, não possui mecanismo para detectar se o código serial embutido em uma iteração pode ou não ser paralelizado.

O Adaptor foi desenvolvido pelo GMD - German National Research Center for Computer Science, e pode ser usado de modo interativo no ambiente $X$-Windows ou na modalidade batch.

\section{SUIF Compiler (Stanford University Intermediate Format Compiler)}

o SUIF Compiler [Ama95] foi desenvolvido, como o próprio nome mostra, na Universidade de Stanford, para traduzir automaticamente o código de um programa científico seqüencial para um código paralelo em máquinas paralelas escaláveis.

O compilador recebe como entrada um código seqüencial escrito em $\mathrm{C}$ ou FORTRAN-77 e esse código fonte é traduzido primeiramente para a representação intermediária do compilador SUIF. Após essa transformação, vários passos de otimização e análise do programa operam sobre a representação SUIF. Com o programa já otimizado e paralelizado ele é convertido em um programa $\mathrm{C}$ e este é compilado pelo compilador nativo da arquitetura destino.

O programa $\mathrm{C}$ gerado contém chamadas para uma biblioteca portátil de tempo de execução, que é link-editada pelo compilador nativo. Os passos de análise e otimização do programa são divididos em quatro etapas:

1. Análise Simbólica (Symbolic Analysis) - nessa primeira fase o compilador faz uma, série de análises simbólicas no programa SUIF para a extração de informações 
necessárias para os próximos passos, como: análise de variáveis escalares, propagação de constantes, identificação de variáveis de indução (variáveis incrementadas ou decrementadas de forma constante em cada iteração do loop), dependência de dados e análise do fluxo de dados.

2. Análise de Paralelismo e Localidade (Parallelism and Locality Analysis) primeiramente esta fase identifica e otimiza o paralelismo ao nível de loop, então o compilador mapeia os dados para os processadores e determina o layout dos dados para variáveis do tipo array.

3. Análise de Comunicação e Sincronização (Communication and Synchronization Analysis) - Esta fase utiliza a informação de mapeamento para identificar acessos a dados não locais e essas informações são utilizadas para gerar as mensagens de send e receive para acessar os dados e reduzir os custos de sincronização.

4. Geração do Código (Code Generation) - A fase de geração do código é dependente de máquina, realizando as transformações requeridas pelas fases anteriores. Primeiro são escalonados os loops paralelos para que cada processador execute as iterações alocadas. Em seguida são inseridos os códigos para a comunicação e sincronização, e finalmente, são alterados os acessos a arrays usando o mapeamento de dados calculado na fase de paralelismo e localidade.

Esse compilador foi desenvolvido para máquinas com espaço de endereçamento distribuído e para máquinas com espaço de endereçamento compartilhado.

O SUIF é um projeto de pesquisa da Universidade de Stanford e pode ser obtido através de ftp anônimo para o diretório pub/suif no endereço suif.stanford.edu.

\subsection{Ferramentas de Análise de Desempenho e Depuração}

Esta categoria de ferramentas está ligada com a análise dos programas paralelos gerados, criando recursos de depuração dos códigos fontes paralelos e informações sobre a execução e o funcionamento dos programas paralelos visando melhorar o seu desempenho. 


\subsubsection{Ferramentas de Depuração}

Essa subclasse surgiu com o difícil problema de acompanhamento da execução de programas paralelos e da grande dificuldade na sua depuração.

As ferramentas de depuração estão ligadas às ferramentas de desenvolvimento, pois são utilizadas para a determinação e correçäo de erros. A determinação de erros pode ser feita de maneira interativa ou após a execução, dando origem a duas categorias: as ferramentas interativas e as post-mortem.

As ferramentas de depuração interativas são mais poderosas e comuns no desenvolvimento de aplicaçōes seqüenciais, permitindo que a execução se processe passo a passo, isto é, seja suspensa periodicamente para que as variáveis possam ser inspecionadas ou mesmo modificadas. Depuradores post-mortem operam depois do término da execução da aplicação, normalmente após uma condiçäo de erro ter sido detectada.

Essa subclasse possui um grande número de ferramentas devido a sua ligação estreita com as ferramentas de desenvolvimento, algumas com grande importância e utilização como TOTALVIEW, XPDB (X-window Parallel DeBugger) [Zin93], PANORAMA, além de outras com menor importância.

\section{TOTALVIEW}

O TOTALVIEW [Cra97] é um depurador de programas paralelos no nível de código fonte e apresenta ao usuário uma interface consistente para todas as suas funçōes.

O TotalView possui dois tipos de interfaces: uma interface no modo linha de comando e outra no sistema $X$-Windows. Se não for especificada a interface pretendida, o TotalView verifica a presença da variável de ambiente DISPLAY e tenta a conexão ao servidor com essa interface. $O$ depurador tem inúmeras opções de configuração, desde 0 tipo de fonte a ser utilizado até a quantidade de processadores da máquina onde será executado o programa.

Na interface $X$-Windows, o TotalView relaciona cada um dos três botôes do mouse com um propósito geral, e os botões acionam funçōes apropriadas dependendo do contexto de utilização. A interface fica mais simples e fica mais fácil utilizar os recursos do. 
depurador. Um usuário pode abrir uma janela separada para mostrar o código fonte referente a cada processo no programa paralelo e fazer várias visualizações dos dados.

O uso do depurador não necessita grande esforço para aprendizado, mas muitas operaçōes requerem atalhos ou menus, exigindo maior esforço para o aprendizado. Ele pode ser utilizado para executar programas produzidos pelos compiladores $\mathrm{C}, \mathrm{C}+\mathrm{H}, \mathrm{CAL}$, CFT77 e FORTRAN 90. Um depurador simbólico está disponível quando o usuário compila todo ou parte do programa com as opções de compilação apropriadas.

\section{PANORAMA}

Essa ferramenta fomece uma interface de depuração padrão para programas paralelos utilizando um arquivo para a tradução entre os comandos da Panorama e aqueles utilizados pelo depurador nativo da máquina. Para aumentar a portabilidade e extensibilidade do sistema é utilizada a interface Tcl/Tk que se comunica através de um socket com o depurador. A Panorama [May93, Sis94] fomece arquivos de comandos para o Intel Paragon, o iPSC/860, e o Ncube/2.

Na Panorama é possível abrir múltiplas janelas para visualizações dos dados e das comunicações. $O$ usuário pode utilizar janelas separadas para visualizar o código fonte referente a cada processador, o controle do programa e a avaliação de expressões. Essas tarefas são realizadas utilizando janelas de texto Tk.

As técnicas de visualização usam primariamente mecanismos gráficos, com botões e manipulação através do mouse. As janelas do Panorama operam de forma independente e as informações são atualizadas conforme solicitado pelo usuário.

Além das propriedades de depuração, a Panorama permite o rastreamento da atividade de comunicação para depuração post-mortem, fomecendo para cada máquina uma biblioteca de rotinas de rastreamento e macros de pré-processador. A apresentação dos dados acrescenta entre 5 e $65 \%$ no custo de comunicação.

O modelo usado para construir a Panorama resultou em uma plataforma altamente portátil para a depuração, com facilidade para a inclusão de novas características na visualização, além de fomecer uma interface padrão com um míniṃo de esforço. 


\subsubsection{Ferramentas de Análise de Desempenho}

Essas ferramentas são responsáveis pela análise do desempenho dos programas paralelos. Elas possuem uma grande importância para a programação paralela, pois o principal objetivo de se paralelizar um código é o de conseguir melhor desempenho.

Para alcançar esse objetivo essas ferramentas fornecern mecanismos para o monitoramento da execução de programas paralelos, gerando uma grande variedade de informações que podem sẹ analisadas através de utilitários de visualização.

O principal objetivo consiste na extração de informações a respeito dos programas, permitindo ao usuário alterar o código de forma a obter ganhos de desempenho.

Essa subclasse possui um grande número de ferramentas, entre elas pode-se citar: PARAGRAPH[Hea91], AIMS (Automated Instrumentation and Monitoring System) e PABLO (Performace Analysis Enviroment). Abaixo segue uma descrição mais detalhada de algumas dessas ferramentas.

\section{PABLO Performace Analysis Enviroment}

A principal meta no desenvolvimento do Pablo [Ree94, Noe93] foi a de criar um ambiente portátil para análise de dados de desempenho que pode ser utilizado em uma variedade de sistemas maciçamente paralelos.

O ambiente de análise de desempenho do Pablo consiste em vários componentes independentes que compartilham o formato de dados SDDF (Self-Defining Data Format) como um meio de troca de informaçōes. A SDDF é uma linguagem de descrição dos dados de desempenho.

O componente SvPablo é uma interface gráfica para instrumentação do código fonte e visualização dos dados de desempenho em tempo de execução. Este componente foi desenvolvido para capturar, analisar e apresentar os dados de desempenho das aplicações.

A Trace Library contém uma biblioteca básica para a captura de dados de desempenho e gravação de registros de eventos. Existem extensões construídas sobre essa biblioteca para gravar informações de desempenho sobre chamadas de passagem de mensagens e pedidos de entrada/saída. 
O componente I/O Analysis contém programas para produzir relatórios resumidos das atividades de entrada e saída de uma aplicação através dos registros de eventos de entrada e saída de um arquivo de rastreio SDDF gerado pela Trace Library I/O Extension.

O Pablo Performance Analysis Environment possui também um componente chamado Analysis GUI. Esse componente consiste em um sistema de visualização de desempenho que fornece uma ferramenta portátil, escalável e extensível para analisar e mostrar os dados escritos no formato SDDF.

O Pablo e todos os seus componentes podem ser encontrados no endereço http://vibes.cs.uiuc.edu/Software/Pablo/pablo.htm.

\section{AlMS (Automated Instrumentation and Monitoring System)}

O AIMS [Fin92, Yan92] é um conjunto de ferramentas desenvolvido para facilitar a avaliação de desempenho de aplicações paralelas em multicomputadores pela medida e avaliação dos rastreios da execução, reduzindo o tempo requerido para encontrar os gargalos de desempenho.

Essa ferramenta requer uma participação mínima do usuário, podendo inserir automaticamente a instrumentaçăo no programa. Oferece suporte para uma larga variedade de paradigmas de programação paralela e plataformas de hardware, pois os processos de instrumentação, monitoração e análise são formecidos por módulos de software separados, com interfaces bem definidas.

O AIMS é formado por quatro componentes principais: um instrumentador de código (xinstrument), uma biblioteca de tempo de execução para monitoração de desempenho (the monitor), duas ferramentas para análise e animação de arquivos de rastreio (VK e Tally) e um pós-processador de rastreios (tpp) para fazer a compensação do custo da coleta de dados.

O xinstrument é responsável por inserir instrumentação no código fonte para guardar dados de desempenho da execuçăo do programa e também criar e gerenciar duas estruturas de dados críticas para a avaliação de desempenho: application database e instrument-enabling profile. 
A biblioteca the monitor contém as rotinas chamadas pelo código instrumentado para rastrear o desempenho durante a execução do programa. A VK fornece animaçōes mostrando o comportamento do programa e a Tally gera estatísticas acumulativas a partir do arquivo de rastreios $e$ as coloca em tabelas;

Atualmente essa ferramenta pode ser utilizada com programas escritos nas linguagens $\mathrm{C}$ e FORTRAN 77, utilizando três mecanismos de passagem de mensagem: Intel NX, TMC's CMMD e PVM, nas plataformas TMC's CM-5, Intel's iPSC/860, iPSC/Delta, Paragon e estações de trabalho HP executando PVM.

\subsection{Ambientes Integrados}

Nessa classe estão as ferramentas que possuem mais de uma das funções citadas acima ou conjuntos de ferramentas integradas para o desenvolvimento ou monitoração de programas paralelos. A grande parte desses ambientes possui ferramentas tanto para o desenvolvimento como para a análise de desempenho e depuração dos programas paralelos.

Levando-se em conta a sua utilização, essa classe poderia ser subdividida em várias subclasses como: (1) ambientes integrados completos, que são formados por ferramentas para o desenvolvimento, depuração, monitoração e análise de desempenho; (2) ambientes integrados para desenvolvimento de software, composto por ferramentas para o desenvolvimento de programas paralelos e (3) ambientes integrados de depuração, monitoração e análise de desempenho. Exemplos dessas ferramentas são: ANNAI, EPPP (Environment for Portable Parallel Programming), PEMPI[Fra95] (Programming Environment for the Message Passing Interface), PADE (Parallel Application Development Environment), SCHEDULE[Don86, Don87], PARALEX[Dav92], MEANDER[Wir93] e ENTERPRISE[Me192, Sza92].

\section{ANNAI}

O ANNAI[Cle94, Cle95] foi desenvolvido pelo Swiss Scientific Computing Center com os objetivos de: (1) projetar e implementar um ambiente de ferramentas integradas que suportem o desenvolvimento de programas paralelos em uma linguagem de paralelismo de dados MIMD de alto nível e/ou usando passagem de mensagens explícita em baixo nívei; 
(2) utilizar linguagens de programação e interfaces de máquina padronizadas com a HPF e a MPI; e (3) propor e implementar extensōes para a linguagem HPF e ferramentas para fornecer paralelização, depuração, monitoramento e análise de desempenho para aplicações científicas.

Há três ferramentas dentro desse ambiente: uma ferramenta de suporte a paralelização (PST), um monitor de desempenho e analisador (PMA) e um depurador paralelo (PDT). Essas ferramentas compartilham uma Interface de Usuário (UI) comum.

A ferramenta PST visa fornecer suporte em tempo de execução para aplicações científicas hoje consideradas difíceis de paralelizar em sistemas distribuídos maciçamente paralelos. Trabalhando como um pré-processador, os códigos fonte são instrumentados para gerar informaçōes de desempenho para o PMA e informaçōes de depuração para o PDT.

O PMA utiliza as informaçōes de rastreio geradas durante a execução de um programa paralelo para ajudar no processo de ajuste de desempenho e interpretação da execução do programa. Diferentes níveis de abstração são possíveis, desde a análise das comunicações e utilização de memória pelos processos individuais até visões globais da execução do paralelismo de dados.

O PDT é um depurador paralelo interativo em nível de código fonte, que oferece a mesma funcionalidade e comandos de um depurador seqüencial padräo e mais algumas extensōes necessárias para depurar programas paralelos em multicomputadores. O PDT trabalha com pontos de parada globais e possibilita que o desenvolvedor possa trocar a visualização dos dados de um processador para outro quando o programa está pàrado para examinar a pilha, os registradores e os dados.

A interface com o usuário é única para todas as ferramentas. Essa interface consiste basicamente em um browser de código fonte que também pode ser acionado pelo PMA e PDT para mostrar características ou regiőes de interesse no código fonte. Os dados de saída de um programa em execução são exibidos sob o controle da interface em uma janela separada.

Atualmente o ANNAI trabalha sobre quatro plataformas de hardware diferentes: NEC Cenju-2, Meiko CS-1, estação de trabalho SUN multiprocessadas e rede de estaçбes de trabalho SUN. 


\section{EPPP ( Environment For Portable Parallel Programming)}

O objetivo do EPPP[Bon94, Hur94] é criar um ambiente para programação paralela portátil para a atual e futuras gerações de computadores paralelos. O ambiente EPPP $́$ E portátil no sentido de que o usuário pode desenvolver e aperfeiçoar a sua aplicação em estaçőes de trabaiho Unix e rapidamente migrá-las para uma grande variedade de máquinas paralelas de memória distribuída.

Para alcançar essa meta, o EPPP é constitaído de vários componentes que são integrados: uma linguagem de programação baseada no paradigma de programação com paralelismo de dados, um pré-processador HPC, um compilador C, um link-editor, um simulador, um depurador e visualizador de desempenho.

A linguagem de programação é a High Performance C, uma extensão da C singlethreaded, que faz uso de um espaço de nomes global para endereçar variáveis e oferece suporte à primitivas de distribuição de dados.

O pré-processador HPC recebe um programa escrito em HPC e a descrição da arquitetura destino e produz um código SPMD correspondente, com instrumentação do código opcional para depuração de desempenho.

O compilador $\mathrm{C}$ recebe o código SPMD gerado pelo pré-processador e gera o código objeto. Esse compilador utiliza técnicas avançadas de otimização para extrair todo o potencial de paralelismo das arquiteturas superescalares.

O link-editor do EPPP é responsável por gerar o código binário através da união do código gerado pelo compilador e da biblioteca de passagem de mensagens PVM com a biblioteca de tempo de execução dependente de máquina ou a biblioteca da máquina de simulação, dependendo do local (máquina real ou simulador) onde esse código será executado.

Usando o EPPP, o programador pode desenvolver, depurar e aperfeiçoar sua aplicação em uma estação de trabalho. $O$ simulador provê ao usuário uma plataforma de execução de baixo custo para depuração funcional. Com tal ferramenta, o usuário não necessita ter acesso à máquina destino. Uma característica importante do simulador é que os dados de desempenho podem ser gerados durante a execução simulada. 
O visualizador de desempenho permite o usuário visualizar o comportamento da execução do programa através de rastreios originados da execução na máquina destino ou no simulador, fornecendo um mecanismo eficiente para detecção de ineficiência no programa. Um dos aspectos chaves do depurador de desempenho é o de prover informação que é diretamente relacionada ao código fonte do usuário e às construções de alto nível da linguagem de programação. Ele ajuda o usuário a entender o impacto da distribuição de dados no desempenho do programa.

Esse trabalho foi desenvolvido pelo Centre de Recherche Informatique de Montréal (CRIM), com apoio de Industry Canada, Alex Parallel Computers, Digital Equipment Canada e IBM Canada.

\section{PADE (Parallel Application Development Environment)}

O PADE[Dev95] é um ambiente flexível e customizado para o desenvolvimento de aplicações paralelas que utilizam a biblioteca de passagem de mensagens PVM. Ele fornece um ambiente integrado para todas as fases do desenvolvimento de aplicações paralelas: edição, compilação, execução, monitoramento e melhoria de desempenho.

O ambiente de desenvolvimento PADE consiste em uma interface de usuário gráfica e intuitiva e uma série de utilitários PVM. Ele é muito utilizado com uma máquina virtual heterogênea com múltiplas arquiteturas e múltiplos sistemas de arquivo. $O$ PADE auxilia o desenvolvedor de aplicações paralelas a manter as informações de quais arquivos-fonte devem ser enviados e compilados em cada máquina. As tarefas de enviar os arquivos, emitir o comando de compilação e exibir os resultados da compilação no terminal do desenvolvedor são de responsabilidade do PADE.

O PADE é basicamente um console de desenvolvimento para a máquina virtual, de forma que todas as tarefas essenciais para o desenvolvimento de aplicações paralelas podem ser feitas em um computador central. Esse computador central, a máquina de desenvolvimento, é o computador onde todos os arquivos fonte da aplicação paralela são mantidos e onde o PADE é executado.

Esse ambiente de desenvolvimento permite que tarefas como a definição da máquina virtual, a organização dos arquivos fonte da aplicação, a edição do código fonte de 
cada máquina, a construção da aplicação paralela com um único comando e a análise dos resultados da compilação/execução possam ser feitas na máquina de desenvolvimento, com acesso transparente para os outros nós da máquina virtual.

O PADE oferece uma representação gráfica da máquina virtual que mostra as máquinas e os arquivos de programa associados a elas em um diagrama bidimensional. Muitas das açōes do gerenciador de arquivos e comandos que são necessárias durante o desenvolvimento da aplicação podem ser feitas pelas operaçōes de "clicar e arrastar" nos objetos desse diagrama.

Esse sistema é um projeto do National Institute of Standards and Technology (NIST) e pode ser obtido através de ftp anônimo para o diretório pub/pade no endereço ftp://math.nist.gov. Informações podem ser obtidas no endereço http://www.itl.nist.gov diretorio/div895/pade/pade.html.

\subsection{Outras Ferramentas para Processamento Paralelo}

As ferramentas com características que não se enquadram nas classes acima citadas, foram agrupadas, e devido a grande variedade de ferramentas nessa classe, toma impossível fazer uma definição genérica. Entre as ferramentas desse grupo estão os escalonadores, simuladores e ferramentas para uso em redes de computadores.

As ferramentas para uso em redes de computadores têm como objetivo de alcançar um maior desempenho na execuçāo de aplicaçōes paralelas/distribuídas. Para alcançá-lo utilizam a capacidade de processamento de máquinas que estão ociosas.

As ferramentas desse grupo geralmente trabalham com filas distribuídas para a distribuição de jobs, utilizam o paralelismo ao nível de job, com escalonamento e balanceamento de carga para obter maior desempenho na execução dos programas e aproveitar o tempo ocioso das outras estaçōes da rede.

As ferramentas SAGE[79], IMPROV (Integrated Manipulation of PROgram Visualization)[Cas93], PARADISE [Koh91, Koh92], PARIX[Rot93], DQS (Distributed Queuing System)[Gre92], CONDOR[Lit88] e PARAPET[Deb92], fazem parte dessa classe 


\subsection{Considerações Finais}

No decorrer deste capítulo foi apresentada uma classificação das ferramentas existentes para computação paralela. Também foram apresentadas algumas ferramentas pertencentes a cada uma das classes e subclasses, suas característica e disponibilidade.

As tabelas a seguir mostram a classificação proposta e as ferramentas que se enquadram em cada uma das classes, de acordo com a pesquisa realizada. Essa pesquisa está sumarizada em [Oli98].

A Tabela 1 apresenta a classe de ferramentas para desenvolvimento de programas paralelos e sua divisão em linguagens para programação paralela, bibliotecas e sistemas para programação paralela e ambientes de desenvolvimento.

Tabela 1 - Ferramentas para Desenvolvimento de Programas Paralelos

\begin{tabular}{|c|c|c|}
\hline \multirow[t]{2}{*}{$\begin{array}{l}\text { Linguagens } \\
\text { para } \\
\text { Programação } \\
\text { Paralela }\end{array}$} & \begin{tabular}{|l} 
Intrinseca- \\
mente \\
Paralelas
\end{tabular} & $\begin{array}{l}\text { LINDA } \\
\text { OCCAM } \\
\text { SISAL } \\
\text { SR }\end{array}$ \\
\hline & $\begin{array}{l}\text { Orientadas a } \\
\text { Objeto }\end{array}$ & $\begin{array}{l}\text { C** } \\
\text { CC+ } \\
\text { CHARM+ } \\
\text { COOL (Concurrent Object Oriented Language) } \\
\text { HPC+ } \\
\text { MELDC } \\
\text { MENTAT } \\
\text { Object Oriented FORTRAN } \\
\text { PARA+ } \\
\text { Parallel Java } \\
\text { PARC+ } \\
\text { PC++ - Parallel C }+ \\
\text { Pssather } \\
\text { uC+ }\end{array}$ \\
\hline
\end{tabular}




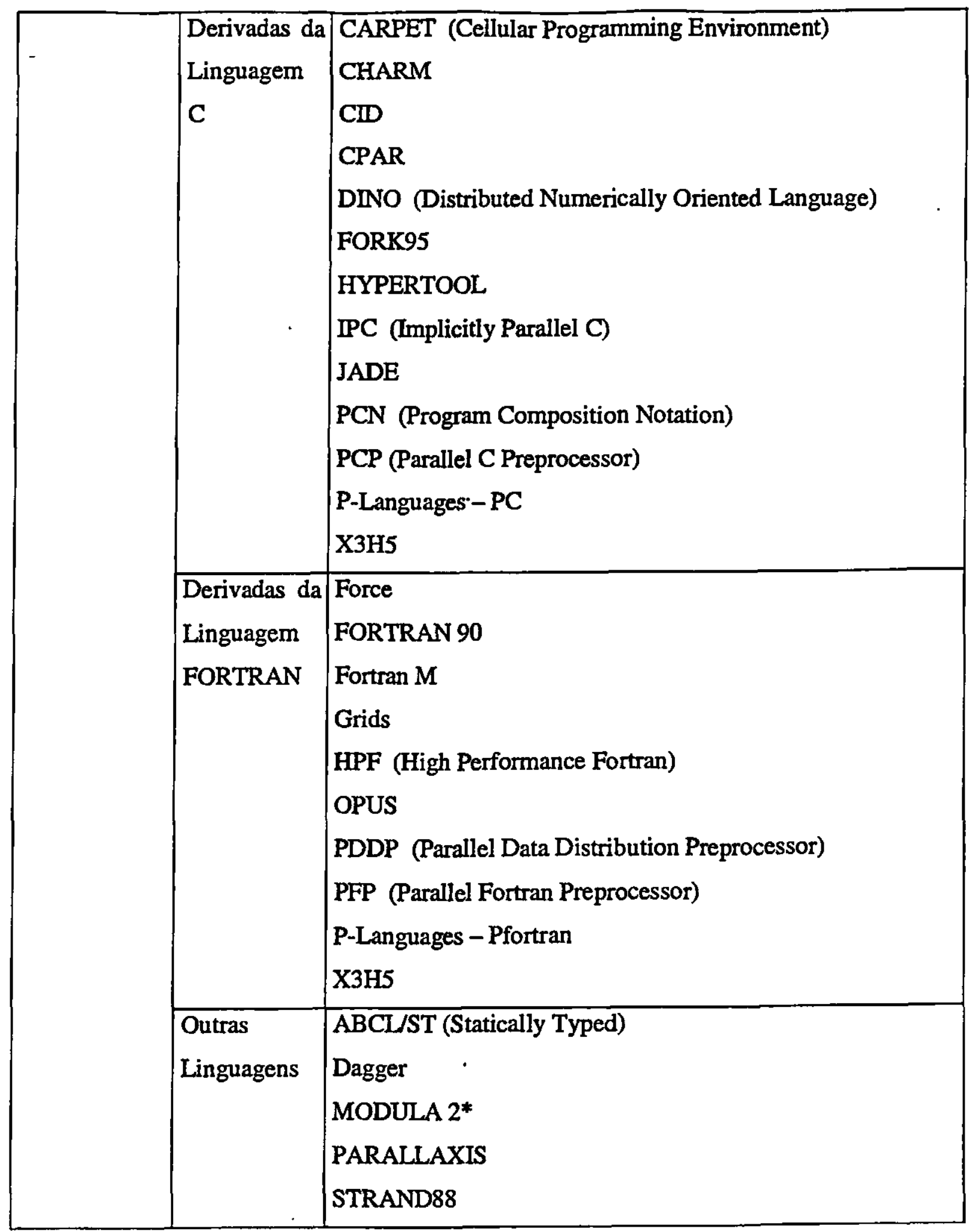




\begin{tabular}{|c|c|}
\hline $\begin{array}{l}\text { Bibliotecas e } \\
\text { Sistemas para } \\
\text { Computação } \\
\text { Paralela }\end{array}$ & 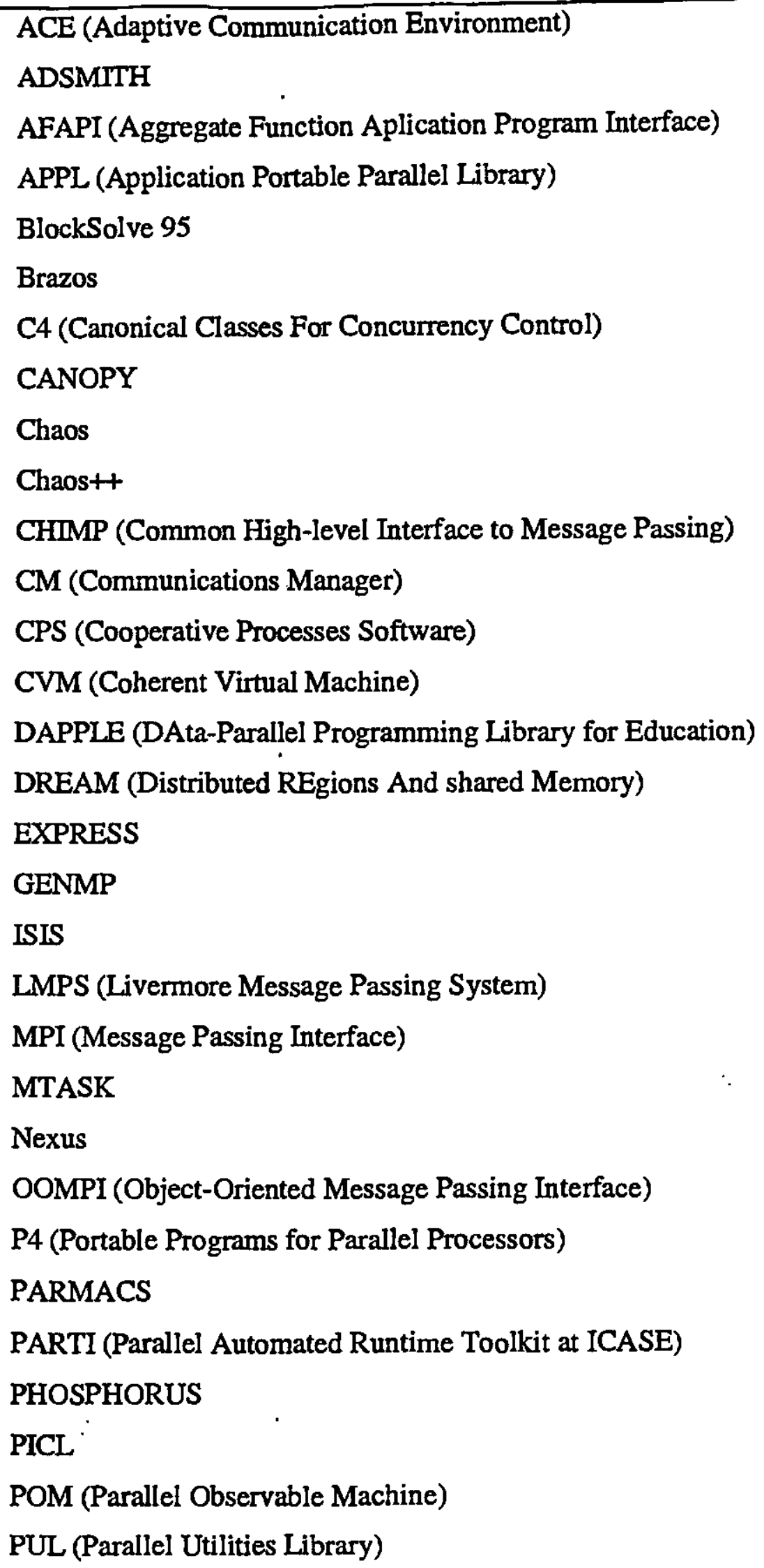 \\
\hline
\end{tabular}




\begin{tabular}{|l|l|}
\hline & PVM (Parallel Virtual Machine) \\
& Regis \\
SCIDDLE & SIMPLE \\
& SPPL (Stuttgart Parallel Processing Library) \\
& TCGMSG (Theoretical Chemistry Group Message Passing System) \\
& Tempest \\
& TreadMarks \\
& Unify \\
\hline Ambientes de & CODE 2.0 \\
Desenvolvi- & DagTool \\
mento & HeNCE (Heterogeneous Network Computing Environment) \\
& LPB (Linda Program Builder) \\
& PYRROS \\
& VPE (Visual Parallel Environment) \\
\hline
\end{tabular}

Na Tabela 2 é apresentada a classe de ferramentas para paralelização de programas sequienciais com sua divisão em ferramentas automáticas e interativas, juntamente com as ferramentas pertencentes a essas subclasses:

Tabela 2 - Ferramentas para Paralelização de Programas Seqüenciais

\begin{tabular}{|l|l|}
\hline Automáticas & ADAPTOR (Automatic Data Parallelism TranslatOR) \\
CRAY/fpp \\
FTS (Forth Translation System) \\
KAP \\
MIPRAC \\
PARCEL \\
POLARIS \\
SUIF Compiler (Stanford University Intermediate Format Compiler) \\
TINPAR (TINy PARallelizer) \\
Vienna Fortran Compilation System \\
\hline
\end{tabular}




\begin{tabular}{|l|l|}
\hline Interativas & FORGE \\
& P2D \\
& PAT (Parallelization Assistant Tool) \\
& PTOPP (Practical Toolset for the Optimization of Parallel Programs) \\
& TINY \\
\hline
\end{tabular}

A Tabela 3 apresenta a classe de ferramentas para depuração e análise de desempenho e as ferramentas pertencentes a subclasse de ferramentas de depuração e subclasse de ferramentas de análise de desempenho.

Tabela 3 - Ferramentas para Depuraçāo e Análise de Desempenho

\begin{tabular}{|l|l|}
\hline Ferramentas & EXECDIFF \\
de Depuração & IPD \\
& PANORAMA \\
& P2D2 \\
& TotalView \\
& UBD - KSR Symbolic Debugger \\
& XAB \\
& XPDB (X-Windows Parallel Debugger) \\
\hline Ferramentas & AIMS (Automated Instrumentation And Monitoring System) \\
de Análise de & ATEXPERT \\
Desempenho & BBN Performance Tools \\
& BLOBS \\
& FALCON \\
& GPMS (General Parallel Monitoring System) \\
& INTEL Performance Analysis Tools \\
& IPS-2 \\
& KSR Performance Tools \\
& NARITXU (NAS Trace Visualizer) \\
& \\
& PABLO Performance Analysis Environment \\
& \\
& \\
& \\
&
\end{tabular}




\begin{tabular}{|l|l|}
\hline Paradyn \\
PARAGRAPH \\
Projections \\
SVMView \\
TMON- Transputer MONitor \\
UPSHOT \\
VOYER \\
XPVM \\
\hline
\end{tabular}

Na Tabela 4 são apresentadas as ferramenta pertencentes a categoria de ambientes integrados que não possui nenhuma subclasse.

Tabela 4 - Ambientes Integrados

\begin{tabular}{|l|l|}
\hline Ambientes & ANNAI \\
CAPER (Concurrent Application Programming Environment) & ENTERPRISE \\
& EPPP (Environment for Portable Parallel Programming) \\
MEANDER & Modula-2* System \\
& MPPE (MasPar Programming Environment) \\
& PADE (Parallel Application Development Environment) \\
& PARALEX \\
PARALLAX & ParaScope \\
PARASPHERE & PEMPI (Programming Environment for the MPI) \\
PRISM & SCHEDULE \\
TOPSYS (TOols for Parallel Systems) \\
TRAPPER \\
VISAGE (VISual Attributed Graph Environment) \\
\end{tabular}


A Tabela 5 apresenta as ferramentas encontradas durante a pesquisa e suas características não se encaixam em nenhuma das classes, formando a classe de outras ferramentas para computação paralela.

Tabela 5 - Outras Ferramentas para Computação Paralela

\begin{tabular}{|c|c|}
\hline $\begin{array}{l}\text { Outras } \\
\text { Ferramentas }\end{array}$ & $\begin{array}{l}\text { ARJUNA } \\
\text { Calypso } \\
\text { CCS (Computing Center Software) } \\
\text { CONDOR } \\
\text { CONVERSE } \\
\text { DBC (Distributed Batch Controller) } \\
\text { DJM (Distributed Job Manager) } \\
\text { DOME (Distributed Object Migration Environment) } \\
\text { DQS (Distributed Queuing System) } \\
\text { FUNNEL } \\
\text { Hector } \\
\text { IMPROV (Integrated Manipulation of PROgram Visualization) } \\
\text { NetSolve } \\
\text { Network Linda } \\
\text { PARADISE (PARallel Animated Debugging and Simulation } \\
\text { Environment) } \\
\text { PARAPET (PARAllel Programming Environment Tools) } \\
\text { PARIX (PARallel extensions for uniX) } \\
\text { POLKA } \\
\text { SAGE + } \\
\text { TOPIDOMDEC (DOMain DEComposition) }\end{array}$ \\
\hline
\end{tabular}

Com essa pesquisa foi possível verificar a grande quantidade de ferramentas existentes para computação paralela e a ausência de uma ferramenta que possua a funcionalidade de todas as classes. Essa ferramenta deve ser capaz de auxiliar a geração de 
um programa paralelo tanto a partir de um programa seqüencial quanto do problema, possuindo funcionalidades para suprir todo o desenvolvimento da aplicação paralela até as fases de depuração e análise de desempenho.

Um outro problema encontrado através desta pesquisa é a falta de metodologias para o desenvolvimento desse tipo de aplicação, como também de uma ferramenta que automatize uma metodologia.

No próximo capítulo serão apresentadas algumas metodologias utilizadas para o desenvolvimento de aplicaçðes convencionais e a possível utilização dessas metodologias no desenvolvimento de aplicaçðes paralelas. 


\section{Metodologias Orientadas a Objetos para Desenvolvimento de Software}

\subsection{Consideraçōes Iniciais}

Para o desenvolvimento deste projeto foi necessário um estudo das principais metodologias utilizadas no desenvolvimento de aplicaçōes convencionais e de alguns conceitos relacionados com programação orientada a objetos. Neste capítulo também é apresentado um estudo detalhado sobre as duas metodologias de desenvolvimento orientado a objeto que possuem grande importância no meio acadêmico e comercial e sua utilização no desenvolvimento de aplicações paralelas.

Na seção 4.2 são apresentados alguns conceitos de orientação a objetos. Na seção 4.3 é apresentada a metodologia orientada a objetos Fusion que surgiu da fusão de várias outras metodologias. Na seção 4.4 e apresentada a linguagem de modelagem UML, que surgiu como um padrão para a modelagem de sistemas. Na seção 4.5 é feita uma análise da utilização de Fusion e UML no desenvolvimento de aplicações paralelas.

\subsection{Tecnologia da Orientação a Objetos}

As técnicas de orientação a objetos surgiram inicialmente com o desenvolvimento de linguagens em que os objetos são o foco da programação. Esses objetos são agrupados em classes que definem de forma precisa a interface para as suas instâncias. Essas classes são os blocos básicos de construção nessas linguagens.

Os objetos são entidades dinâmicas, que trocam mensagens entre si. Essas mensagens invocam métodos que executam as atividades relevantes do sistema. Os objetos que enviam uma mensagem não precisam conhecer os detalhes da implementação interna do objeto ao qual a mensagem foi enviada, apenas a interface com a qual ele se relaciona.

A abordagem orientada a objetos diminui a distância entre os conceitos da aplicação no mundo real e a implementação desta através de uma linguagem de programação. $O$ 
mesmo conceito de objeto é usado ao longo de todas as fases do desenvolvimento, com diferentes níveis de abstração.

Atualmente existem vários métodos orientados a objetos para o desenvolvimento de aplicações. Entre eles pode-se citar, Booch [Boo91], OMT [Rum91], que evoluiu de métodos tradicionais como a análise estruturada, Fusion que surgiu da união de outros métodos orientados a objetos e a UML, que surgiu como uma padronização para modelagem de objetos, unindo técnicas de modelagem de vários métodos.

\subsection{Fusion}

O método Fusion [Col96] para desenvolvimento de software orientado a objetos foi criado por Coleman, para abranger as fases de analise, projeto e implementação. $O$ conjunto de modelos do método é conciso e a passagem de uma fase para outra é bem definida, sendo sempre seguida de atividades de inspeção para verificação da consistência dos modelos.

O nome Fusion indica que o método foi criado a partir de notações e conceitos propostos por outros métodos, estendendo e integrando essas abordagens. Esse método divide-se basicamente em três fases: análise, projeto e implementação.

\subsubsection{Análise}

A fase de análise produz o modelo de análise do sistema, que é composto por dois modelos: o modelo de objetos e o modelo de interface.

Nesta fase esses dois modelos devem ser desenvolvidos e verificados antes de avançar para a fase de projeto, na tentativa de eliminar problemas nas próximas fases. $O$ processo de desenvolvimento do modelo de análise é composto pelas etapas de confecção dos modelos e a verificação dos mesmos.

\subsubsection{Modelo de Objetos}

Esta etapa consiste no desenvolvimento de um Modelo de Objetos para o domínio do problema. O principal objetivo é representar os conceitos existentes no domínio do 
problema e suas relações. Esse modelo permite representar classes, atributos e relacionamentos entre classes, inclụindo agregação e especialização/generalização.

A análise deve iniciar em um alto nível de abstração, recomendando-se que os detalhes sejam inseridos somente depois que a estrutura geral for considerada satisfatória.

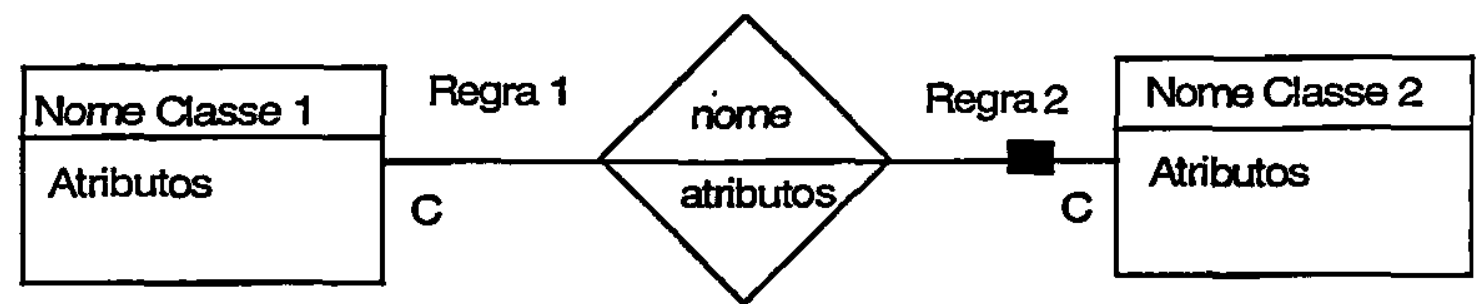

Figura 14 - Modelo de Objelos

A representação de classes e relacionamentos é a mostrada na, onde as classes são representadas por retângulos e os relacionamentos por losangos. Os rótulos Regral e Regra2 representam os papéis das classes no relacionamento e devem ser significativos, para deixar claro as ordens de leitura dos relacionamentos, C e a cardinalidade deste relacionamento.

Os objetos, na fase de análise, não incluem os métodos, que sర serão incorporados na fase de projeto. Nesta fase não se entra em detalhes de como os objetos interagem e qual a sua interface, apenas são determinadas as operações que serão realizadas pelo sistema.

No modelo de objetos, existem dois tipos especiais de relacionamentos que podem ser representados: a agregação e a especialização/generalização. Esses relacionamentos são utilizados para fomecer estruturação ao modelo.

A agregação é implementada por uma tupla referente aos componentes que participam deste relacionamento. Somente as tuplas do relacionamento fazem parte da agregação, isto é, as referências estão ligadas pelo relacionamento.

A generalização permite que uma classe, chamada de supertipo, seja formada possuindo as propriedades comuns de várias classes, denominadas subtipos. $\mathrm{O}$ modelo de objeto permite a especialização múltipla, onde, um subtipo pode ser definido como especialização de mais de um objeto supertipo. 
Quando os limites do sistema säo definidos, algumas classes e relacionamentos são excluídos, dando origem aos agentes do ambiente (ou entidades externas). $\mathrm{O}$ modelo, com essa delimitação, é denominado Modelo de Objetos do Sistema.

\subsubsection{Modelo de Interface do Sistema}

Esse modelo consiste na identificação dos agentes, operaçōes e eventos e em refinar o modelo de objetos do sistema, adicionando-lhe limites. Nesta fase deve-se elaborar o Modelo de Ciclo de Vida è o Modelo de Operações.

A interface de um sistema é modelada como uma entidade ativa que se comunica com o ambiente através de agentes. Agentes modelam seres humanos ou outros sistemas de hardware ou software.

O ambiente é o conjunto de agentes com o qual o sistema se comunica. Um evento é definido como uma unidade atômica $c$ instantânea de comunicação entre o sistema e o seu ambiente.

As entradas do sistema são denominadas de eventos de entrada e podem estar acompanhadas de dados de entrada. A cada evento de entrada corresponde uma operação do sistema. As operaçōes tratam os dados de entrada e podem dar origem a eventos de saida. Os eventos de entrada podem alterar o estado do sistema e podem gerar eventos de saída. Tanto os dados de entrada como os dados de saída são instâncias de classes do modelo de objetos.

\subsection{Modelo de Ciclo de Vida}

o Modelo de Ciclo de Vida descreve o comportamento completo de como o sistema se comunica com o ambiente, desde a sua criação até o seu término. Sua sintaxe geral é mostrada na Figura 15, onde Nome especifica o Nome do sistema. As expressōes regulares definem a seqüência de eventos que o sistema pode participar durante toda a sua vida. Do mesmo modo que nas gramáticas elas definem as sequiências de símbolos da linguagem que podem ser aceitas pelo compilador. 
life cycle [Nome:] Expressão-Regular (nome-bcal = Expressão-Regular)*

Figura 15 - Modelo de Ciclo de Vida

As expressões regulares podem ser combinadas com operadores de forma a gerar todo o ciclo de vida do sistema. A Tabela 6 mostra os possíveis operadores e suas funçōes.

\begin{tabular}{|l|c|l|}
\hline \multicolumn{1}{|c|}{ Operadores } & $\begin{array}{c}\text { Expressão } \\
\text { Resultante }\end{array}$ & \multicolumn{1}{|c|}{ Significado } \\
\hline concatenação & $\mathrm{x} \cdot \mathrm{y}$ & $\mathrm{x}$ seguido de $\mathrm{y}$ \\
\hline I escolha & $\mathrm{x} / \mathrm{y} .$. & Ou x ou y \\
\hline * repete 0 ou mais & $\mathrm{X}^{*}$ & Repete $\mathrm{x}$ zero ou mais vezes \\
\hline + repete 1 ou mais & $\mathrm{X}^{+}$ & Repete $\mathrm{x}$ uma ou mais vezes \\
\hline [ ] opcional & {$[\mathrm{x}]$} & $\mathrm{x}$ é realizado opcionalmente \\
\hline II concorrência & $\mathrm{x} \| \mathrm{y}$ & $\begin{array}{l}\mathrm{x} \text { e y são realizados } \\
\text { concorrentemente }\end{array}$ \\
\hline $\begin{array}{l}\text { ( ) agrupamento }- \\
\text { altera a precedência }\end{array}$ & $(\mathrm{x} \| \mathrm{y})^{*} . \mathrm{z}$ & $\begin{array}{l}\mathrm{x} \text { e y são intercalados e } \mathrm{z} \text { Termina } \\
\text { Ex: xxxyyxyxz }\end{array}$ \\
\hline
\end{tabular}

Tabela 6 - Operadores das Expressōes Regulares do Modelo de Ciclo de Vida

\subsection{Modelo de Operações}

O Modelo de Operações especifica o comportamento de uma operação de forma declarativa em termos de mudanças de estado do sistema e geração de eventos de saída, descrevendo o comportamento de uma operação individual do sistema.

Fusion usa uma notação textual, na forma de um gabarito apresentado na Figura 16. Nesse gabarito há entradas para descrever informalmente a operação e para especificar:

a) os dados que são fomecidos junto com os eventos de entrada ou estão disponíveis globalmente; 
b) os objetos a que a operação pode ter acesso, mudando ou não seu estado;

c) os eventos de saída que a operação gera e os agentes que os recebem;

d) as pre-condiçōes que devem ser satisfeitas e os resultados da operação, descritos como uma pós-condição.

\begin{tabular}{|l|l|}
\hline Operação & Nome da Operação \\
\hline Descrição & Descrição da Operação \\
\hline Lê & Itens de dados \\
\hline Modifica & Itens de dados \\
\hline Envia & Agentes e Eventos \\
\hline Assume & Condição (pre-condição) \\
\hline Resultado & Estado (pós-condição) \\
\hline
\end{tabular}

Figura 16 - Modelo de Operaçåo

\subsubsection{Verificação dos Modelos da Análise}

Nesta etapa é verificado se o modeło está consistente e completo. Um modelo está consistente quando não existem contradiçōes entre as partes do modelo, e completo se todas as abstraçōes significativas do domínio foram captadas e se o modelo de análise é condizente com as expectativas do usuário.

\subsubsection{Projeto}

O propósito principal da fase de projeto é especificar como as funcionalidades do sistema, definidas no modelo de operaçōes, serão implementadas através da interação dos objetos do sistema.

Nessa fase são introduzidas estruturas de software para satisfazer as abstraçōes produzidas na fase de análise, essas estruturas são os objetos de projeto, que além de terem identificadores e atributos, têm uma interface, os métodos e seus parâmetros. A fase de 
projeto do método Fusion é baseada nos métodos CRC [Wir90] e de Booch [Boo91]. Para a conclusão da fase de projeto deve-se cumprir as etapas abaixo descritas.

\subsubsection{Elaboração de Grafos de Interação de Objetos}

Nessa primeira etapa devem ser desenvolvidos grafos de interação para cada uma das operações do Modelo de Operações. Através desses grafos é possível mostrar a participação dos objetos na execução de uma operação e a sequiência de trocas de mensagens entre eles.

O objeto controlador da operação e os colaboradores devem ser especificados. As trocas de mensagens entre o controlador é os colaboradores e entre os colaboradores dá origem aos métodos, que são associados às classes nesta fase.

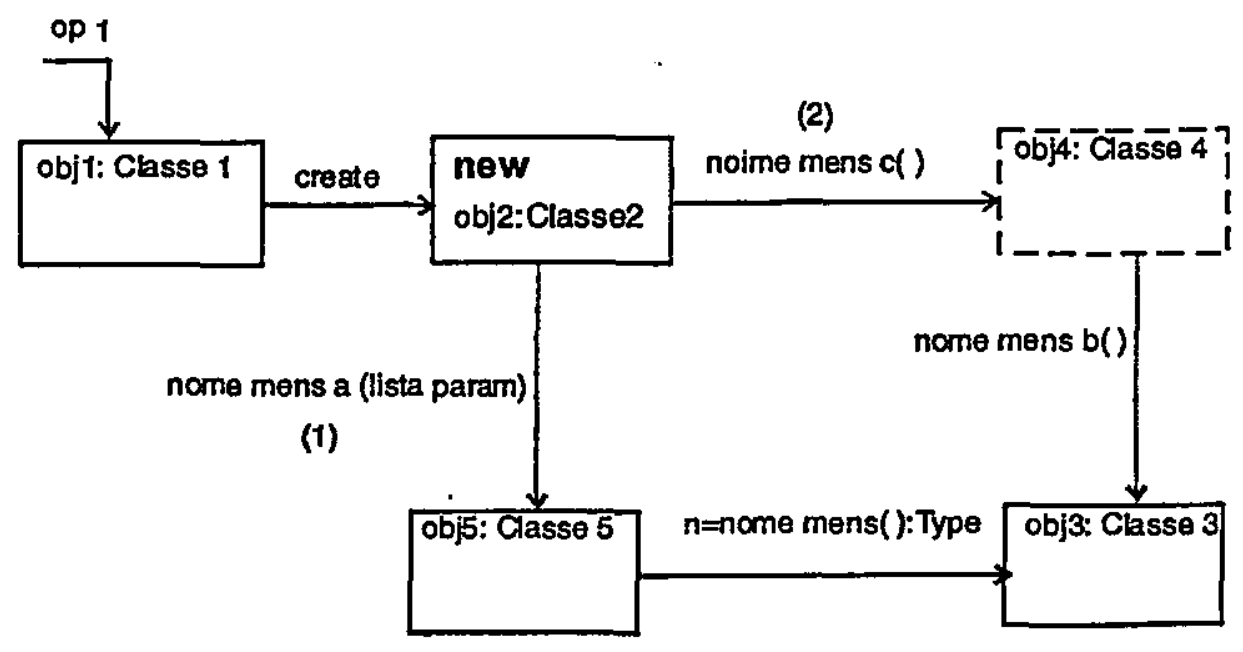

Figura 17 - Grafo de Interaçāo de Objetos

A sequiência de mensagens entre os objetos de projeto produz o comportamento funcional dos objetos especificado pelo esquema da operação correspondente. A notação usada no Grafo de Interação de Objetos é a mostrada na Figura 17. Os retângulos com linhas sólidas representam um objeto típico de uma classe e os com linhas tracejadas representam coleções de objetos de mesma classe.

Mensagens enviadas a partir de uma coleção fazem parte do comportamento de cada objeto da coleção e nāo da coleção propriamente dita. Por default, as mensagens para uma coleção são recebidas por todos os objetos da coleção, sem uma ordem pré-definida. 
A eficiência de uma operação pode ser medida pela quantidade de troca de mensagens entre os métodos que participam da operação, bem como por necessidades de referências entre os objetos.

\subsubsection{Elaboração de Grafos de Visibilidade}

Esta etapa consiste na construção de Grafos de Visibilidade para cada uma das classes existentes. A identificação $\mathrm{e}$ o endereçamento dos objetos são chamados de "referenciação", isto $\epsilon$, um objeto servidor deve ser visível por um cliente para que o cliente possa enviar-lhe uma mensagem. $O$ grafo de visibilidade deve especificar os objetos que uma instância de classe pode referenciar o tipo apropriado de referência.

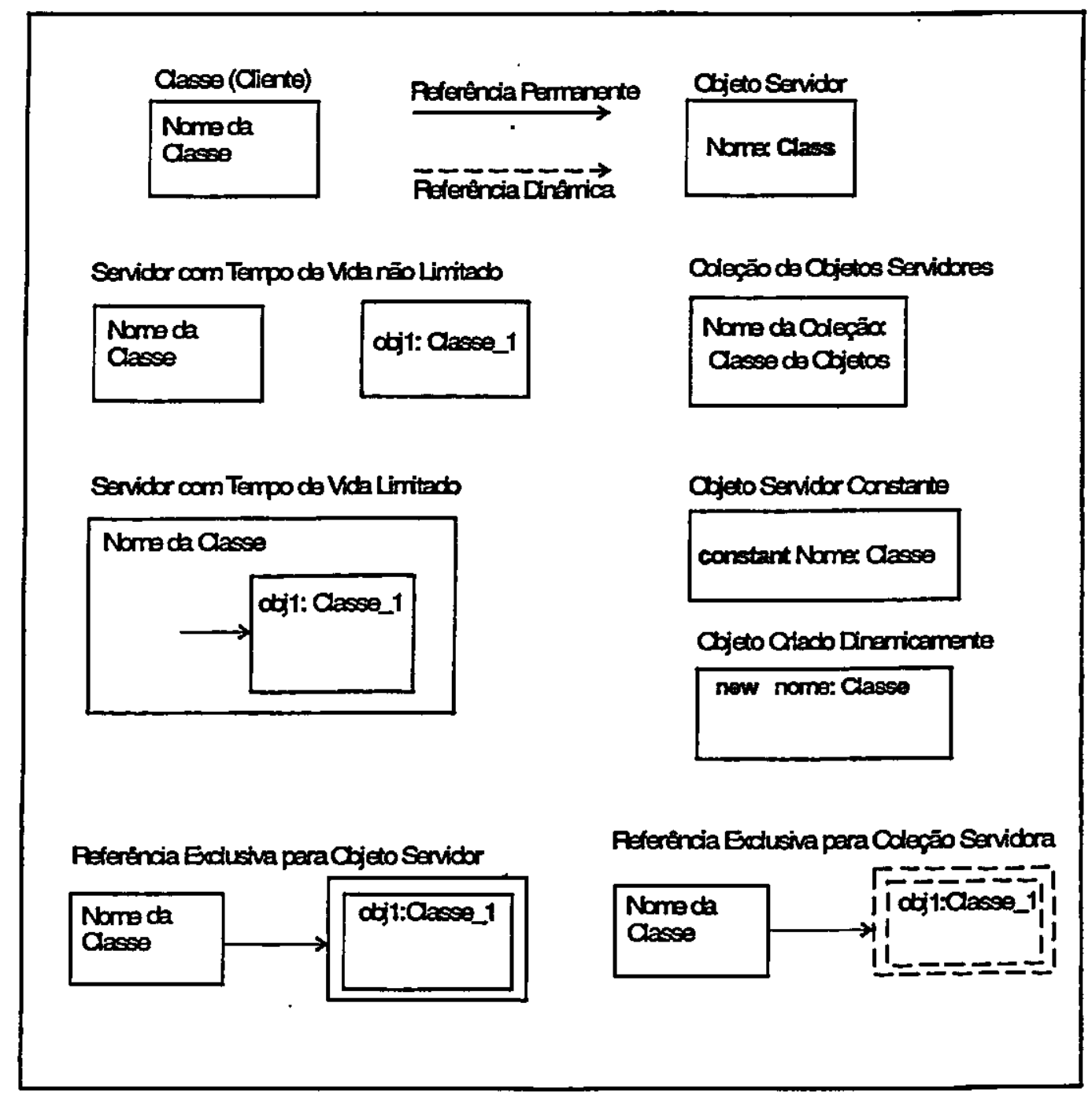

Figura 18 - Notação para o Grafo de Visibilidade 
As classes são denotadas por caixas e visibilidade por setas. A Figura 18 apresenta a notação para a diagramação de um grafo de visibilidade para o método Fusion.

As referências podem ser classificadas segundo quatro aspectos: duração indica se a referência deve ser dinâmica ou permanente, visibilidade do servidor indica se o acesso a um objeto servidor pode ser feito apenas por um certo objeto cliente ou se pode ser feita por qualquer objeto, dependência do servidor indica se a vida do objeto servidor depende de um objeto cliente, e mutabilidade que indica se a referência a um objeto servidor pode ser alterada após ter sido criada.

\subsubsection{Elaboração da Descrição de Classes}

Nessa fase deve ser elaborada uma descrição de cada classe, através de uma notação textual, especificando os atributos de cada objeto e a sua interface externa. Os atributos de dados, atributos de referência a objetos e métodos são definidos para todas as classes do sistema. A notação utilizada é apresentada na Figura 19.

class $<$ Nome da Classe $>$ [is a $<$ Nome da super Classe $>$ ]

// para cada atributo

[attribute] [Mutabilidade]<a_nome>:[Compartilhamento][Dependência]<Tipo>

/ / para cada método

[method] $<$ m_nome $><$ lista de argumentos $>[:<$ tipo $>]$

endclass

Figura 19 - Descriçāo de Classes 


\subsubsection{Construção de Grafos de Herança}

Os Grafos de Herança usam a mesma notação do modelo de objetos para representar herança $e$ as classes. Esses grafos são utilizados para complementar as descrições de classes. Novas abstrações podem ser acrescentadas, diferentes daquelas usadas no Modelo de Objetos do sistema, refletindo decisöes de projeto.

O Grafo de Herança é o proprio Modelo de Objetos do Sistema com o acréscimo das relações de generalização/especialização definidas na fase de projeto e daquelas do domínio preservado.

\subsubsection{Atualização da Descrição da Clasṣe}

Nessa etapa é necessária a atualização da Descrição de Classe com as novas informaçōes de herança, verificando se as relaçōes de subtipos são preservadas no Modelo de Objetos do Sistema, se todas as classes estão representadas no Grafo de Interação e no Grafo de Herança, e por fim, se a Descriçăo de Classes atualizada implementa todas as funcionalidades das anteriores.

\subsubsection{Implementação}

A última fase consiste na implementaçäo do modelo. A fase de implementação deve mapear o projeto para uma implementaçāo efetiva, correta e econômica. $O$ processo de implementação é composto de três partes principais: codificação, desempenho e revisão, que não exigem uma ordem de conduçăo rígida.

\subsubsection{Codificaçäo}

Nessa primeira parte traduz-se cada classe descrita na fase de projeto para a sintaxe e semântica de uma linguagem de programação em particular. Entre os aspectos importantes pode-se destacar a tradução das classes, o desenvolvimento do corpo dos métodos, o tratamento de erros e a satisfação de requisitos de desempenho. 


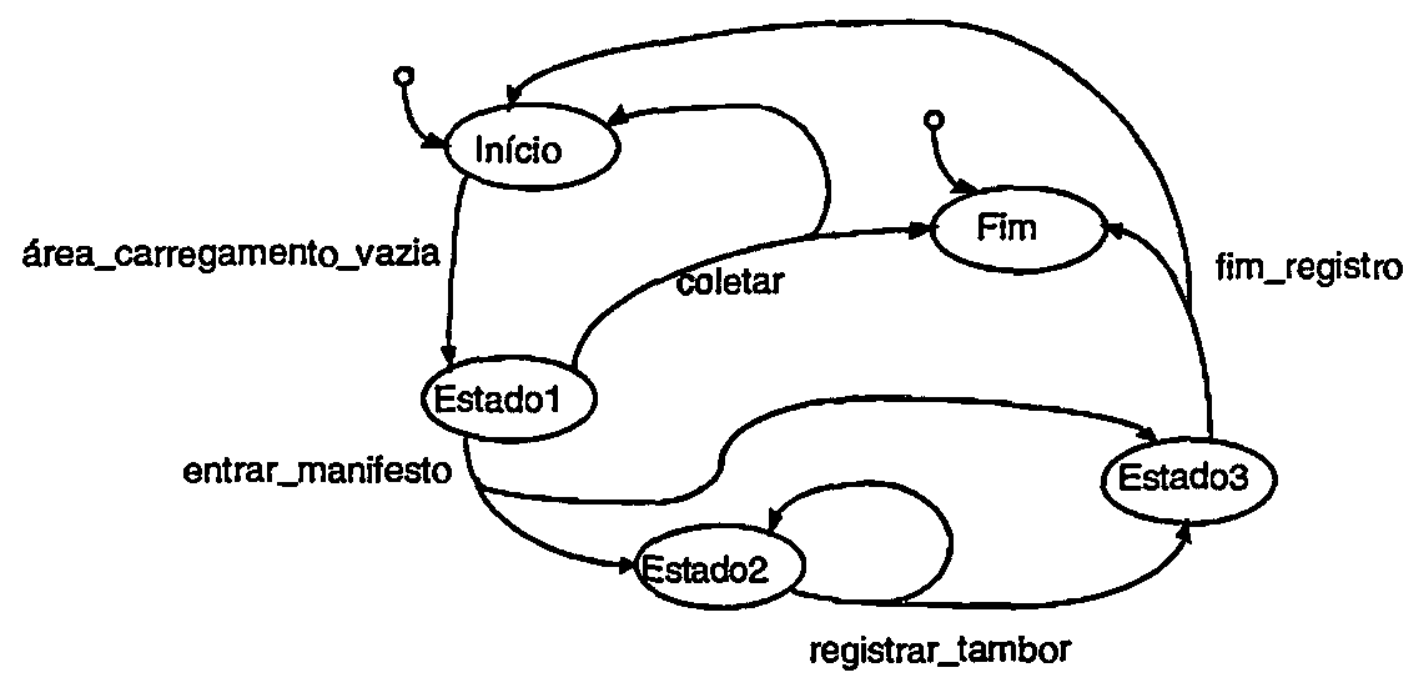

Figura 20 - Grafo de Máquina de Estados Finitos

As sequiências de operaçōes permitidas descritas pelo ciclo de vida definem a interface do sistema e são implementadas por um objeto controlador da interface. $O$ controlador é desenvolvido através da transformação da expressão regular do ciclo de vida em uma máquina de estados e desta para o código. O Grafo de Máquina de Estados Finitos é apresentado na Figura 20.

\subsubsection{Desempenho}

O desempenho deve ser considerado durante as três fases: análise, projeto e implementação, não devendo ser deixado para uma fase "especial", de obtenção de desempenho. Partes do código que são menos eficientes e usam muitos recursos devem ser identificadas e melhoradas.

\subsubsection{Revisão}

Nesta fase deve-se garantir que o código produzido possa ser entendido por outras pessoas. Os testes devem ser realizados para verificar o comportamento atual do sistema ou parte do sistema, em relação aos requisitos inicialmente solicitados. 


\subsection{UML - Unified Modeling Language}

A Unified Modeling Language [Fow97, Omg99] é a mais recente ferramenta em relação ao desenvolvimento orientado a objetos. Ela foi criada por Grady Booch, Jim Rumbaugh e Ivar Jacobson tendo como ponto de referência os seus métodos. Tem como intuito principal a criação de uma linguagem de modelagem unificada que possa suprir as necessidades dos desenvolvedores de software e a definição de um padrão a ser utilizado mundialmente. Atualmente ela foi definida como um padrão pela OMG (Object Management Group).

A UML não é uma metodologia completa, pois as metodologias são formadas por linguagens de modelagem e processos de desenvolvimento. Uma linguagem de modelagem é a notação gráfica utilizada pelos métodos e o processo de desenvolvimento são os passos a serem seguidos para o desenvolvimento completo do software.

Essa linguagem de modelagem é formada por oito diagramas que são utilizados para a modelagem completa de um software. Na maioria dos casos não são necessários todos os diagramas para a conclusão da modelagem. Os diagramas da UML são Diagrama Use Case, Diagrama de Classes, Diagrama de Sequiência, Diagrama de Colaboração, Diagrama de Pacotes, Diagrama de Estados, Diagrama de Atividades e Diagrama de Deployment.

\subsubsection{Diagrama Use Cases}

Essa classe de ferramentas, por um longo tempo, foi utilizada apenas em cenários típicos para o entendimento dos requisitos da aplicação, e era tratada muito informalmente. A importância dela cresceu muito, devido ao fato da mesma ser capaz de mostrar a interação do usuário com o sistema de computação.

Devido a importância dos Use Cases foram criados diagramas para visualizá-los, como o apresentado na, esses diagramas foram incorporados à UML e chamados de Diagramas Use Cases.

Os diagramas Use Cases são formados por atores e use cases. Os atores são as pessoas que interagem com o sistema e os use cases são as ações que os atores podem realizar. 


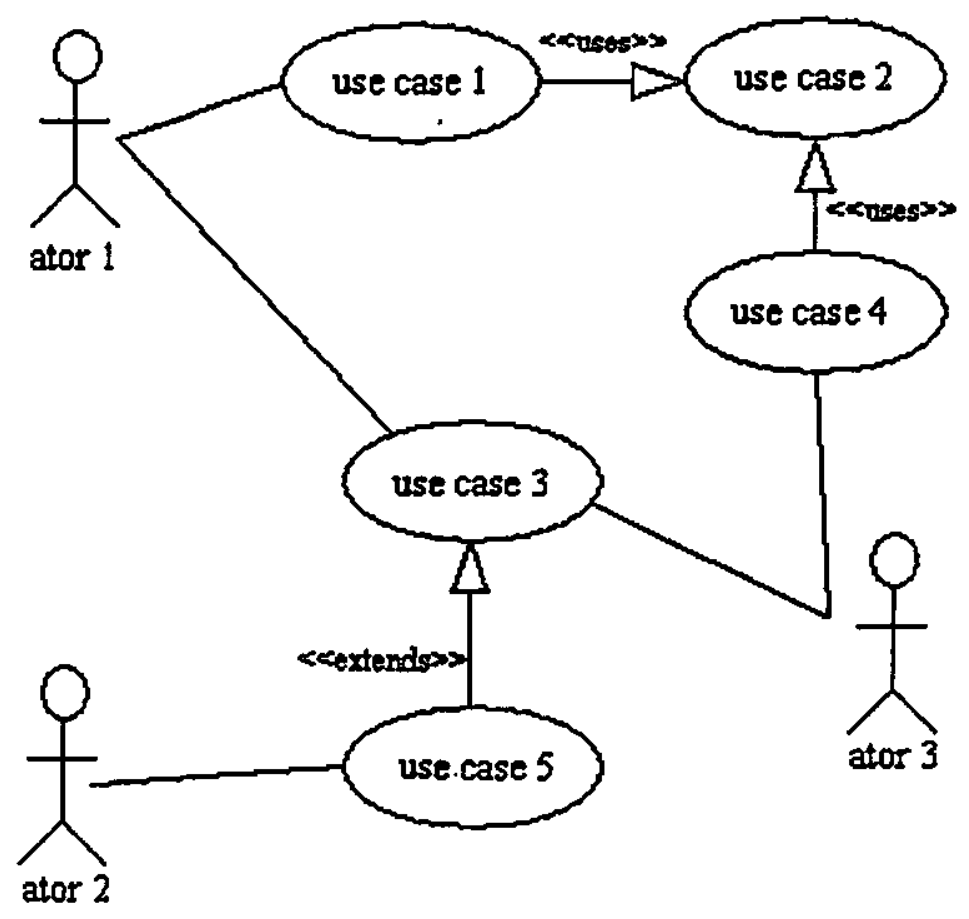

Figura 21 - Diagrama Use Cases

Um use case pode ser estendido para realizar uma ação diferente daquela que é realizada pelo mesmo, ou até mesmo um use case pode utilizar um outro use case para conseguir realizar sua função. Para esses dois casos é necessário colocar as cláusulas $<$ extend $>\mathrm{e}<$ uses> respectivamente, e definir o sentido do relacionamento.

\subsubsection{Diagrama de Classes}

O Diagrama de Classes é a idéia central dos métodos orientados a objetos, e devido a isso ele está sujeito a uma grande faixa de conceitos de modelagem. Um Diagrama de Classes descreve os tipos de objetos do sistema e os vários tipos de relacionamentos estáticos que existem entre esses objetos. Os principais tipos de relacionamentos estáticos são: Associações e Subtipos.

Além disso, o diagrạma de classes pode mostrar os atributos e operações de uma classe e também as restrições aplicadas nas conexões entre os objetos. Para esse diagrama pode-se modelar o sistema a partir de três perspectivas: 
- Conceitual - O diagrama representa os conceitos do domínio que está sob estudo;

- Especificação - O diagrama representa o software, buscando levar em consideração as interfaces do software, não a implementação;

- Implementação - É a perspectiva mais utilizada e focaliza os requisitos ao nível de implementação.

Nos itens abaixo são apresentados alguns termos utilizados pela UML, na construção do diagrama de classes:

- Associaçōes - Representam relacionamentos entre instâncias de classes e podem representar multiplicidade, ou seja, a indicação de quanto objetos podem participar de um dado relacionamento;

- Atributos - são como campos de dados para os objetos, são dados das características de um determinado objeto;

- Operações - são as operaçōes referentes a cada uma das classes, que correspondem aos métodos de uma classe e podem públicas ou privadas;

- Generalização - Ocorre quando duas classes possuem características semelhantes que são englobadas em uma classe maior, ou supertipo;

- Regras de Restrição - São regras colocadas nos relacionamentos entre classes para validar o modelo.

A Figura 22 apresenta um diagrama de classes. O diagrama de classes é essencial a qualquer modelo, pois através deste e possível visualizar as classes e seus relacionamentos, mas deve-se prestar muita atenção à construçāo desse diagrama devido a grande quantidade de notações disponíveis. 


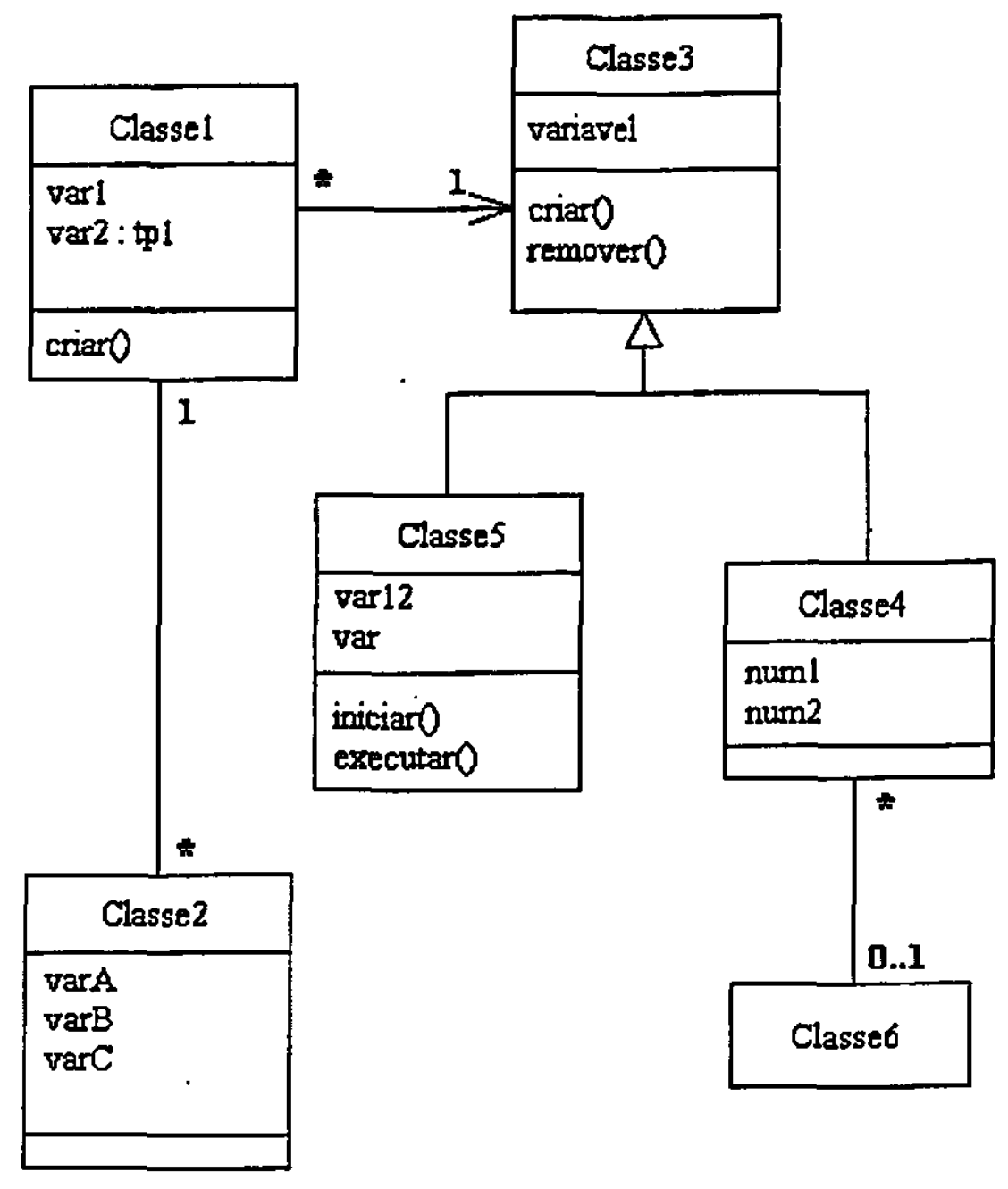

Figura 22 - Diagrama de Classes

\subsubsection{Diagramas de Interação}

Os diagramas de interação descrevem como grupos de objetos colaboram em algum comportamento. Geralmente um diagrama de interação captura o comportamento de um único use case e através dele é possível mostrar os objetos e as mensagens passadas entre esses objetos dentro de um use case.

Esses diagramas podem ser de dois tipos: Diagramas de Seqüência e Diagramas de Colaboração. 


\subsubsection{Diagramas de Seqüência}

Nos Diagramas de Sequiência, os objetos são mostrados como uma caixa no topo de uma linha vertical tracejada, como mostra a Figura 23. Essa linha é chamada linha de vida do objeto. Através deste diagrama é possível mostrar a passagem de mensagem entre os objetos durante o tempo de execução do use case.

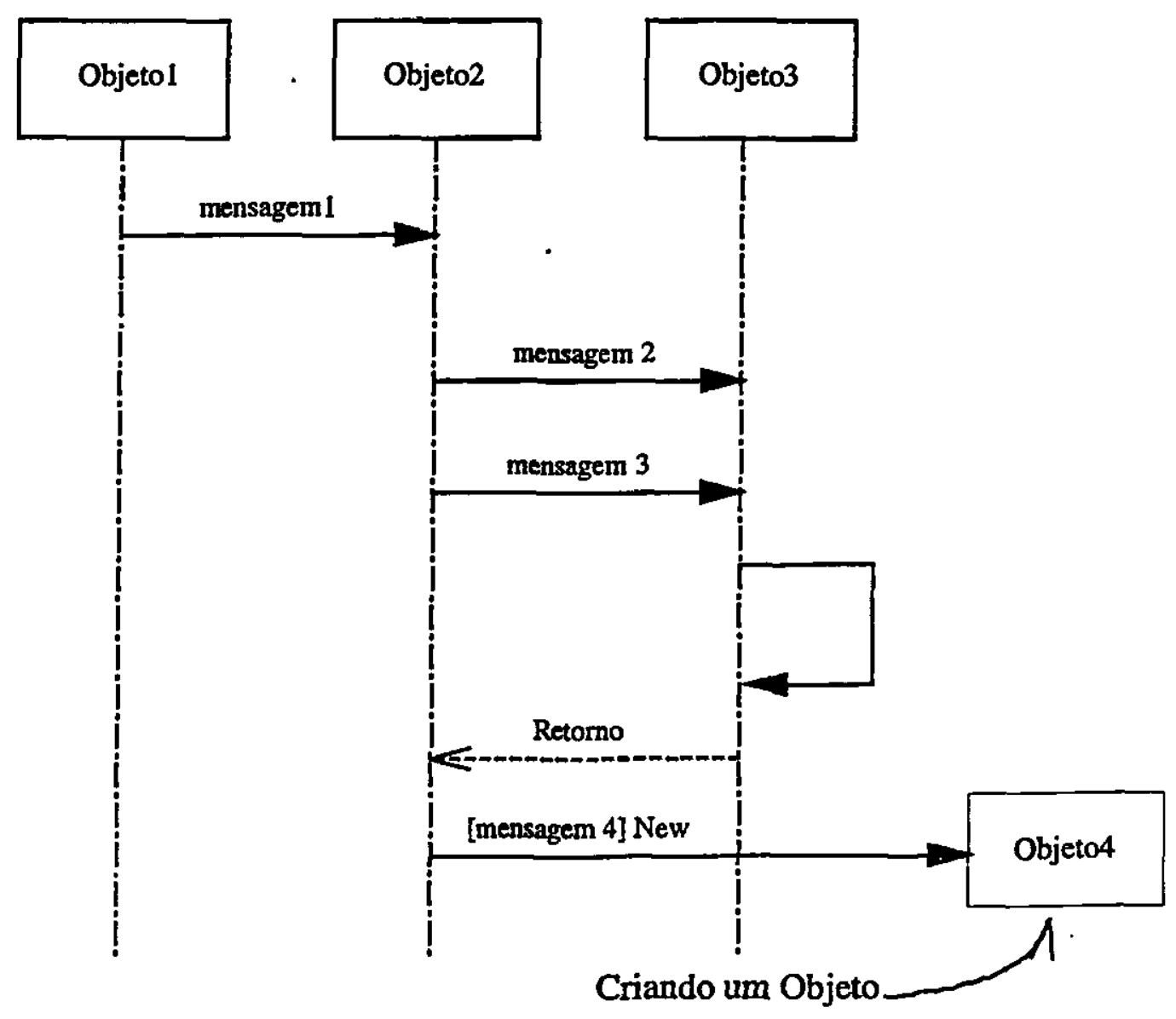

Figura 23 - Diagrama de Sequiência

As mensagens são representadas através de setas entre as linhas de vida de dois objetos. Cada uma dessas mensagens deve ter um nome e pode também conter uma condição para o envio desta mensagem. 


\subsubsection{Diagramas de Colaboração.}

Esse diagrama é a segunda forma de mostrar a interação entre os objetos em um use case. Da mesma forma que o diagrama de seqüência é possível mostrar as mensagens enviadas dentro de um use case.

Esse diagrama utiliza a numeração para mostrar a ordem das mensagens. Para essa numeração pode-se utilizar diferentes esquemas. Na Figura 24 é apresentado o diagrama de colaboração e o esquema de numeração.

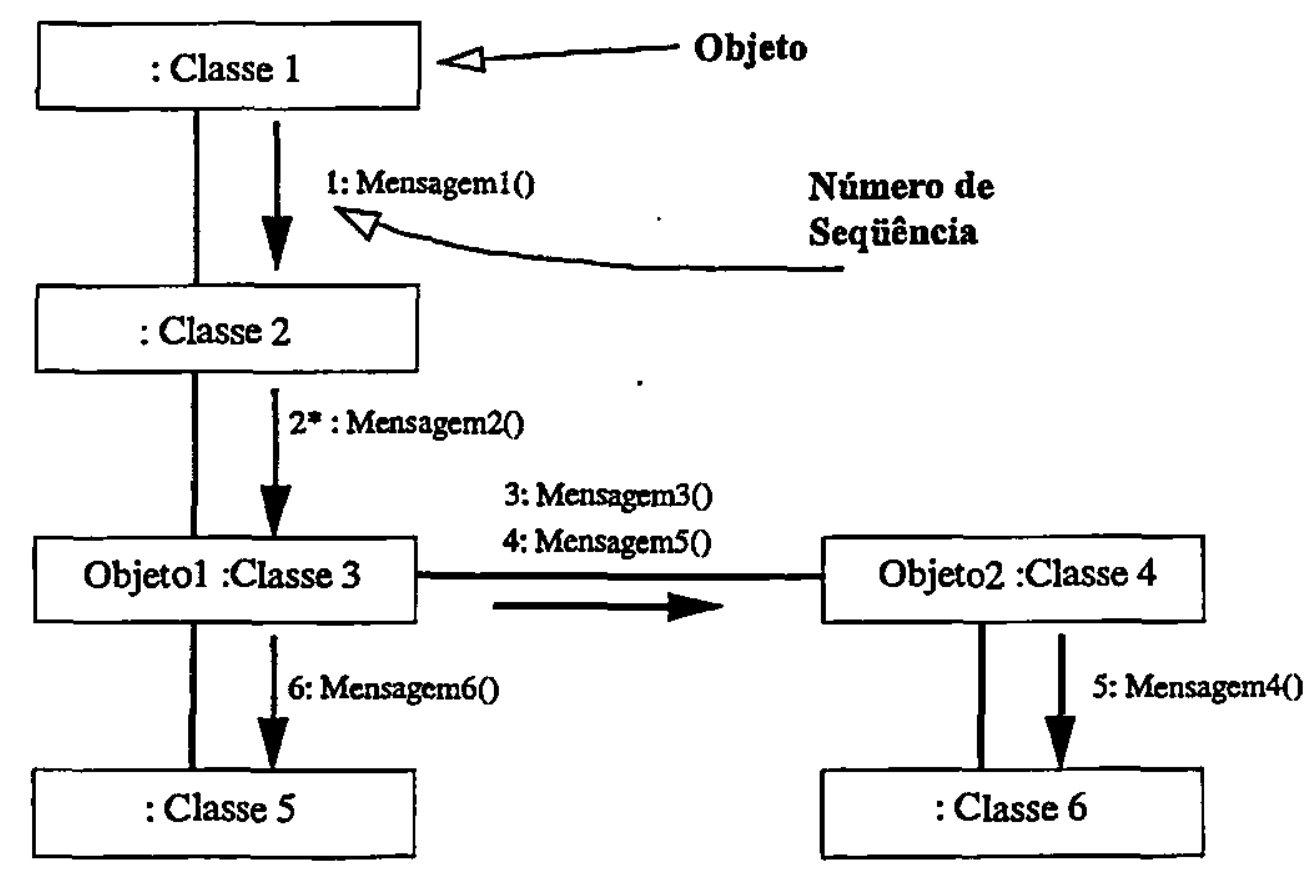

Figura 24 - Diagrama de Colaboração

Não há a necessidade de se utilizar estes dois diagramas para os Use Cases, é mais recomendada utilização do diagrama de sequiência, pois este facilita a visualização da ordem de execução, como também a passagem de mensagem entre os objetos. Já o diagrama de colaboração mostra como os objetos estão estaticamente conectados.

\subsubsection{Diagrama de.Pacotes}

A construção de grandes sistemas toma difícil o entendimento e a manutenção desses, devido a grande quantidade de estruturas. Para a solução deste problema nos métodos estruturados é utilizada a decomposição funcional. Para os métodos orientados a objeto isso 
se torna difícil, pois os processos e os dados estão agrupados em uma s6́ estrutura. Para essa separação é necessário o agrupamento das classes em estruturas de alto nível. Na UML esse mecanismo de agrupamento chama-se pacote.

A UML usa o termo Diagrama de Pacotes para o diagrama que mostra os pacotes de classes $e$ as dependências entre eles. Essa dependência existe entre dois pacotes se as mudanças na definição de um elemento podem causar mudanças para o outro. A Figura 25 mostra o diagrama de pacotes da UML.

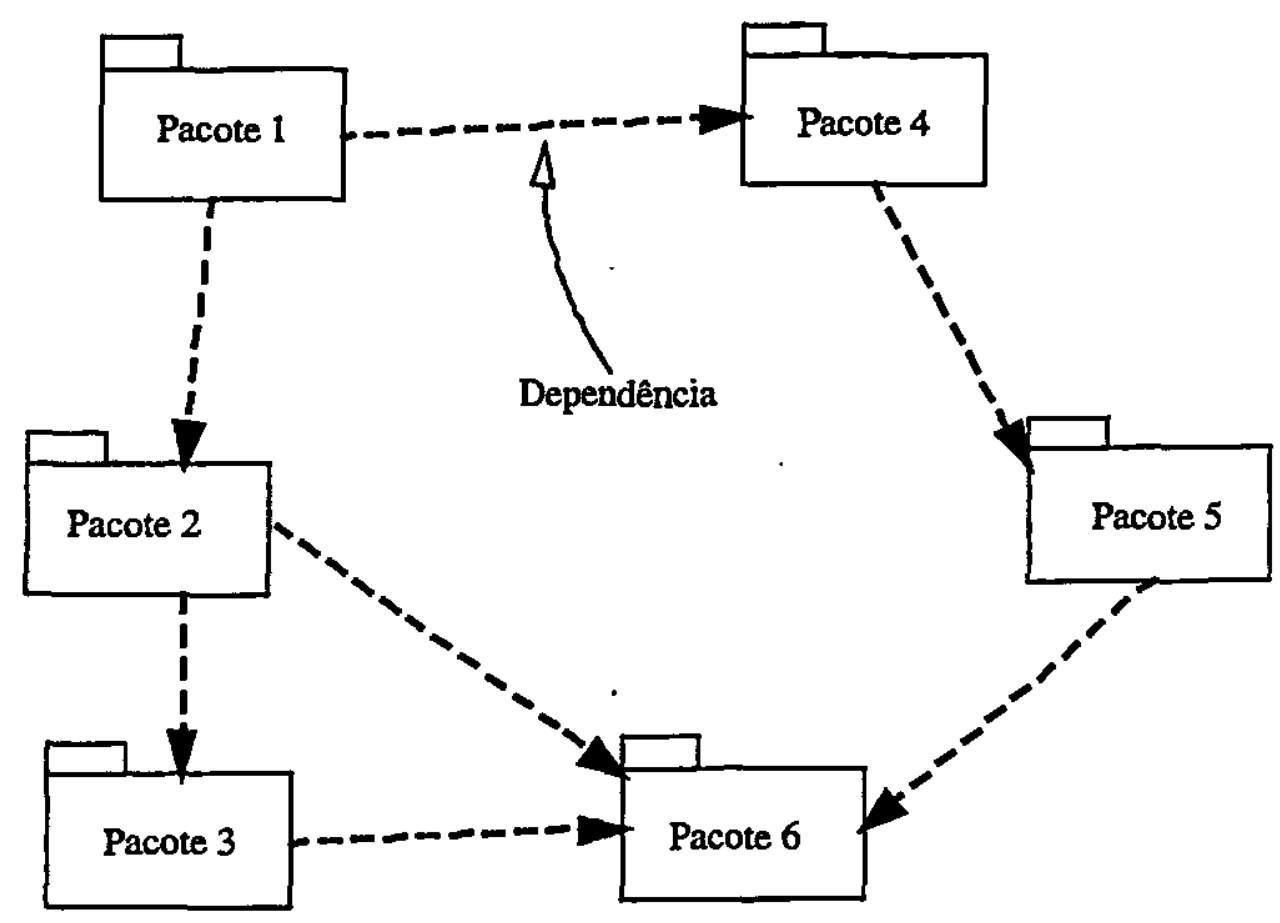

Figura 25 - Diagrama de Pacotes

Os diagramas de pacotes devem ser utilizados no desenvolvimento de grandes projetos, mas a dependência deve ser minimizada para reduzir o acoplamento e facilitar o entendimento do software como um todo.

\subsubsection{Diagrama de Estados}

Os Diagramas de Estados são técnicas familiares para descrever o comportamento de um sistema, descrevendo todos os possíveis estados de um particular objeto, como também a mudança desses estados. Há várias formas de diagramas de estados. 
O Diagrama de Estados da UML trabalha basicamente com as ações (actions) e as atividades (activity), onde as ações estão associadas com transições que ocorrem rapidamente e não são interrompidas e as atividades são associadas a estados que podem tomar um grande tempo, e podem ser interrompidas por algum evento. Pode-se também colocar uma condição para a passagem de um estado para o outro e essa condição é chamada "guard".

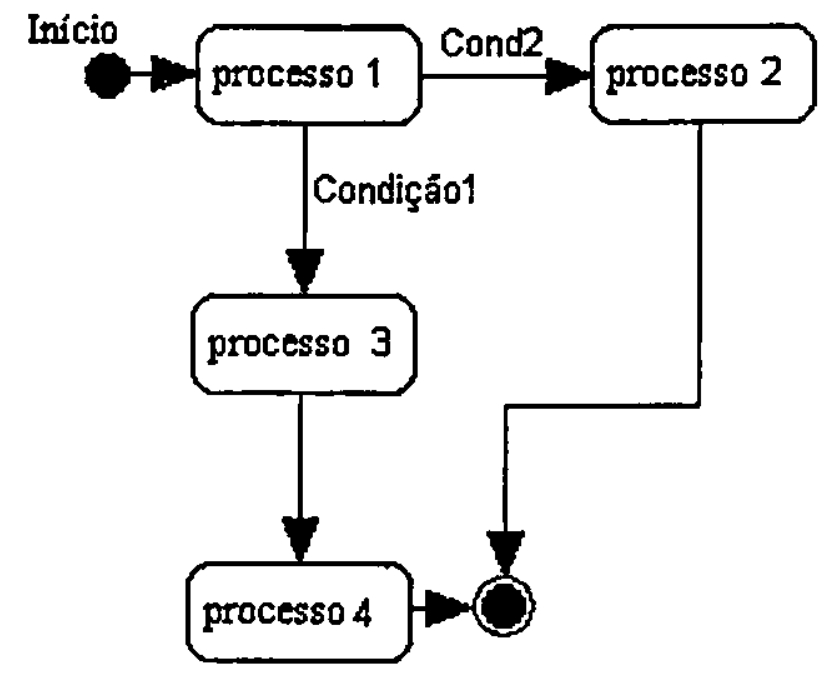

Figura 26 - Diagrama de Estados

A Figura 26 mostra o diagrama de estados utilizado pela UML e sua notação. Esse tipo de diagrama é de grande importância, pois trabalha em um nível mais baixo, quase na implementação, e trata todos os possíveis estados de um determinado objeto em vários use cases. Ele porém não é muito útil para descrever comportamentos onde há colaboração entre vários objetos.

\subsubsection{Diagrama de Atividades}

Os diagramas de atividades surgiram na UML, sem que se esperasse, e através deles é possível mostrar o comportamento com estruturas de controle. Com esse tipo de diagrama pode-se mostrar muitos objetos sobre vários use cases, ou muitos objetos em um mesmo use case, ou até mesmo a implementação de um método. 


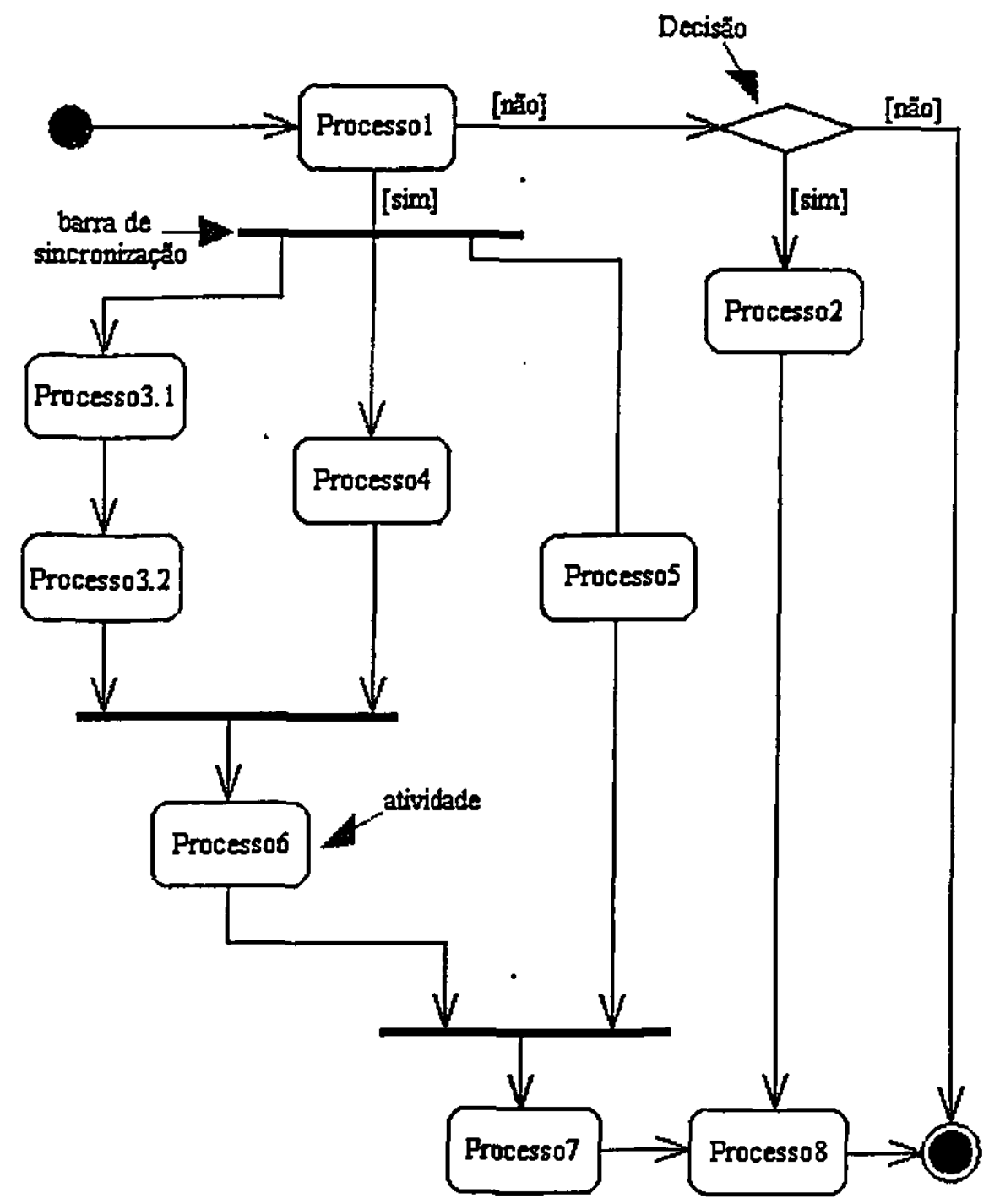

Figura 27 - Diagrama de Atividades

Através desse diagrama e possível mostrar a sequiência que será executada para se conseguir o resultado final. Esse diagrama pode expressar facilmente 0 processamento paralelo das atividades.

A Figura 27 apresenta um diagrama de atividades e seus principais elementos. $O$ elemento de maior importância nesse diagrama é a atividade, ou seja, qualquer atividade que será executada dentro de um diagrama. Dependendo da perspectiva utilizada, ela pode ser uma tarefa a ser executada dentro de um método, ou até mesmo um método de uma classe. 
Outro elemento importante do diagrama de atividades é a atividade de decisão, onde é possível definir o caminho a ser seguido a partir de uma decisão. Nesse diagrama também são utilizados os "guards", que permitem a execução da seqưência de atividades se estes forem verdadeiros, caso contrário a execução é interrompida.

Um outro elemento do diagrama de atividades é a barra de sincronização, que é responsável pela sincronização das atividades, sendo de grande importância para expressar concorrência. Os diagramas de atividades sầo geralmente utilizados para:

- Analisar um Use Case. Para essa análise é interessante alocar as atividades para os objetos;

- Entender o fluxo de execução através de vários Use Cases, quando os use cases interagem com outros;

- Criar aplicações multi-threaded, devido ao fato das mesmas apresentarem facilidades para expressar paralelismo.

\subsubsection{Diagramas de Deployment}

Os diagramas de Deployment mostram o relacionamento físico entre os componentes de software e de hardware em um sistema. Nesse diagrama é um bom local para mostrar como os componentes e objetos são roteados, mapeados e se movem através de um sistema distribuído. A Figura 28 ilustra um diagrama de Deployment.

Cada nó em um diagrama de Deployment representa algum tipo de unidade computacional, que pode ser de um sensor até uma máquina. As conexões entre nós mostram os caminhos de comunicação por onde o sistema interage. Os componentes representam módulos físicos de código, e correspondem aos pacotes do diagrama de pacotes. As dependências entre os componentes são as mesmas dependências dos pacotes.

Esse diagrama para o desenvolvimento de aplicações convencionais não está sendo muito utilizado, mas é de grande importância quando se trabalha com sistemas distribuídos ou até mesmo para o processamento paralelo. 


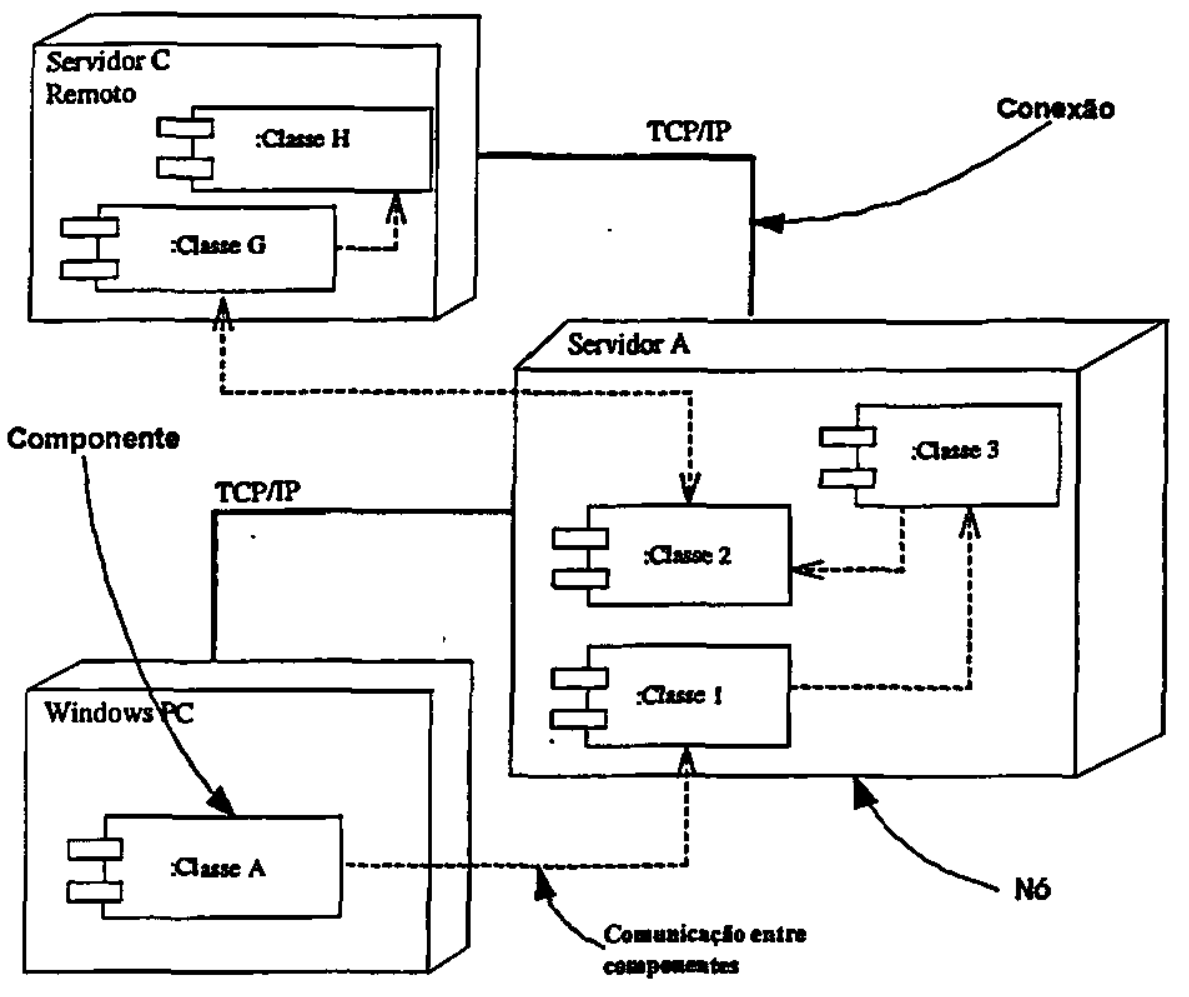

Figura 28 - Diagrama de Deployment

A notação apresentada neste tópico é utilizada pela UML, no intuito de criar aplicações com qualidade e seguras, além da geração de documentação para as etapas de manutenção.

\subsection{A Utilização das Metodologias no Desenvolvimento de Aplicaçōes Paralelas}

Nesta seção é analisada a utilização de metodologias convencionais orientadas a objetos no desenvolvimento de aplicações paralelas. Para essa análise foi utilizada a Unified Modeling Language e a metodologia Fusion.

\subsubsection{Requisitos Essenciais para Aplicações Paralelas}

Em aplicaçōes convencionais, os principais requisitos a serem alcançados são a qualidade do software, documentação completa, fácil manutenção, e sobretudo o atendimento das necessidades dos usuários. 
Para se alcançar esses objetivos os desenvolvedores de aplicações convencionais utilizam metodologias no desenvolvimento da aplicação. Essas metodologias oferecem várias ferramentas para modelagem da aplicação, como também uma documentação bem detalhada para facilitar a manutenção $e o$ entendimento dessa aplicação.

Tanto no desenvolvimento de aplicações paralelas como no de aplicações convencionais há a necessidade de suprir os requisitos básicos citados. Em alguns aplicações paralelas alguns requisitos adicionais são importantes: o balanceamento de carga entre processadores, a minimização da comunicação entre processos e a maximização da eficiência.

A grande vantagem da utilização do paralelismo em uma aplicação é a diminuição do tempo de processamento da mesma. Isso só é possível se a distribuição de dados e processamento entre as unidades de processamento de processamento forem homogêneas, alcançando um balanceamento de carga eficiente.

No processamento paralelo há a necessidade de cooperação entre os processos, para isso é utilizada alguma forma de comunicação entre eles. Para conseguir o desempenho desejado também é necessário minimizar essa comunicação, gerando a menor quantidade de mensagens a serem passadas pelo meio de comunicação.

A ultima grande necessidade da programação paralela é a maximização da eficiência, fazendo com que cada processador da máquina paralela dedique a maior parte possivel do seu tempo realizando tarefas úteis na solução do problema.

\subsubsection{Fusion $X$ Processamento Paralelo}

O Fusion é uma metodologia completa para o desenvolvimento de aplicações, possuindo sua linguagem de modelagem, derivada de outros métodos com algumas alterações, como também um processo para o desenvolvimento de aplicações.

Em seu processo de desenvolvimento, essa metodologia não especifica procedimentos ou etapas para suprir os requisitos essenciais das aplicações paralelas, devido ao fato da mesma ter sido definida para o desenvolvimento de aplicações convencionais. 
Apesar de sua origem tratar de aplicaçōes convencionais, alguns diagramas desse método possibilitam expressar o paralelismo, geralmente de baixo nível. Entre os diagramas pode-se citar:

- Grafo de Interaçāo entre Objetos, mostra a passagem de mensagens entre os objetos pertencentes ao sistema, que podem estar em diferentes localidades. Esse diagrama possibilita verificar a quantidade de mensagens, como também o tamanho destas, que são passadas entre os objetos, sendo assim útil para a minimização da comunicaçāo;

- O diagrama de Máquina de Estados Finitos, que permite mostrar as ações que devem ser executadas e estas podem estar em paralelo. Geralmente esse paralelismo é interno ao método, tomando-se de baixo nível. Não tem grande utilidade em aplicações paralelas que são executadas em ambientes MIMD de memória distribuída (as mais utilizadas, devido à fácil utilização e preço relativamente baixo dessas máquinas).

Esse método é muito utilizado na área acadêmica no desenvolvimento de aplicações convencionais, mas não é muito adequado para o desenvolvimento de aplicaçōes paralelas por não tratar de forma adequada os requisitos fundamentais desse tipo de aplicação.

$\mathrm{Na}$ área comercial essa metodologia não foi muito difundida, devido ao seu aprendizado não sẹ muito simples e sua grande complexidade, diferindo em muito da UML, que torna o desenvolvimento relativamente simples e flexível, por não haver processo de desenvolvimento.

\subsubsection{Unified Modeling Language X Processamento Paralelo}

A UML, da mesma forma que a metodologia Fusion, não especifica nenhum procedimento para tratar os requisitos necessários no desenvolvimento de software paralelo. Isso também se deve ao fato de sua definição ter como foco principal o desenvolvimento de aplicações convencionais.

Na UML, o paralelismo de alto nível pode ser expresso através de vários diagramas, dentre eles pode-se citar: 
- Diagrama de Sequiência - Através dele é possível visualizar a interação entre os objetos da aplicação durante o tempo de execução de um use case, tendo grande utilidade na minimização da comunicação, como também para a maximização da eficiência. Esse diagrama possibilita expressar o paralelismo de alto nível, como mostrado na Figura 29;

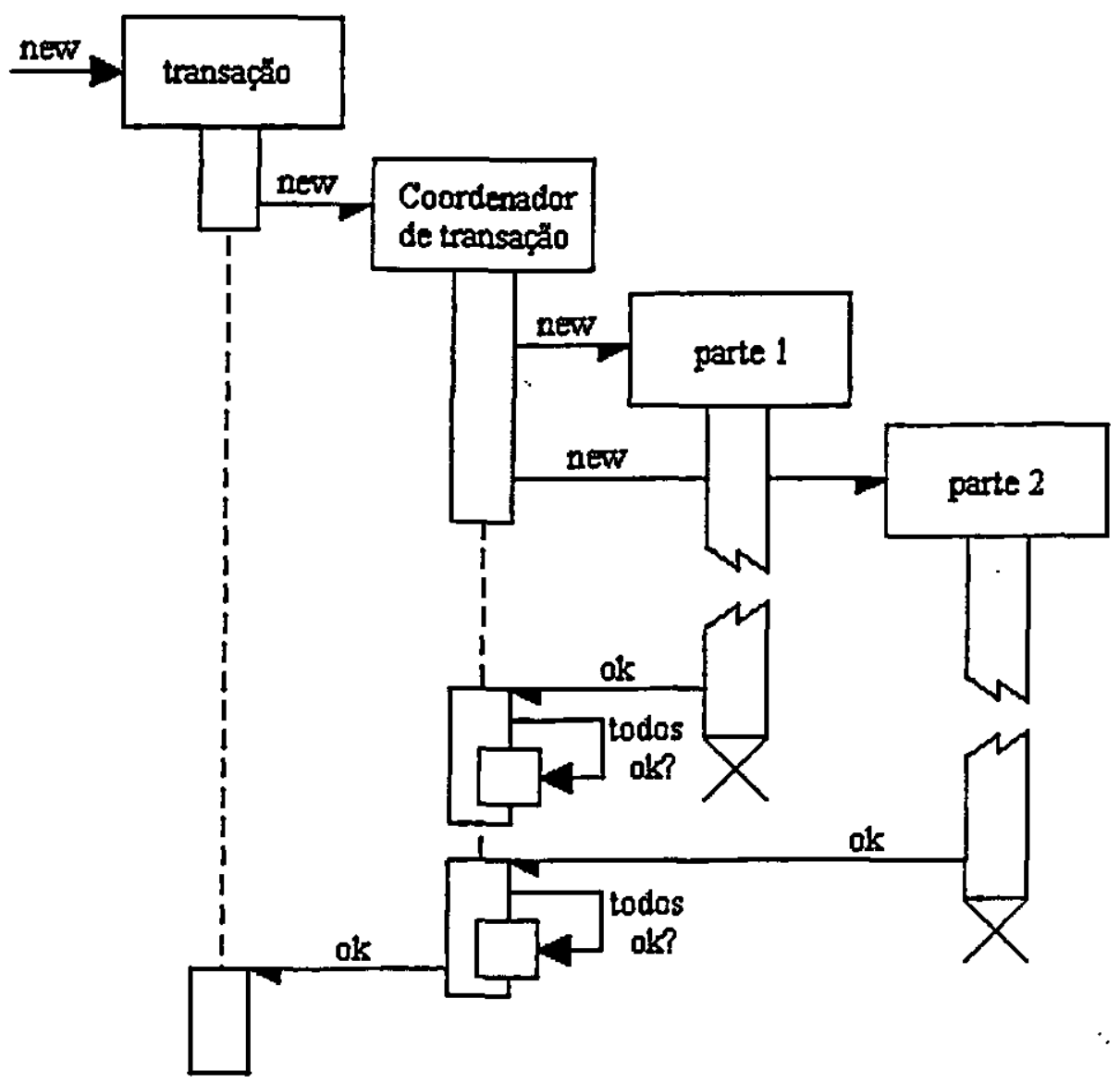

Figura 29 - Paralelismo no Diagrama de Seqüência

- Diagrama de Colaboração - Esse diagrama permite a visualização estática da comunicação entre os objetos pertencentes ao modelo e pode ser de grande utilidade para a minimização da comunicação;

- Diagrama de Estados - Esse tipo de diagrama apresenta o comportamento de um objeto, descrevendo todos os seus possíveis estados. Através deste diagrama é possível expressar o paralelismo em baixo nível, não tendo muita utilidade para 
aplicações com passagem de mensagens. A Figura 30 apresenta a utilização deste diagrama para expressar paralelismo;

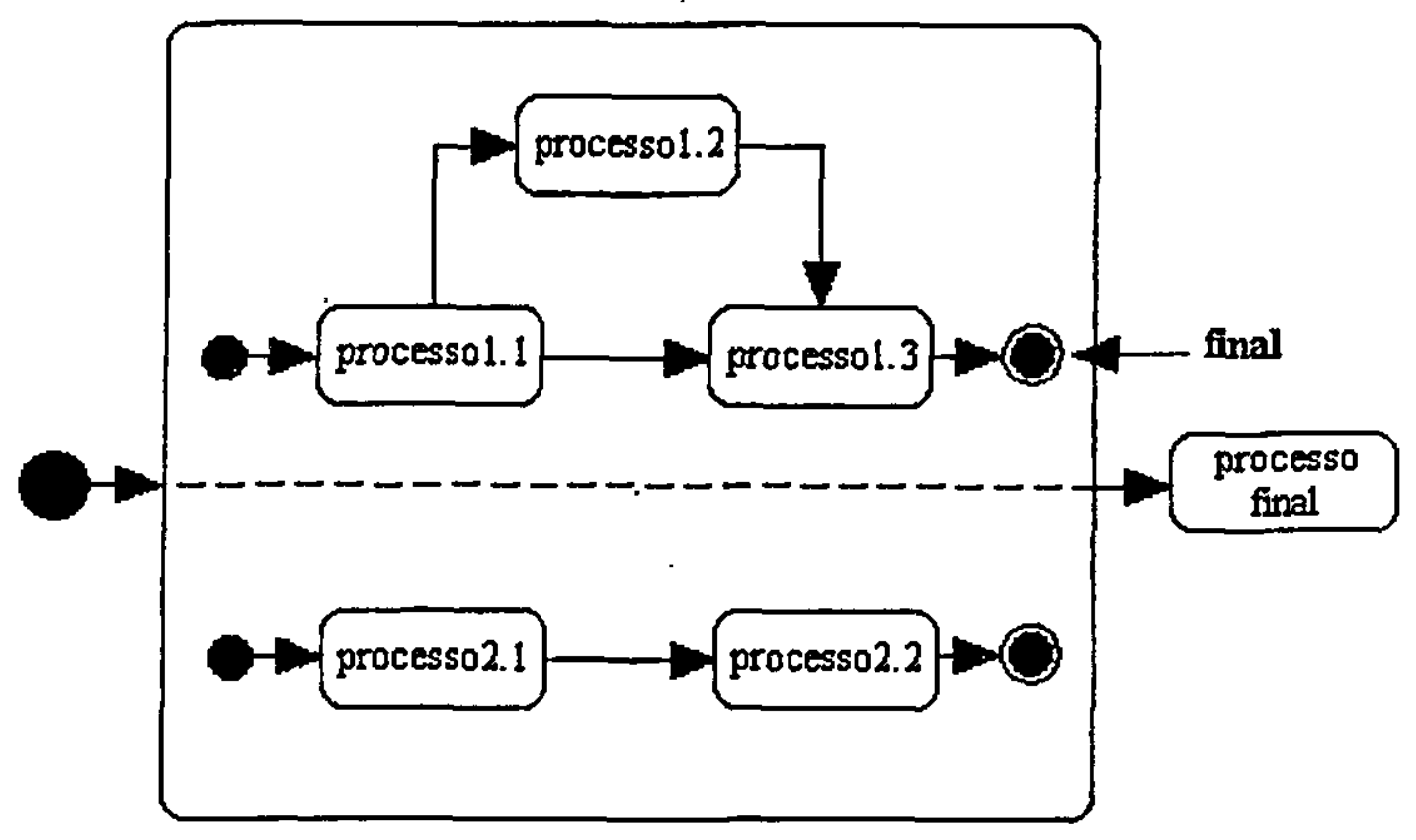

Figura 30 - Paralelismo com Diagrama de Estados

- Diagrama de Atividades - $\varepsilon$ a melhor maneira de se expressar o paralelismo através da UML, devido a existência de um mecanismo de sincronização de tarefas chamado barra de sincronização, que permite fazer a execução paralela sincronizada, sendo possível também expressar o paralelismo não sincronizado. O diagrama de atividades utilizando a barra de sincronização é mostrado na Figura 27;

Um outro diagrama que pode ser de grande importância para o desenvolvimento de aplicações paralelas é o Diagrama de Deployment, que permite mostrar onde cada um dos objetos ficará localizado dentro da máquina paralela, mas para isso também é necessária a utilização do diagrama de pacotes.

Apesar de possuir vários diagramas que permitem expressar o paralelismo e a concorrência, não existem na UML mecanismos para avaliar a carga dos processos que serão executados em paralelo. Esses mecanismos são necessários para se conseguir um 
balanceamento de carga eficiente. A minimização da comunicaçăo entre processos também não é priorizada pela UML. Esses mecanismos não existem devido ao fato da UML não especificar o processo para a utilização desses diagramas.

\subsection{Considerações Finais}

Neste capitulo foram apresentadas as principais metodologias para desenvolvimento de aplicaçōes convencionais, como também algumas definiçōes sobre a tecnologia de orientaçāo a objetos.

Um estudo mais detalhado foi realizado sobre as principais metodologias de desenvolvimento orientado a objetos, Fusion e UML, com uma análise da sua possível utilização no desenvolvimento de aplicaçōes paralelas. Dessa análise foi selecionada a UML para servir de base na especificação da metodologia proposta neste trabalho. No próximo capítulo será apresentada essa metodologia, desde o seu ciclo de vida, os diagramas utilizados, suas fases, como também os recursos disponíveis para suprir os requisitos essenciais das aplicaçōes paralelas. 


\section{O Método UMP²D}

\subsection{Considerações Iniciais}

Neste capítulo é apresentada a metodologia orientada a objetos definida por esse projeto para o desenvolvimento de aplicaçoes paraleias. São mostradas suas fases, o cicio de vida dessa metodologia e os diagramas utilizados.

A metodologia apresentada utiliza para a modeiagem de software alguns dos diagramas da UML e os problemas do desenvolvimento de aplicaçoes paralelas são abordados de forma bem aprofundada, mostrando-se como a metodologia definida vem a suprir essas necessidades.

No item 5.2 é apresentado o ciclo de vida da metodologia, citando-se suas fases e os objetivos de cada uma delas. $O$ item 5.3 mostra os diagramas utilizados por essa metodologia e em que fases do ciclo de vida eles são utilizados. No item 5.4 é feita uma avaliação da metodologia quanto ao atendimento dos requisitos necessários para o desenvolvimento de aplicações paralelas.

Os ítens 5.5 e 5.6 apresentam dois estudos de caso simples para mostrar como a metodologia definida neste capítulo pode ser efetivamente utilizada no desenvolvimento de aplicações paralelas.

\subsection{Ciclo de Vida e as Fases}

O ciclo de vida do UMP²D é baseado no Ciclo de Vida Clássico [Pre95] e no ciclo de vida do Unified Process [Fow97], definido peios mesmos criadores da UML. Este ciclo de vida é apresentado na Figura 31.

$O$ ciclo de vida da $U M P^{2} D$ possui as seguintes fases para o desenvolvimento de aplicações paralelas.
A. Coleta de Requisitos
B. Elaboração 
C. Implementação

D. Testes

E. Análise de Paralelismo

F. Transição

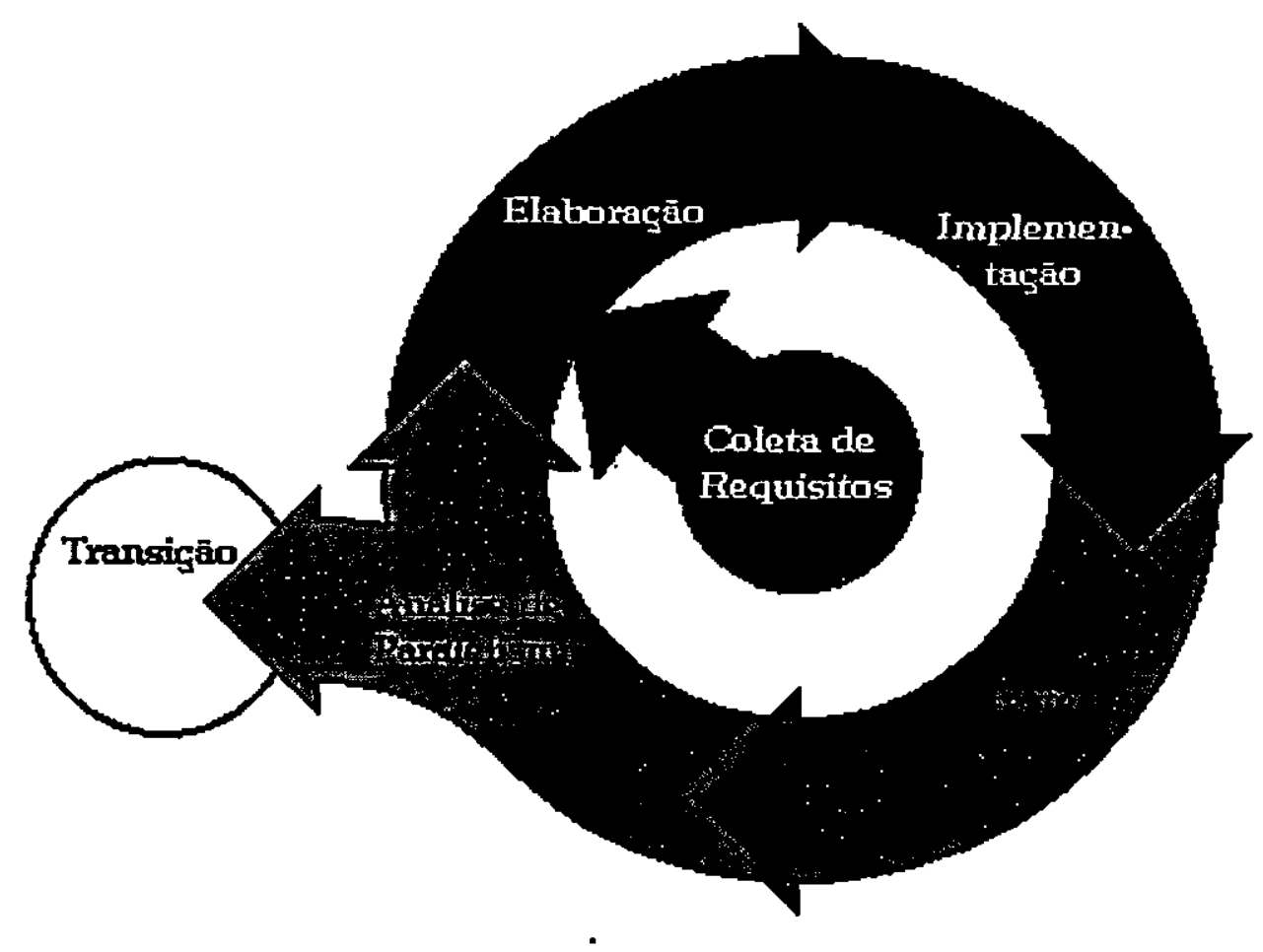

Figura 31 - Ciclo de Vida de UMP2D

\subsubsection{Coleta de Requisitos}

Nessa fase do ciclo de vida da metodologia $\operatorname{UMP}^{2} \mathrm{D}$, o desenvolvedor de aplicações paralelas é responsável por coletar todas as informações necessárias para o desenvolvimento, definindo o escopo da aplicação e como fazer a verificação dos riscos do desenvolvimento desta aplicação. Esta é uma fase essencial para este modelo, um pequeno erro nessa etapa pode comprometer todo o projeto.

$\mathrm{Na}$ fase de coleta de requisitos o desenvolvedor deve estar em contato com o usuário final, ou o problema, o maior tempo possível para se conseguir detalhar todo o escopo do problema, sem deixar nenhuma parte sem definição ou com definição incompleta ou inconsistente. 
O resultado desta fase deve ser uma definição completa e concisa do trabalho feita em forma textual, de maneira informal. Essa definição deve conter todas as informações importantes em relação ao problema.

\subsubsection{Elaboração}

A fase de Elaboração é a principal fase do UMP² $\mathrm{D}$, pois é responsável por grande parte do desenvolvimento e da documentação da aplicação a ser implementada. Nesta fase é definida a estrutura da aplicação, como também as restriçōes e os limites do problema a ser implementado.

A fase de elaboração possui um mini-ciclo de vida iterativo dentro do ciclo de vida principal da metodologia, como mostrado na Figura 32. Essa fase é composta basicamente por três etapas:

1. Análise

2. Projeto

3. Análise de Desempenho

Nos itens seguintes são descritas as etapas do mini-ciclo de vida da fase de elaboração.

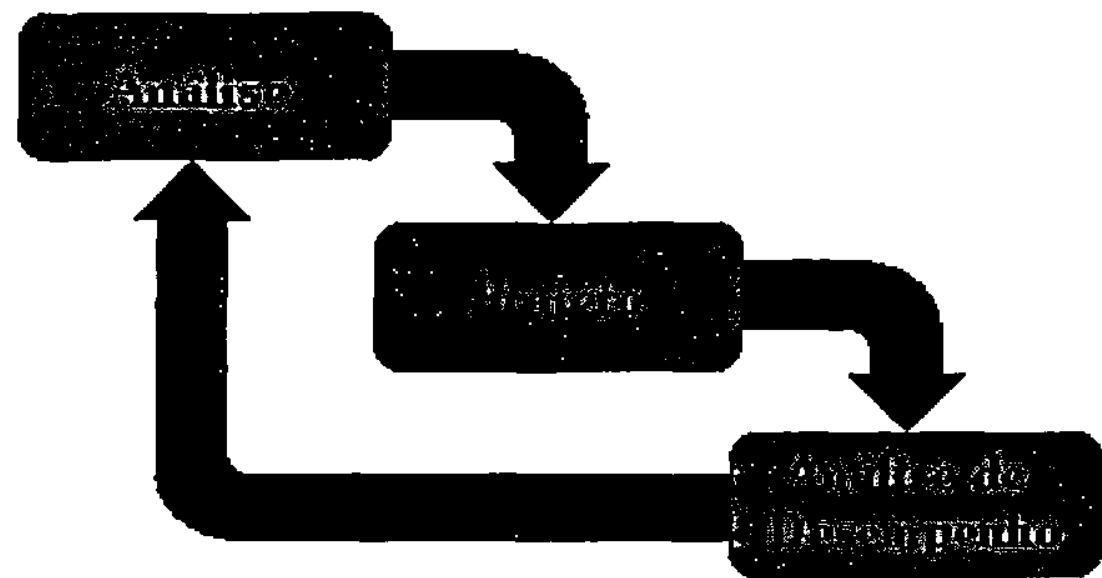

Figura 32 - Mini-Ciclo de Vida 


\subsubsection{Análise}

Na etapa de análise o desenvolvedor, partindo dos requisitos coletados na primeira fase, é responsável por especificar o modelo de classes, como também refinar os requisitos, com a finalidade de eliminação de falhas da primeira etapa.

Nessa etapa deve ser dada grande importância na definição do modelo do sistema, definindo-se os principais componentes pertencentes ao problema e classificando os mesmos. Também deve ser dada ênfase aos relacionamentos entre as classes pertencentes ao modelo do problema.

A documentação resultante dessa etapa deve ser um diagrama de classes mostrando as classes utilizadas para a resolução do problema, juntamente com os relacionamentos entre elas. Nessa etapa não existe a necessidade de definição dos métodos pertencentes a essas classes. Essa tarefa deve ser realizada na etapa de projeto, juntamente com a utilização de outros conceitos de relacionamento entre objetos.

\subsubsection{Projeto}

A etapa de projeto tem como principal objetivo a definição do modelo do problema, como também da máquina paralela a ser utilizada na execução da aplicação a ser desenvolvida.

Nesta etapa, o modelo de classes, definido na etapa de análise, deve ser refinado e atualizado, com o intuito de deixá-lo completo e consistente. A arquitetura do software deve ser totalmente definida, mostrando a interação entre as classes e seus relacionamentos. Deve-se cuidar também dos conceitos de agregação, generalização, especialização e os demais aceitos pela UML.

Outro assunto importante que deve ser levado em consideração é o mapeamento dos processos na máquina paralela a ser utilizada. Nesse mapeamento os processos são ligados aos elementos de processamento onde serão executados, para a coleta de dados de comunicação e carga.

A definição da máquina paralela, juntamente como o mapeamento são de grande importância para a conclusão dessa fase do desenvolvimento, pois através desses será possível coletar dados de comunicação e carga. 
A etapa de projeto é responsável por grande parte da documentação referente a aplicação desenvolvida. Nessa fase deve-se ter como documentos resultantes:

- Modelo completo de classes, contendo conceitos como agregação, generalização e os métodos referentes a cada uma das classes;

- Modelo de interação entre as dasses, mostrando como é feita a comunicação entre os objetos;

- Modelos de atividades realizadas, onde são mostradas a partir de diagramas as operações realizadas em cada um dos métodos nos objetos;

- Definição da máquina paralda, mostrando os elementos de processamento pertencentes à máquina onde a aplicação será executada, como o poder de processamento e comunicação dos mesmos;

- Mapeamento dos processos nos processadores; deve ser mostrado utilizando um diagrama próprio para esse propósito.

\subsubsection{Análise de Desempenho}

A última fase dessa etapa do ciclo de vida é responsável pela análise do desempenho do modelo definido. Nesta etapa deve ser feita uma análise no modelo especificado, coletandose informações que possam servir para o balanceamento de carga e a minimização da comunicação entre os objetos.

Os passos para se conseguir desempenho será discutido no item 5.4 deste capítulo. A última tarefa do desenvolvedor nessa é verificar a possibilidade de alteração do modelo para conseguir maior desempenho aplicação resultante.

Se o desempenho alcançado não for satisfatório, deve-se retornar a primeira etapa da fase de elaboração, caso contrário, o desenvolvedor avança para a fase de implementação da aplicação, com base no modelo especificado nessa fase. 


\subsubsection{Implementação}

Na etapa de implementação, o desenvolvedor, ou o responsável pela codificação, deve codificar o modelo criado pelas fases anteriores em uma linguagem paralela, preferencialmente orientada a objetos, como High Performance $\mathrm{C}++$ e Object-Oriented Fortan. Alternativamente, pode utilizar uma linguagem sequiencial orientada a objetos como $\mathrm{C}++$, Java, e até mesmo uma linguagem seqüencial como C e Fortran, juntamente com uma biblioteca de comunicação como PVM e MPI.

\subsubsection{Testes}

Nessa etapa são executadas rotinas de testes para a verificação da qualidade da aplicação resultante, como também para a localização de possíveis erros de implementação e elaboração.

\subsubsection{Análise de Paralelismo}

Esta etapa é a que mais se difere do desenvolvimento de aplicações sequienciais, ela é responsável pela análise do desempenho do software resultante a partir da visualização das informaçőes de rastreio geradas durante a execução da aplicação, ou atraves da monitoração on-line. Essa execução pode ser na máquina paralela destino, ou em um simulador.

Nesta etapa, se o desempenho alcançado não for satisfatório, 0 desenvolvimento retorna a segunda fase da metodologia para que se possa alterar o modelo com o intuito de conseguir o desempenho esperado.

$\mathrm{Na}$ análise de paralelismo podem ser utilizadas várias ferramentas com esse propósito e que geralmente dependem da linguagem e biblioteca de comunicação utilizada para a codificação da aplicação. Dentre as ferramentas existentes para esse propósito podese citar: PARAGRAPH, AIMS, PABLO Performace Analysis Environment, XMPI, XPVM, além de outras que possam suprir as necessidades de análise de desempenho em diversas máquinas, principalmente em máquinas $\mathrm{MMD}$ de memória distribuída. 


\subsubsection{Transição}

Na última etapa do método é feita a instalação da aplicação na máquina destino para utilização pelos usuários. No final dessa etapa a aplicação deve estar sendo utilizada na sua capacidade máxima para a resolução dos problemas por ela implementados.

\subsection{A Linguagem de Modelagem}

Como já citado, o UMP²D utiliza como linguagem de modelagem a UML e os diagramas da UML são utilizados durante a segunda fase dessa metodologia. Na primeira fase deve ser escrito apenas um relatório com as informaçōes importantes para o entendimento do problema.

Nessa fase, coleta de requisitos da aplicação, pode-se também elaborar um Diagrama Use Case que apresenta visualmente o contexto da aplicação e a interação com o usuário. Como em aplicações paralelas raramente há interação com o usuário, nơrmalmente pode-se descartar esse diagrama.

Durante as etapas da fase de elaboração são utilizados grande parte dos diagramas da UML, pois essa fase é responsável pela definição da arquitetura e da estrutura da aplicação.

$\mathrm{Na}$ análise, o diagrama de classes, que mostra a estrutura de classes da aplicação, deve ser elaborado, com os principais atributos de cada uma das classes. Não se deve preocupar com os métodos das classes, apenas com a definição das classes e os relacionamentos entre as classes.

Nessa etapa deve-se iniciar a construção do diagrama de atividades que é capaz de apresentar o comportamento interno de um use case, ou do sistema inteiro. Esse diagrama é capaz de expressar paralelismo de forma assíncrona e síncrona através de barras de sincronização. Esse diagrama já foi apresentado na Figura 27.

Na segunda etapa dessa fase, o projeto, é feito o refinamento do diagrama de classes adicionando-se os métodos, as relaçōes de agregação, especialização, generalização, como outros conceitos permitidos pela UML. 
O diagrama de atividades, desenvolvido durante a fase de análise, deve ser refinado visando um maior detalhamento dos processos da aplicação, para um maior entendimento do sistema como um todo.

Um diagrama de máquina paralela deve ser definido com base na máquina a ser utilizada, mostrando-se os elementos de processamento e as linhas de comunicação entre esses elementos. Para cada elemento de processamento deve ser estipulado o poder d processamento, memória, velocidade da comunicação e outras informaçōes important para ä análise do balanceamento de carga.

Nessa etapa deve-se também elaborar diagramas de seqüência mostrandoparalelismo da aplicação no nível de objetos, ou seja, paralelismo de granulosidade gri Esse diagrama permite visualizar a cooperação entre os processos durante o temp execução dos métodos dos objetos, sendo de grande utilidade na maximização da eficiê da aplicação.

Para visualizar a cooperação entre os objetos, pode-se também elaborar o diagr de colaboração, que apresenta como os objetos estão estaticamente conectados, send grande importância para a minimização da comunicação, pois esse diagrama mostr mensagens enviadas e recebidas pelos objetos.

A última tarefa da etapa de projeto é a definição do mapeamento, para issı interessante a utilização do diagrama de deployment, que permite mostrar quais serão objetos a serem executados em cada uma das máquinas pertencentes a máquina parale definida no diagrama de máquina paralela, como também a troca de mensagens éntre essé máquinas.

Um outro diagrama que pode ser utilizado caso a aplicação for muito complexa, envolvendo uma quantidade grande de objetos e classes, é o diagrama de pacotes. Esse tipo de diagrama também não é muito utilizado em aplicações paralelas, pois as mesmas geralmente não se decompõem em muitos objetos e classes, apesar da complexidade desse tipo de desenvolvimento. 


\subsection{A Metodologia UMP²D e os Requisitos das Aplicaçōes Paralelas}

Como citado no item 4.5.1, do capítulo 4 , no desenvolvimento de aplicações convencionais são utilizadas metodologias de desenvolvimento de software para se alcançar qualidade do software, documentação completa, fácil manutenção e para suprir as necessidades dos usuários.

No desenvolvimento de aplicações paralelas deve-se tratar outros requisitos que são exclusivos desse tipo de aplicação, o balanceamento de carga entre processadores, a minimização da comunicação entre processos e a maximização da eficiência.

A definição desta metodologia tem como principal função atender a esses requisitos das aplicações paralelas. Para se consegair esse objetivo foi necessário a definição de um ciclo de vida que difere em alguns pontos dos ciclos de vida convencionais, como visto durante esse capítulo.

A principal diferença desse ciclo de vida é a inclusão de uma etapa na fase de elaboração chamada análise de desempenho, responsável pela análise do modelo antes da implementação. Nesse item é comentado o processo de verificação dos requisitos das apiicações paralelas.

Com a definição do modelo de classes compietada, deve-se atribuir valores de carga aos métodos dessas classes, através de uma análise detalhada da complexidade dos diagramas de atividades desenvolvidos para cada um dos métodos. Com o valor da carga já estipulado, deve-se fazer um estudo do balanceamento de carga, com o auxílio da definição do mapeamento, ou seja, através do diagrama de Deployment.

Nesse estudo tem-se de se levar em consideração o poder computacional dos nós, como também o tempo de retardo e a velocidade do meio de comunicação. Com essas informações é possível verificar o balanceamento de carga da aplicação. Caso não seja satisfatório o modelo deve ser alterado para se conseguir uma distribuição de carga mais homogênea entre os processadores, e conseqüentemente um desempenho mais satisfatório.

Para suprir o segundo requisito essencial das aplicaçōes paralelas, a minimização da comunicação, é necessária a utilização do diagrama de colaboração. Através dele é possível 
visualizar as mensagens que são passadas entre os objetos. Com uma análise detalhada desse diagrama é possível verificar o tamanho e a quantidade de mensagens passadas entre os objetos, se há um número grande de mensagens pequenas, deve-se verificar se essas podem ser agrupadas em uma só mensagem.

Caso seja verificada ineficiência na comunicação, altera-se esse diagrama para a melhor forma possível e com ele alterado, analisa-se os outros diagramas do modelo para verificar onde devem ser feitas novas alteraçōes para deixar o modelo consistente.

A maximização da eficiência é o último e mais problemático requisito a ser conseguido, pois ela depende não somente de um atributo, e sim de vários. Para suprir essa necessidade a metodologia fornece um procedimento relativamente simples. Após o balanceamento de carga estar adequado, é necessário analisar a fundo o diagrama de seqülência, pois através dele é possível visuạizar os processos que estarão em execução ao mesmo tempo.

Esse diagrama deve ser redesenhado utilizando os valores de carga atribuídos no balanceamento. Dessa maneira pode-se visualizar corretamente a execuçăo dos processos, a comunicação e se não há processadores ociosos.

Apesar dos procedimentos para se conseguir suprir as necessidades das aplicaçōes paralelas, essas análises todas são feitas sobre valores atribuídos, e nāo valores reais. Devicio a esse fato, o balanceamento e a eficiência conseguida pode núo ser a esperada. Para se conseguir um balanceamento de carga correto e a eficiência desejada, deve-se fazer a realimentação do modelo, isto $e$, após a implementação conclứda fazer a análise de desempenho sobre a execuçāo, conseguindo-se dados reais sobre a carga dos métodos dos objetos. Esses dados devem ser colocados no lugar dos dados estimados no primeiro passo da etapa de Análise de Desempenho, alterando-se o modelo de acordo com a análise realizada com os dados reais.

Dessa forma a metodologia consegue um modelo eficiente, com qualidade de software e documentaçẫo completa, balanceamento homogêneo de carga que pode satisfazer as necessidades dos usuários. 


\subsection{Estudo de Caso - Multiplicação de Matrizes}

O estudo de caso apresentado nesse item é o desenvolvimento de uma aplicação de multiplicação de matrizes [Qui87, Van94]. A multiplicação de matrizes é um componente fundamental em muitos problemas numéricos e não numéricos. É utilizada no tratamento de imagens, em vários problemas de matemática e necessita de grande poder computacional.

O poder computacional para sua resolução aumenta de acordo com o tamanho das matrizes utilizadas. Em multiplicação de matrizes pequenas não são necessários muitos cálculos, em contraste a isto, em uma matriz de 1500 X 1500, a quantidade de cálculos necessária é muito grande.

Apesar da pequena complexidade desse problema, ele é um problema clássico para processamento paralelo, sendo exposto em uma grande quantidade de livros que tratam desse assunto.

\subsubsection{Definição do problema}

O produto de uma matriz A do tipo $l \times m$ e uma matriz $\mathbf{B}$ do tipo $m \times n$ é uma matriz C do tipo $l \times n$, onde os elementos são definidos por:

$$
c_{i, j}=\sum_{k=0}^{m-1} a_{i, k} b_{k, j}
$$

Simplificando, sejam as matrizes $\mathrm{A}$ e $\mathrm{B}$, o produto de $\mathrm{AB}$ é uma matriz $\mathrm{C}$ do tipo $l x$ $n$ onde cada elemento $\mathrm{c}_{\mathrm{i}, \mathrm{j}}$ é obtido multiplicando ordenadamente os elementos correspondentes a i-ésima linha de A pelos elementos da j-ésima coluna de B e logo após, somando os resultados, como citado em [Car76].

A operação definida acima pode ser ilustrada através da Figura 33. 


$$
\begin{aligned}
{\left[\begin{array}{cccc}
a_{1,1} & a_{1,2} & \ldots & a_{1, m} \\
a_{2,1} & a_{2,2} & \ldots & a_{2, m} \\
\ldots . & \ldots . & \ldots & \ldots . \\
a_{l, 1} & a_{l, 2} & \ldots & a_{l, m}
\end{array}\right] \bullet\left[\begin{array}{cccc}
b_{1,1} \\
b_{2,1} \\
\ldots . \\
b_{1,2} & \ldots . & b_{1, n} \\
b_{2,2} & \ldots . & b_{2, n} \\
\ldots . & \ldots . & \ldots . \\
b_{m, 1} & b_{m, 2} & \ldots & b_{m, n}
\end{array}\right]=\left[\begin{array}{cccc}
c_{1,1} & c_{1,2} & \ldots . & c_{1, n} \\
c_{2,1} & c_{2,2} & \ldots . & c_{2, n} \\
\ldots & \ldots . & \ldots . & \ldots . \\
c_{l, 1} & c_{l, 2} & \ldots . & c_{l, n}
\end{array}\right] } \\
\text { Onde } c_{l, 1}=a_{l, 1} \cdot b_{l, 1}+a_{l, 2} \cdot b_{2,1}+\ldots+a_{l, m} \cdot b_{m, 1}
\end{aligned}
$$

Figura 33 - Multiplicação de Matrizes

\subsubsection{Utilização da Metodologia para a Resolução do Problema}

O problema especificado no item acima, não envolve grande complexidade, mas é um exemplo clássico de problema paralelo a ser resolvido. Neste item será utilizada a metodologia $U \mathrm{UP}^{2} \mathrm{D}$ definida neste trabalho para a resolução deste problema. Devido a pequena complexidade do problema, alguns diagramas foram suprimidos.

\subsubsection{Coleta de Requisitos}

A primeira etapa a ser cumprida de acordo com a metodologia é a coleta de requisitos, onde devem ser coletadas todas as informações necessárias. $\mathrm{O}$ resultado desta fase deve ser uma definição completa e concisa do problema feita em forma textual, e de maneira informal. Deve conter todas as informações importantes em relação ao problema. Essa etapa está descrita no tópico de definição do problema. O diagrama de Use-Cases foi descartado por esse problema não necessitar de grande interação com o usuário.

\subsubsection{Elaboração - Análise}

A etapa de elaboração é divida em 3 fases, análise, projeto e análise de desempenho. $\mathrm{Na}$ fase de análise, o desenvolvedor deve analisar os requisitos coletados na etapa de coleta dos requisitos, é responsável por especificar o modelo de classes, como também refinar os requisitos, com a finalidade de eliminar as falhas da primeira etapa.

Nessa etapa deve ser dada grande importância à definição do modelo do sistema, definindo-se os principais componentes pertencentes ao problema e classificando os mesmos. Também deve ser dada ênfase aos relacionamentos entre as classes pertencentes ao modelo do problema. 


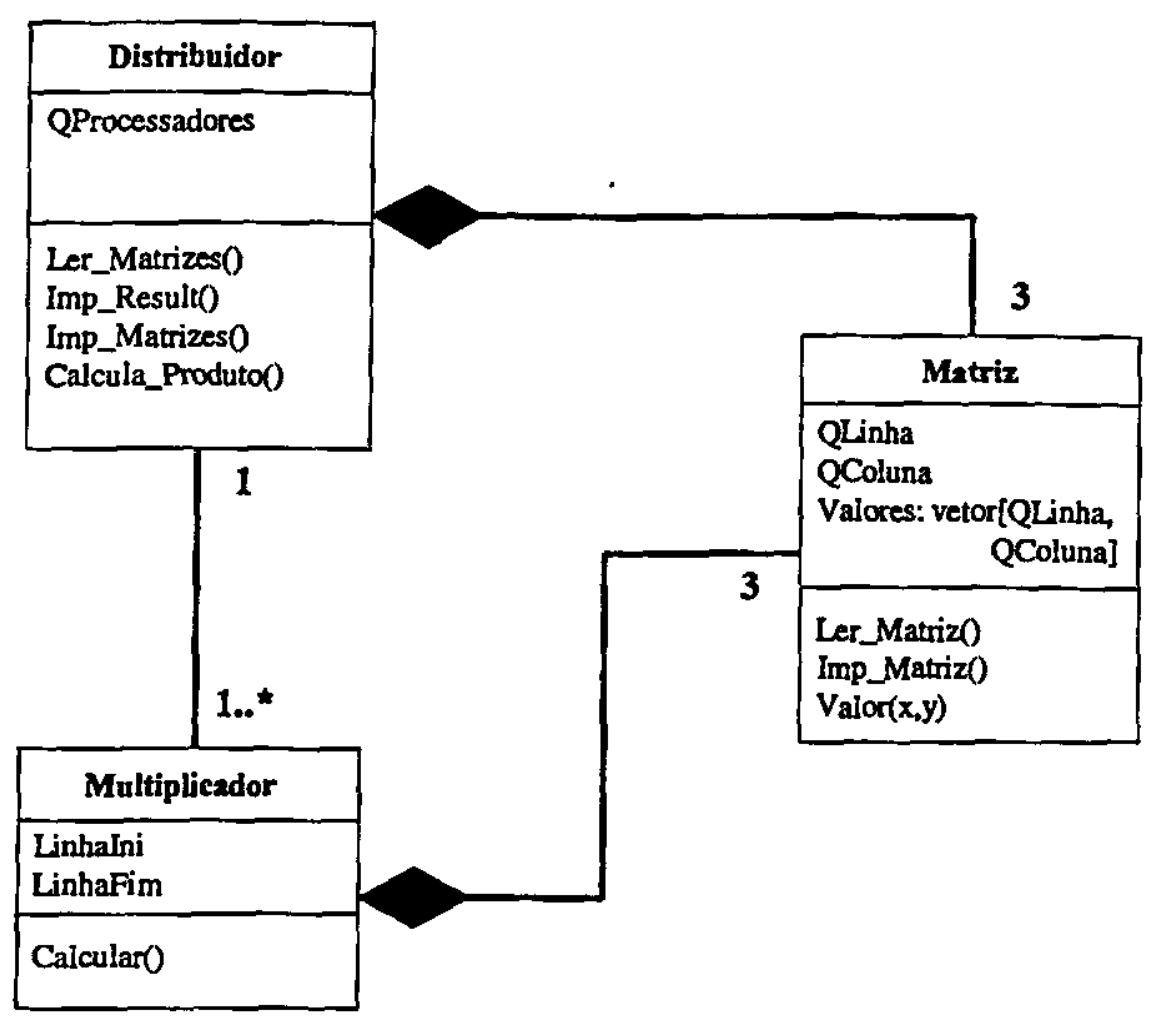

Figura 34 - Diagrama de.Classes - Produto de Matrizes

A Figura 34 apresenta o modelo de classes definido levando em consideração os requisitos coletados na etapa de Coleta de Requisitos. Neste diagrama foram definidas três classes. A classe Distribuidor é responsável pelo cálculo dos dados a serem passados para os processadores, a distribuição desses dados e a ativação dos processos em paralelo. As outras funções da classe distribuidor são: fazer a leitura dos dados iniciais, mostrar os resultados finais e o conteúdo das matrizes de entrada. Essa classe é um tipo de controlador de toda a aplicação, atuando como um processo mestre responsável pela divisão das tarefas.

A segunda classe definida neste estudo de caso é a classe Multiplicador. Essa classe é dependente da classe Distribuidor, sendo responsável pelo cálculo das linhas da matriz resultante. Dessa classe são instanciados vários objetos que são executados paralelamente nas máquinas definidas pelos diagramas de Máquina Paralela e Deployment. $\mathrm{O}$ seu relacionamento com a classe Distribuidor é que um objeto da classe Distribuidor pode instanciar muitos objetos da classe Multiplicador.

A terceira e última classe desse diagrama é a classe Matriz, que como o nome diz, é uma classe que representa uma matriz de QLinhas por QColunas. Nessa classe é possível 
preencher a matriz, mostrar o seu conteúdo e inserir ou ler um valor de uma determinada posição. Essa classe possui um relacionamento de composição com as classes Distribuidor e Multiplicador, pois esses possuem três matrizes em seu interior, e isso é representado pelo losango preenchido.

\subsubsection{Elaboração - Projeto}

Na segunda fase da etapa de elaboração. deve-se definir completamente o modelo do problema, como também os elementos pertencentes à máquina paralela a ser utilizada. Nessa fase deve ser feito um refinamento no modelo de classes. A arquitetura do software deve ser totalmente definida, mostrando a interação entre as classes, com seus devidos relacionamentos. Caso o modelo definido na fase de análise estiver completo, isso pode ser eliminado.

Outra tarefa importante é o mapeamento dos objetos na máquina paralela definida, pois através destes será possível coletar dados de comunicação, carga e eficiência. A fase de projeto deve ter como documentação resultante:

1. Modelo completo de classes, apresentado na Figura 34;

2. Modelo de interaçāo entre as classes, mostrando as chamadas aos objetos responsáveis pelo cálculo de linha a linha da matriz e o retomo do resultado ao objeto principal responsável pela apresentação do resultado final da aplicação. $O$ diagrama de colaboração é apresentado na Figura 35, onde são apresentadas as três classes pertencentes ao problema e a passagem de mensagens entre elas. Da classe Distribuidor são enviadas mensagens de leitura de matriz para vários objetos da classe Matriz, e o mesmo é feito com os objetos da classe Multiplicador, mas enviando a mensagem Calcular. Na mensagem enviada para a classe Multiplicador, entre chaves está o conteúdo da mensagem passada, que é de grande utilidade para a verificação da comunicação entre os nós.

No diagrama de seqüência também aparece uma seta tracejada representado os dados que a classe Multiplicador retorna para a classe Distribuidor. Sob esta seta está o conteúdo dessa mensagem de retorno. 
No diagrama de sequiência também aparece uma seta tracejada representado os dados que a classe Multiplicador retorna para a classe Distribuidor. Sob esta seta está o conteúdo dessa mensagem de retorno.

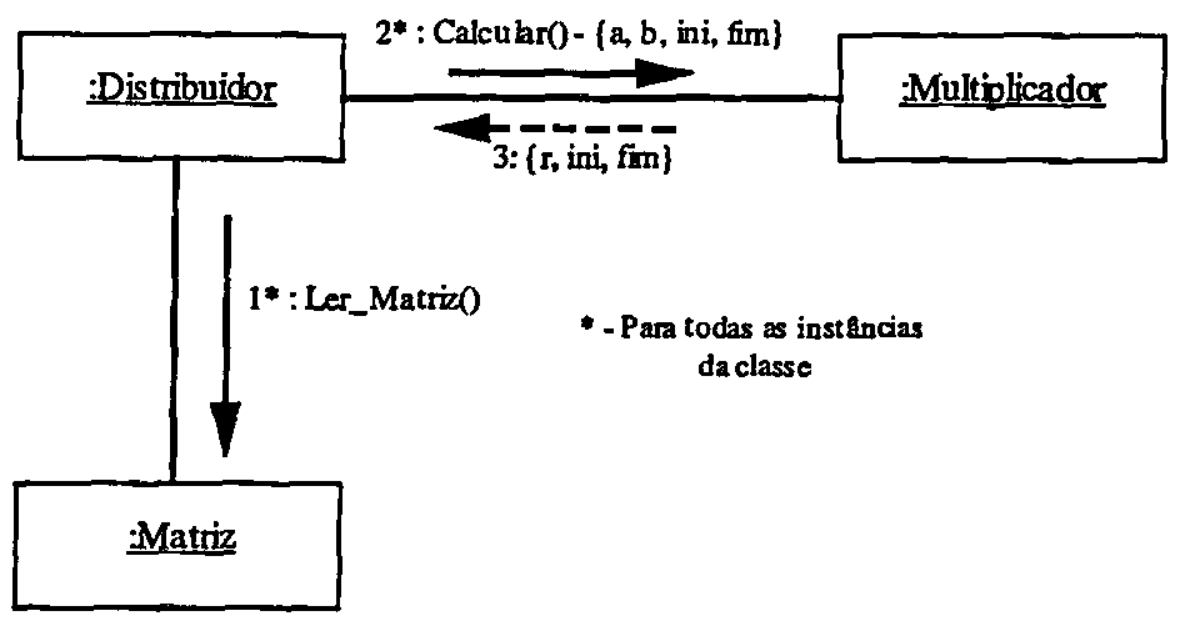

Figura 35 - Diagrama de Colaboraçāo - Multiplicação de Matrizes

O outro diagrama pertencente ao modelo de interaçăo é o diagrama de sequîtencia que esta ilustrado na

Figura 36. Através deste diagrama é possível verificar a execução dos objetos no tempo, podendo-se mostrar o paralelismo.

A classe Matriz é suprimida, pois essa não é de grande interesse para a execução paralela. Nesse diagrama os objetos da classe Multiplicador são instanciados como Primeiro Multiplicador, Segundo Multiplicador, Terceiro Multiplicador e Quarto Multiplicador, devido ao fato de existirem apenas 4 máquinas e para minimizar a comunicação entre elas. As mensagens entre elas são mostradas.

Neste diagrama também foi utilizada a notação de chaves para apresentar os dados enviados em cada uma das mensagens entre um objeto e outro. 


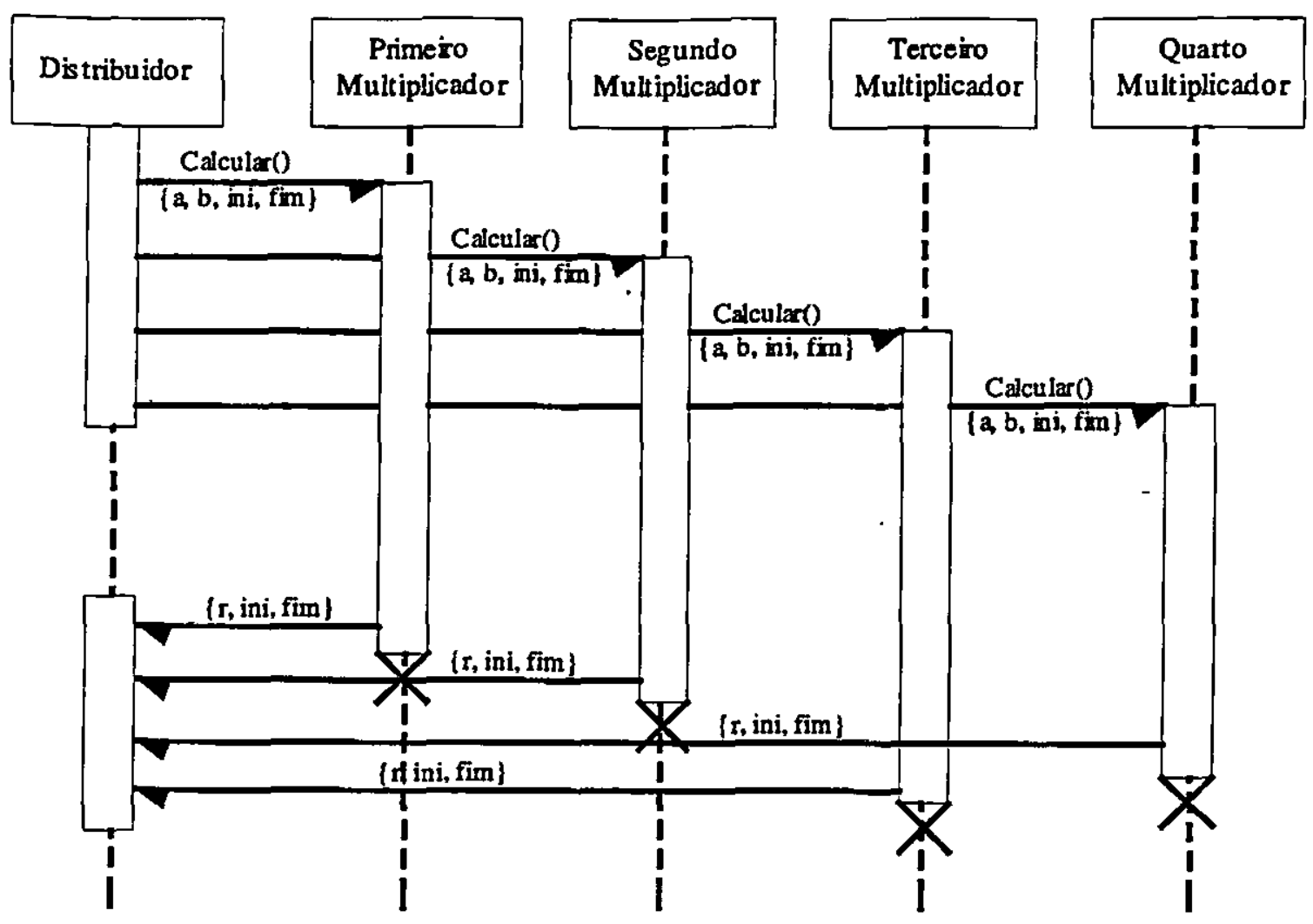

Figura 36 - Diagrama de Seqüência - Multiplicação de Matrizes

3. Modelos de atividades realizadas, onde são mostradas a partir de diagramas as operações realizadas durante toda a execução da aplicação. Na Figura 38 é apresentado o Diagrama de Atividades do problema de multiplicação de matrizes. Esse diagrama não apresenta os objetos onde está sendo executada cada uma das tarefas, mas possibilita a visualização do paralelismo da aplicação. Ele funciona como um diagrama de fluxo de dados, mas sem os dados. Nesse diagrama é mostrada a utilização das barras de sincronização, onde a execução da aplicação irá continuar apenas quando todas as atividades que estão entre as barras de sincronização forem realizadas, garantindo-se resultados confiáveis; 


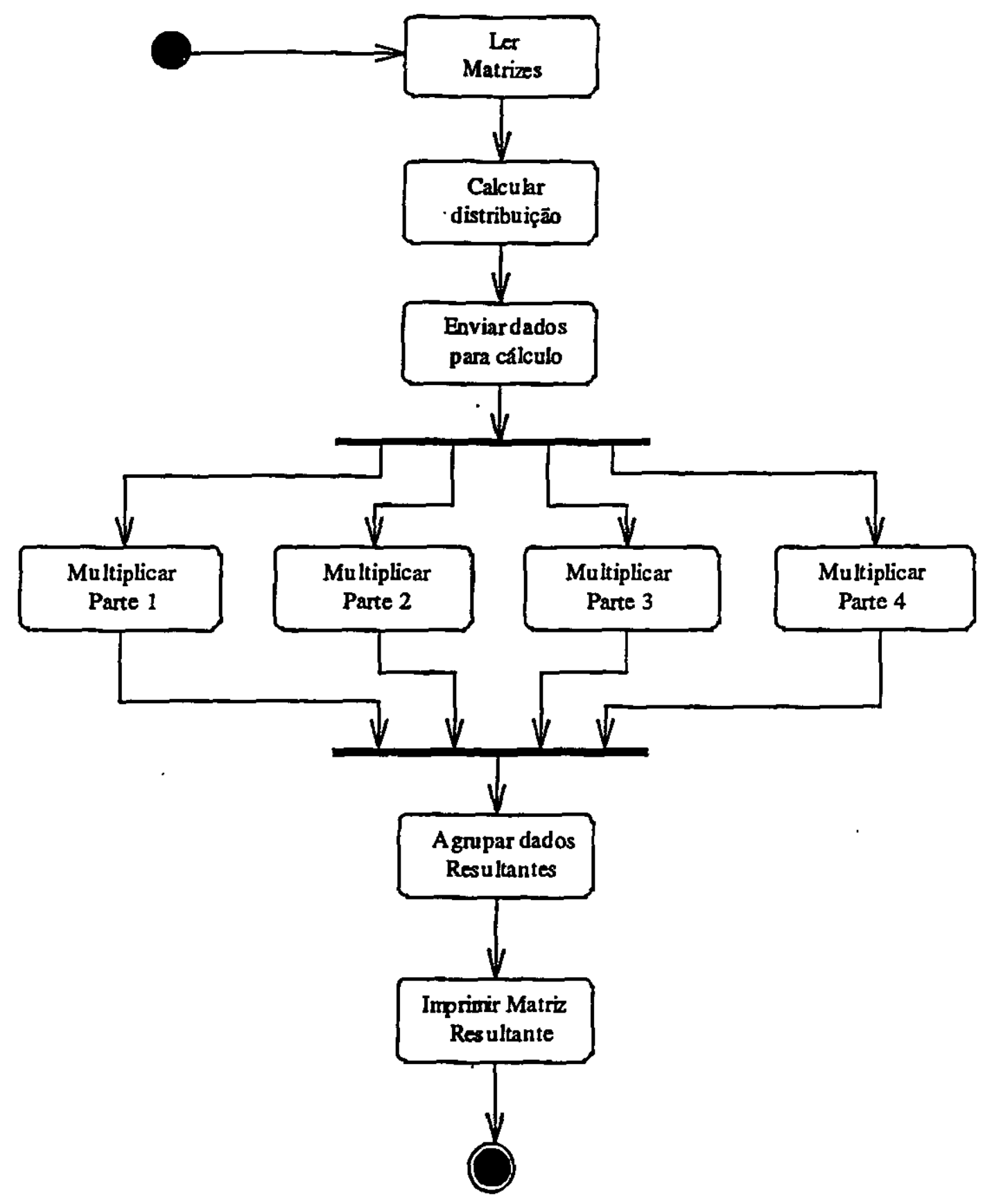

Figura 38 - Diagrama de Atividades - Multiplicação de Matrizes

4. Definição da máquina paralela, mostrando os elementos de processamento pertencentes à máquina onde a aplicação será executada e o poder de processamento e comunicação dos mesmos. $O$ diagrama de máquina paralela é ilustrado na Figura 39, onde existem quatro máquinas interligadas através de 
uma rede de comunicação. Essas máquinas podem possuir características diferentes de velocidade, memória e arquitetura;

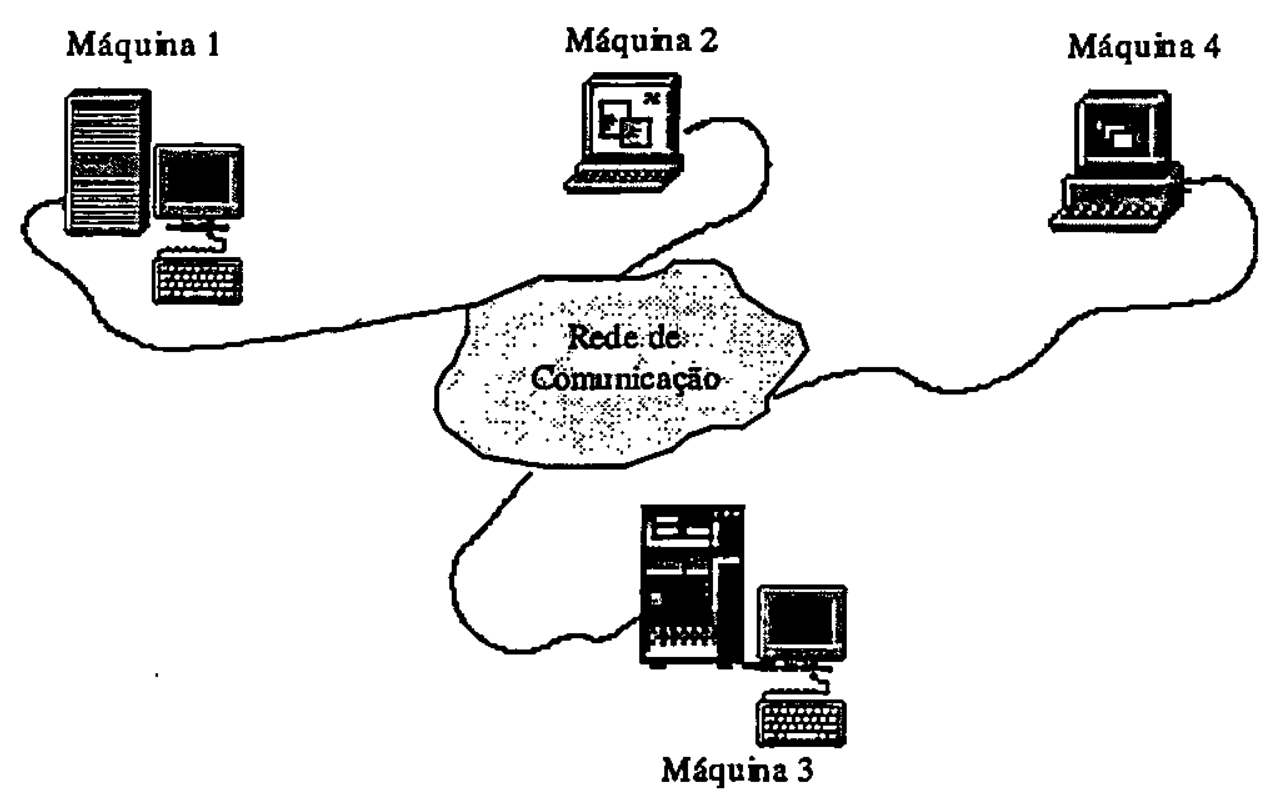

Figura 39 - Diagrama de Máquina Paralela

5. Mapeamento dos processos nos processadores deve ser mostrado utilizando um diagrama próprio para esse propósito, ou o diagrama de Deployment. 0 diagrama de Deployment é apresentado na Figura 40. Neste estudo de caso o diagrama mostra que na máquina 1 estão objetos da classe Distribuidor e Multiplicador, pois essa máquina é responsável pela distribuição dos objetos nos processadores. Durante o tempo de espera do objeto da classe Distribuidor nela será executado um objeto da classe Multiplicador, para que ela de não fique ociosa. Nas máquinas 2, 3 e 4, somente será instanciado um objeto da classe Multiplicador. 


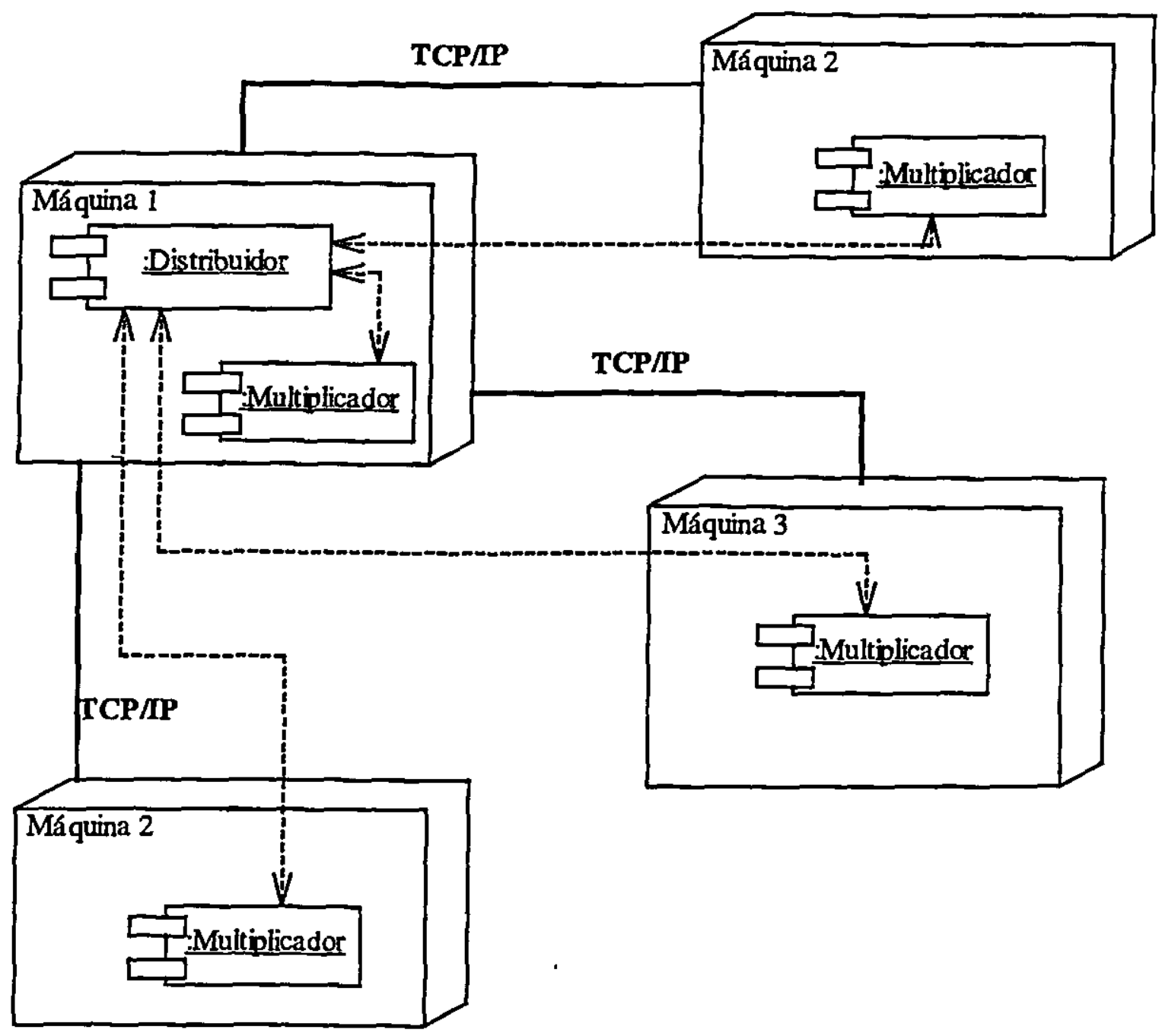

Figura 40 - Diagrama de Deployment - Multiplicação de Matrizes

O diagrama de pacotes neste estudo de caso foi suprimido devido à pequena complexidade do modelo gerado.

\subsubsection{Elaboraçāo - Análise de Desempenho}

A última fase dessa etapa do ciclo de vida é responsável pela análise do desempenho do modelo definido. Nessa etapa deve ser feita uma análise no modelo especificado, coletando-se informaçōes que possam servir de fonte para o balanceamento de carga, a minimização da comunicação entre os objetos e a maximização da eficiência, antes da implementação. 
Neste ponto deve-se atribuir valores de carga aos objetos, de acordo com o estudo da complexidade dos métodos dos objetos. Como esse problema foi resolvido utilizando o paralelismo de dados, as tarefas possuem a mesma carga, atribuindo-se portanto o valor 1 para a carga de todos os processos que estão em paralelo. Com o valor da carga definido, deve-se levar em conta o poder computacional dos nós, como também o tempo de retardo e a velocidade do meio de comunicação.

Também é necessária uma análise no diagrama de colaboração, onde se é possível visualizar as mensagens que são passadas. entre os objetos. Com essa análise é possível verificar o tamanho e a quantidade de mensagens passadas entre os objetos, nesse estudo de caso foi utilizada uma mensagem broadcast enviando para todas as instâncias do objeto calculador o conteúdo das matrizes, assim evitando o envio de várias mensagem , uma para cada objeto calculador.

A última tarefa a ser executada nessa etapa é analisar a fundo o diagrama de seqüência, pois através dele é possível visualizar os processos que estarão em execuçăo ao mesmo tempo, como esses processos possuem a mesma carga, o tempo de execução de cada um deles depende exclusivamente do poder computacional do nó.

A áltima tarefa do desenvolvedor nessa etapa é verificar a possibilidade de alteração do modelo para conseguir maior desempenho na aplicação resultante.

\subsubsection{Implementação}

Após a etapa de elaboração do modelo da aplicação, passa-se para a etapa de implementação deste modelo utilizando uma linguagem (preferencialmente orientada a objetos), juntamente com uma biblioteca de passagem de mensagens.

Para a implementação da aplicação foi utilizada a linguagem orientada a objetos $\mathrm{C}+$. Como biblioteca de passagem de mensagens foi utilizada a PVM++, que fornece suporte a comunicação entre os processos em diversas máquinas utilizando a linguagem C++.

A biblioteca PVM++ foi desenvolvida no Institute of Computer Design and Fault Tolerance da University of Karlsruhe. Essa biblioteca é formada por um conjunto de classes que possibilita: 
- Facilmente enviar e receber mensagens em redes heterogêneas;

- Acessar todas as informações sobre tarefas e máquinas utilizadas;

- Utilizar handlers de mensagens;

- As mensagens serem desempacotadas automaticamente na chegada.

Além das classes que fornecem facilidades na utilização da biblioteca, a PVM++ também possui fácil instalaçăo e configuração em todas as plataformas Unix, está disponível sob a licença pública GNU e o código fonte está disponível para alterações e inclusões.

A implementação inicia com a definição da estrutura das classes utilizando a linguagem definida para a implementação. A classe Matriz não será definida devido sua simplicidade, como também pela possível utilização da classe predefinida de vetores.

A classe Distribuidor pode ser implementada da forma apresentada abaixo.

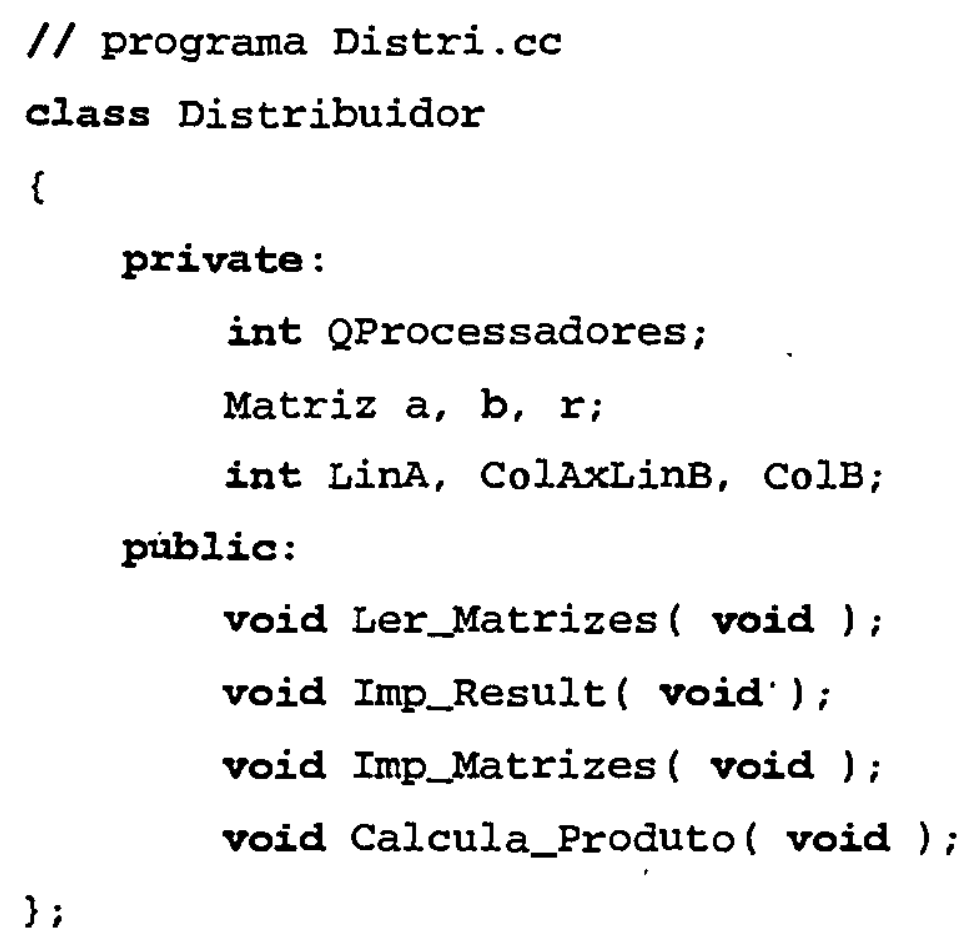

A próxima classe a ser definida é a classe Multiplicador, responsável pela multiplicação das linhas da matriz. Essa classe pode ser implementada como mostrado abaixo. 


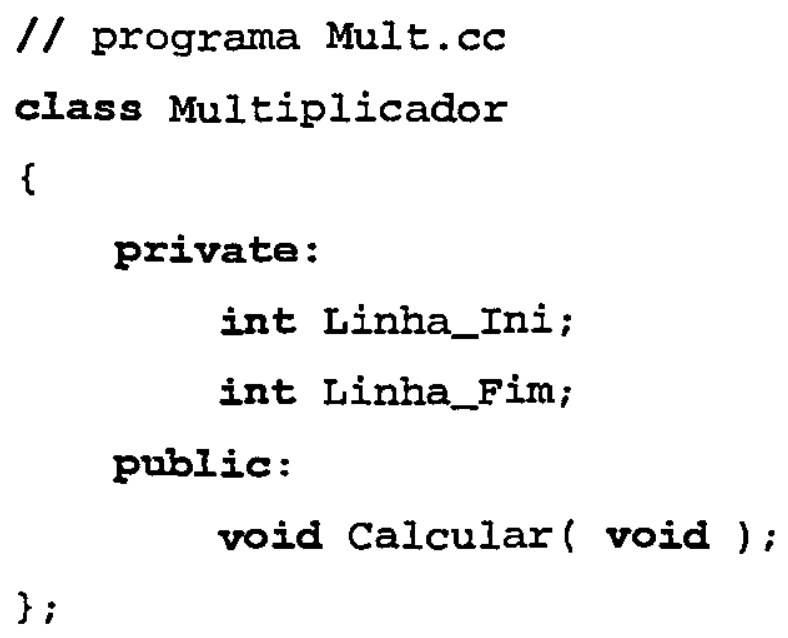

Como os objetos da classe Distribuidor e da classe Multiplicador serão executadas em paralelo, as classes deverão ser confeccionadas em dois arquivos separados, pois serão gerados dois programas executáveis diferentes: um responsável pela distribuição dos dados e tarefas entre os elementos de processamento pertencentes a máquina paralela e o outro executado em cada uma das máquinas utilizadas na multiplicação da matriz.

A segunda etapa da implementação é a codificação dos métodos pertencentes a cada uma das classes. Os métodos de impressão e aquisição de dados não são apresentados, são apresentados apenas os métodos referentes à comunicação entre os objetos que estão em diferentes máquinas e aqueles responsáveis pela multiplicação das matrizes. O primeiro método a ser apresentado é o Calcular_Produto(), que pertence a classe Distribuidor.

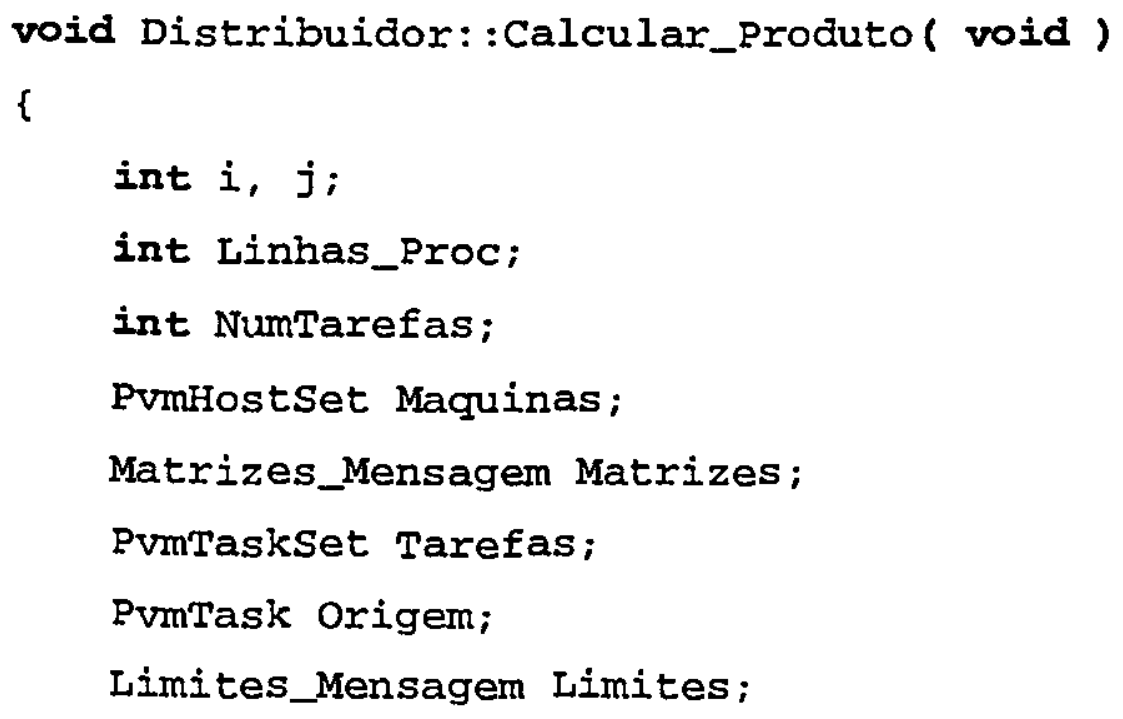




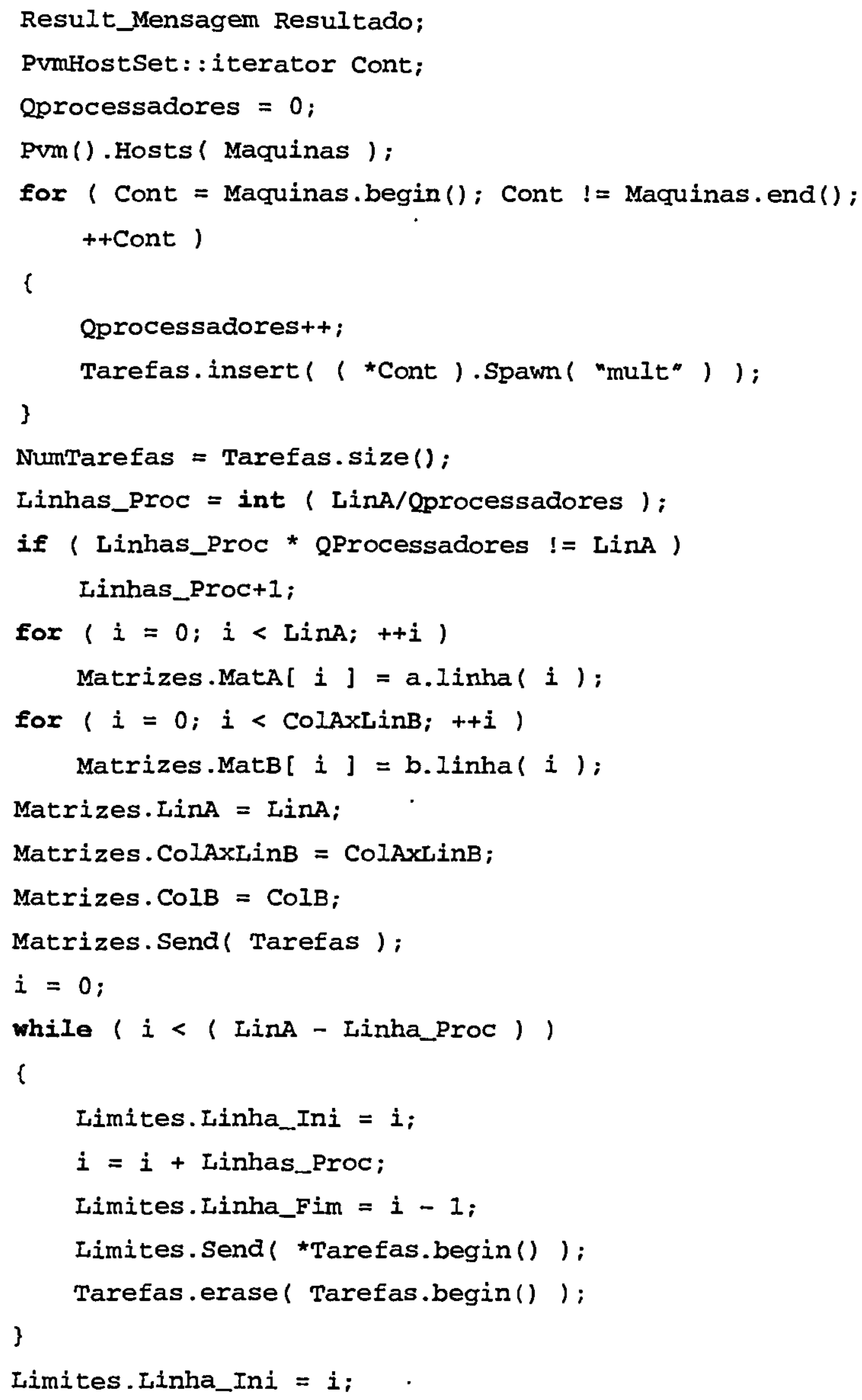




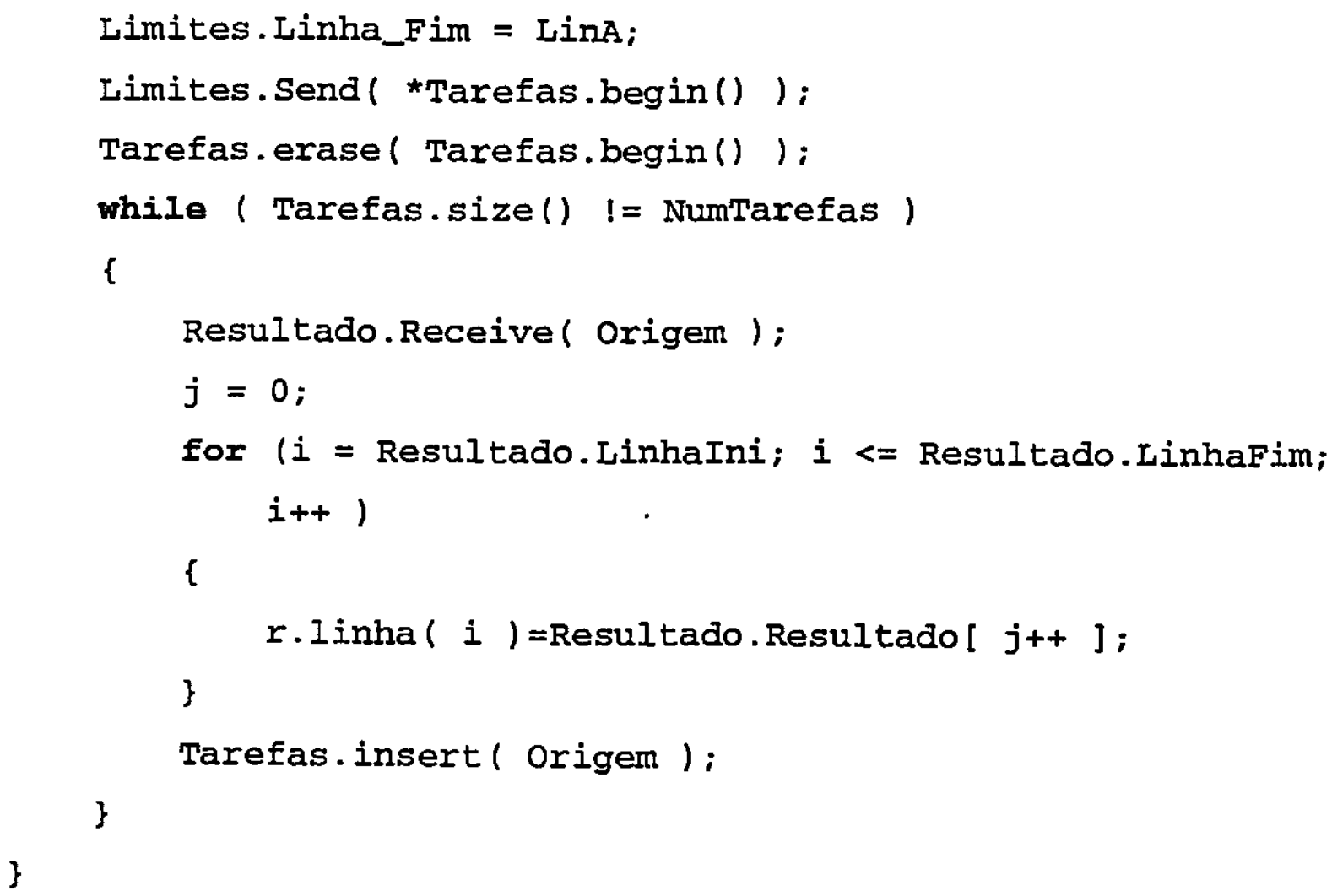

O método Calcula_Produto() é responsável pelas seguintes tarefas:

1. Receber do PVM as máquinas que estão preparadas para a execução do programa, ou seja, aquelas que estão com o daemon em execução;

2. Ativar em todas as máquinas preparadas o programa responsável pela multiplicação, ou seja, o mult, onde está a classe Multiplicador;

3. Dividir a quantidade de linhas da matriz que cada uma das máquinas será responsável por resolver;

4. Preencher a estrutura da mensagem de matrizes com o conteúdo das matrizes que pertencem ao objeto distribuidor;

5. Enviar para todos os multiplicadores as matrizes inteiras que serão utilizadas para a obtenção do resultado;

6. Enviar para cada um dos multiplicadores os limites superior e inferior para utilização no cálculo do problema, ou seja, serão enviadas para os multiplicadores a linha inicial e a linha final do cálculo; 
7. Receber dos processos multiplicadores o resultado da operação realizada, até que todos tenham retornado com esse resultado.

No objeto Multiplicador, o método que possui importância é o Calcular(), onde é feita a multiplicação da matriz. Nesse método não foi utilizada a classe Matriz por problemas de desernpenho, pois a troca dos elementos da matriz recebida na mensagem poderia comprometer o desempenho da aplicação como um todo. Para isso foram utilizadas as próprias estruturas das mensagens Matrizes_Mensagem e Result_Mensagem.

void Multiplicador: :Calcular(void)

\{

Matrizes_Mensagem Matrizes;

PvmTask Origem;

Iimites_Mensagem Limites ;

int col, $i, j$;

PvmStructset Espera;

Result_Mensagem Result;

int Iin;

Origem $=\operatorname{Pvm}() \cdot I() \cdot$ Parent ();

Matrizes.ReceiveFrom( Origem );

Espera.insert( Limites );

Result.IinhaIni = Limites.LinhaIni;

Result.LinhaFim = Limites.IinhaFim

$j=0$;

for $($ Lin = Limites.LinhaIni; Lin $<=$ Limites.IinhaFim; ++ in $)$

\{

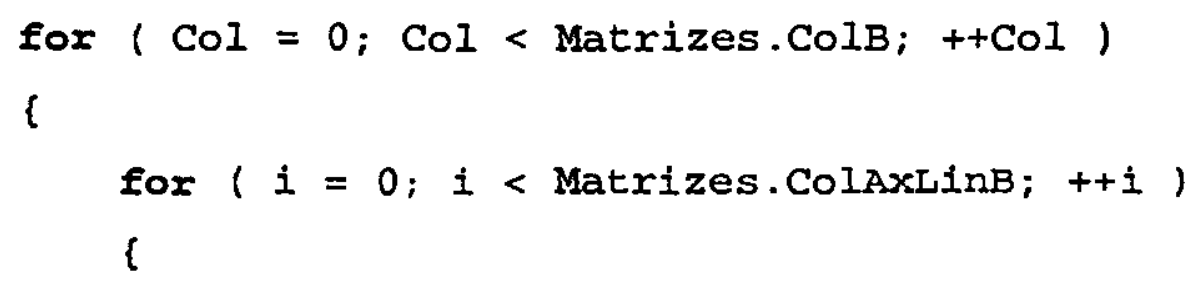




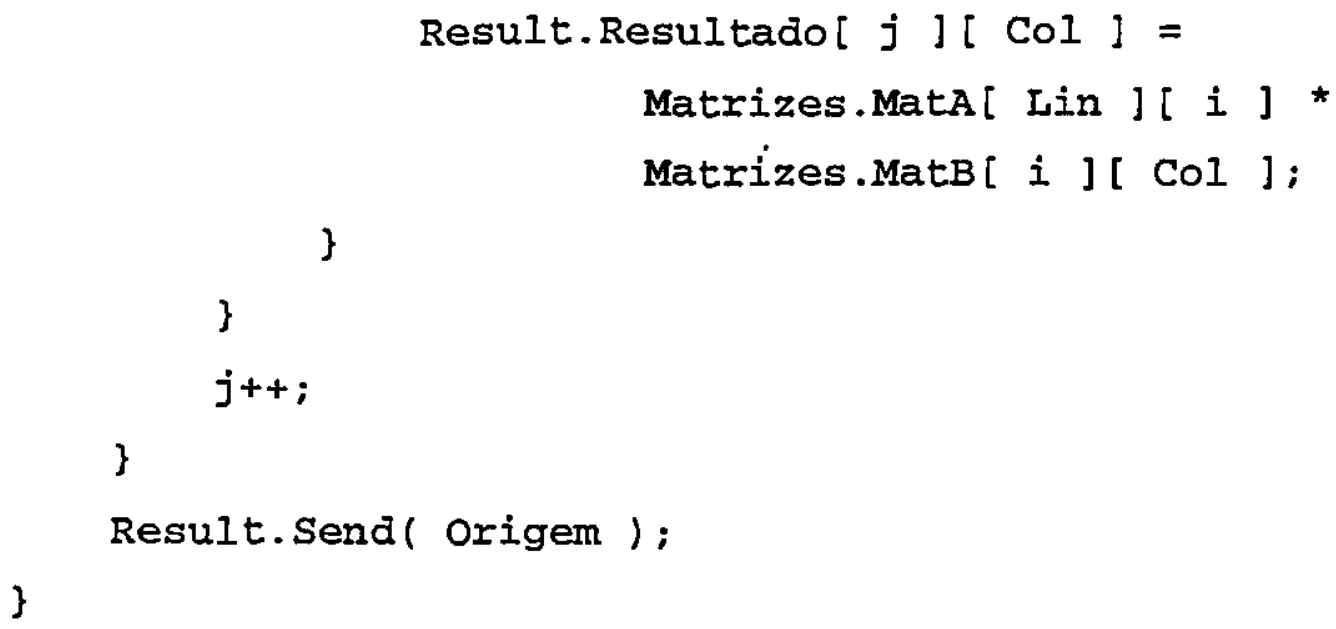

O método Calcular() da classe Multiplicador é o método mais importante, tanto dessa classe quanto da aplicação como um todo, pois é através dele que a multiplicação de matrizes é efetuada. Esse método realiza as seguintes operaçōes:

1. Verifica quem o criou, ou seja, qual é a aplicação origem, para que essa receba os resultados dos cálculos efetuados pelo método;

2. Recebe a mensagem contendo as matrizes para o cálculo;

3. Aguarda uma mensagem que indica quais serão as linhas a serem calculadas, ou seja, uma mensagem do tipo Limites_Mensagem, para continuar o processamento;

4. Após receber a mensagem, ou seja, as linhas a serem calculadas, são efetuadas as operações para a multiplicação das matrizes.

Além dos métodos apresentados, também são importantes as estruturas utilizadas na comunicação entre os dois programas. Essas estruturas são apresentadas e detalhadas abaixo.

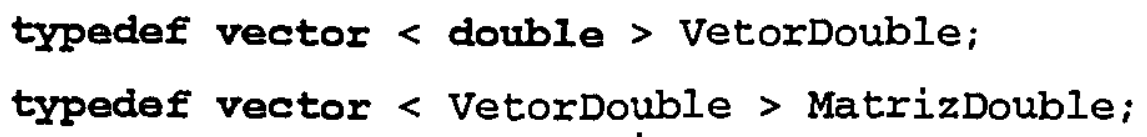


O tipo definido como VetorDouble é um vetor unidimensional do tipo double, que é utilizado para a criação do tipo MatrizDouble. Esse tipo é um vetor de vetores, também pode ser visto como uma matriz bidimensional do tipo double.

O tipo MatrizDouble é utilizado na definição das estruturas das mensagens, como também pode ser utilizado no lugar da classe matriz, no desenvolvimento do problema. Esses dois tipos definidos podem ser utilizados para vários fins. As próximas estruturas serão utilizadas para a passagem de mensagem entre os objetos que estão em diferentes máquinas.

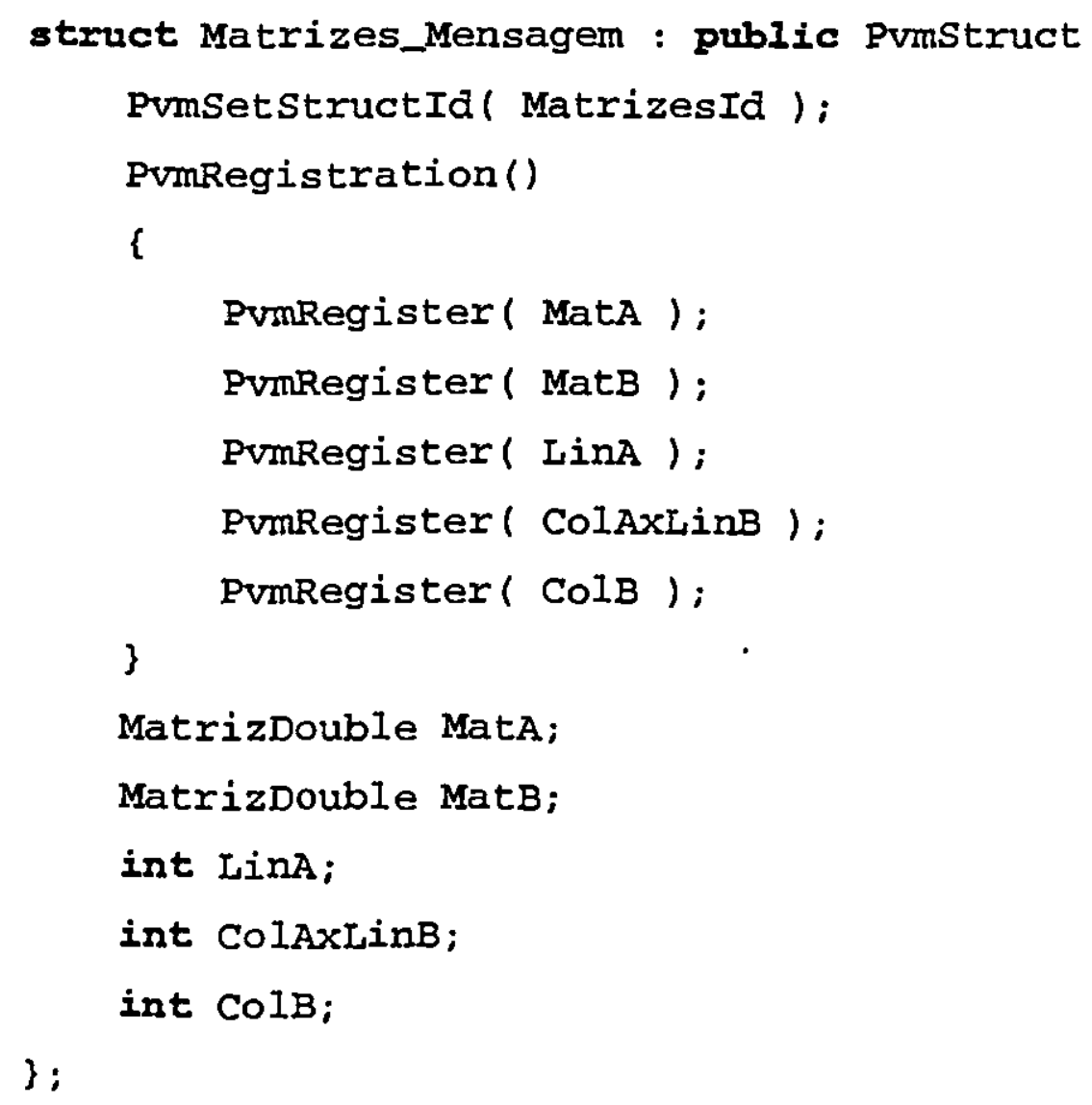

A estrutura Matrizes_Mensagem é a primeira estrutura a ser utilizada para a passagem de mensagem, devido a isso, ela é derivada da estrutura PvmStruct. Essa estrutura é utilizada para enviar as matrizes que serão utilizadas na multiplicação, possuindo duas estruturas do tipo MatrizDouble, que são as duas matrizes a serem multiplicadas e três variáveis do tipo inteiro simbolizando a quantidade de linhas da matriz 
$A$, a quantidade de colunas da matriz $A$, que deve ser igual a quantidade de linhas da matriz $B$ e a quantidade de colunas da matriz $B$.

struct Limites_Mensagem : public PvmStruct

\{

PvmSetStructId( LimitesId);

PvmRegistration()

\{

PvrRegister( LinhaIni );

PvmRegister ( LinhaFim );

\}

int LinhaIni;

int LinhaFim;

\};

A estrutura apresentada acima é utilizada para o envio dos limites para o cálculo em cada um dos multiplicadores, ou seja, é a linha inicial e a linha final a ser calculada por cada um dos multiplicadores. Esta estrutura por ser utilizada para a comunicação entre os elementos é derivada da estrutura PvmStruct.

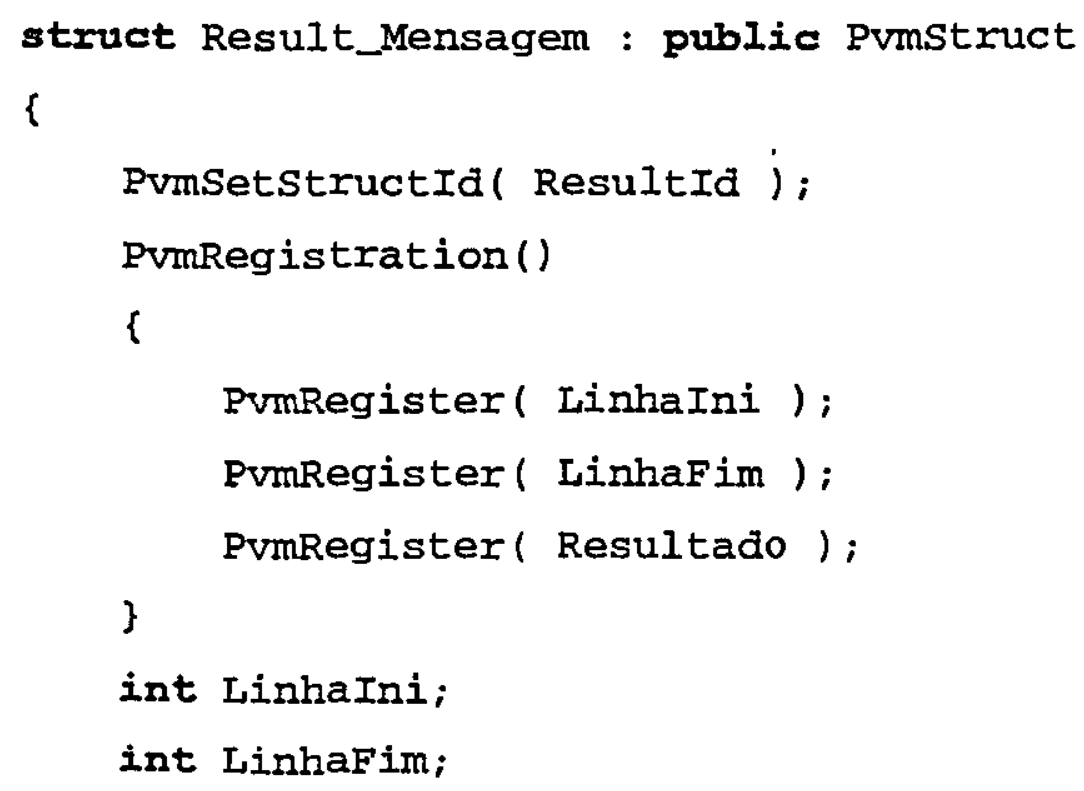


MatrizDouble Resultado;

;

A estrutura Result_Mensagem também é uma estrutura utilizada para a comunicação entre os processos, portanto derivada da estrutura PvmStruct. Ela é responsável pelo envio dos dados resultantes das operações realizadas nos multiplicadores para o distribuidor, que é responsável por montar a matriz resultado. Esta estrutura possui um elemento do tipo MatrizDouble, que é a matriz resultante e dois elementos inteiros que simbolizam as linhas inicial e final da matriz que será montada pelo objeto do tipo distribuidor. Neste item também são apresentadas algumas constantes que são de grande importância para o problema, principalmente para a comunicação.

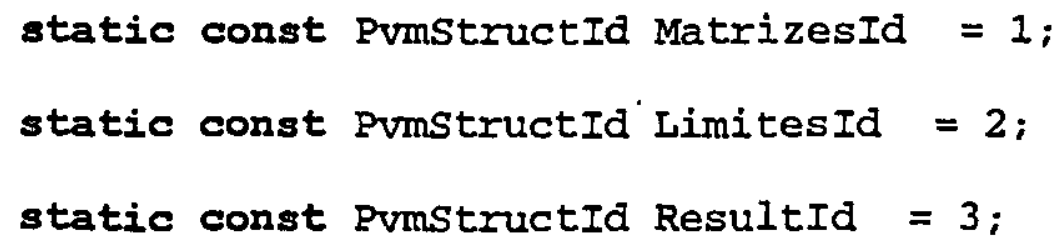

As constantes apresentadas acima são utilizadas nas estruturas apresentadas e representam identificadores para as mensagens enviadas, sendo a constante MatrizesId o identificador da estrutura Matrizes_Mensagem, a LimitesId o identificador para a estrutura Limites_Mensagem e a ResultId como identificador para Result_Mensagem.

Neste item foi apresentado um estudo de caso sobre a multiplicação de matrizes, utilizando a metodologia desenvolvida, mostrando todos os passos desde a coleta de requisitos e definição do problema, até a implementação da aplicação, com o uso de rotinas de comunicação. Apesar do problema não ser de grande complexidade, é interessante para demonstrar a utilização da metodologia. No próximo item será apresentado um outro estudo de caso, um pouco mais complexo, a tranșformada rápida de Fourier e sua utilização na multiplicação de polinômios. 


\subsection{Estudo de Caso - Transformada Rápida de Fourier}

O segundo estudo de caso a apresentado neste trabalho é a transformada rápida de Fourier. A transformada rápida de Fourier tem muitos usos em ciência e engenharia. As aplicaçōes incluem transmissāo de voz e processamento de imagens. $O$ descobrimento de um algoritmo rápido para a transformada discreta de Fourier foi um evento particularmente significativo.

\subsubsection{Definição do Problema}

Para um melhor entendimento da transformada rápida de Fourier, será apresentado um exemplo de sua utilização, a multiplicação de dois polinômios de grau $(n-1)$. Onde o produto dos polinômios

$$
\begin{gathered}
p(x)=\sum_{i=0}^{n-1} a_{i} x^{i} \text { e } \\
q(x)=\sum_{i=0}^{n-1} b_{i} x^{i}
\end{gathered}
$$

É o polinômio de grau $(2 n-2)$

$$
p(x) q(x)=\sum_{i=0}^{2 n-2} \sum_{j=0}^{i} a_{j} b_{i-j} x^{i}
$$

Os coeficientes do polinômio resultante $p(x) q(x)$ podem ser encontrados fazendo-se à somatória apresentada acima. Utilizando esse algoritmo a multiplicaçāo polinomial pode ser realizada em $O\left(n^{2}\right)$.

A observação que um polinômio $p(x)$ de grau $n-1$ é unicamente determinado por seus valores na n-ésima raiz de unidade, obtém-se um outro algoritmo. Calculando-se a transformada de Fourier dos coeficientes de um polinômio de grau $n-1$ gera-se o valor do polinômio na raiz de unidade $n$. O valor do produto em qualquer ponto é simplesmente o produto dos valores dos dois polinômios naquele ponto. Ao contrário, fazendo-se a 
transformada inversa de Fourier nos valores do polinômio de grau $n$ - 1 na $n$-ésima raiz de unidade são gerados os coeficientes desse polinômio.

Na Figura 41 é ilustrado o algoritmo de multiplicação de polinômios utilizando a transformada de Fourier. Nessa figura os polinômios utilizados são $3 x-2$ e $4 x+1$. A transformada de Fourier é aplicada nesses polinômios para determinar seus valores nas quatro raízes de unidade. As quatro raízes de unidade são $\{1, i,-1 \mathrm{e}-i\}$ onde $\mathrm{i}=\sqrt{-1} .0$ par de valores em cada raiz é multiplicado, por exemplo, $(2+3 i)(1+4 i)=-14-5 i$. Os quatro valores resultantes determinam unicamente o produto polinomial, cujos coeficientes são encontrados utilizando a transformada inversa de Fourier.

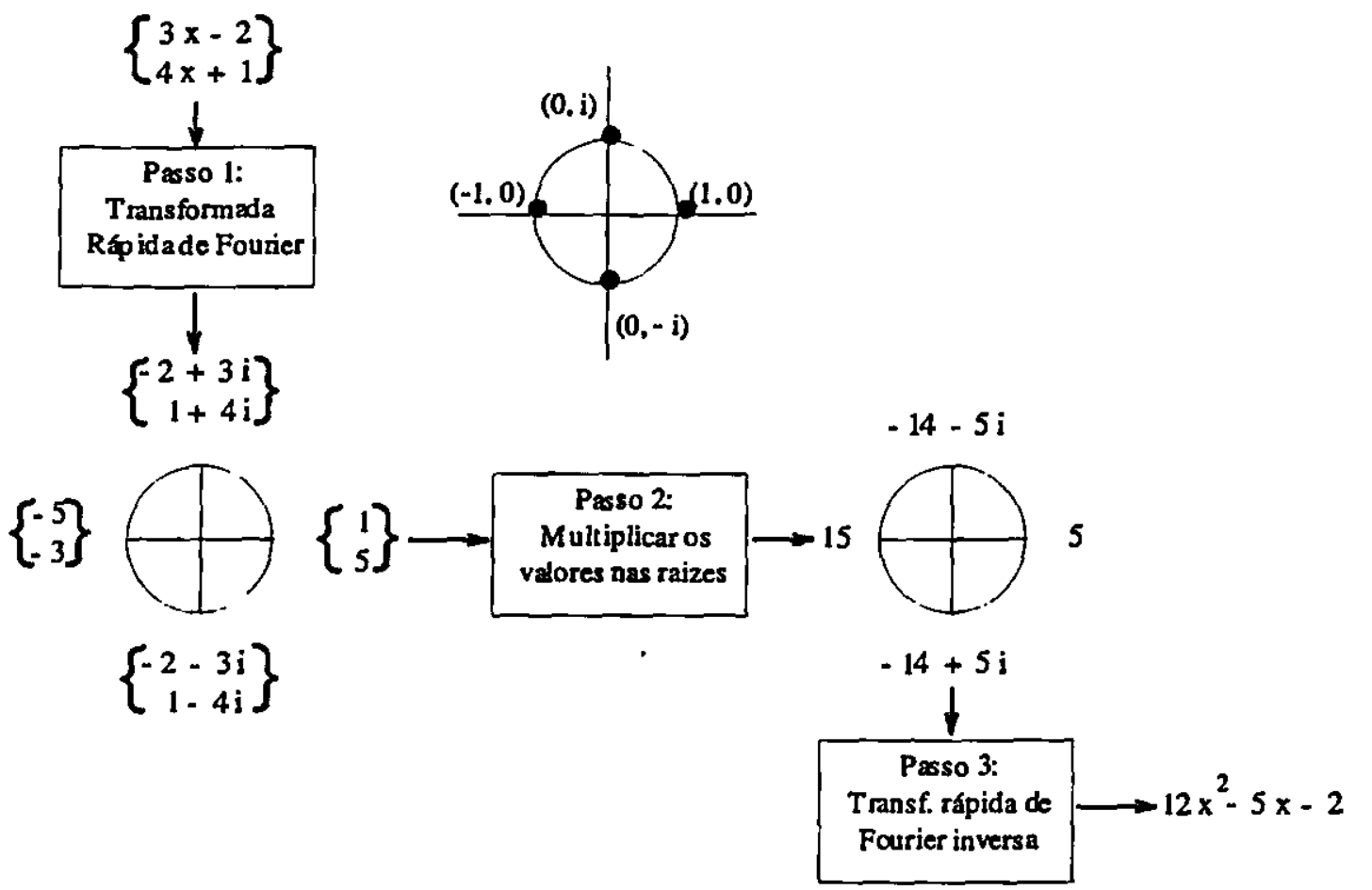

Figura 41 - Funcionamento do algoritmo de multiplicação de polinômios

A utilização da transformada de Fourier na multiplicação de polinômios permite realizá-la em $O(n \log n)$, ao invés de $O\left(n^{2}\right)$, chegando assim ao resultado de uma forma mais rápida. A transformada rápida de Fourier utiliza a técnica de dividir e conquistar para realizar a transformada discreta de Fourier em $O(n \log n)$. 
O algoritmo para a transformação rápida de Fourier abaixo apresentado faz a transformação de um vetor de coeficientes $a$ em um vetor de valores $b$. Esse é um al goritmo seqüencial que mostra o funcionamento da transformada rápida de Fourier. Esse algoritmo resolve a transformada rápida de Fourier em níveis, que são definidos por k. $\mathrm{O}$ número de elementos do vetor é igual a $2^{k}$.

\section{Transformada Rápida de Fourier}

\section{Inicio}

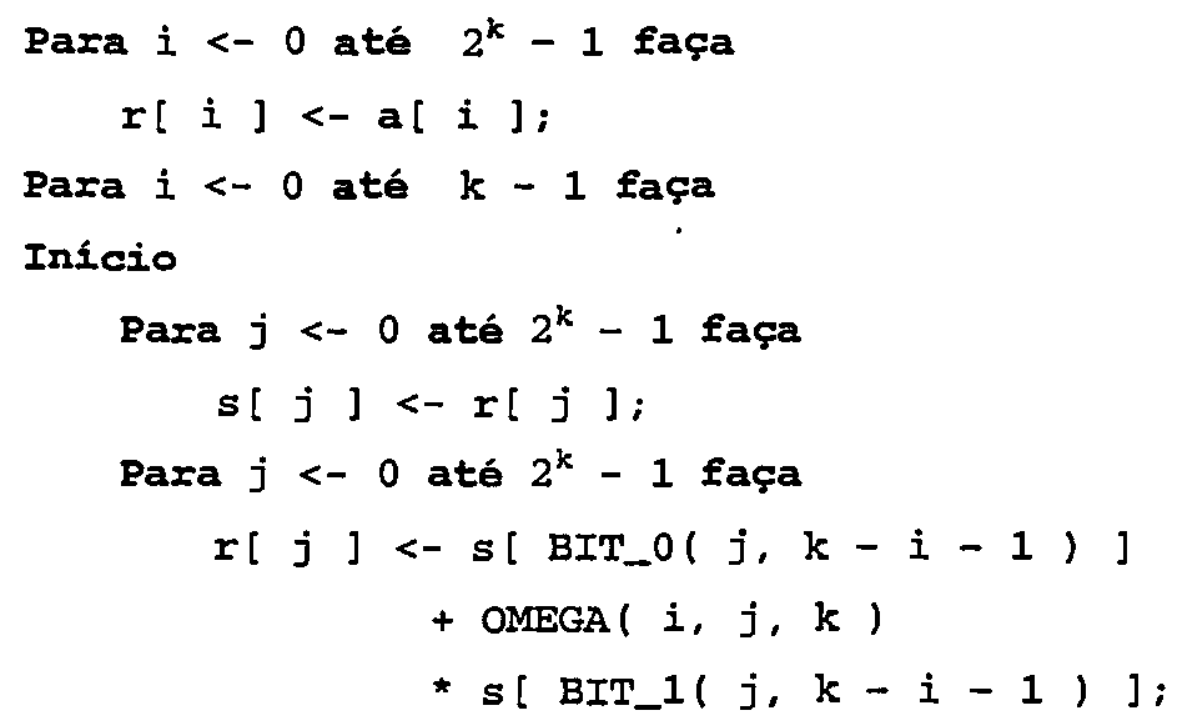

Fim

O algoritmo utiliza quatro funções para realizar a transformada rápida de Fourier, BIT_O( inteiro, inteiro ), BIT_1( inteiro, inteiro ), OMEGA( inteiro, inteiro, inteiro ) e REVERSE( inteiro, inteiro ). A utilização dessas funções facilita o entendimento do algoritmo como um todo.

A função BIT_0 recebe dois inteiros, $x$ e $y$ e retorna um número inteiro correspondendo ao inteiro $x$ com a alteração do bit $y$ para 0 . A Figura 42 traz um exemplo do funcionamento dessa função. 


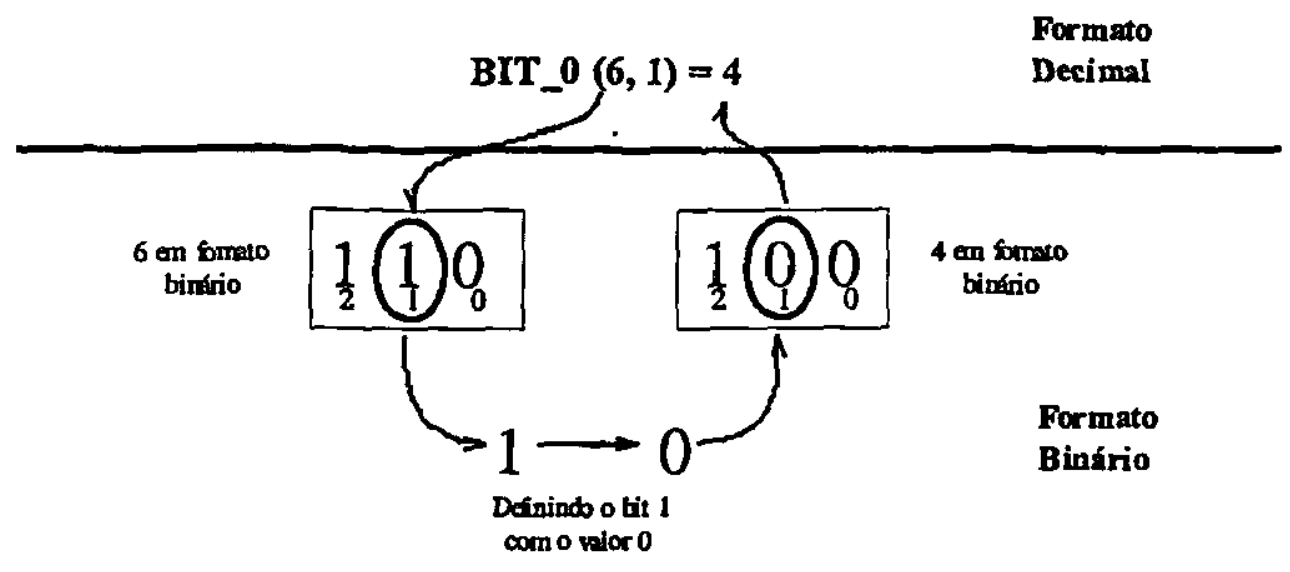

Figura 42 - Exemplo da Função BIT_O( x,y ).

A segunda função possui funcionalidade semelhante a da função BIT_o. A função BIT_1 recebe também dois números inteiros $x$ e $y$ como parâmetros, e retorna um inteiro correspondente a troca do bit $y$ da variável inteira $x$ por 1, como mostrado na Figura 43.

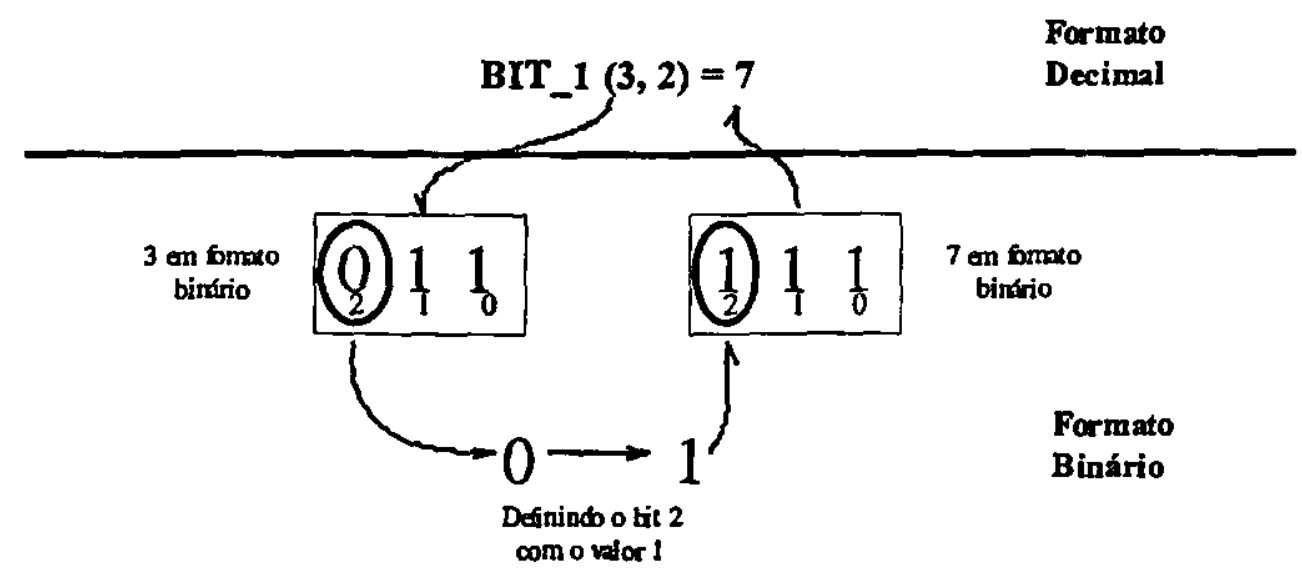

Figura 43 - Exemplo da Função BIT_l( $x, y)$.

A função $\operatorname{OMEGA}(x, y, z)$ recebe três variáveis inteiras e retorna a $n$-ésima raiz primitiva de unidade, onde $n$ é o valor encontrado invertendo os $x+1$ bits mais significativos do inteiro $y$ e substituindo os $z-x-1$ bits menos significativos do resultado com zeros. O exemplo do funcionamento desta função é apresentado na Figura 44. 


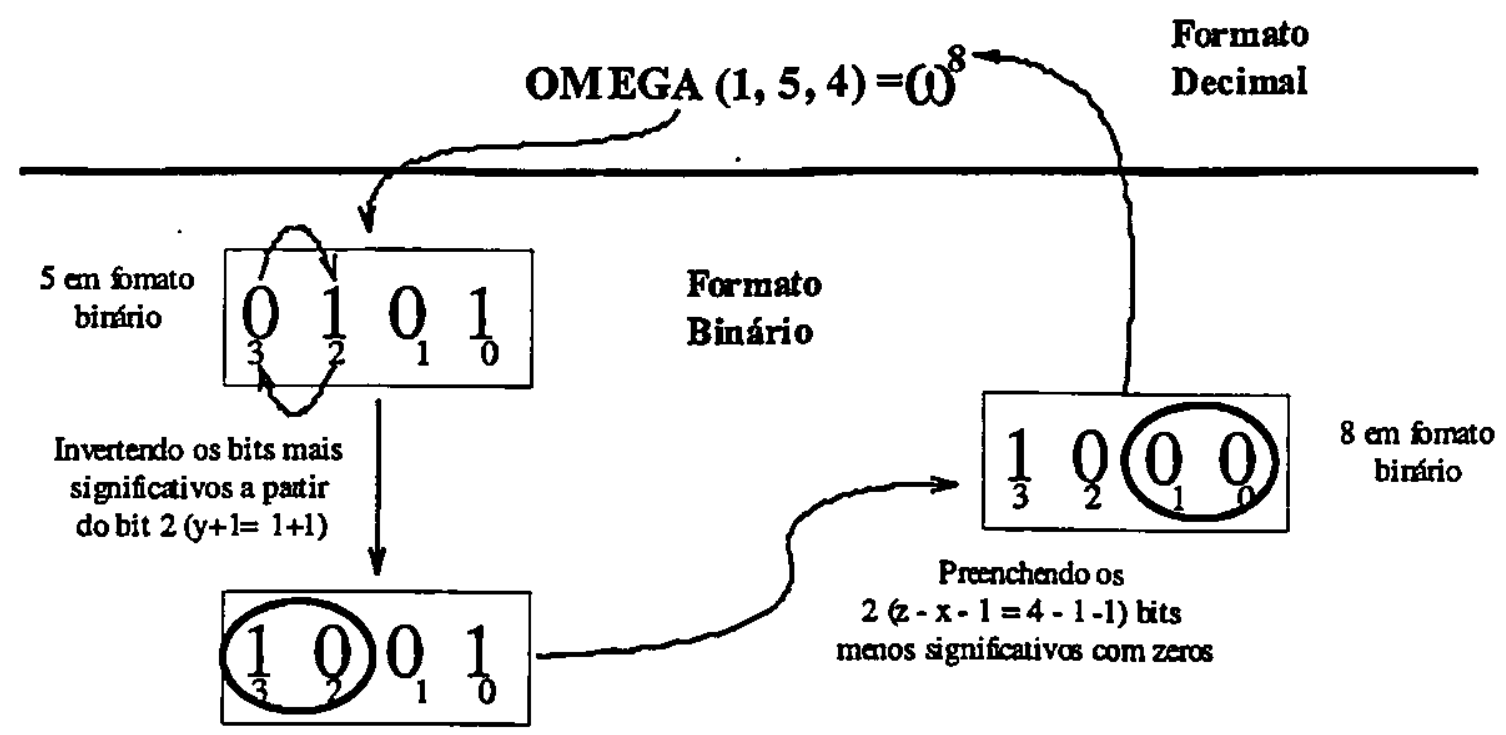

Figura 44 - Exemplo da Função $\operatorname{OMEGA}(x, y, z)$.

A última função é a $\operatorname{REVERSE}(x, y)$, que recebe dois números inteiros e retoma um valor entre 0 e $2^{y}-1$, que é encontrado invertendo a representação binária do número inteiro de $x$ com y bits, como é apresentadơ na Figura 45.

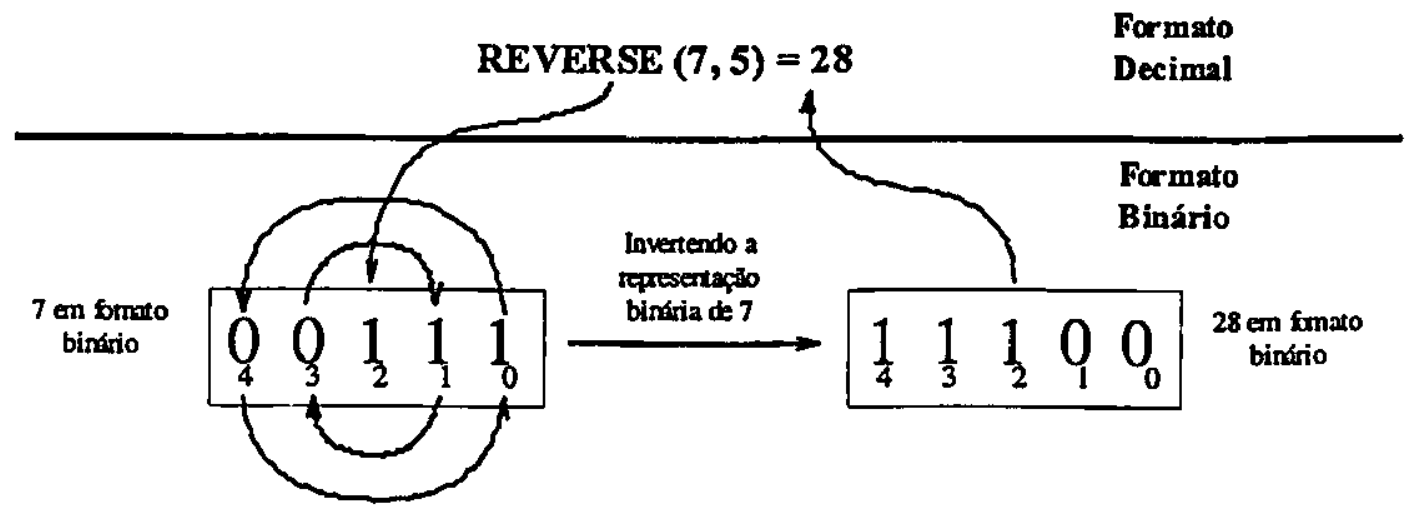

Figura 45 - Exemplo da Função REVERSE( $x, y)$

\subsubsection{Utilização da Metodologia para a Resolução do Problema}

O problema da transformada rápida de Fourier apresentado no item acima possui uma complexidade relativamente maior que o da multiplicação de matrizes apresentado no item 5.5, mas mesmo assim não é de grande complexidade. Nos item a seguir são apresentadas 
as etapas do ciclo de vida da metodologia $\mathrm{UMP}^{2} \mathrm{D}$ e sua utilização na resolução desse problema. Alguns dos diagramas ou etapas necessárias foram suprimidas.

\subsubsection{Coleta de Requisitos}

Nessa primeira etapa do ciclo de vida, é feita uma análise sobre o problema apresentado nos itens anteriores, com o intuito de coletar a maior quantidade de informações sobre o problema, como também recolher quaisquer informações que poderão ser utilizadas para implementar a aplicação em uma máquina paralela. Nesse item deve ser confeccionado um diagrama de Uses-Case, apresentando toda a interação com os usuários e entre as partes do problema, mas como essa interação é pequena, o diagrama pode ser suprimido.

A documentação resultante desta etapa é apenas um relatório contendo todas as informações coletadas durante essa fase. $\mathbf{O}$ relatório resultante desta fase pode possuir a aparência do item 5.6.1.

\subsubsection{Elaboração}

A fase de Elaboração necessita da documentação confeccionada na etapa de Coleta de Requisitos para a elaboração dos outros diagramas da metodologia UMP2 D. Para a confecção e verificação desses diagramas essa etapa utiliza-se de três fases: análise, projeto e análise de desempenho.

\subsection{Análise}

Na Figura 45 é apresentado o diagrama de classes confeccionado a partir das informações contidas no relatório. Nesse diagrama são apresentadas quatro classes, a classe Escal-FFT, responsável por dividir as tarefas, a classe Vetor, a classe Calculador, responsável por calcular a parte transformada rápida de Fourier, e a classe Inversa, que inverte binariamente o vetor resultante da classe Calculador.

A classe Escal-FFT é o controlador de toda a aplicação, possuindo como principais funções: o cálculo dos dados que serão passados para as instâncias da classe Calculador, a distribuição desses dados para os processadores e a ativação os processos em paralelo. Essa 
classe também é responsável por fazer a leitura inicial do vetor, mostrar os dados do vetor de entrada e apresentar o vetor com os resultados.

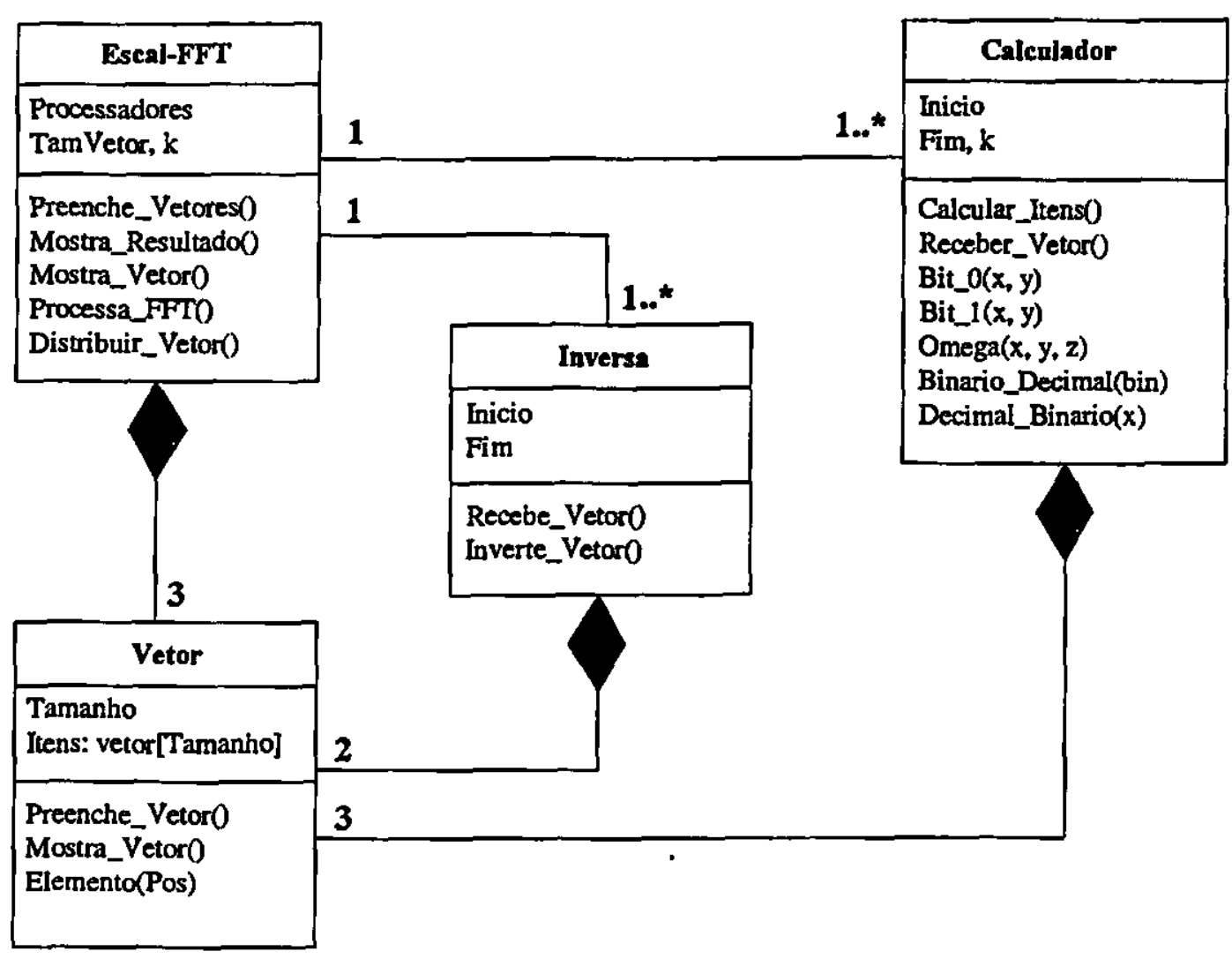

Figura 45 - Diagrama de Classes - Transformada de Fourier

A segunda classe a ser apresentada é a classe Calculador, que é ativada a partir da classe Escal-FFT, sendo uma classe serva ou escrava. Essa classe possui apenas a funçāo de calcular a transformada rápida de Fourier para cada um dos elementos do vetor de entrada. A classe Calculador possui métodos para receber o vetor com os valores da classe EscalFFT, fazer o cálculo do BIT_0, do BIT_l, e de OMEGA.

Uma outra classe responsável pelo cálculo da transformada rápida de Fourier é a Inversa, que apenas faz a inversão binária do vetor resultante. Para a inversāo ela recebe o vetor calculado, a posição inicial e a final do vetor a ser invertido. 
A última classe pertencente a esse modelo é a classe Vetor que possui propriedades de um vetor, sendo possível mostrar o vetor inteiro, receber os dados e armazená-los e colocar ou mostrar uma determinada posição do vetor.

As classes Calculador e Inversa possuem relacionamentos com a classe Escal-FF onde uma instância da classe Escal-FFT pode se relacionar com várias instâncias dess duas classes. A classe Vetor possui um tipo de relacionamento diferente com as outr classes, a agregação. Por exemplo, pode haver 3 instâncias da classe vetor dentro da clas Escal-FFT. Esse relacionamento de agregação é representado pelo losango preenchido.

Depois de confeccionado o diagrama de classes, representando o modelo sistema, passa-se para a proxima fase, o projeto.

\subsection{Projeto}

Na fase de projeto deve-se definir toda a estrutura da aplicação, como também aspecto: referentes à máquina paralela utilizada e o mapeamento dos objetos nos elementos de processamento. A documentação utilizada pela fase de projeto é o relatório da Coleta de Requisitos e o diagrama de classes confeccionado na fase de Análise.

A primeira tarefa a ser cumprida nessa fase é a revisão do diagrama de classes, que é apresentado na Figura 45. Após a revisão do diagrama de classes é necessária a definição do modelo de interação entre as classes, onde é apresentada a comunicação entre os objetos pertencentes ao diagrama de classes. Essa interação pode ser apresentada de dois modos, o diagrama de Colaboração e o diagrama de Seqüência. Para facilitar o entendimento da comunicação entre os objetos e a coleta de dados de comunicação, carga e eficiência, os dois diagramas são apresentados.

Nos dois diagramas será suprimida a classe Vetor, por não ser de grande importância para a coleta de informações sobre processamento paralelo. Na Figura 46 é apresentado o diagrama de Colaboração. A classe Escal-FFT envia a mensagem Receber_Vetor para todos os objetos da classe Calculador instanciados em diversas máquinas, os dados enviados durante essas mensagens são o vetor $a$ e os inteiros tam $e k$ (esses dados são mostrados entre chaves). 


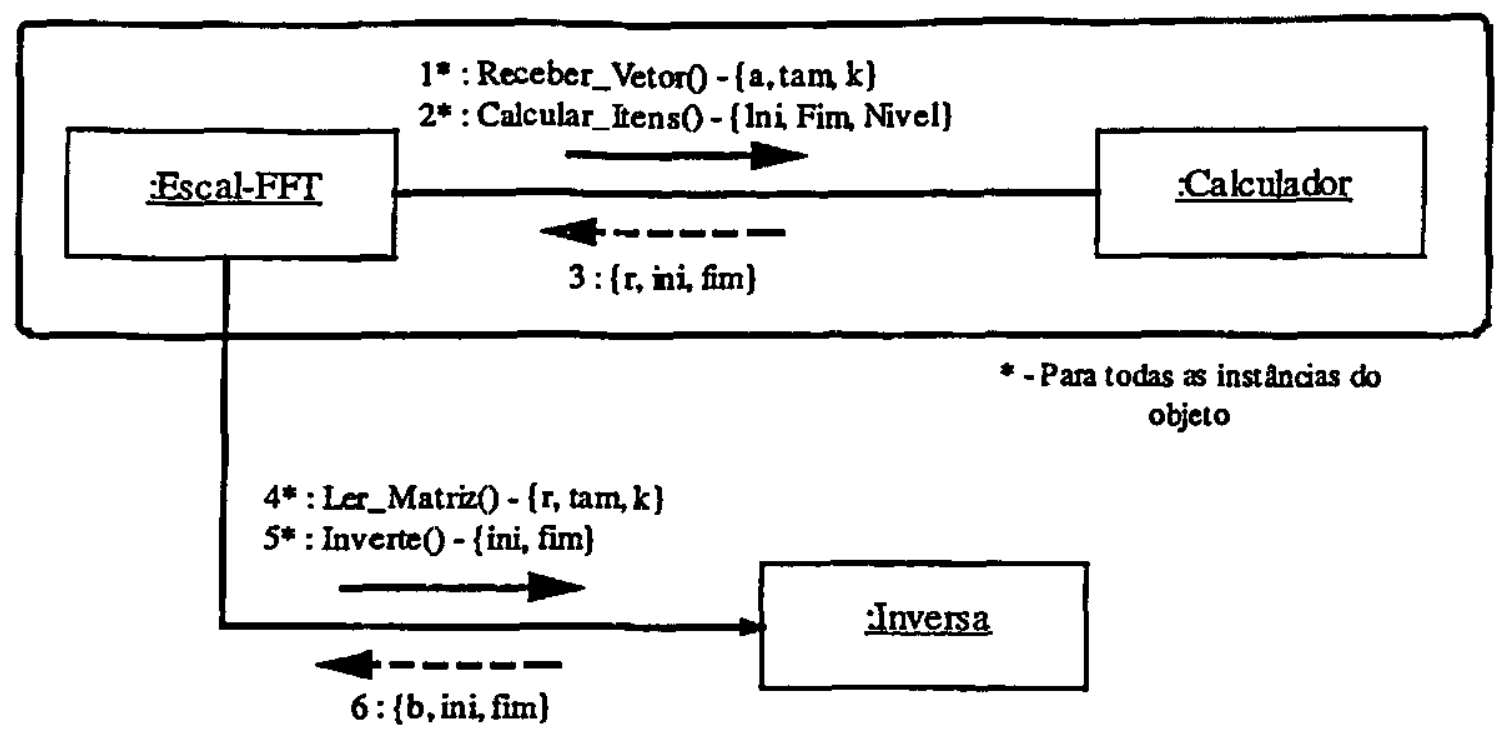

Figura 46 - Diagrama de Colaboração - Transformada de Fourier

A segunda mensagem enviada, também para todas as instâncias da classe Calculador, é a Calcular_Itens. Essa mensagem leva os inteiros ini e fim que correspondem a posição inicial e final. As instâncias do objeto Calculador enviam para a classe Escal-FFT uma mensagem contendo o vetor resultante $r$, e os inteiros ini e fim. Essa mensagem de retorno é representado por uma seta tracejada.

As mensagens 1,2 e 3, assinaladas pelo retângulo são repetidas $k$ vezes, ou seja. para cada nível do cálculo da transformada rápida de Fourier essas mensagem são enviadas.

A mensagem Receber_Vetor é enviada para todas as instâncias da classe Inversa, e o seu conteúdo é $r$ do tipo vetor, e tam do tipo inteiro, representando o vetor e seu tamanho. Após seu recebimento pelas instâncias da classe inversa, outra mensagem é enviada, a mensagem Inversa, contendo dois inteiros representando a posição inicial e final do vetor, para a inversão binária. Os objetos da classe Inversa após a inversão retornam uma mensagem contendo um vetor $b$ e dois inteiros ini e fim, sendo esse retomo representado por uma seta tracejada. 


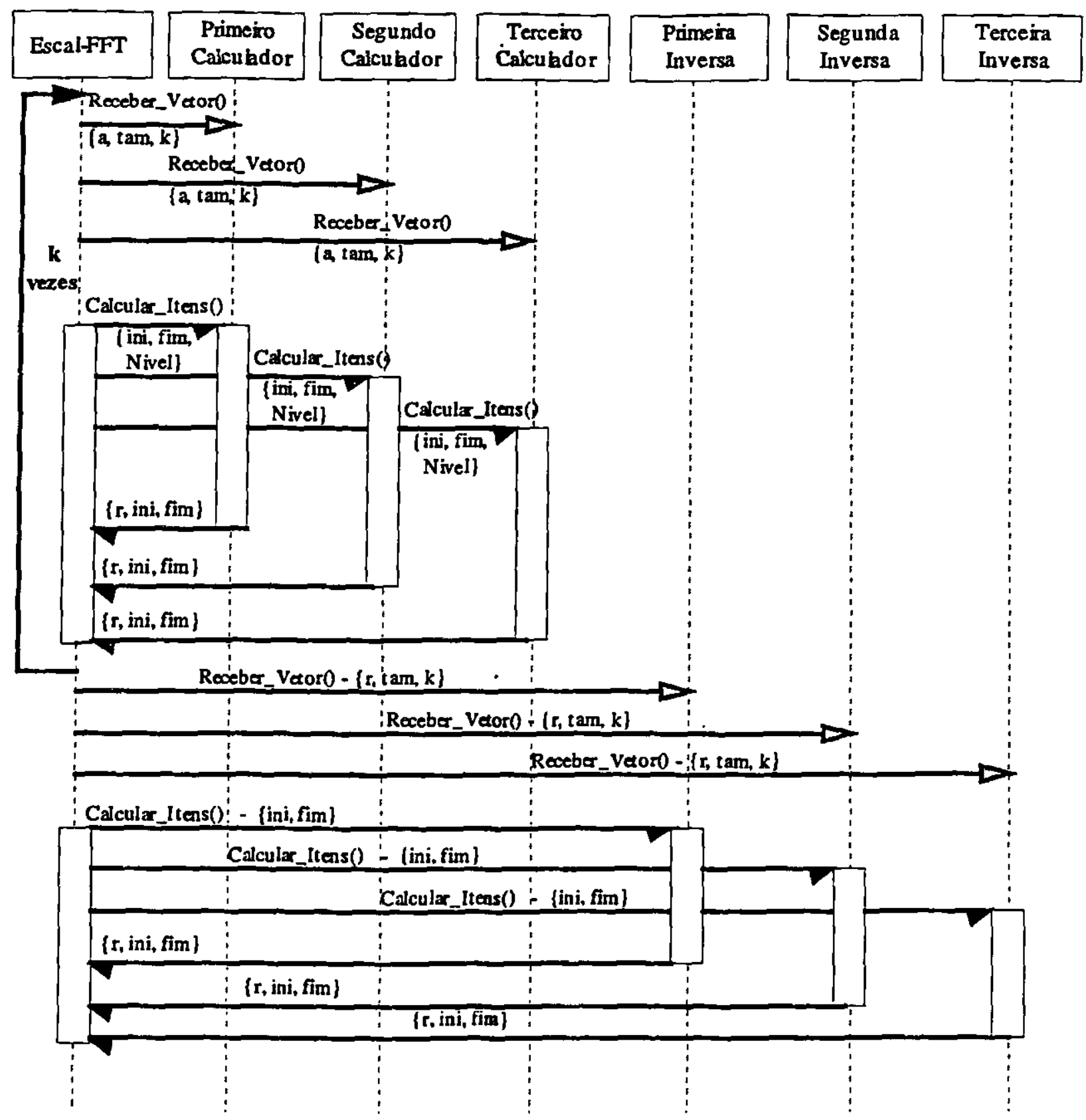

Figura 47 - Diagrama de Seqüência - Transformada de Fourier

O segundo diagrama utilizado para representar a comunicação entre os componentes da aplicação é o diagrama de sequiência, que é apresentado na Figura 47. Nesse diagrama é apresentada a execução dos métodos no domínio do tempo, podendo-se visualizar o paralelismo, a passagem de mensagens e o tempo de espera dos processadores que estão em paralelo. Através desse diagrama é possível verificar que a classe Escal-FFT envia dados primeiramente para os objetos calculadores e depois para os Inversores. 
Na primeira instância são enviadas mensagens Receber_Vetor para todos os calculadores, contendo uma variável $a$ do tipo vetor e as duas variáveis inteiras tam e $\mathrm{k}$. Depois de recebido os vetores, são enviadas mensagens de Calcular_Itens, contendo duas variáveis inteiras ini e fim. No final da execução são enviadas mensagens de retorno contendo um vetor $\mathrm{r}$ e dois valores inteiros ini e fim. Depois do recebimento das mensagens pelo objeto da classe Escal-FFT, o mesmo procedimento é feito com respeito aos objetos da classe Inversa.

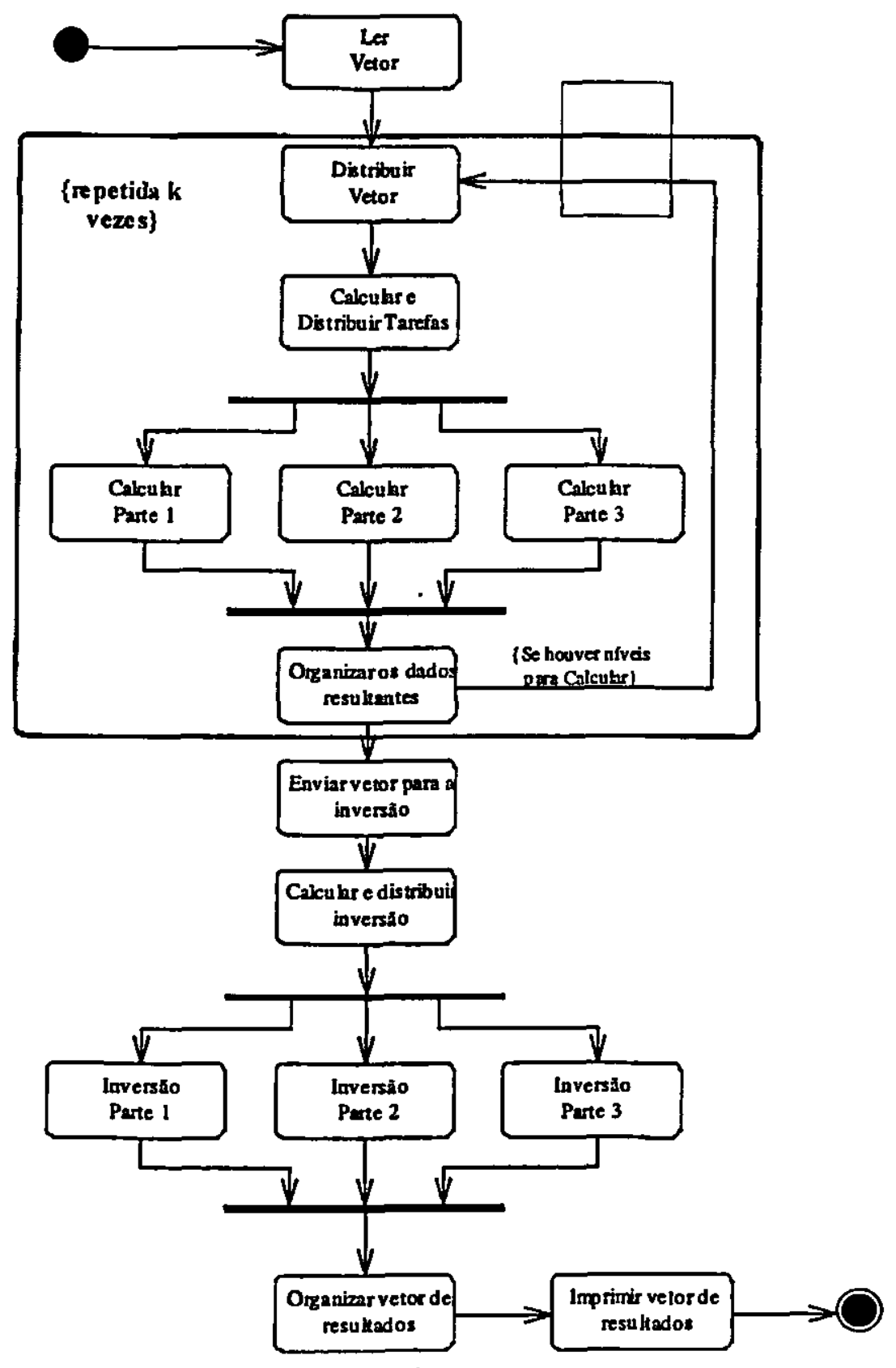

Figura 48 - Diagrama de Atividades - Transformada de Fourier 
O próximo passo a ser seguido é o modelo de atividades, que é representado pelo diagrama de atividades. Esse diagrama é apresentado na Figura 48. Através desse diagrama é possível verificar todo o funcionamento da aplicação, ou seja, os passos a serem seguidos, e as atividades que estão sendo executadas em paralelo.

No diagrama de Atividades é possível ver todas as tarefas a serem realizadas para a conclusão da Transformada de Fourier. Inicia-se lendo o vetor, que é distribuido e finalmente mostrando os calculadores em paralelo. Após a execução em paralelo, os dados são agrupados e depois enviados para os Inversores, para que estes façam a inversão concorrentemente.

O próximo diagrama a ser confeccionado é o diagrama de Máquina Paralela, ou seja, o diagrama contendo as máquinas utilizadas para a execução da aplicação. Esse diagrama é o mesmo do estudo de caso da multiplicaçāo de matrizes Figura 38. Após o diagrama de máquina paralela é necessário o mapeamento dos objetos nas máquinas definidas, utilizando o diagrama de Deployment, apresentado na Figura 49.

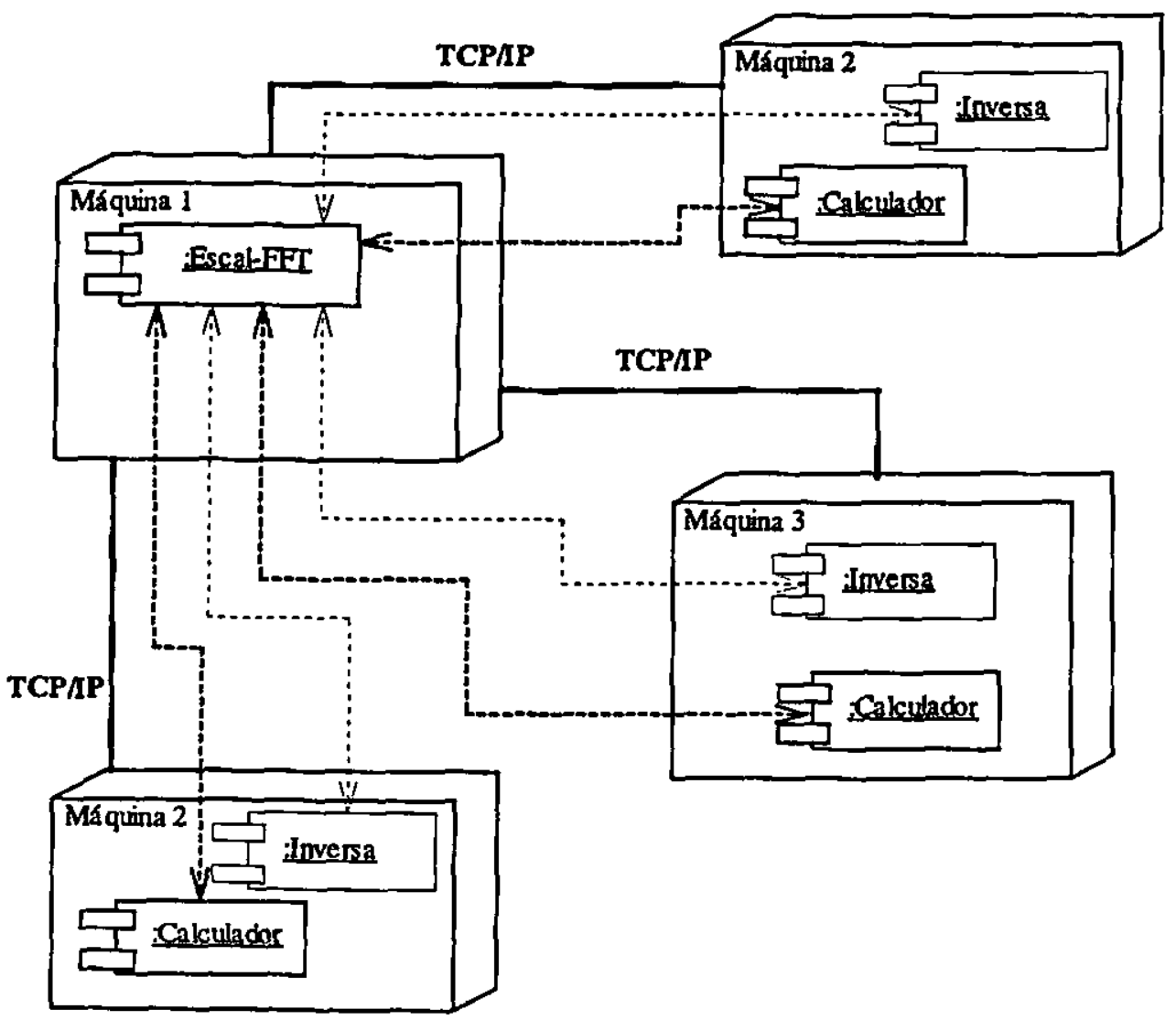

Figura 49 - Diagrama de Deployment - Transformada de Fourier 
Nesse diagrama é possível visualizar que na máquina 1 está apenas o objeto da classe Escal-FFT, pois esta máquina está responsável por coordenar toda a operação da aplicação e nas máquinas 2, 3 e 4 estão instâncias dos objetos Calculador e Inversa, que são responsáveis pelo trabalho de cálculo da transformada. Essas máquinas estão interligadas por linhas de comunicação utilizando o protocolo TCP/IP.

O diagrama de Pacotes foi suprimido devido a pequena complexidade do problema, a exemplo do caso da multiplicação de matrizes. A próxima e última fase da elaboração é a Análise de Desempenho.

\subsection{Análise de Desempenho}

Na etapa de Análise de Desempenho o desenvolvedor deve fazer uma análise sobre o modelo confeccionado. Através dessa análise é possível verificar que se repete o ocorrido na multiplicação de matrizes, ou seja, as tarefas possuem o mesmo tamanho, possuindo portanto carga igual a 1 e houve a necessidade novamente da mensagem broadcast para todos os elementos calculadores, evitando o envio de várias mansagens.

Para conseguir um bom balanceamento de carga é extremamente necessário uma análise sobre o software resultante. Essa etapa é de maior importância nos casos em que as tarefas possuem cargas diferentes.

\subsubsection{Implementação}

A etapa de implementação é responsável pela codificação da aplicação. Para a implementação da Transformada Rápida de Fourier foi utilizada a linguagem orientada a objetos $\mathrm{C}++\mathrm{e}$ a biblioteca de passagem de mensagens PVM++.

A primeira tarefa a ser executada é a definição das classes utilizando a linguagem $\mathrm{C}++$, com base no modelo de classes elaborado durante a fase de Análise da etapa de Elaboração. Pode-se utilizar para vetor uma classe já definida.

A definição das classes começa pela classe Escal-FFT, responsável pela divisão das tarefas e dos dados, como também pela leitura e impressão dos vetores. A estrutura da classe Escal-FFT é apresentada abaixo. 


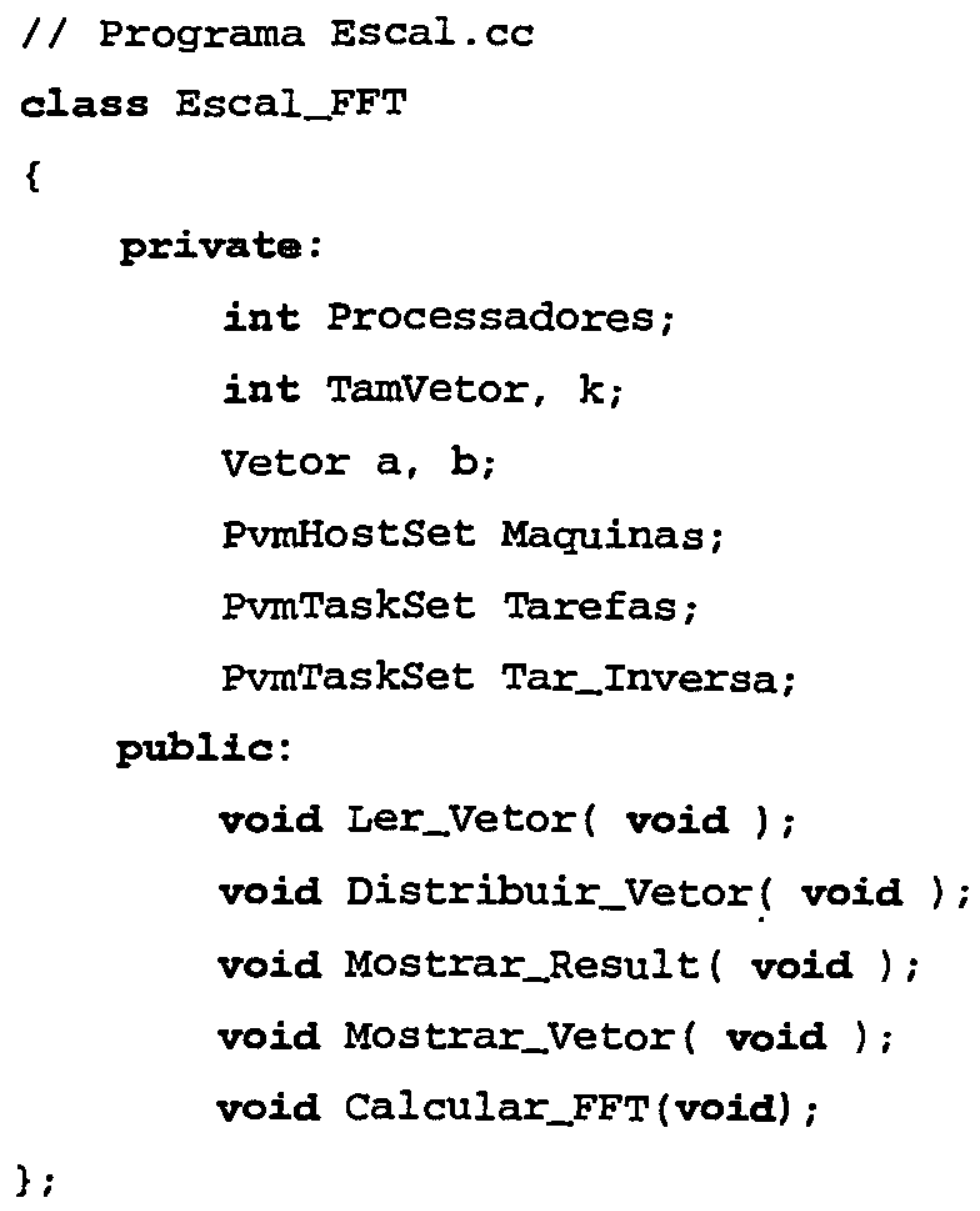

Na classe Escal-FFT foi necessária a inclusão de duas outras estruturas para facilitar a implementação da aplicação. A variável Maquina do tipo PvmHostSet, que representa as máquinas pertencente à máquina paralela virtual, a variável Tarefas do tipo PvmTaskSet, que representa os objetos da classe Calculador que estão sendo executados pela aplicação, e a variável Tar-Inversa do tipo PvmTaskSet, representando os objetos da classe Inversa que estão sendo executados. Essas variáveis são necessárias, uma vez que essa classe é responsável pela coordenação de toda a execução da aplicação.

Também foram feitas duas instânciaș do objeto Vetor, $a$ e $b$. Essas instâncias foram feitas devido ao relacionamento de agregação entre a classe Vetor e a classe Escal-FFT.

A segunda classe definida é a classe Calculador, que é responsável por grande parte do cálculo da transformada rápida de Fourier, e é instanciada em cada uma das máquinas 
utilizadas para a execução da aplicação. Por esse motivo deve ser codificada em um outro arquivo. Sua definição é mostrada a seguir.

// Calc.cc

class Calculador

l

private:

int inicio;

int final;

int $k_{i}$

Vetor s, $r$;

PvmTask Origem;

public:

void Calcular_Itens ( void );

void Receber_Vetor( void);

int BIT_o( int, int);

int BIT_I( int, int);

int OMEGA ( int, int, int);

int Bin_Dec( Bin);

Bin Dec_Bin( int);

\};

$\mathrm{Na}$ classe Calculador também foram inseridos algumas variáveis e métodos. As variáveis $r$ e $s$ foram inseridas por causa da agregaçāo e a variável Origem foi colocada para representar a origem da mensagem. O método Bin_Dec $\varepsilon$ utilizado para a transformação de binário e decimal e o Dec_Bin tem a função inversa, ou seja, transformar de decimal para binário. Esses métodos foram inseridos para a utilização nos métodos BIT_0, BIT_1 e OMEGA, evitando duplicação de código.

A última classe definida é a classe inversa, responsável pela inversão binária do vetor resultante do cálculo da transformada rápida de Fourier, também instanciada em cada 
um dos elementos processadores pertencentes a máquina paralela virtual. Sua definição é mostrada no trecho de código abaixo.

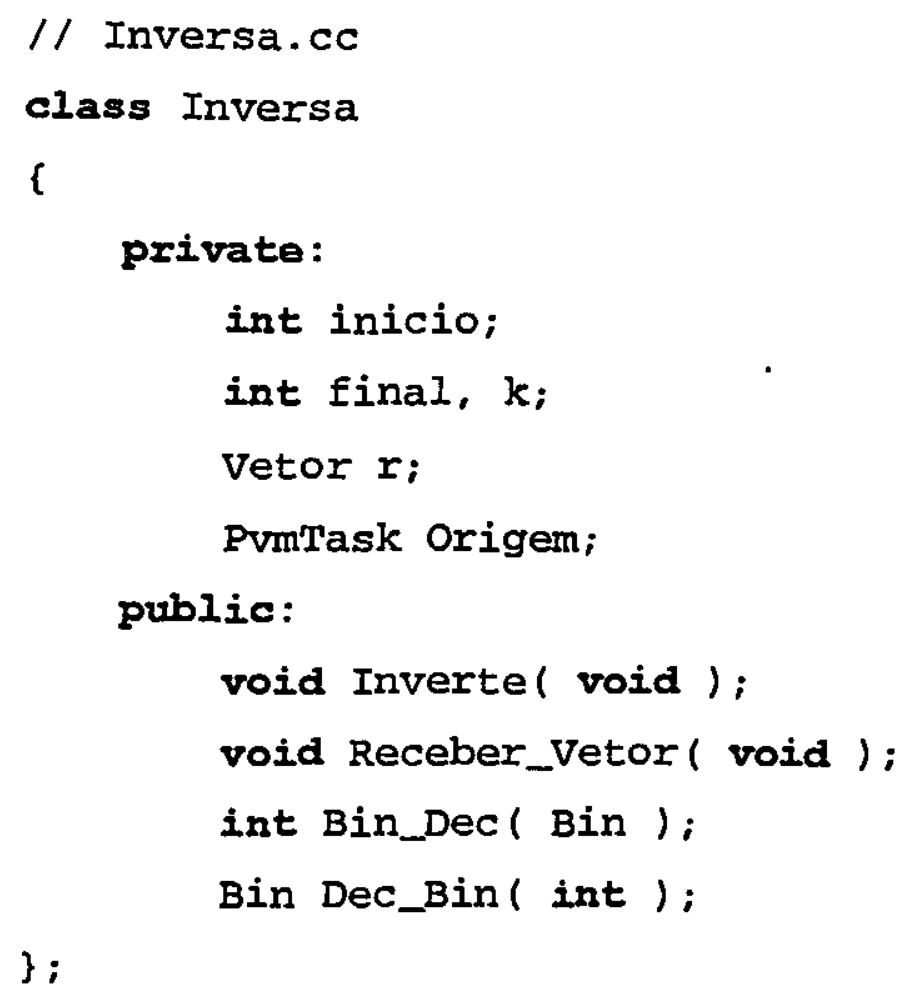

A classe Inversa também foi acrescida de algumas variáveis e métodos, como as variáveis $r$ e Origem e os métodos Bin_Dec e Dec_Bin que possuem a mesma função da classe calculador.

Após a definição da estrutura das classes, são apresentadas as estruturas utilizadas na comunicação entre os programas. Antes das estruturas, é necessário a definição de algumas constantes. Essas constantes são apresentadas abaixo.

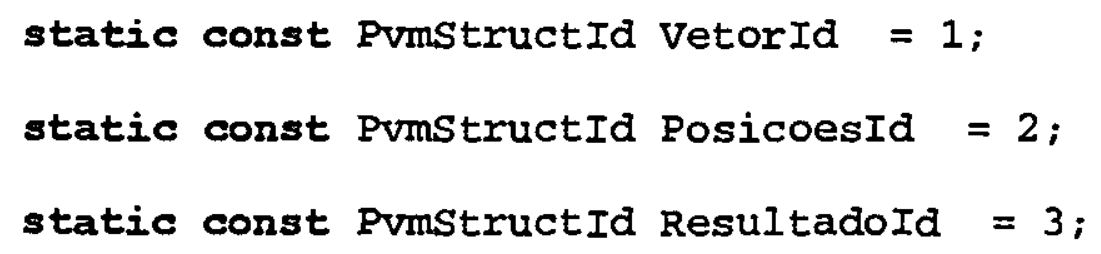

Essas constantes representam identificadores para as mensagens enviadas, sendo a constante VetorId o identificador da estrutura Vetor_Mensagem, a PosicoesId o 
identificador da estrutura Posicoes_Mensagem e a Resultadold o identificador de Resultado_Mensagem. Depois de definidas as constantes, são apresentadas as estruturas utilizadas para a resolução do problema.

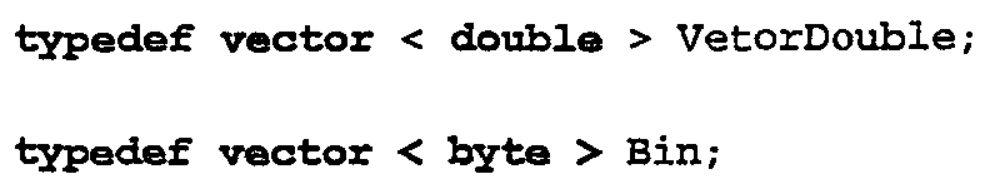

O tipo VetorDouble é o mesmo definido na multiplicação de matrizes, sendo portanto um vetor unidimensional do tipo double. Esse tipo é utilizado pelas estruturas de comunicação e também pode ser utilizado a classe vetor. A estrutura Bin é utilizada pelos métodos BIT_0, BIT_1, OMEGA da classe Calculador e pelo método Inverter da classe Inversa.

As próximas estruturas são utilizadas especialmente para comunicação sendo derivadas da classe PvmStruct. Essas estruturas compõesm são as mensagens enviadas entre os componentes da aplicação.

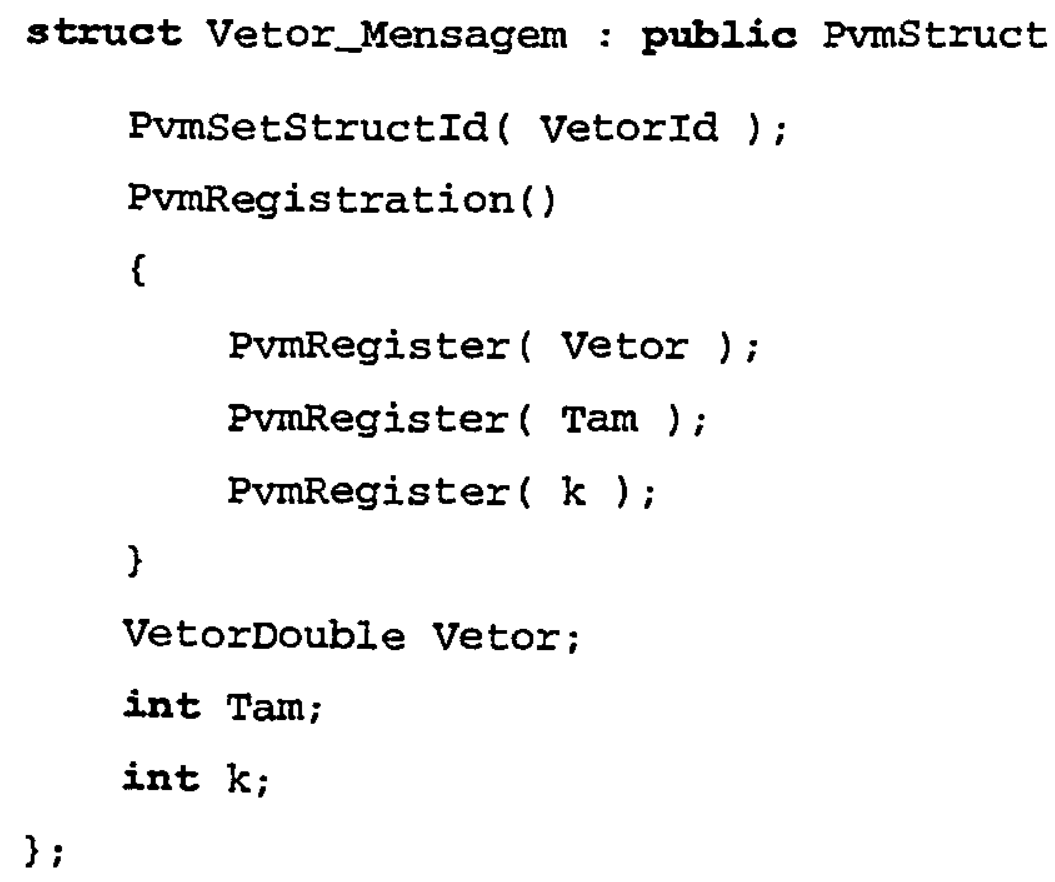

A Vetor_Mensagem é a estrutura utilizada para enviar um vetor juntamente com o seu tamanho e também a variável $k$, entre o objeto da classe Escal-FFT e as instâncias das 
classes Calculador e Inversa. Essa estrutura possui como identificador da mensagem a constante VetorId. A estrutura Posicoes_Mensagem é utilizada para o envio da posição inicial e final a ser calculada pelos objetos da classe Calculador e da classe Inversa.

struct Posicoes_Mensagem : public PumStruct

\{

PvmSetStructId( PosicoesId);

PumRegistration()

l

PvmRegister( Ini );

PvmRegister( Fim);

PvmRegister( Nivel);

\}

int Ini;

int Fim;

int Nivel;

\} ;

Essa estrutura é formada por dois inteiros representando a posição inicial e posição final do vetor a serem calculadas e um outro inteiro representando o nível a que pertence este cálculo. $O$ identificador dessa estrutura é a constante PosicoesId.

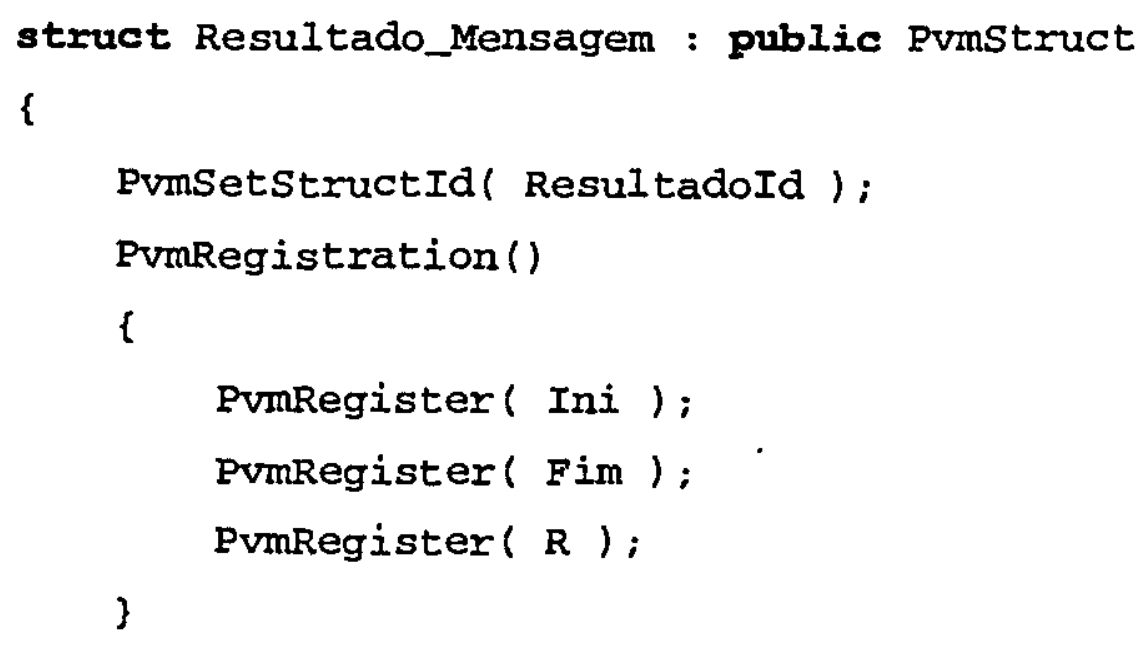


int Ini;

int Fim;

VetorDouble $R$;

\};

A estrutura Result_Mensagem é responsável pelo envio dos dados resultantes das operaçōes realizadas nos objetos da classe Calculador e Inversa para o objeto da classe Escal-FFT, responsável por montar o vetor resultante. Essa estrutura possui um elemento do tipo VetorDouble, que é a vetor calculador no objeto e duas variáveis do tipo inteiro que simbolizam as posições inicial e final do vetor que é montado pelo objeto do tipo EscalFFT.

Depois de definidas todas as constantes, classes e estruturas utilizadas para a resolução do problema, os principais métodos de cada uma das classes são apresentados, ou seja, aqueles métodos que tratam da comunicação e do cálculo da transformada rápida de Fourier. Os primeiros métodos apresentados são aqueles pertencentes a classe Escal-FFT, os métodos Distribuir_Vetor() e Calcular_FFT().

O método Distribuir_Vetor() é responsável por localizar todas as máquinas pertencentes a máquina paralela virtual e colocá-las na estrutura Maquinas, ativar instâncias do objeto Calculador e Inversa em todas as máquinas e inserir essas tarefas nas estruturas Tarefas e Tar_Inversa respectivamente, e enviar a todos os elementos da estrutura Tarefas o vetor de entrada, juntamente com seu tamanho, utilizando a estrutura Vetor_Mensagem. A implementação do método Distribuir_Vetor é apresentada abaixo.

void EscaI_FFT: :Distribuir_Vetor( void )

\{

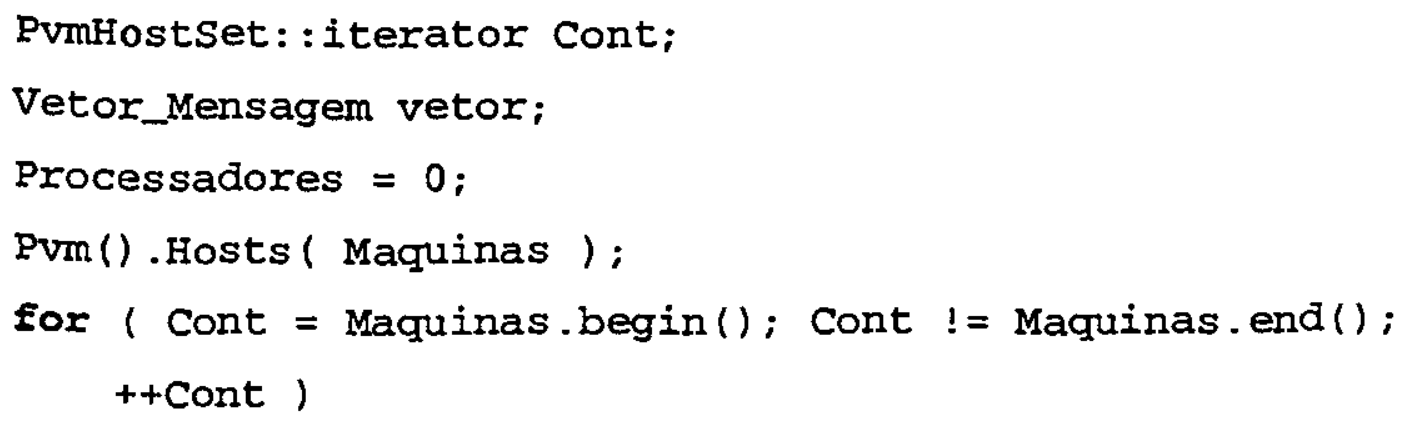




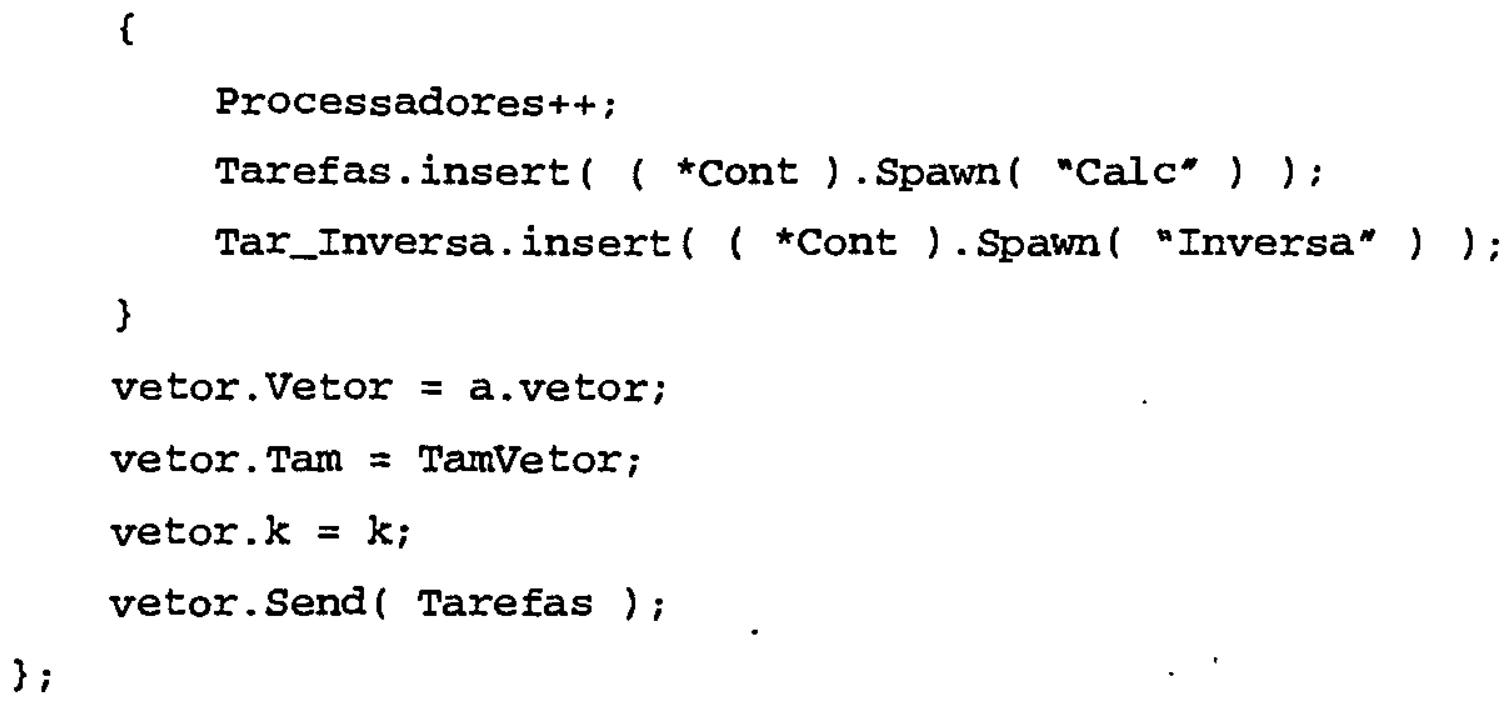

O segundo método apresentado é o Calcular_FFT, que é responsável por dividir as posições do vetor que serão executadas por cada um dos objetos do tipo Calculador, preencher mensagens do tipo Posicoes_Mensagem e enviar para cada um desses objetos, receber os resultados referentes ao cálculo da transformada e uni-los em um vetor até que todos os níveis sejam calculados, somente após isto, enviar o vetor resultante para todas as instâncias da classe Inversa, preencher mensagens do tipo Posicoes_Mensagem e enviá-las para as instâncias dessa classe e por fim receber os resultados finais dos objetos da classe inversa e montar o vetor resultante. A implementação deste método é representada pelo código abaixo.

void Escal_FFT: :Calcular_FFT( void )

\{

Resultado_Mensagem $r$;

Posicoes_Mensagem Pos:

Vetor_Mensagem vetor;

PvmTask Origem;

int $i$;

int $j$;

int 1 ;

int QPosicoes;

QPosicoes $=$ int ( TamVetor / Processadores ); 


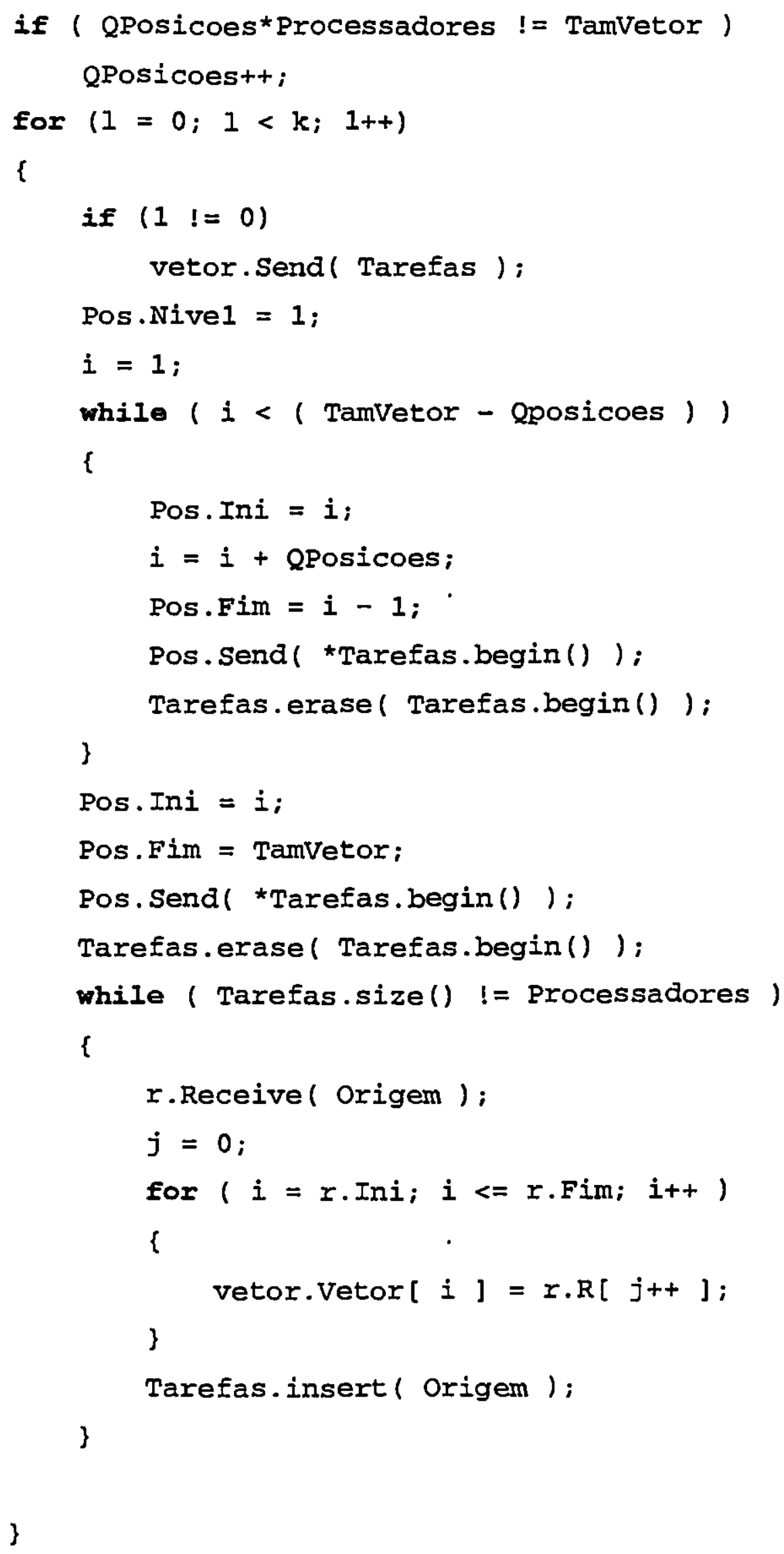




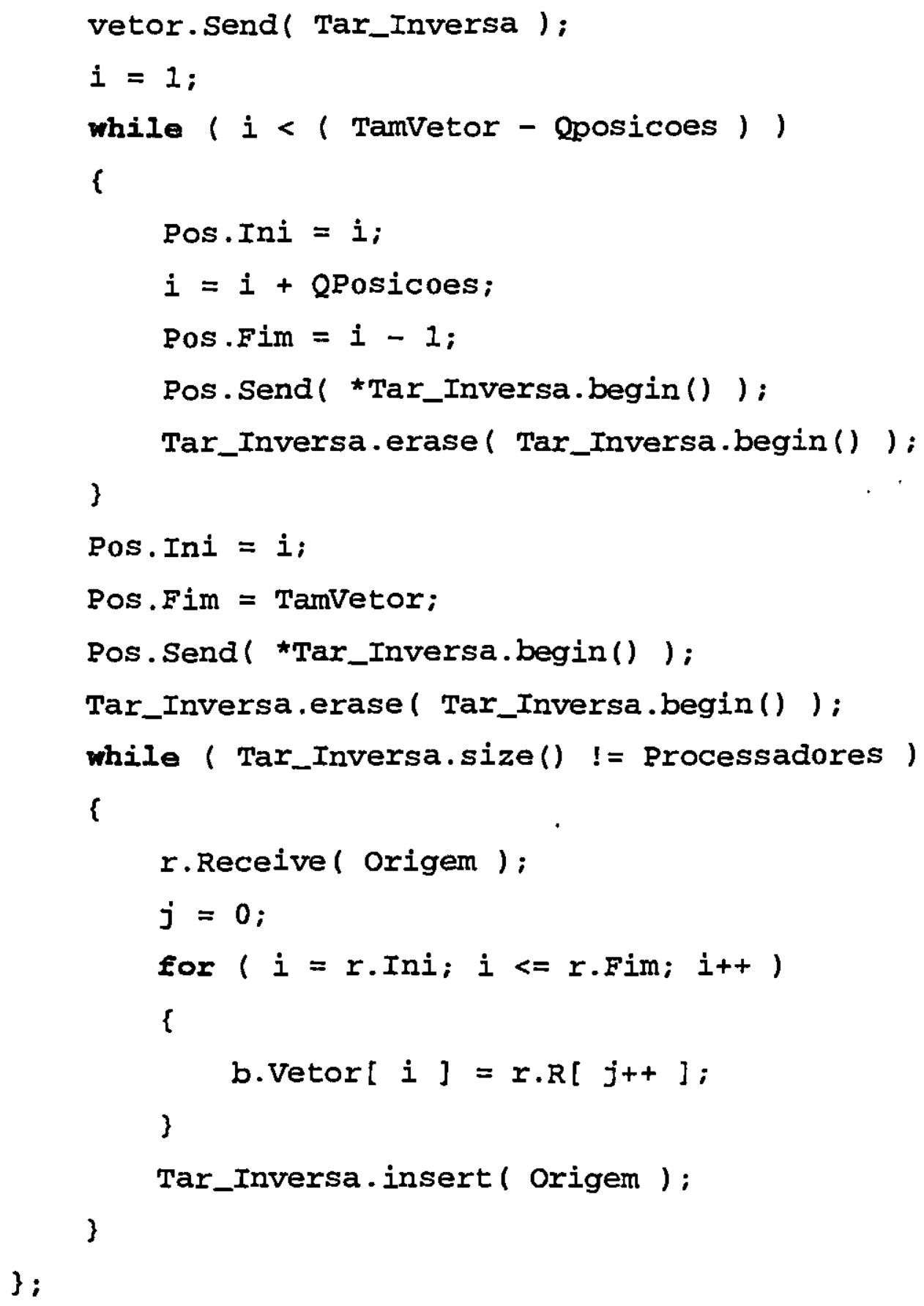

A classe Calculador é responsável pela principal parte do cálculo da transformada rápida de Fourier. Dessa classe são apresentados apenas os métodos Receber_Vetor, responsável por receber os dados do objeto da classe Escal_FFT e Calcular_Itens responsável pelo cálculo e envio dos resultados. Os métodos BIT_0, BIT_1 e OMEGA, não serão apresentados pois já foram explicados de forma gráfica. A implementação do método Receber_Vetor é apresentada a seguir: 
void Calculador: :Receber_Vetor( void )

\{

Vetor_Mensagem vetor;

Origem $=$ Pvm().I().Parent ();

vetor.ReceiveFrom ( Origem );

$r$. Vet $=$ vetor. Vetor;

$r \cdot$ Tamanho $=$ vetor $\cdot$ Tam;

$\mathrm{k}=$ vetor. $\mathrm{k}$;

\} ;

O código correspondente ao método Calcular_Itens da classe Calculador é apresentado na sequîuencia.

void Calculador: :Calcular_Itens ( void )

\{

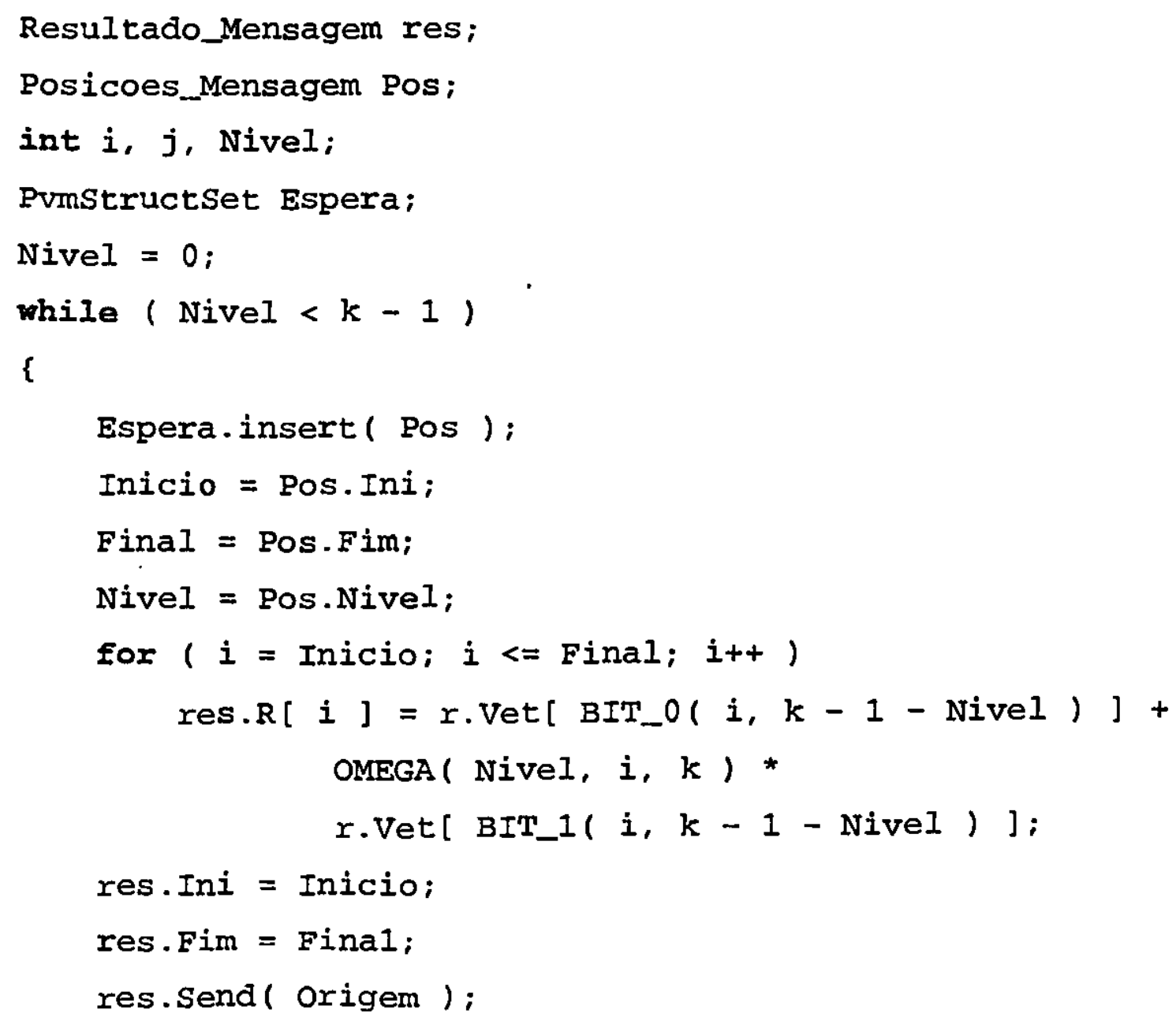




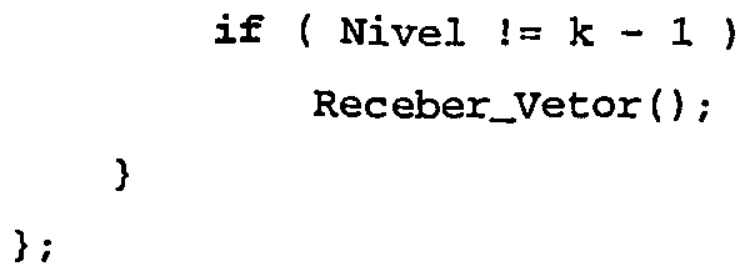

Esse código é responsável por fazer os cálculos das posições do vetor representadas por Inicio e Final, em todos os níveis do cálculo, desta forma executando as seguintes tarefas:

1. Receber as posiçōes a serem calculadas e colocá-las nas variáveis Inicio e Fim do objetos da classe Calculador, como também colocar o nível a ser calculador na variável Nivel;

2. Calcular todas as posições do vetor que estão entre Inicio e Final e colocá-las na mensagem result e enviá-la para o programa representado por Origem;

3. Enquanto não forem calculados todos os níveis, receber o vetor no próximo nível e retorna para a primeira tarefa.

A classe Inversa possui dois métodos, semelhantes aos da classe Calculador, o método Receber_Vetor que possui a mesma função do Receber_Vetor da classe Calculador, e o método Inverter que é responsável por receber as posiçōes a serem invertidas, fazer a inversão binária a ele atribuída e por fim enviar os resultados para a classe Escal-FFT, para que a mesma possa organizar o vetor de resultados. A implementação do método Inveter é representada pelo código abaixo.

void Inversa: : Inverter( void )

\{

Resultado_Mensagem result;

Posicoes_Mensagem Pos;

int $i, j, 1$;

Bin NBinario, BinInv;

int NDecimal;

PvmStructset Espera; 


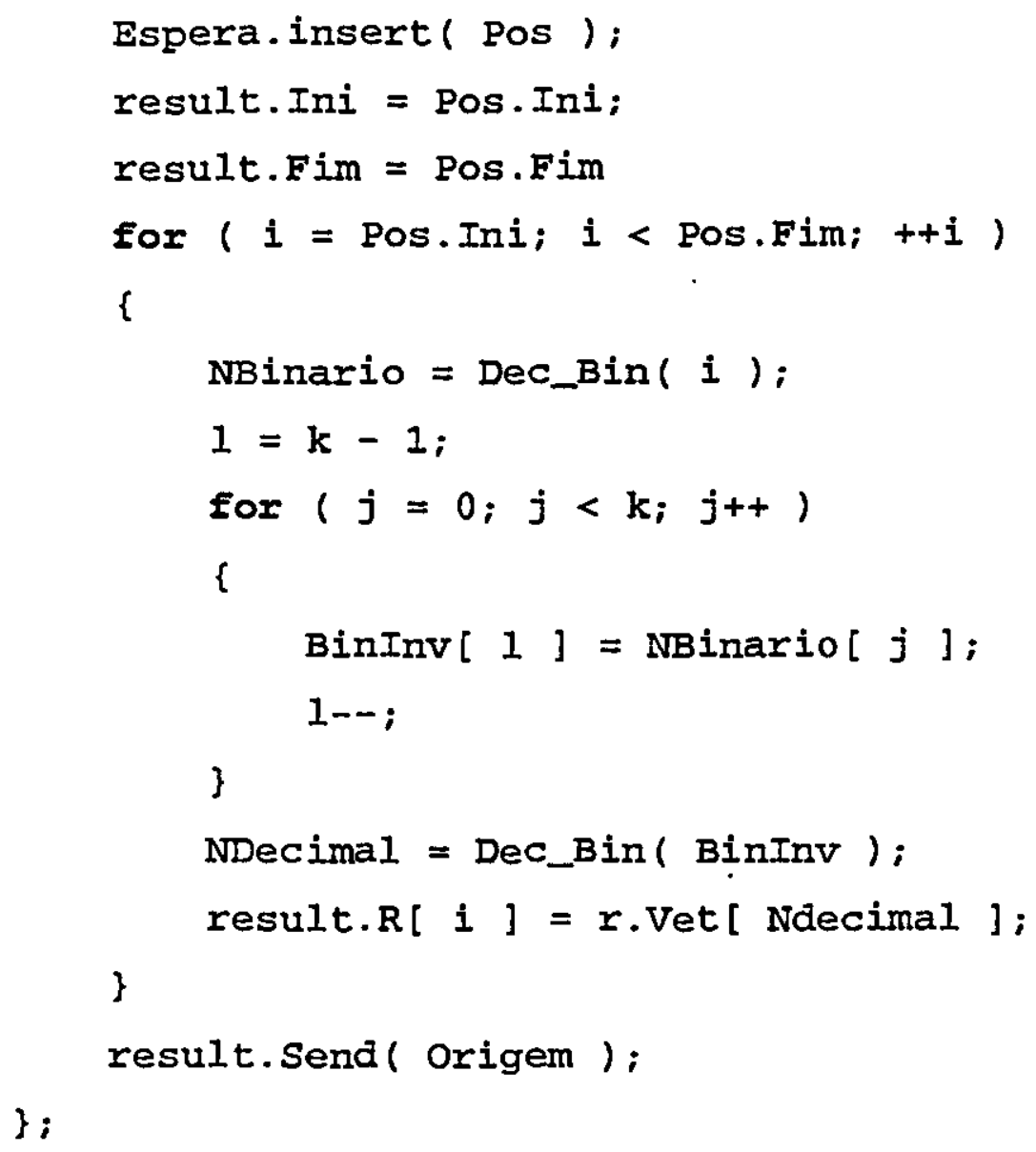

O último método a ser apresentado faz a inversão binária das posições do vetor. Para realizar essa operação o método recebe a posição inicial e final a ser invertida, transforma o inteiro representado por $i$ para a forma binária, faz a inversão dos bits desse número binário, transforma-o novamente em decimal e atribui ao vetor da mensagem Result na posição i, o conteúdo da posição i invertida binariamente e finalmente envia o vetor resultante para o objeto Escal_FFT.

\subsection{Considerações Finais}

Neste capítulo foi apresentada a metodologia $\mathrm{UMP}^{2} \mathrm{D}$, que foi definida para 0 desenvolvimento de aplicações paralelas, com a utilização da UML como linguagem de modelagem.

Entre os principais tópicos detalhados neste capítulo estão o ciclo de vida desta metodologia, suas fases e tarefas pertencentes a mesma, os diagramas utilizados para a 
confecção do modelo da aplicação a ser desenvolvida, a ordem de utilização destes diagramas e as ferramentas e recursos utilizados para tratar as necessidades das aplicações paralelas.

Este capítulo também apresentou dois estudos de caso utilizando a metodologia desenvolvida. Para esses estudos foram utilizados problemas clássicos de processamento paralelo. A partir desses estudos de caso foi possível verificar que a utilização da metodologia, o processo de desenvolvimento fica mais detalhado e a documentação completa e consistente para uma posterior fase de manutenção.

No próximo capítulo será feita a definição de uma ferramenta para auxiliar na utilização da metodologia apresentada neste trabalho, mostrando-se os possíveis módulos a serem implementados e suas funções. 


\section{Ferramenta CASE para o Método UMP²D}

\subsection{Consideraçōes Iniciais}

No quinto capítulo foi apresentada a metodologia $U \mathrm{UP}^{2} \mathrm{D}$ que integra as metodologias atuais da engenharia de software e a programação paralela, com o intuito de tornar as aplicaçōes paralelas mais eficientes e de mais fácil manutenção. Para alcançar esse objetivo foi utilizada a UML, juntamente com um processo que visa o desenvolvimento deste tipo de aplicação.

Neste capítulo será apresentada uma proposta de ferramenta para auxiliar na utilização da metodologia definida. No item 6.2 são apresentadas as razões da necessidade dessa ferramenta, juntamente com as características essenciais para a mesma. $O$ item 6.3 apresenta a estrutura interna dessa ferramenta, os módulos que a compõe e também as características e o propósito de cada um desses módulos.

\subsection{Caracteristicas Essenciais da Ferramenta}

A principal característica para uma ferramenta que automatize o método proposto é a integração entre suas funções, pois uma metodologia que é executada de forma totalmente manual ou que utiliza várias ferramentas isóladas para a conclusão do projeto não atende os requisitos atuais da engenharia de software.

A utilização de um ambiente CASE integrado é ideal para a automatização desta metodologia, pois atende a todas as fases da metodologia, permitindo a elaboração dos diagramas de maneira fácil e rápida, tornando possível a troca de informações sem a necessidade de digitá-las novamente em outra ferramenta.

Uma outra característica importante nesse tipo de ferramenta é a interface gráfica, que deve ser simples e amigável ao usuário e ainda ser bem difundida no meio acadêmico, onde estão seus principais usuários. $\mathrm{A}$ interface $\mathrm{X}$-Windows do Unix é aquela que mais se enquadra neste requisito, devido ao fato do Unix ser o sistema operacional mais utilizado para o desenvolvimento e utilização de aplicações paralelas, e o X-Windows é o ambiente gráfico mais utilizado nesse sistema operacional. 
Um terceiro requisito desse ambiente integrado é a linguagem de programação utilizada na implementação. $O$ ideal é essa linguagem esteja disponível para vários sistemas operacionais como também para vários tipos de máquinas, sua utilização seja livre e sem a necessidade de licença de uso, e ainda, que seja bem difundida dentro do meio acadêmico. Uma linguagem que se enquadra nesse prospecto é a linguagem $\mathrm{C}++$.

Outro requisito bastante importante para a implementação de uma ferramenta que utilize esse método é a linguagem a ser utilizada para a implementação dos métodos das classes definidas com a ferramenta, ou seja, o código fonte a ser gerado pela ferramenta. Essa linguagem deve ser Fortran, $\mathrm{C}$ ou $\mathrm{C}++$ ou suas extensões. Essas linguagens são as mais utilizadas no desenvolvimento de programas paralelos e são de conhecimento de grande parte dos cientistas ligados a essa área de conhecimento.

$O$ último requisito de grande importância para o ambiente é a comunicação entre os processos. Essa comunicação pode ser feita de duas formas: a utilização de primitivas da própria linguagem que está sendo utilizada, caso essa seja uma linguagem paralela, ou a utilização de uma biblioteca de passagem de mensagens.

Em máquinas MIMD de memória distribuída, a forma ideal de comunicação é através da passagem de mensagens. Para implementar a passagem de mensagens podem ser utilizadas bibliotecas de comunicação. As principais bibliotecas utilizadas para a implementação das aplicações paralelas são PVM e a MPI. Devido a grande utilização dessas bibliotecas, a ferramenta deve utilizar qualquer uma das duas bibliotecas citadas.

\subsection{Componentes da Ferramenta}

Para que a ferramenta supra todas as necessidades do desenvolvimento de aplicações paralelas, é necessário o desenvolvimento de vários módulos.

Esses módulos são responsáveis pelas etapas da metodologia que devem ser cumpridas para se conseguir os propósitos desejados. Esses módulos trocam informações entre si, gerando uma base de dados complexa, que é responsável por toda a integridade $\mathrm{e}$ facilidade na construção dos modelos. 


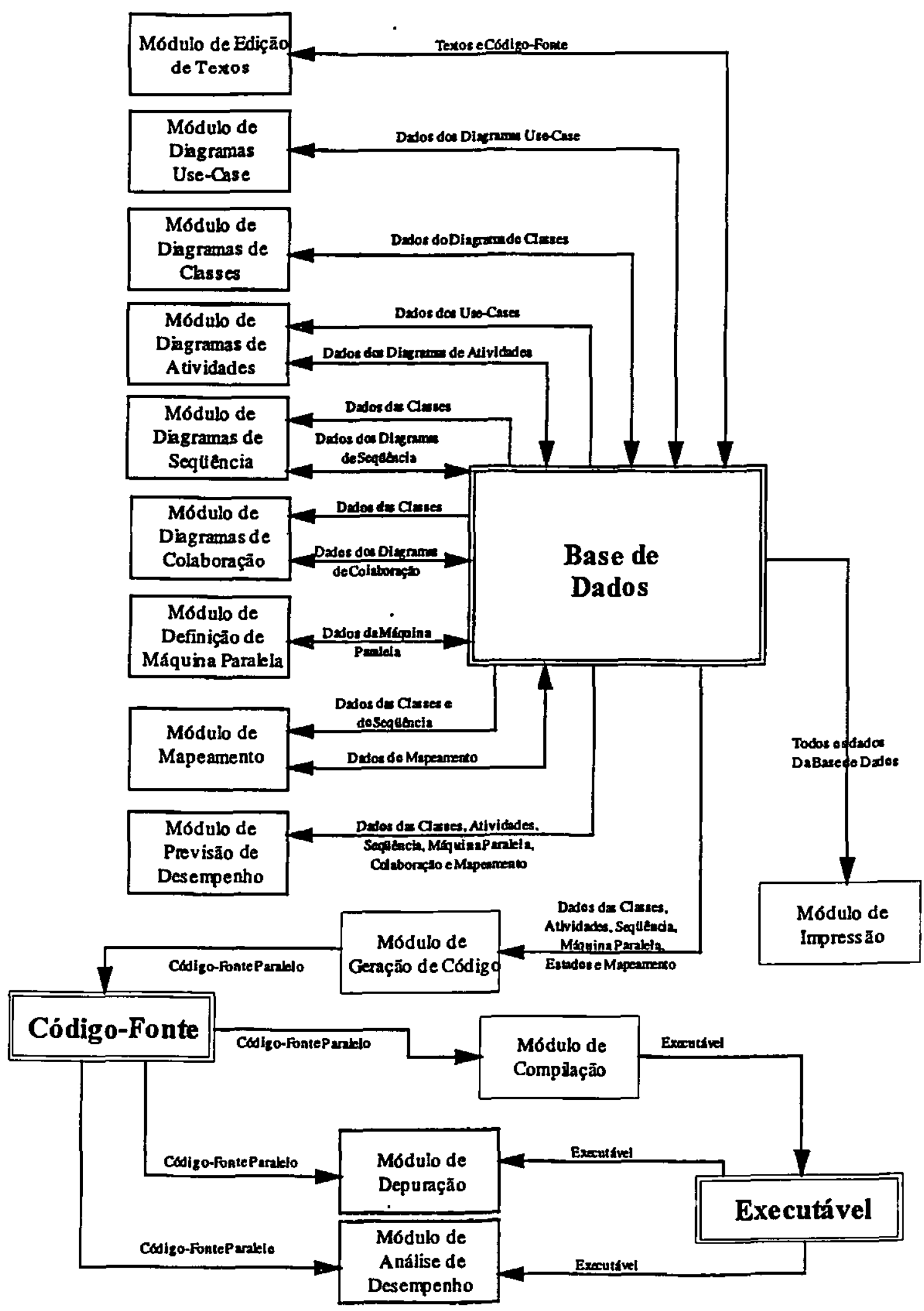

Figura 50 - Estrutura Interna da Ferramenta 
A figura 50 apresenta a estrutura interna dessa ferramenta e a interação entre os módulos. Esses módulos são apresentados abaixo.

1. Módulo de Edição de Textos;

2. Módulo de Diagramas Use Case;

3. Módulo de Diagramas de Classe;

4. Módulo de Diagramas de Seqiîencia;

5. Módulo de Diagramas de Colaboração;

6. Módulo de Diagramas de Atividades;

7. Módulo de Definição da Máquina Paralela;

8. Módulo de Mapeamento;

9. Módulo de Análise e Previsão de Desempenho;

10. Módulo de Geração de Código;

11. Módulo de Compilação;

12. Módulo de Depuração;

13. Módulo de Análise de Desempenho;

14. Módulo de Impressão.

Nos itens abaixo são apresentadas as funçøes e atividades relacionadas a cada um desses módulos, como também as informações que serão armazenadas na base de dados para interação entre os módulos.

\subsubsection{Módulo de Edição de Textos}

O módulo de Edição de Textos é responsável pela edição dos requisitos da aplicação e da descrição do problema a ser resolvido, para que essas informações sejam impressas juntamente com o manual do sistema da aplicação. Quando utilizado com esse propósito, durante a fase de Coleta de Requisitos, as informaçðes de entrada e aquelas geradas por esse módulo são úteis apenas para o módulo de impressão. 
Uma outra tarefa importante desse módulo, na fase de Implementação, é a edição do código referente aos métodos de cada uma das classes do diagrama de classes. Essa codificação deve ser feita em uma das linguagens disponíveis e sem a utilização de chamadas às bibliotecas de comunicação.

Esse módulo quando utilizado para a implementação das classes, gera informações que serão armazenadas na base de dados, e posteriormente utilizadas pelo módulo de geração de código na geração dos programas juntamente com as chamadas às bibliotecas de comunicação. Essas informações são também utilizadas pelo módulo de impressão para a confecção do manual da aplicação.

\subsubsection{Módulo de Diagramas Use Case}

Apesar de não ser muito utilizado esse tipo de diagrama no desenvolvimento de aplicações paralelas, é interessante a sua implementação para que a documentação seja mais detalhada, principalmente quando o ambiente for utilizado para o desenvolvimento de aplicações de grande porte e com interação com o usuário.

Quando não houver muita interação com o usuário, o desenvolvedor pode ignorar esse estágio do desenvolvimento. Nesse módulo, durante a fase de Coleta de Requisitos, o desenvolvedor elaborará o diagrama use cases para a especificação dos requisitos da aplicação.

Esse módulo deve contar com facilidades para alteração dos diagramas, sem destruir o modelo anteriormente diagramado. As informaçōes de entrada, como também os dados gerados devem ser armazenados na base de dados, para a impressão do manual, e serão utilizados nos módulos de Diagrama de Seqüência e Diagrama de Colaboração, para a confecção de diagramas de interação.

\subsubsection{Módulo de Diagramas de Classes}

Esse módulo é o de maior importância para a ferramenta, pois nele é feita a edição do diagrama de classes, onde o desenvolvedor definirá, a partir de estudos sobre o problema, as classes que serão utilizadas na implementação do software. 
No módulo de Diagramas de Classes, além da confecção deste diagrama, ele também é responsável pela entrada dos dados de carga dos métodos. Nesse módulo deve ser possivel representar os relacionamentos entre as classes, os conceitos de generalização, especialização, especialização múltipla, agregação, além dos outros conceitos utilizados pela UML.

A implementação desse módulo deve permitir a alteração e movimentação das classes pertencentes ao modelo, como também a definição da interface destas classes, ou seja, colocar os métodos referentes a essa classe e seus parâmetros.

Esse módulo é utilizado durante a etapa de Elaboração, e as informações resultantes deste módulo, que devem ser armazenadas na base de dados, são utilizadas na confecção do manual e por todos os outros módulos de diagramação da ferramenta. Essas informações são nome das classes, atributos e métodos das mesmas, carga dos métodos, parâmetros dos mesmos, e outras informações de menor importância.

\subsubsection{Módulo de Diagramas de Seqüência}

O módulo de Diagramas de Seqüência permite a definição da interação entre as classes na forma de um diagrama de seqüência especificado pela UML. Através dele é possível mostrar a seqüência das mensagens passadas entre as classes do modelo, no domínio do tempo.

Esse módulo lê as informaçōes da base de dados referente as classes e aos use cases, que servirāo de base para a confeç̧ão dos diagramas. Além dessas informações o desenvolvedor deverá mostrar a interação e as mensagens passadas entre os objetos pertencentes ao modelo.

Esse módulo deve permitir a manutenção desse diagrama, seguindo as restrições desse tipo de diagrama, fazendo a verificação de existência das classes no diagrama de classes, como também as mensagens passadas e o conteúdo dessas mensagens.

As informações resultantes desse módulo são úteis para o módulo de Mapeamento para mostrar as mensagens enviadas entre as máquinas onde estão mapeados os objetos, e de grande importância para o módulo de Análise e Previsão de Desempenho, na verificação da eficiência do modelo. 
As informaçōes armazenadas nesses diagramas são os relacionamentos entre as classes, as mensagens passadas, a seqüência das operaçőes, além de informaçőes sobre a localização dos objetos no diagrama, que não possuem grande importância para os outros módulos.

\subsubsection{Módulo de Diagramas de Colaboração}

O módulo de Diagramas de Colaboração é responsável pelo desenvolvimento dos diagramas de colaboração entre as classes dentro de um use case. Esse tipo de diagrama permite visualizar como os objetos estão estaticamente conectados e as mensagens que são passadas entre os mesmos.

As informações da base de dados utilizadas por esse módulo são as mesmas do módulo de Diagramas de Sequiência, que também possui a função de mostrar a interação entre as classes. Esse tipo de diagrama é de grande utilidade para a visualização das mensagens, sendo utilizado na minimização da comunicação pelo módulo de Análise e Previsão de Desempenho e também pelo módulo de Mapeamento.

As informações de saída também são semelhantes, entre elas estão informações sobre os relacionamentos entre as classes, a ordem desses relacionamentos através de um esquema de numeração, e também o conteúdo das mensagens enviadas.

\subsubsection{Módulo de Diagramas de Atividades}

Com o auxílio deste módulo, o desenvolvedor definirá as atividades realizadas em um use case, um método, ou no sistema inteiro, não sendo possível a definição da localidade das atividades e a qual objeto pertence essa atividade. $O$ grande interesse da utilização desse diagrama é a definição das atividades realizadas dentro de um método, sendo de grande utilidade para o cálculo da carga do mesmo.

Para a confecção dos diagramas, o módulo necessita de informações armazenadas na base de dados provenientes do módulo de diagrama use case, caso o diagrama a ser desenvolvido seja referente a um use case, informações do diagrama de classes, caso o diagrama estiver referindo-se ao conteúdo de um método. Se esse diagrama de atividade for 
em relação à aplicação como um todo, necessita-se apenas informações da descrição do problema.

As informações de saída a serem armazenadas na base de dados são as atividades a serem executadas, a referência do diagrama, o posicionamento das atividades e outros componentes desse diagrama. Essas informaçōes são úteis para o módulo de impressão gerar o manual da aplicação e também para o módulo de Análise e Previsão do Desempenho, no cálculo da carga dos métodos dos objetos, através da análise da quantidade de atividades realizadas em cada um dos métodos.

\subsubsection{Módulo de Definição da Máquina Paralela}

O módulo de Definição da Máquina Paralela permite a definição da máquina destino para a aplicação, especificando os elementos de processamento, a conexão entre eles, seu poder de processamento e velocidade dos canais de comunicação.

$\mathrm{Na}$ definição dos elementos de processamento, o desenvolvedor deverá especificar o endereço IP (ou qualquer outro endereço de rede, conforme o sistema), como também o nome da máquina, para facilitar o entendimento e a localização dos processos.

Esse módulo não utiliza dados de outros módulos, ou da base de dados. Os dados são informados apenas pelo desenvolvedor. Os dados desse módulo são utilizados para a distribuição dos objetos nos elementos de processamento, através do módulo de Mapeamento, pelo módulo de Análise e Previsão de Desempenho no cálculo do balanceamento de carga e também pelo o módulo de Geração de Código na inserção das chamadas à biblioteca de passagem de mensagens.

\subsubsection{Módulo de Mapeamento}

O módulo de Mapeamento é responsável pela distribuição dos objetos nos elementos de processamento. Através dele é possível saber onde os objetos estarão localizados durante a execução da aplicação.

O mapeamento dos processos necessita de informações da base de dados, provenientes do módulo de Definição da Máquina Paraiela, dos elementos de 
processamento, e do módulo de Diagrama de Colaboração, onde é definida a cooperação entre os objetos e as mensagens utilizadas nessa comunicação.

As informações resultantes desse módulo são utilizadas para a verificação das necessidades das aplicações paralelas, no módulo de Análise e Previsão de Desempenho, e para a inclusão das chamadas à biblioteca de passagem de mensagens, no módulo de Geração de Código. Os dados armazenados são relacionamentos entre os elementos de processamento e os objetos.

\subsubsection{Módulo de Análise e Previsão de Desempenho}

O módulo de Análise e Previsão de Desempenho é o mais complexo dos módulos do ambiente, pois este é responsável por fazer uma estimativa da carga de cada um dos objetos, como também fazer a verificação nas mensagens passadas entre esses objetos, através do modelo criado pelos modulos anteriores, na tentativa de se conseguir um maior desempenho da aplicação.

Para essa análise, o módulo utilizará as informações da base de dados provenientes de vários módulos do ambiente. Dependendo do requisito a ser analisado, haverá a necessidade de diferentes informações. Entretanto, as informações de distribuição dos objetos nos elementos de processamento do módulo de Mapeamento e as informações dos elementos de processamento, provenientes do módulo de Definição da Máquina Paralela, são utilizadas em todas as análises.

Para o balanceamento de carga são necessários os dados do módulo de Diagramas de Classes, como classes, métodos e propriedades das classes. Do módulo de Diagramas de Colaboração, as mensagens, relacionamentos entre os objetos e parâmetros das mensagens. Do módulo de Diagramas de Atividades, as atividades referentes a cada um dos métodos para o cálculo da carga dos objetos e métodos.

Na minimização da comunicação são utilizados os dados dos diagramas de classes, e dos diagramas de colaboração. Caso houver muitas mensagens essas devem ser agrupadas para diminuir a comunicação. Na maximização da eficiência são utilizados basicamente os dados provenientes do módulo de Diagramas de Seqüência, como ordem de execução, 
objetos que serão executados em paralelo e as cargas dos objetos e métodos calculadas para o balanceamento de carga.

Os dados resultantes desses processamentos, enquanto o desempenho alcançado não for o satisfatório, são armazenados na base de dados temporariamente, apenas para a impressão do relatório das análises, através do módulo de impressão. Os dados deverão ser armazenados por definitivo quando o desempenho for satisfatório.

\subsubsection{Módulo de Geração de Código}

O modulo de Geração de Código é responsável pela geração do código-fonte da aplicação a partir do modelo desenvolvido. Essa tarefa é feita a partir dos diagramas elaborados e da codificação de cada um dos métodos feita através do editor de textos. Esse código-fonte é gerado de acordo com as informações da máquina paralela, da linguagem e da biblioteca utilizada.

Na geração do código da apilicação, esse módulo utiliza as definições armazenadas na base de dados da ferramenta provenientes dos módulos de Diagrama de Classes, do Diagrama de Colaboração e do Editor de Textos, que é responsável pelo auxílio na codificação dos métodos. Também são utilizadas informaçōes do módulo de Máquina Paralela, como endereçamento e nome das máquinas e do módulo de Mapeamento, principalmente quanto à localidade dos objetos e métodos.

As informaçס̄es resuitantes deste módulo, os programas, não são armazenadas na base de dados. Esses programas devem ser armazenados em arquivos separados para a sua posterior compilação pelo módulo de compilação.

\subsubsection{Módulo de Compilação}

O módulo de Compilação é responsável por transformar o código-fonte em código executável, fazendo a união da biblioteca de passagem de mensagens ao código final da aplicação.

Este módulo também não utiliza a base de dados da ferramenta. Ele recebe os arquivos gerados pelo módulo de geração de código, juntamente com os locais das 
bibliotecas utilizadas durante o processo de compilação e gera um código executável para a máquina destino da aplicação.

Para a maior eficiência deste módulo e integridade da aplicação resultante, podem ser utilizados bons compiladores para as linguagens utilizadas na implementação dos métodos. É necessária apenas sua adaptação ao ambiente a ser desenvolvido.

\subsubsection{Módulo de Depuração}

O módulo de Depuração é utilizado após a implementação e compilação das classes para correção de erros de codificaçăo localizados durante a etapa de compilação do código fonte, como também erros de lógica introduzidos durante a fase de codificação.

Com esse módulo deve ser possível a partir de uma só máquina fazer a execução linha a linha do programa, verificar as mensagens passadas entre os objetos, o conteúdo de algumas variáveis essenciais à resolução do problema.

$\mathrm{Na}$ implementação do módulo de Depuração é interessante a utilização de ferramentas já existentes que possam suprir de forma adequada às necessidades identificadas, dada à complexidade do seu desenvolvimento.

\subsubsection{Módulo de Análise de Desempenho}

O módulo de Análise de Desempenho é utilizado após a impiementação das classes, da geração do código paralelo e a compilação do mesmo. Esse módulo não utiliza dados da base de dados, apenas do código fonte gerado e do código executável da aplicaçāo.

Com esse módulo e é possível verificar a eficiência e o desempenho do software resuitante, como também o balanceamento de carga e as mensagens passadas entre os componentes da aplicação. Esse módulo é responsável também pela realimentação dos pesos dos objetos e métodos atribuídos durante a fase de elaboração, para se conseguir um melhor desempenho.

Nesse módulo, como no anterior, é de grande interesse a utilização de ferramentas já existentes como o Pablo e AIMS, pois o desenvolvimento desse tipo de ferramenta é de grande complexidade. 


\subsubsection{Módulo de Impressão}

O módulo de Impressão é importante para o ambiente pois através dele é possível a impressão da documentação do software, como também dos resultados das análises.

A documentação do software inicia com a descrição do problema, passa por todos os tipos de diagramas utilizados pela metodologia, até o código fonte implementado. Esse módulo utiliza informaçōes armazenadas na base de dados que são provenientes de todos os módulos do ambiente.

Com a descrição dos módulos é possível verificar a abrangência do ambiente CASE a ser desenvolvido para suprir as necessidades do método $U \mathrm{UP}^{2} \mathrm{D}$.

\subsection{Consideraçōes Finais}

Neste capítulo foi apresentada uma especificação preliminar de uma ferramenta CASE para a automatização da metodologia definida neste trabalho, mostrando suas principais necessidades, como também os módulos necessários para todas as etapas do desenvolvimento de uma aplicação paralela.

Em alguns dos módulos podem ser utilizadas ferramentas já desenvolvidas que possuam o código-fonte gratuito, no intuito de simplificar o desenvolvimento dessa ferramenta.

No próximo capítulo serão apresentadas as conclusões alcançadas no decorrer do projeto, como também algumas propostas para trabalhos futuros. 


\section{Conclusões e Trabalhos Futuros}

\subsection{Considerações iniciais}

A utilização de computadores na área científica vem se tomando cada vez mais intensa, principalmente na solução de problemas matemáticos, físicos e químicos. Esse tipo de aplicação exige grande poder computacional. Para se conseguir esse poder computacional a forma mais simples e barata é a utilização de várias unidades de processamento trabalhando de forma associativa na solução dos problemas, ou seja, o processamento paraielo.

Para a utilização das máquinas paralelas é necessário o desenvolvimento de aplicaçōes paraielas Esse desenvolvimento é uma tarefa complexa, devido ao fato deste tipo de aplicação possuir um grande potencial para comportamento não determinístico. Para a resolução deste problema podem ser utilizadas ferramentas para programação paralela, mas essas necessitam de metodologias de desenvolvimento de software para se conseguir aplicações corretas, com bom desempenho, aita qualidade e documentação completa. Este trabalho apresenta uma metodologia orientada a objetos para o desenvolvimento de aplicações paralelas.

A metodologia definida por este projeto utiliza como linguagem de modelagem a UML e um novo processo de desenvolvimento, que foi definido visando o desenvolvimento de aplicações paraielas. Esse processo tem como principal objetivo tratar de forma adequada os requisitos essenciais de uma aplicação paralela, que são o balanceamento de carga eficiente, a minimização da comunicação entre os processos que estão executando em máquinas diferentes e a maximização da eficiência da aplicação resultante.

Neste trabaiho também é definida a estrutura de uma ferramenta CASE que pode auxiliar na aplicação da metodologia $U \mathrm{MP}^{2} \mathrm{D}$ para 0 desenvolvimento de aplicações paralelas complexas, que exigem manutenção constante e documentação. 


\subsection{Contribuiçōes do Trabalho}

Este trabalho tem como principal contribuição a definição de uma metodologia orientada a objetos para o desenvolvimento de aplicações paralelas. Essa metodologia é baseada na linguagem UML e estende a sua utilização introduzindo novos diagramas e requisitos voltados especificamente para programação paralela.

Uma característica que torna essa metodologia realmente interessante é a possibilidade de se avaliar o balanceamento de carga através da atribuição de pesos para os métodos que serão executados em paralelo, como também a verificação da eficiência do algoritmo através do diagrama de seqüência, que torna possível visualizar uma estimativa do tempo ocioso dos processadores.

Os estudo de caso apresentados permitem uma avaliação inicial do potencial proporcionado pela metodologia, embora sua utilidade somente poderá ser perfeitamente julgada com a implementação da ferramenta CASE sugerida no capítulo 6 deste trabalho.

Outra contribuição importante deste trabalho é o documento [Oli98] que apresenta uma nova classificação para as ferramentas existentes de programação paralela e um resumo de cada uma das ferramentas revistas. Esse documento deverá ser mantido atualizado pelos alunos do LCAD-USP.

\subsection{Trabalhos Futuros}

Com a realização deste trabalho verificou-se a crescente utilização da programação paralela, como também o aumento das ferramentas disponíveis para o desenvolvimento deste tipo de aplicação. Com esses estudos verificou-se também a grande quantidade de trabalhos que podem ser realizados partindo da metodologia definida. Algumas propostas de trabalhos futuros podem ser citadas.

\subsubsection{Utilização da UMP²D no Desenvolvimento de uma Aplicação Paralela de Grande Porte}

Apesar dos casos de estudo apresentados ilustrarem a utilização da metodologia UMP² eles são muito simples para permitir uma avaliação mais criteriosa do método proposto. $O$ 
desenvolvimento de uma aplicação paralela real de grande porte permitiria o refinamento do método proposto. Essa atividade é bastante importante antes do empreendimento do esforço de desenvolvimento da ferramenta CASE proposta no capítulo 6 .

\subsubsection{Implementação da Ferramenta CASE}

Uma proposta de trabalho bastante interessante é a implementação da ferramenta CASE especificada no capítulo 6 . 0 esforço para o desenvolvimento dessa ferramenta é bastante grande e deve ser realizado em mais de um trabalho de mestrado. Para minimizar esse esforço é interessante analisar a possibilidade de utilização de ferramentas correlatas que tenham código fonte disponível, conforme sugerido no item seguinte.

\subsubsection{Utilização de Ferramentas Existentes na Implementação da Metodologia}

Este item propõe a seleção e utilização de ferramentas existentes (com código fonte disponível), para minimizar o esforço de desenvolvimento da metodologia apresentada. Essa abordagem foi utilizada no trabalho de mestrado do aluno Mário Augusto Andreta Carvaiho [Car99], realizado no LCAD-USP. 


\section{REFERÊNCIAS BIBLIOGRÁFICAS}

[Alm94] Almasi, G. S. and Gottlieb, A. Highly Parallel Computing - 2.Edition. The Benjamin Cummings Publish Company, Inc., 1994.

[Ama95] Amarasinghe, S. P.; Anderson, J. M.; Lam, M. S. and Tseng C.W. An Overview of the SUIF Compiler for Scalable Parallel Machines. Stanford University, Stanford, 1995.

[App89] Appelbe, B. and Smith, K. Start/Pat: A Parallel-Programming Toolkit. IEEE Software, pp. 29-38, July, 1989.

[Apr92] Applied Parallel Research. FORGE 90 Version 8.0 Baseline System User's Guide. California, April, 1992.

[Bar90] Barrett, G. The development of OCCAM: typec, classes and sharing. In OCCAM Users group: Real Time Systems with Transputers, 13, pp. 119-147, IOS Press, 1990.

[Bec96] Beckman, P.; Gannon, D.; and Johnson, E. Portable Parallel Programming in HPC H. Indiana University, Bloomington, 1996.

[Beg91] Beguelin, A.; Dongarra, J.; Geist, A.; Manchek, R.; Moore, K. and Wade, R. HeNCE: A user's guide (Draft). Oak Ridge National Laboratory, November, 1991.

[Beg91a] Beguelin, A.; Dongarra, J.; Geist, A.; Manchek, and Sunderam V. S. Graphical development tools for network-based concurrent supercomputing. In Proceedings of Supercomputing 1991, pages 435-444, Albuquerque, 1991.

[Beg94] Beguelin, A.; Dongarra, J.; Geist, A.; Manchek, R.; and Sunderam, V. A Users' Guide to PVM Parallel Virtual Machine. Oak Ridge National Laboratory. September, 1994.

[Bon94] Bonello, C.; Hurteau, G.; Dongen, V. V. and Gao, G. EPPP - An Integrated Environment for Portable Parallel Programming. Rapport Technique CRIM-EPPP-94/07-20, 1994.

[Boo91] Booch, G. Object-Oriented Design with Applications. Benjamin Cummings, Redwood City, CA, 1991. 
[Bra92] Brandes, T. Efficient Data Parallel Program without Explicit Message Passing for Distributed Memory Multiprocessors. GMD Technical Report - TR92-4, 1992.

[Bra92a] Brandes, T. ADAPTOR: Users guide. Internal Report Adaptor 2. German National Research Institute for Computer Science, October, 1992

[But92] Butler, R. and Lusk, E. User's guide to the p4 programming system. Technical Report ANL-92/17. Mathematics and Computer Science Division, Argonne National Laboratory, Argonne, October, 1992.

[Car76] Carakushansky, M. S. and La Penha, G. M. S. M. Introduçāo à Álgebra Linear. McGraw-Hill do Brasil, São Paulo, 1976.

[Car89] Carriero, N. and Gelernter, D. How to Write Parallel Programs: A guide to the perplexed. ACM Computing Survey, vol. 21, September, 1989.

[Car99] Carvalho, M. A. A. Um Ambiente de Desenvolvimento de Aplicaçōes Paralelas - Análise e Projeto Preliminar. Dissertação de mestrado. Universidade de São Paulo, Sāo Carlos, Novembro, 1999.

[Cas93] Casavant, T. L. and Kohl, J. A. The IMPROV Meta-Tool Design Methodology for Visualization of Parallel Programs. Invited Paper, International Workshop on Modeling, Analysis, and Simulation of Computer and Telecommunication Systems (MASCOTS), January, 1993.

[Cha91] Chapman, B.; Mehrotra, P. and Zima H. P. Vienna FORTRAN - A Fortran Language Extension for Distributed Memory Multiprocessors. In Compilers and Runtime Software for Scalable Multiprocessors, Amsterdam, 1991.

[Cha93] Chandy, K. M. And Kesselman, C. CC+t: A Declarative Concurrent Object Oriented Programming Notation. California Institute of Technology, Mach, 1993.

[Che93] Cheng, D. Y. A Survey of Parallel Programming Languages and Tools. NASA Ames Research Center, Report RND-93-005, March, 1993.

[Cle94] Clémençon, C.; Decker, K.M.; Endo, A.; Fritscher, J.; Jost, G.; Masuda, N., Müller, A.; Rühl, R.; Sawyer, W.; Sturler, E. and Wylie, B. J. N. Application-Driven Development of an Integrated Tool Environment for Distributed Memory Parallel Processors. Technical Report CSCS-TR-940. NEC SX-Center, Switzerland, January, 1994. 
[Cle95] Clémençon, C.; Endo, A.; Fritscher, J.; Müller, A.; Rühl, R. and Wylie, B. J. N. The "ANNAI" Environment for Portable Distributed Parallel Programming. In Proceedings of $28^{\text {th }}$ Hawaii International Conference on System Science (HICSS-28), Vol. II, pp. 242-251. IEEE Computer Society Press, January, 1995.

[Col96] Coleman, D. Desenvolvimento Orientado a Objetos: O Método Fusion. Editora Campus, Rio de Janeiro, 1996.

[Cra97] Cray Research, In. Introducing the Cray TotalView Debugger - Release 3.0. IN-2502 3.0. May, 1997.

[Dav92] Davoli, R.; Giachini, L. A.; Amoroso, A. and Alvisi, L. Parallel Computing in Networks of Workstations with Paralex. Technical Report UBLCS-924, October, 1992.

[Deb92] Debbage, M. and Hill, M. B. PARAPET: A Parallel Programming Environment Toolkit. University of Southampton, Parallel Application Center, November, 1992.

[Dev95] Devaney, J. E.; Lipmen R.; Lo, M. and Mitchell W.F. The Parallel Applications Development Environment (PADE). November, 1995.

[Don86] Dongarra, J. J. and Sorensen, D. C. SCHEDULE: Tools for Developing and Analyzing Parallel Fortran Program. Tech. Memo 86, Argonne National Laboratory, November, 1986.

[Don87] Dongarra, J. J. and Sorensen, D. C. SCHEDULE Users Guide. Argonne National Laboratory, June, 1987.

[Dun90] Duncan, $R$. A survey of parallel computer architectures. IEEE Computing Magazine, v. 23, p. 5-16, 1990.

[Eig93] Eigenmann, R. and Macclaughry, P. Practical Tools for Optimizing Parallel Programs. Center for Supercomputing research and Development, University of Illinois at Urbana-Champaign, 1993.

[Eli95] Elias, D. Introduction to Parallel Programming Concepts. Workshop on Parallel Programming on the IBM SP, Cornell Theory Center, 1995.

[Fin92] Finemam, C.; Hontalas, P.; Listgarnen, S. and Yen, J. A User's Guide to AIMS - Version 1.1. May, 1992.

[Fos89] Foster, I. and Taylor, S Strand New Concepts in Parallel Programming. Prentice Hall, 1989. 
[Fos92] Foster, I. T. and Chandy, K. M. Fortran M: A language for modular parallel programming. Mathematics and Computer Science Division, Argonne National Laboratory, Argonne, June, 1992.

[Fos95] Foster, I. Designing and Building Parallel Programs. Addison-Wesley, 1995.

[Fow97] Fowler, M.; Scott, K. UML Distilled: Applying the Standard Object Modeling Language. Addison-Wesley Pub Co. June, 1997.

[Fra95] Frang, N, and Burkhart, H: PEMPI: An Integrated Environment for Structured MPI Programming. University Basel, Department of Informatics.Presented in MPI Developers Conference, June, 1995

[Geh88] Gehani, N.H.; Roome, W.D. Rendezvous facilities: Concurrent $C$ and Ada language. IEEE Trans. on Software Engineering v.14, n.11. November, 1988.

[Geh92] Gehani, N.H.; Roome, W.D. Implementing Concurrent C. Software Practice and Experience, v.22, n.3, p.267-85. March, 1992.

[Gei90] Geist, G. A.; Heath, M. T.; Peyton, B. W. and Worley, P. H. PICL: A portable instrumented communications library. Technical Report TM11130. Oak Ridge National Laboratory, Oak Ridge, Tennessee, 1990.

[Gre92] Green, T. P. and Snyder, J. S. DQS, A Distributed Queuing System. DQS Documents, March, 1992.

[Gro92] Gropp, B. and Lusk, E. A test implementation of the MPI draft messagepassing standard. Mathematics and Computer Science Division, Argonne National Laboratory, 1992.

[Gup92] Gupta, A.; Chandra, R. and Hennesy, J. L. Integrating Concurrency and Data Abstraction in the COOL Parallel Programming Language. Technical Report CSL-TR-92-511. Computer Systems Lab, Stanford University, February 1992.

[Har92] Harrison, W. L. and Ammarguellat, Z PARCEL and MIPRAC: Parallelizers for Symbolic and Numeric Programs. National Science Foundation, May, 1992.

[Hea91] Heath, M. T. and Etheridge, J. A. Visualizing the Performance of Parallel Programs. IEEE Software, Vol. 8, No. 5, pp. 29-39, September, 1991. 
[Hen93] Hennesy, J. L.; Gupta, A. and Chandra, R. Data Locality and Load Balancing in COOL. Appear in the Symposium on Principles and Practices of Parallel Programming (PPoPP), May, 1993.

[Hig93] High Performance Fortran Forum. High Performance Fortran Language Specification - Version 1.0 Draft. January, 1993.

[Hur94] Hurteau, G.; Bonello, C.; Freehill, C.; Reiher, E. and Roque, J. M. Environment for Portable Parallel Programming: User's Guide. Rapport Technique CRIM-EPPP-95/03-18.Centre de Recherche Informatique de Montreal, Montréal, Québec, Canada, April, 1995.

[Iso91] ISO/IDE. Information technology - Programming languages - Fortran. Reference number ISO/IEC 1539:1991, 1991.

[Kal92] Kale, L.V. A Tutorial Introdnction to Charm. Internal Report, Parallel Programming Laboratory, Department of Computer Science, University of Illinois, Urbana-Champaign, 1992.

[Kal94] Kale, L. V. and Krishnan, S. CHARM+t: A Portable Concurrent Object Oriented system Based On C+H. Department of Computer Science, University of Illinois, Urbana-Champaign, 1994.

[Kes93] Kesselman, C.; Chandy, K. M. and, Carlin, P. The Compositional C+t Language Definition. Califomia Institute of Technology, Mach, 1993.

[Koh91] Kohl, J. A. and Casavant, T. L. Use of PARADISE: A Meta-Tool for Visualizing Parallel Systems. Proceedings of the Fifth International Parallel Processing Symposium (IPPS), Anaheim, California, pp. 561-567, May, 1991.

[Koh92] Kohl, J. A. and Casavant, T. L. A Software Engineering, Visualization Methodology for Parallel Processing Systems. Proceedings of the Sixteenth Annual International Computer Software\&Applications Conference (COMPSAC), Chicago, Ilinois, pp. 51-56, September, 1992.

[Lam91] Lam, M. S. Jade: a coarse-grain parallel programming language. In Proceedings of the Heterogeneous Network-Based Concurrent Computing Workshop, Tallahassee, October, 1991.

[Lar92] Larus, J. R.; Richards, B. e Viswanathan, G. C**: A Large-Grain, ObjectOriented, Data-Parallel Programming Language. Computer Science Department, University of Wisconsin-Madison, Madison, USA, November, 1992. 
[Lit88] Litzkow, M. J.; Livny, M. and Mutka, M. W. Condor - a hunter of idle workstations. In Proceedings of the 8th International Conference on Distributed Computing Systems, pages 104--111, San Jose, June, 1988.

[Lus92] Lusk, R. and Butler, R. Portable parallel programming with p4. In Proceedings of the Workshop on Cluster Computing, Tallahassee, December, 1992.

[Mac92] Macclaughry, P. E. PTOPP - An Practical Tool set for the Optimization of Parallel Programs. University of Illinois at Urbana-Champaign, 1992.

[Mar96] Martins S. L. Ferramentas para Programação Paralela em Ambientes de Memória Distribuída. Pontifícia Universidade Católica do Rio de Janeiro, Departamento de Ciência da Computação, Janeiro, 1996.

[May93] May, J. and Berman F. Panorama: a portable, extensible parallel debugger. SIGPLAN Notices, pp. 96-106, December, 1993.

[Me192] Melax S.; Lu, G. P.; Parsons, L.; Schaeffer, J.; Smith, C. and Szafron, D. The Enterprise Model for Developing Distributed Applications. TR 92-20. Department of Computing Science, University of Alberta, 1992.

[Nav89] Navaux, P. O. A. Introduçāo ao Processamento Paralelo. Revista Brasileira de Computação, vol. 5, no. 2, Rio de Janeiro, Outubro/Novembro, 1989.

[New92] Newton, P. and Browne, J. C. The CODE 2.0 Parallel Programming Language. Proc. ACM International Conference on Supercomputing, July, 1992.

[New95] Newton, P. and Dongarra, J. Overview of VPE: A Visual Environment for Message-Passing Parallel Programming. 1995.

[Nik94] Nikhil, R. S. CID: A Parallel, 'Shared-Memory' C for DistributedMemory Machine. Cambridge Research Laboratory, Digital Equipment Corporation, September, 1994.

[Noe93] Noe, R. J.; Reed, D. A.; Aydt, R. A.; Roth, P. C.; Shields, K. A.; Schwartz, B. and Tavera, L. F. Scalable Performance Analysis: The Pablo Performance Analysis Environment. Proceedings of the Scalable Parallel Libraries Conference, IEEE Computer Society, 1993.

[Oli98] Olivete, A. L.; Carvalho, M. A. A. and Trindade, O. Uma Classificação das Ferramentas para Programaçāo Paralela Disponíveis - Revisão e 
Disponibilidade. Relatório Técnico em formulação. Universidade de São Paulo, São Carlos, 1998.

[Omg99] Object Management Group Inc. OMG Unified Modelling Language Version 1.3. January, 1999.

[Pad93] Padua, D. A.; Eigenmann, R.; Hoefinger, J.; Petersen, P.; Tu, P.; Wearterford, S. and Faigin, K. Polaris: A New-Generation Parallelizing Compiler for MPPs. Uniyersity of Ilinois, R\&D Status Report, June, 1993.

[Per96] Perez, P. A. S. P2D - Um Ambiente de Auxilio à Paralelização de Aplicaçōes FORTRAN. Universidade de São Paulo, São Carlos, Setembro, 1996.

[Pre95] Pressman, R. S. Engenharia de Software. Makron Books, São Paulo, 1995

[Qui87] Quinn, M. J. Designing Efficient Algorithms for Parallel Computers. McGraw-Hill Series in Supercomputing and Artificial Intelligence. McGrawHill, Inc, 1987.

[Ree91] Reese, D. S. and Luke, E. Object oriented Fortran for development of portable parallel programs. In Proceedings of the 3rd IEEE Symposium on Parallel Distributed Processing, pages 608-615, Dallas, TX, December 1991.

[Ree94] Reed, D. A.; Aydt, R. A.; Madhyastha, T. M.; Noe, R. J.; Shield, K. A. and Schwartz, B.W. The Pablo Performance Analysis Environment. Technical Report, University of Illinois, 1994.

[Rin92] Rinard, M. C.; Scales, D. J. and Lam, M. S. Heterogeneous parallel programming in Jade. In Proceedings of the Workshop on Cluster Computing, Tallahassee, December, 1992.

[Rot93] Röttger, P.; Schroeder, U. and Simon, J. Virtual Topology Library for PARIX. Department of Mathematical and Computer Science, University of Paderborn, Germany, 1993.

[Rum91] Rumbaugh, J. Object-Oriented Modeling and Design. Prentice Hall International, Englewood Cliffs, 1991.

[Sat92] Sato, L. M. Um sistema de programação e processamento para sistemas multiprocessadores. Simpósio Brasileiro de Arquitetura de Computadores Processamento de Alto Desempenho, São Paulo, SP. Anais. p.95-107, 1992.

[Sc092] Scott, L. R. Pfortran: a parallel dialect of Fortran. Fortran Forum 11,vol. No. 3, pp. 20-3I, September, 1992. 
[Sis94] Sistare, S.; Allen, D.; Bowker, R.; Joudenais, K.; Simons, J. and Title, R. A scalable debugger for massively parallel Message-Passing programs. IEEE Parallel \& Distributed Technology: Systems \& Applications, Vol. 2, No. 2, pp. 50-6, Summer, 1994.

[Smi90] Smith, K; Appelbe, B. and Stirewalt, K. Incremental Dependence Analysis for Interactive Parallelization. ICS, pp. 330-341, June, 1990.

[Smi92] Smith, P.H. System Software and Tools for High Performance Computing Environments. 1992.

[Smi92a] Smith, G. Object-oriented Fortran tutorial. Engineering Research Center, Mississippi State University, 1992.

[Sni95] Snir, M.; Otto, S.; Huss-Lederman, S.; Walker, D. and Dongarra, J. MPI: The Complete Reference. MIT Press, 1995.

[Sun92] Sunderam, V. Concurrent computing with PVM. In Proceedings of the Workshop on Cluster Computing, Tallahassee, December, 1992.

[Sza92] Szafron, D.; Schaeffer, J.; Wong, P. S.; Chan, E.; Lu, G. P. and SMITH, C. The Enterprise Distributed Programming Model. Programming Environments for Parallel Computing, pp. 67-76, Elsevier Science Publishers, 1992.

[Tic90] Tichyand, W.; Christian, F. and Herter, G. Modula-2*: An Extension of Modula-2 for Highly Parallel, Portable Programs. Technical Report KAINF, 1990.

[Tur93] Turcotte, L. H. A Survey of Software Environments for Exploiting Networked Computing Resources. Engineering Research Center for Computational Field Simulation, Mississippi State, June, 1993.

[Uil97] The Charm+t (4.5) Programming Language Manual. Department of Computer Science, University of Illinois, Urbana-Champaign, August, 1997.

[Wir93] Wirtz, G. A Visual Toolset for Message-Passing Parallel Programming. Westfälische Wilhelms Universität, Department of Computer Science, 1993.

[Wir90] Wirfs-Brock, R.; Wilkerson, B.; Wiener, L. Designing Object-Oriented Software. Prentice Hall International, Englewood Cliffs, 1990.

[Yan92] Yan, J. C. Performance Tuning with AIMS - An Automated Instrumentation and Monitoring System for Multicomputers. NASA Ames Research Center, Moffett Field, 1992. 
[Zin93] Zink, R. The Stuttgart Parallel Processing Library SPPL and the $\mathbf{X}$ Windows Parallel Debugger XPDB. Presented at the Seventh International Parallel Processing Symposium Parallel Systems Fair, Newport Beach, April, 1993. 